\title{
WestVirginiaUniversity
}

THE RESEARCH REPOSITORY @ WVU

Graduate Theses, Dissertations, and Problem Reports

2019

\section{West Virginia University's Changing Mission in the 21st Century}

Katlin Swisher

katlin.swisher@mail.wvu.edu

Follow this and additional works at: https://researchrepository.wvu.edu/etd

Part of the Higher Education Commons

\section{Recommended Citation}

Swisher, Katlin, "West Virginia University's Changing Mission in the 21st Century" (2019). Graduate

Theses, Dissertations, and Problem Reports. 3919.

https://researchrepository.wvu.edu/etd/3919

This Dissertation is protected by copyright and/or related rights. It has been brought to you by the The Research Repository @ WVU with permission from the rights-holder(s). You are free to use this Dissertation in any way that is permitted by the copyright and related rights legislation that applies to your use. For other uses you must obtain permission from the rights-holder(s) directly, unless additional rights are indicated by a Creative Commons license in the record and/ or on the work itself. This Dissertation has been accepted for inclusion in WVU Graduate Theses, Dissertations, and Problem Reports collection by an authorized administrator of The Research Repository @ WVU.

For more information, please contact researchrepository@mail.wvu.edu. 
West Virginia University's Changing Mission in the $21^{\text {st }}$ Century

\author{
Katlin Swisher
}

Dissertation submitted to the College of Education and Human Services

at West Virginia University

in partial fulfillment of the requirements for the degree of

Doctor of Philosophy in Higher Education Administration

\author{
Erin McHenry-Sorber, Ph.D., Chair \\ Nathan Sorber, Ph.D. \\ Rodney Hughes, Ph.D. \\ L. Christopher Plein, Ph.D. \\ Department of Curriculum and Instruction/Literacy Studies
}

\title{
Morgantown, West Virginia \\ 2019
}

Keywords: Higher education, higher education administration, mission, strategic planning, leadership, organizational theory, land-grant universities, land-grant mission, university presidents, West Virginia, saga

Copyright 2019 Katlin Swisher 


\section{ABSTRACT \\ West Virginia University's Changing Mission in the $21^{\text {st }}$ Century}

\section{Katlin Swisher}

In the midst of the ongoing shifts of the perception of higher education and the public's question of the role and value of public universities, West Virginia University has simultaneously experienced institutional change through five different presidential administrations in a decade. As seen through WVU's historical context as the state of West Virginia's land-grant, flagship, research university, the institution has and continues to face many administrative, policy, and contextual changes as it strives to meet its strategic goals and operationalize its mission. Through document analysis and interviews with key officials, this qualitative, multi-case study seeks to understand how WVU's mission as a land-grant university and its resulting strategic plan have shifted in the $21^{\text {st }}$ century from one presidential administration to the next; how those changes have positioned the University within the overarching land-grant saga; and how those changes have influenced the work of the administrations as they operationalized the land-grant mission. 


\section{TABLE OF CONTENTS}

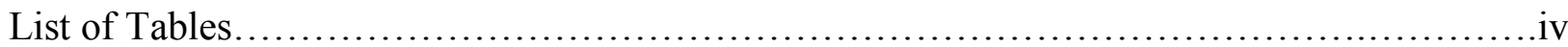

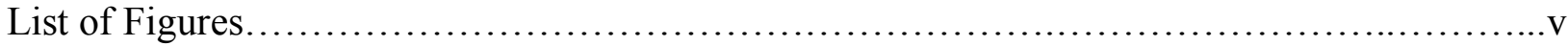

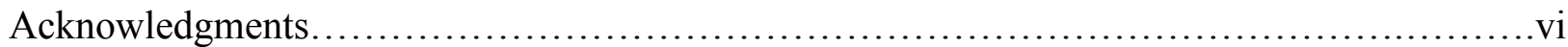

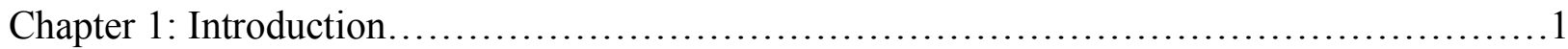

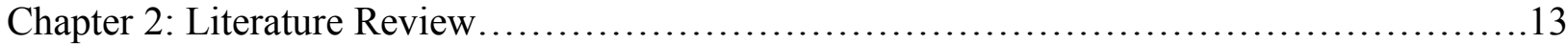

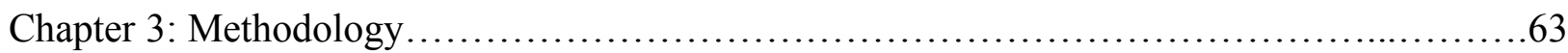

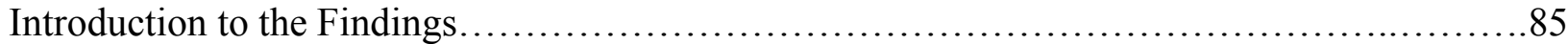

Chapter 4: David C. Hardesty's Administration.................................................92

Chapter 5: Michael Garrison Administration................................................ 156

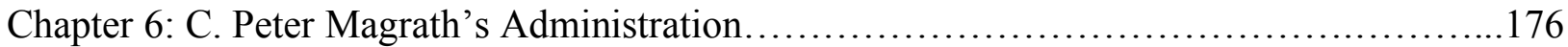

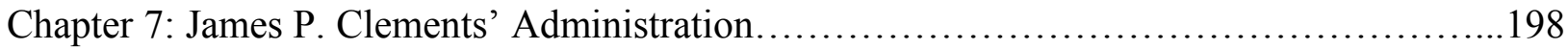

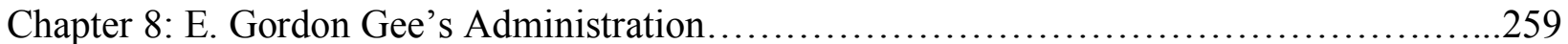

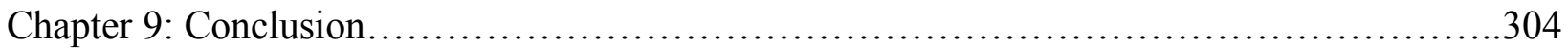

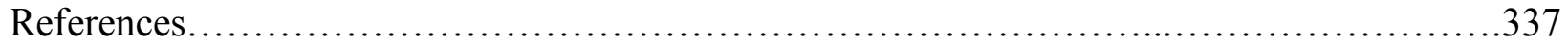

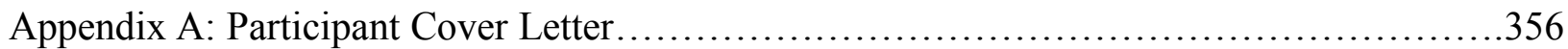

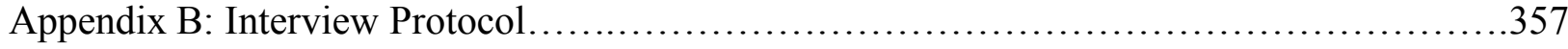




\section{LIST OF TABLES}

Table 3.1: List of Participants.................................................... 77 


\section{LIST OF FIGURES}

Figure 4.1: Hardesty Timeline...........................................................93

Figure 4.2: Hardesty Organizational Saga ............................................... 94

Figure 5.1: Garrison Timeline ....................................................... 157

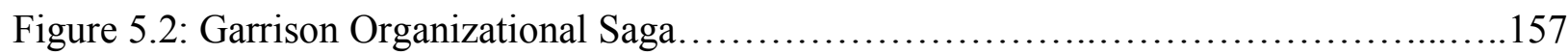

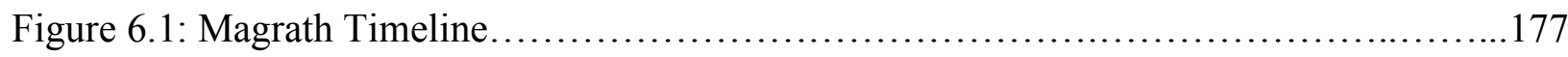

Figure 6.2: Magrath Organizational Saga...............................................177

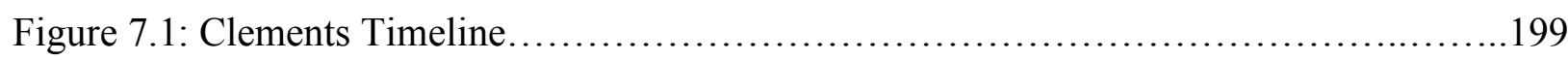

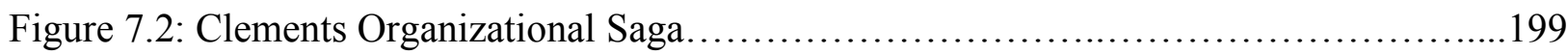

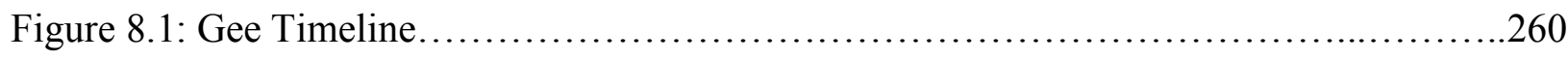

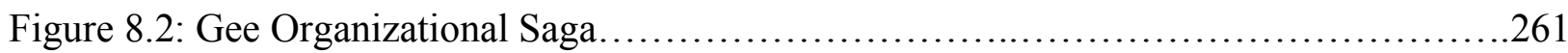




\section{Acknowledgments}

I am deeply indebted to my best friend and husband, Kyle Swisher, for his constant support and willingness to always brainstorm, listen, and talk through ideas with me.

My parents have provided invaluable support and encouragement over the course of my entire education. Mumsy, thank you for your willingness to proofread every last paper and article I send your way. Dad, thank you for teaching me that no goal is ever beyond my reach-"It's not where you start; it's where you finish." I am also grateful to my entire family for their support, patience, and flexibility throughout the research and writing process.

This study would not have been possible without the support and guidance of Dr. Erin McHenrySorber, whose words of wisdom and critical questions helped shape, improve, and refine my thinking and writing. I want to thank Dr. Nathan Sorber, whose passion for land-grant universities and innovative course on the topic inspired this study. Dr. Rodney Hughes shared ideas for many aspects of the research. Dr. Christopher Plein provided a wealth of knowledge and insightful conversations throughout this study.

As a first-generation student, I am deeply grateful to the many educators with whom I crossed paths over the years at Hurricane Town Elementary School, Hurricane Middle School, Hurricane High School, and WVU's Reed College of Media. You molded me into the student and scholar I am today. To my undergraduate advisors: Dr. Diana Martinelli, thank you for encouraging me every step of the way since my first day as a WVU student. You are a shining example of leadership in higher education. Dr. Jan Boyles, thank you for pushing me to apply to become an orientation leader as a freshman. You recognized what my future could look like before I even knew what was possible. I also wish to thank my marching band directors, Mr. Sam Leffingwell, Mr. John Hendricks, Mr. Jay Drury, and Mr. Christopher Nichter, for instilling in me discipline, attention to detail, work ethic, and leadership skills that parallel none. I continue to use the lessons I learned from you every day.

To Kate McKeen, Adele Siba, Kate Padula, and Ryan Boyd: Thank you for your mentorship and for taking a chance on a young, aspiring administrator with big dreams. I would not be where I am today without the opportunities you gave me early on in my career. To Ernie Goeres, who first encouraged me to pursue a doctoral degree.

Finally, I would like to extend my sincere thanks to the leaders at West Virginia University who were willing to take the time to share their stories and experiences with me. 
Chapter 1: Introduction 
Since the Great Recession in 2007-2008, universities have experienced decreasing state appropriations coupled with rising costs of resources. This increasing privatization of American public higher education institutions, particularly land-grant universities, reflects a transition from the Golden Age of land-grant universities, which featured enrollment growth and expansion of services and resources (Sorber \& Geiger, 2015), to an era of neoliberalism and privatization (Brackmann, 2015).

Decreasing state funding since the Great Recession continues to change the economic context of higher education. Per-student appropriations to Association of Public and Land-Grant (APLU) institution members decreased by $27 \%$, or $\$ 2,718$, from $2006-2007$ to $2012-2013$, and institutions responded by increasing tuition and fee revenues on average by $\$ 2,400$ per student (Johnson \& Yanagiura, 2015). This trend toward increased privatization has pushed land-grant universities to reconceptualize their missions, and, ultimately, their legacies.

Land-grant universities have experienced competing and conflicting mandates of how their missions should be carried out from their inception via the Morrill Act of 1862 . While the legislation broadly called them to be an alternative for practical education and instruction in agriculture, science, mechanics, and technology, nearly every state approached the establishment of the land-grant university differently based on political demands and socioeconomic contexts in the regions they were located. Examples ranged from creating new universities and agricultural and mechanical institutions to giving the land-grant to pre-existing institutions, both agricultural and non-agricultural (Sorber \& Geiger, 2015). These variances were also seen in the development and delivery of the curriculum and other offerings, broadly categorized as practical and vocational application verses scientific and liberal arts (Sorber \& Geiger, 2015) and even home economics (Thelin, 2011). 
A commonality shared by the land-grant universities is the romantic narrative that surrounds them, idealized by the notion that they were created to bring education to the people, expanding access more than any other institution type. More recently, likely motivated by the Morrill Act's 2012 sesquicentennial anniversary, land-grant universities have faced critiques of this ideal, both in terms of access for women and African Americans (Sorber \& Geiger, 2015; Thelin, 2011) as well as their lack of engagement in and accountability to the communities they serve (Brackmann, 2015; Gavazzi, 2015; Kellogg Commission on the Future of State and LandGrant Universities, 1999; Klein \& Woodell, 2015; Fitzgerald, Bruns, Sonka, Furco, \& Swanson, 2012; McDowell, 2001; McDowell, 2003; Reilly, 2003).

These critiques reflect a shift in the land-grant saga, particularly the ways in which landgrants are perceived across stakeholder groups - agriculture, industry, higher education, government, and the communities they serve. As they face these challenges of declining state appropriations, resulting budget cuts, and public accountability critiques, many institutions have been forced to make a choice: maintain their operational status quo while monitoring the changes; move away from their traditional missions of access, affordability, and practical education in favor of increased tuition revenue and changing academic offerings; or reengage with their missions through increased accountability to their communities and innovative, economic development- and partnership-based approaches to research, teaching, and service.

Though these state-level funding cuts to higher education funding came several years later in West Virginia than most other states, the current situation in the state is no different. As a result, West Virginia University (WVU), the state's 1862 land-grant institution, faces similar challenges of declining state investment in higher education coupled with a declining collegegoing age population and ongoing questions of the public value of higher education. 
West Virginia as a whole is facing an economic crisis that continues to impact public higher education. Only $11 \%$ of the state's base budget, or about $\$ 497$ million, is appropriated for higher education (O’Leary \& Boettner, 2016). In fiscal year 2015, West Virginia cut higher education more than any other state except Wyoming, decreasing per-student appropriations by more than 20\% since the 2008 recession (Mitchell, Palacios, \& Leachman, 2014). Consequently, the state's public higher education institutions decreased their budgets by three percent, or $\$ 9.6$ million overall, equating to about $\$ 330$ per student (Mays, 2014). This response ultimately translated to personnel and program cuts for the higher education institutions coupled with tuition increases to decrease costs to ultimately generate revenue. To mitigate the expected $\$ 500$ million budget deficit for fiscal year 2017, state budget proposals included up to $\$ 600$ million in overall budget cuts (McElhinny, 2017), including up to 15\% of WVU's base budget. Yet, at \$2.2 billion (Bowen \& Meszaros, 2016), WVU is the only higher education institution in America to be its state's top economic generator.

In the midst of these ongoing shifts of the perception of higher education and the state legislature's question of the role and value of public universities, as seen through the previous discussion of decreased appropriations, WVU has also experienced institutional change through five different presidential administrations in a decade. As a result of these administrative, policy, and contextual changes, this study seeks to understand how WVU's mission as a land-grant university and its resulting strategic plan have shifted in the $21^{\text {st }}$ century from one presidential administration to the next; how those changes have positioned the University within the overarching land-grant saga; and how those changes have influenced the work of the administrations as they operationalized the land-grant mission.

\section{WVU Historical Context}


West Virginia University's history as a higher education institution has been captured comprehensively via two books: William Doherty and Festus Summers's (1982) West Virginia University: A Symbol of Unity in a Sectionalized State and Ron Lewis's (2013) Aspiring to Greatness: West Virginia University Since World War II. Additionally, David Hardesty’s (2007) memoir of his presidential tenure situates his administration's role in the broader historical context through his perspective.

A prominent theme across these histories is the strategies by which WVU sought to fulfill its goal of becoming a Carnegie Foundation Highest Research Activity institution (i.e. Research 1 or R1). While WVU achieved that classification in 2015 a premise in these histories, especially Lewis's (2013), is the process of reaching that goal and challenges the University faced in reaching it. Three overarching obstacles to goal attainment include: lack of sufficient financial resources due to the state's perpetually weak economy and declining financial commitment to the institution; persistent and corrosive intra-state regionalism and geographic divide, particularly in public attitudes, state and local politics and the media due to the small state's mountainous terrain and poor infrastructure; and continual shifts in higher education governance systems and state processes. While these challenges were identified early in WVU's history, they are themes that continue to influence WVU's mission and strategic plan today as described in the next chapter's literature review.

\section{Research Questions}

As the state's land-grant, flagship, research university with a comprehensive medical center, WVU has and continues to face many administrative, policy, and contextual changes as it strives to meet its strategic, missional, and policy-related goals. The following research questions seek to explore WVU's mission as a land-grant university, its resulting mission and strategic 
planning shifts in the $21^{\text {st }}$ century from one presidential administration to the next, and the ways in which those changes have positioned the University within the land-grant saga.

1. How has West Virginia University's mission and strategic plan changed across the presidential administrations of David Hardesty (1995-2007), Mike Garrison (2007-2008), C. Peter Magrath (2008-2009), James Clements (2009-2013), and E. Gordon Gee (2013present)?

2. How did those shifts in mission and strategic plan influence WVU's positionality within the land-grant saga?

3. 3. How did this shifting positionality influence the work of the institution across these periods?

\section{Theoretical Framework}

Higher education organizational saga (Clark, 1971; Clark, 1972) will serve as the theoretical framework for this study. While most higher education theory focuses on college students and their development, learning, and experiences (e.g. Pascarella \& Terenzini, 2005), this theoretical framework is specific to higher education as an institution and as an organization. It is also based in qualitative inquiry, specifically the constructionist epistemology. Therefore, it is the most appropriate theory for these research questions as they relate to leadership, institutional structure, governance, mission, and strategic planning.

There are several ways to understand higher education as an enterprise through Clark's organizational saga because the framework offers multiple stages and settings in which the saga can develop, both in the short-term and over time. The framework also offers the opportunity to make meaning from the context of what occurs in the organization. In addition, it reflects how “different groups of actors, policymakers, academics, managers, and administrators interact and shape the field of higher education" (Fumasoli \& Stensaker, 2013).

As an organization or enterprise, higher education has many specific features that characterize it: maturity; slowness (or in some cases, unwillingness) to change; loosely-coupled 
system(s); concrete, bureaucratic structures and processes; complacency about the security of its market niche (i.e. teaching, research, and learning); the need to work actively to remain dynamic as a result of this potential for complacency; a mix of interdependence and independence among individuals, programs, and other entities that comprise the organization; unique practices (e.g. granting tenure to faculty); and the public versus private good debate (Manning, 2013; Gayle, Tewarie, \& White, Jr., 2003). While organizational saga assumes the higher education institution is rational, meaning there are reasonable explanations for why decisions are made or why actions are taken, it also reflects the emotional connections for stakeholders involved in the organization, which demonstrates how a "formal place can become a beloved institution" (Clark, 1972, p. 178).

Clark defines organizational saga as "a collective understanding of unique accomplishment in a formally established group" (Clark, 1972, p. 178). That understanding is a narrative that not only represents the history of the organization but also represents the beliefs of a core group of individuals. "The element of belief is crucial, for without a credible story, the events and persons become history; with the development of belief, a particular bit of history becomes a definition full of pride and identity for the group" (Clark, 1972, p. 178). As a result of this reliance on normative bonds, or the beliefs and loyalties of the individuals in the organization, organizational saga moves beyond just structural composition of the organization to focus on the cultural, emotional, and expressive aspects, demonstrating how organizations can be humanized by the individuals who are a part of them. "With a general emphasis on normative bonds, organizational saga refers to a unified set of publicly expressed beliefs about the formal group that (a) is rooted in history, (b) claims unique accomplishment, and (c) is held with sentiment by the group," (Clark, 1972, p. 179). 
Organizational saga develops in two stages: initiation (short-term) and fulfillment (longterm). Initiation is characterized by strong purpose, a short time-frame, and execution by a single leader or small group (Clark, 1971, 1972). Initiation can occur in a variety of settings: a new organization or an organization under new leadership; an organization in crisis, such as one dealing with a major controversy or scandal; and an organization that is established but ready and poised for evolutionary change (Clark, 1971, 1972). After a saga develops, it takes time for it be fulfilled, and it does so in a more predictable manner than the initiation stage. For the saga to achieve fulfillment, it must reach five populations or places within the higher education institution: personnel, program, social base, student subculture, and imagery (Clark, 1971, 1972).

Personnel primarily encompasses a set of key believers - faculty. While the saga can be initiated by a single leader (e.g. the president) or small group, fulfillment requires commitment from the faculty. Their buy-in results in their taking responsibility for carrying out the saga over time and protecting it against possible threats, such as new leadership (Clark, 1972).

Program is comprised of the visible practices of the saga's implementation that reflect the mission, vision, and values of the institution through the saga. Examples include curriculum offerings, approaches to instruction, research accomplishments, and service opportunities, the practices that demonstrate the organization's distinctiveness (Clark, 1972).

Social base refers to another key population-alumni. These are "believers devoted to the organization" who "hold beliefs enduringly pure" because they are rooted in the past and have not been jaded with the challenges facing the current administration (Clark, 1972, p. 182).

Student subculture represents a key population currently connected to the organizationthe students themselves. Like faculty, when students buy in to the saga, they also hold 
themselves responsible for maintaining and contributing to it while also taking pride in it (Clark, 1971, 1972).

Imagery is the final place the saga must reach to be fulfilled. Imagery is how the saga is most widely expressed, not only across faculty, staff, students, and alumni, but in the traditions of the institution itself, e.g. through its brand, statues, ceremonies, events, signage, and other cultural representations (Clark, 1972). "As the account develops, believers come to sense its many constituent symbols as inextricably bound together, and the part takes its meaning from the whole" (Clark, 1972, p. 183).

The durability of sagas varies based on the organization type. Robust sagas struggle to develop strongly in passive organizations (Clark, 1971). Instead, they are more likely to develop and have a lasting impact in highly structured contexts, which is why higher education is an optimal venue for organizational saga (Clark, 1971).

Once fulfilled, the organizational saga gives the institution unity and helps overcome silos and boundaries while bringing connection to the intricate complexities of the structure. "When the saga is firmly developed, it is embodied in many components of the organization, affecting the definition and performance of the organization and finding protection in the webbing of the institutional parts," (Clark, 1972, p. 179).

The examination and interpretation of Clark's higher education organizational saga will help explicate the nature and significance of this study on how WVU's mission and strategic plan have changed across five presidential administrations in a decade, how those shifts have influenced WVU's positionality within the land-grant saga, and how those shifts have affected the work of the institution across this time period. The study will use the stages of Clark's organizational saga to identify how and when changes were initiated and how those changes 
were operationalized in the five subsequent stages of personnel, program, social base, student subculture, and imagery.

As we trace the effects of an organizational saga on belief and trust and then on the problems of governance, we turn our attention away from structure changes ... and focus instead on the size and scope and mission of the entity that is to be governed. We return to the embodiment of goals in the historical development of an organization and what meaning is thus available to those who give so much of their lives there. (Clark, 1971, p. $515)$

\section{Significance of the Study}

As discussed above, West Virginia University has two formally documented histories, Doherty and Summers (1982) and Lewis (2013). At the time of this writing, at least six years will have passed from the most recent published historical account. While this may seem like a short timeframe given the institution's long history, since these publications, West Virginia has experienced shifting political and economic contexts, which, in turn, have influenced changes in higher education, especially WVU.

WVU has been led by five presidents in 10 years. It departed the Big East Conference and joined the "power five"-member Big 12 Conference in 2012, bringing with it increased revenue from the new conference membership, athletic fundraising, and beer sales at athletic events (Jessop, 2013). It earned the Carnegie Classification of Institutions of Higher Education's distinct R1 highest activity research designation in 2015 (West Virginia University, 2017). It set record enrollments in terms of first-time freshman students, academic profile, Honors College, and diversity (Bolt, 2017; Dobies, 2014). It moved a divisional campus to a new location 
(Loftstead, 2015), celebrated its sesquicentennial, and concluded a 10-year, \$1.2 billion capital campaign in 2017 (Nevin, 2018).

Simultaneously, WVU has been influenced by state-level economic and political contexts, facing a series of cuts to state appropriations to public higher education (Mitchell, Palacios, \& Leachman, 2014; Mays, 2014; McElhinny, 2017) coupled with more responsibility, flexibility, and autonomy through bills like West Virginia House Bill 2542, which permits more flexible hiring and firing practices (West Virginia University Bureaucracy Busters, 2017). As a land-grant university, it is also navigating the movement to define its mission as an engaged institution in the midst of calls for accountability, community partnership, and economic development (Brackmann, 2015; Gavazzi, 2015; Kellogg Commission on the Future of State and Land-Grant Universities, 1999; Klein \& Woodell, 2015; Fitzgerald et al., 2012; McDowell, 2001, 2003; Reilly, 2003).

This rapid transformation in such a brief time period presents multiple layers of significance for the study. It is an opportunity to fill the gap in WVU's history; to document and explore WVU's current situation within the land-grant saga and relationship with the state of West Virginia; and to highlight how and why these changes have come about through the documents that represent them and the individuals who were catalysts for making them happen.

Beyond documenting the historical and institutional knowledge, this study seeks to exemplify the land-grant saga through the narrative of a specific university and its changes in leadership, mission, and strategic planning. While there is a significant body of literature on the history of land-grant universities and how the land-grant movement has progressed over time, fewer studies have been published about the land-grant movement since the sesquicentennial of the Morrill Act of 1862 in 2012, which offers an opportunity to conduct an emerging exploration 
of the land-grant saga by examining the modern land-grant university in the face of changing broader contexts for higher education and in more specific state-level contexts. Through the lens of a specific institution, i.e. WVU, this study is an opportunity to define what it means to be an engaged land-grant university, including identification of accountable publics, missional expectations, and responsibilities.

With that said, these changes would not occur without the leadership initiating them. This study is also an opportunity to highlight the presidential visions pursuing these changes. Presidential aspirations are often just that—aspirations. The real test of an administration is to manage the embedded culture of higher education as an industry and the challenges it faces, and this study is an opportunity to consider those approaches through characteristics like the role of the presidency, presidential retention, average tenure, political capital, and institutional reputation. By considering how these changes were operationalized in the presidential administrations, the study will also demonstrate how the leadership's interpretation of the landgrant mission influenced the institution's positionality in the land-grant saga and the work of the institution across these time periods. 
Chapter 2: Literature Review 


\section{The Land-Grant Saga}

The land-grant saga is not easily defined despite the rich history magnifying the institutions that were established by or evolved out of the Morrill Act of 1862 and other subsequent legislation. Conflicting definitions and mandates of how the land-grant mission should be interpreted and implemented outwardly have faced land-grant colleges and universities from the very beginning of their inception.

Created by the Morrill Act of 1862, the legislation allocated land to each state to establish a university for the people - a higher education institution that offered an alternative to the private, elite universities, one that featured practical, useful education and instruction in mechanics, sciences, and technology to use science to improve the workforce and industry, e.g. agriculture and mechanical arts, leading to ground-breaking research that has been the catalyst in transforming the United States into the global economic power it is today. However, because many states were so settled and populated by this time, there was often not enough land to meet the minimum allocation requirement. In these instances, states received scrip equivalent to the value of land (based on the number of senators and representatives) to sell to establish landgrants, often as part of pre-existing institutions. The universities established as land-grants were called to be "accessible to all, but especially the sons of toil;" provide "instruction in the practical avocations of life" as well as "other scientific and classical studies," and be "the guidance of the industry of this country" (Morrill Act of 1862, 2018) with motives ranging from democratizing education and developing a utilitarian curriculum featuring instruction, research, and public service to emphasizing developing industries in the applied sciences, especially agriculture and engineering (Williams, 1991). Even with these guiding tenants, nearly every state approached their institutional and organizational development differently based on political 
demands and socioeconomic contexts in the regions they were located. Some states created new universities or new agricultural and mechanical colleges, while others opted to award the landgrant to previously established institutions (Sorber \& Geiger, 2015). The curriculum and the delivery of that curriculum saw just as much variance, ranging from practical applications and vocational courses to the arts and sciences (Sorber \& Geiger, 2015; Thelin, 2011). For example, "the classical curriculum of antebellum colleges [was] consistently portrayed as the villain in the land-grant saga, by contemporary proponents of practical education and by present-minded historians" (Geiger, 1998, p. 8).

As a result, the original land-grants under the Morrill Act of 1862 offer an eclectic approach to higher education, sharing few defining characteristics beyond their connection to the original Morrill Act. George Williams (1991) describes the movement as a "collective story" about institutions with an "exclusive relationship with the federal government" and a few shared obligations encased by the "expression and diffusion of certain political, social, economic, and educational ideals" (p. 1). Broadly, a characteristic that has united these institutions over the years is the romanticized view of the land-grants as colleges providing education "for the people" and celebrations of democracy and access (Williams, 1991). The reality, though, is that most students who enrolled came from the middle class or were even children of wealthy farmers aspiring to exit their agrarian upbringing in favor of a new life in an emerging white-collar career path. Further, the "for the people" definition was not reached until much later, as widespread offerings were not available for African Americans until the Morrill Act of 1890 or women until the 20th century (Sorber \& Geiger, 2015; Thelin, 2011; Williams, 1991).

While still commonly personified, the romantic vision may be, in part, a thing of the past. The sesquicentennial of the Morrill Act presented an opportunity for critique of that ideal as the 
realities set in of the challenges land-grant universities faced, not unlike other public, research universities: declining state support for higher education and subsequent budget cuts and consideration of alternative revenue sources, including student tuition (Brackmann, 2015). For example, in response to growing public frustration regarding perceived unresponsiveness of public and land-grant universities, the Kellogg Commission on the Future of State and LandGrant Universities (1999) published a report. The report called on land-grant institutions to return to their roots and engage more with the communities where they are located to become more aware of local problems and use their expertise in a more targeted, intentional way. Authored by 26 land-grant presidents and chancellors and framed as a dear colleague letter, the report gave land-grant leaders a test to measure their responsiveness to and engagement with the community. The test included seven components: responsiveness to community needs, respect for community partners, academic neutrality, accessibility, integration, coordination, and sharing of scarce resources (Kellogg Commission on the Future of State and Land-Grant Universities, 1999).

Beyond giving the institutions an unprecedented expectation of how to fulfill their missions moving forward, this literature also served as the foundation for other missional and accountability critiques of land-grant universities as well as recommendations for engagement. The Association of Public and Land-Grant Universities' "The Centrality of Engagement in Higher Education" report is just one example (Fitzgerald et al., 2012). In this white paper by the APLU's Council on Engagement and Outreach, the authors provide a historical look at how land-grant universities have engaged with their communities over time, including through the original Morrill Act; the Hatch Act, which established research centers for sharing agricultural and nutritional knowledge in communities; and the Smith-Lever Act, which created the 
extension services. Together, these three policies established mandated educational opportunities in communities where, for the most part, they previously didn't exist. Fitzgerald et al. (2012) also created a new definition of engagement based off the Kellogg Commission's report (1999) as well as those from other national higher education organizations, including the Association of American Colleges and Universities, the American Association of Community Colleges, the Council of Independent Colleges, Campus Compact, and Imagining America. It states that engaged scholarship should be scholarly; should cut across institutions' research, teaching, and service missions; should be reciprocal and mutually beneficial for the higher education institutions and their communities; and should reflect a civil democracy (Fitzgerald et al., 2012). Beyond defining engagement, the report also makes recommendations for higher education leaders as to how they can change the culture of their institutions to reflect engagement and makes the case for why engagement makes sense in the current public outlook of higher education.

Similarly, Gavazzi (2015) calls for universities to shift their culture to one of community engagement through town-gown relationships, where they make direct contributions to human capital in the communities where they are located. Following a mixed methods study to analyze institutions town-gown relationships, he found that both communities and universities seek a harmonious relationship, which requires high effort and high comfort. Gavazzi (2015) goes on to suggest that institutions need to do more than just share their physical space (e.g. campus buildings and other resources); instead, he recommends that university leadership should meet regularly with community members to identify what their needs are and how the university can support those needs. While this recommendation is primarily to serve the communities, Gavazzi (2015) also indicates that this approach could also be what "saves" higher education with regard 
to questions of value, perception, and funding - a culture shift toward innovation and engagement could be the solution to many challenges currently facing higher education.

Gavazzi also collaborated with WVU President E. Gordon Gee (2018) to explore the future of higher education and the land-grant's role in that. They call for land-grant universities to reengage with their missions to better serve the public good and respond to the challenges facing higher education by becoming "more fiercely land-grant in [their] orientation" (p. 1) rather than the more homogenized higher education marketplace. To achieve this differentiation, they recommend a servant leadership mentality for all land-grant presidents, allowing them to be "more mindful of their original purpose and attentive to their intended audience" (p. 5) because of the "bilateral bond" land-grant universities have with their communities. "Critical decisions made at all levels of leadership should be filtered first through the lens of what provides maximum benefit for the citizens of each state and for American society at large" (Gavazzi \& Gee, 2018, p. 34).

Like Gavazzi and Gee (2018), Robert Sternberg, former provost at Oklahoma State University, believes servant leadership is what will help differentiate land-grant universities from other institution types. In his 2012 edited book on the modern land-grant university, Sternberg acknowledges that "land-grant institutions will be challenged to be true to their missions" (p. xi), especially as state appropriations and support continues to decline, and that servant leadership is an opportunity to reengage with their missions. "If land-grant institutions forget this mission of service, they will lose the essence that makes them special and unique valuable as institutions of higher learning" (Sternberg, 2012, p. xi).

Michael Crow and William Dabars, president and senior research fellow, respectively, at Arizona State University, the nation's largest public research university, also endorse this idea of 
differentiation in their call for and description of what they coined the "New American University." In their book (2015), they recognize that the traditional structure, organization, and design of the American university is excessively steeped in tradition to the point of stalling progress, or filiopietism. They believe the deeply rooted and celebrated traditions of the university, such as tenure, traditional college, school, and department organization, and traditional selective admission requirements, to name a few, have actually held the university back over time, becoming a status quo, inhibiting the university from adapting to environmental circumstances and contexts to remain relevant in the marketplace. To overcome this complacency, Crow and Dabars created a blueprint for what the "New American University" could look like, a design that features research in partnership with the community and motivated by serving the public good and is organized in a way that is nimble and pragmatic, interdisciplinary, and can adapt to the changing environments around it. The design is not prescriptive; rather, it gives institutions the flexibility to make the choices that best represent their respective identities, missions, values, and communities, supporting the diversification of the public research university.

In another report from the APLU, Klein and Woodell (2015) make recommendations for how land-grant universities can support economic development in their region through increased engagement. It is more specific than Fitzgerald et al.'s (2012) engagement discussion because it focuses on a specific type of engagement-economic development. It follows a similar model to that white paper as well as the Kellogg Commission's (1999) report by first providing a definition (i.e. how they define economic development for higher education institutions) followed by a set of principles for reaching that definition, and then recommendations for best practices for carrying them out. Klein and Woodell (2015) start by defining university economic 
and development to provide institutions with a common definition and culture, and define best practices for community engagement and implementing strategies for economic development. They define economic development in higher education as "creating the conditions for economic prosperity" in the areas where higher educations are located (Klein \& Woodell, 2015, p. 4). Their framework for action includes the intersection of research and innovation, human capital and talent development, and stewardship of place. They indicate that institutions achieve high levels of economic development when they have active and effective programs in place in all three areas.

Simultaneously, other leaders called for increased public accountability in the cooperative extension services offered by land-grant universities. McDowell (2001) offers a history of the cooperative extension service and its relationship with land-grant universities, describes how extension has changed over time, and calls for a change in direction because of what he sees as a failed system. He indicates that universities may deny or remain unaware that the social contract between universities and the public has been abandoned, or at the very least, distanced, and he also makes recommendations for how extension can improve upon its dysfunction and regain its social contract and trust with the public. McDowell follows up his 2001 book with a 2003 article on lessons learned from land-grant universities and extension, highlighting examples of how the land-grants can be more engaged with and more relevant in their communities while simultaneously overcoming challenges they face in the $21^{\text {st }}$ century. Motivated, like many other authors discussing engagement and land-grant universities (Brackmann, 2015; Fitzgerald et al., 2012; Gavazzi, 2015; Klein \& Woodell, 2015; McDowell, $2001 \& 2003)$ by the Kellogg Commission (1999), Reilly (2003) uses a multi-case study approach to highlight examples of institutions using extension and outreach to better engage with 
their communities. He opens with a discussion how the public university is striving to make itself relevant to its communities in the changing, more digitally-focused information age. Reilly posits that universities will be acknowledged in the future by the way they use public service to inform both their research and teaching efforts. While he does highlight several institutions for their engagement efforts, he does not go into much detail to explain what those efforts are or to define how he chose those particular institutions. Similarly, Reilly (2003) highlights a list of points that will define what the "New University Extension" service looks like, but he does not explain how he identified those criteria or how to reach that vision.

Jongbloed, Enders, and Salerno (2008) call for all higher education institutions, not just land-grant universities, to better connect their mission, vision, values, and strategic plans to their communities through engagement strategies because they have been so entrenched in the communities they were established from the time of their inception. "If we take a leap through history, from the days of the early universities that provided education for the church and other elites to the present times of massified higher education systems, we may conclude that higher education has become inextricably linked to the notion of progress both at an individual and a societal level" (p. 320). They also indicate that the legitimacy and reputation of higher education institutions will continue to rely more and more on community stakeholders and engagement strategies because higher education is becoming more competitive. "For the university to be an effective institution in an increasingly complex environment, it is not just a matter of generating sufficient income to remain in business, but that it is equally essential that the institution proves its relevance to society and the various entities in society that it regards as important" (Jongbloed, Enders, \& Salerno, 2008, p. 308). 
The above paragraphs reflect many of the challenges land-grant universities and their leaders alike are facing. The following section further extrapolates challenges faced by higher education leaders in general as well as recommendations for how to navigate them through a discussion of higher education as an organization as well as of leadership typologies.

\section{Leading in Higher Education}

Higher education leaders in the $21^{\text {st }}$ century face many challenges for leading their institutions as organizations while navigating the complexities of the public agenda set before them. Challenges identified by Duderstadt (2009) include the hypercompetitive, global, knowledge-driven economy that requires a highly skilled, trained, and educated workforce (that only a college education can provide); continuing to define higher education as a public good amidst decreasing public support and funding; and the nation's changing demographics and growing diversity without the appropriate mobilization of educational opportunities for the entire workforce. Forest and Kinser (2002) echo these challenges, identifying several factors that constrain presidents and limit the degrees of freedom in their leadership, including competing and conflicting organizational goals, federal and state policy and/or governance; expanding internal governance, public criticism, accountability, changing student markets, among others.

With these challenges in mind, Duderstadt (2009) recommends the following public agenda for higher education: improved quality, based on increased support at the state and federal levels, evidence-based assessments, and support through public-private partnerships, all of which should be guided by the aspiration to meet changing societal needs; increased innovation, particularly at the highest levels of administration and management, including presidents; increased access to higher education, particularly for minority populations; and a commitment to lifelong learning, particularly with the nation's aging population in mind. Forest 
and Kinser (2002) also recommend that presidents need to be "more effective managers of meaning, since multiple interpretations of reality exist" (p. 481). These recommendations offer a framework for how all university leaders, but especially presidents, can manage the changing dynamics of culture in higher education within its decentralized organizational model, particularly how it is perceived by the public and in the political arena. As the public's perception of higher education becomes more negative, it is causing its value to decrease and its purpose to be questioned. While his article is not directed specifically to land-grant presidents, Duderstadt's framework for change in university leadership and governance is similar to that of the Kellogg Commission's "Returning to our Roots" report, which was composed by several land-grant presidents.

Gavazzi and Gee (2018) also highlight challenges experienced by leaders of land-grant universities and how they responded. Following interviews with 27 presidents, chancellors, and other leaders of land-grant institutions, they identified seven overarching challenges: funding declines versus the need for efficiencies, research prowess versus teaching and service excellence, pursuing knowledge for knowledge's sake versus applied research, rankings versus and access and affordability, meeting the needs of rural communities versus urban areas, having a global reach versus making an impact closer to home, and determining the value of a college degree.

These challenges reflect the high expectations set before higher education leaders, particularly university presidents, by their many constituencies. They have to balance the expectations of "doing it all." "No longer just the academic leader, a college president is now expected to be top executive, head fundraiser, and cheerleader in chief. The president is often the institution's top lobbyist, testifying before legislative committees, navigating regulatory hurdles, 
and wrangling appropriations in tough budget times" (Fischer, 2005). "As a result of these competing and often contradictory expectations, presidents spend more time in consultation with constituents than ever before" (Forest \& Kinser, 2002, p. 481). Presidents are most often criticized for not meeting those expectations when they do not fit into the culture of the campus, particularly when following a transformative or heroic past president (Bornstein, 2002), which is one of the many limitations on degrees of freedom experienced when beginning a new presidential administration.

The president is accountable to an array of constituencies that serve as channels of influence on their administration - faculty, staff, administrators, students, alumni, donors, prospective students and their families, community members, state government, and more. Interacting with these diverse groups can also be a challenge of managing the culture of higher education while also navigating the degrees of freedom they can expect to receive because of the shared governance required for the role and the organizational structure (Bornstein, 2002; Fisher, 1984; Forest \& Kinser, 2002; Glassner \& Shapiro, 2017; Marcy, 2008). After all, it is the responsibility of the governing board to "set the state for strong, assertive, enlightened presidents" and support them because of the hiring structure (Fisher, 1985, p. 38). "Presidents move among multiple and diverse constituencies ... creating a sense of community through narratives about the institution's history and a shared vision for the future" (Bornstein, 2002, p. 18). This particular degree of freedom, i.e. relationships with the constituents with whom the presidents interact and how they manage shared governance, is a vital part of their political capital as they create a strategic plan, shape the institution's mission and identity, and inform policymaking.

\section{Leading Higher Education Institutions as Organizations}


As an organization or enterprise, higher education has many specific features that characterize it (Manning, 2013): maturity; slowness (or in some cases, unwillingness) to change (Pusser, 2003); loosely-coupled systems (Weick, 1976); a garbage can in which various issues and challenges are "dumped" by stakeholders and addressed only when the timing is right (Cohen, March, \& Olsen, 1972); concrete, bureaucratic structures and processes; complacency about the security of its market niche, i.e. teaching, research, and learning; the need to work actively to remain dynamic as a result of this potential for complacency; a mix of interdependence and independence among individuals, programs, and other entities that comprise the organization; unique practices, traditions, and symbols (Meyer \& Rowan, 1977); and the public versus private good debate. As a result, to understand how higher education institutions are governed, their role in policymaking and mission-building, their relationships with stakeholders, and how leaders navigate all of these processes, we must first understand how higher education institutions function as organizations. However, the study of higher education as an organization is not neatly bounded. Numerous bodies of literature have characterized higher education in as an organization in different ways.

Birnbaum (1988) offered one of the first analyses of higher education as an organization, classifying higher education institutions as open systems with a discussion of how their leaders conceptualize their decision-making and the way their institutions work. Following early organizational theorists Baldridge, Curtis, Ecker, and Riley (1976), Cohen, March, and Olsen (1972), Meyer and Rowan (1977), and Weick (1976), Birnbaum (1988) posited that leaders have the power to define their organizational realities and cultures, whether or not they acknowledge it (Neumann, 2012). Birnbaum (1988) identified several forms that higher education organizations 
take (either in isolated or blended constructs) and that their leaders reflect: bureaucracy, collegium, political body, culture, and cybernetic system.

Manning (2013) updated Birnbaum's organizational forms with a synthesis of higher education organization that offers a variety of contexts that originate at different points in higher education's history as well as the opportunity to make meaning from the context of what occurs in the organization. These included organized anarchy, collegial, bureaucratic, political, cultural, feminist, spiritual, and new age. In addition to expanding on Birnbaum's original forms, this approach to characterizing higher education as an organization reflects how "different groups of actors, policymakers, academics, managers, and administrators interact and shape the field of higher education" (Fumasoli \& Stensaker, 2013).

Bolman and Deal's (2013) four frames of leadership — structural, collegial, political, and symbolic — provide a typology for individuals' approaches to leadership and recommendations

for how to reframe their leadership style depending on the situations and environments they face. Simultaneously, their leadership frames also help to make sense of how organizations operate and function, similar to Manning's (2013) frameworks and characterizations of organizations.

\section{Organizational and Leadership Typologies}

A leadership typology or frame is a "coherent set of ideas or beliefs forming a prism or lens that enables you to see and understand more clearly what goes on from day to day" (Bolman \& Deal, 2013, p. 41). The typologies seen across the higher education organizational literature will help link the leadership styles seen throughout the five presidential administrations in this study with the changes over time in mission and strategic plan, land-grant saga positionality, and the operationalizing of the mission and strategic plan within the land-grant saga. 
The typologies included here reflect the most commonly introduced typologies among all the higher education organizational theorists discussed above: organized anarchy, structural, human resource, political, and symbolic. These typologies not only categorize leadership styles and organizational activity, but also "identify practices and signals that help to suggest the thrust of organizations and the leaders who head them" (Gamble, 2003 p. 2).

Organized anarchy. The organized anarchy typology reflects the paradoxical nature of higher education (Manning, 2013). In an organized anarchy, the higher education institution "operates on the basis of a variety of inconsistent and ill-defined preferences" (Cohen, March, \& Olsen, 1972, p. 1). Rather than a lack of order as just the term anarchy implies, organized anarchies require participation by the communities they serve (e.g. students, professors, administrators, alumni, donors, legislators, communities, etc.), and all these individuals are expected and encouraged to participate in the organization. However, there is simultaneous autonomous decision-making, from students choosing what to learn (e.g. their majors, course schedules, whether or not to attend class), to professors choosing what to research or teach, to alumni choosing whether or not to donate (and how), to the state government choosing what to support and/or fund (or not) through policymaking and appropriations. The organized anarchy typology is best reflected in the role of the independent-minded faculty, which is further exemplified in Hammond's (2004) analogy of higher education leaders "herding cats": "the faculty members' problematic goals, unclear technology, and fluid participation in decision making are taken as suggesting that the universities can be described in decidedly nonhierarchical terms" (p. 92).

Structural. While early universities were not bureaucracies, modern administrations at higher education organizations are typically categorized as bureaucracies. The structural, or 
bureaucracy, typology is based on the foundation of designing an organization to perform as efficiently as possible and supports putting the right individuals in the right roles with the right responsibilities to make the most use of their talent, personality, and skillset for maximum effectiveness and efficiency. The structural typology is "rooted in traditional rational images (e.g. a factory) but goes much deeper to develop versatile and powerful ways to understand social architecture and its consequences" (Bolman \& Deal, 2013, p. 41). Features include a fixed division of labor, hierarchy of positions and offices, standard rules and policies governing performance and operations, a separation of personal life and official property and rights, basing hiring practices on qualifications and merit rather than personal connections, and employment as the cornerstone for success and primary occupation (Birnbaum, 1988; Bolman \& Deal, 2013; Hammond, 2004; Manning 2013).

In stable environments, the structure is flexible to meet the goals and needs of the organization, rather than being "machinelike or inflexible" (Bolman \& Deal, 2013, p. 48). When it is working well, it enhances the organization's morale and helps the individuals reach their goals. When it fails, it is seen as unnecessary bureaucracy, control, and micromanagement.

The structural typology is seen in higher education leaders when they approach planning with strategies to set objectives and coordinate resources; use sequential steps to reach decisions; realign roles and responsibilities of their teams or organizations to best fit the tasks at hand; use personnel evaluations as the basis for reviewing performance; encourage managers to resolve content to maintain hierarchy; focus on the organization's direction as the basis for goal-setting; communicate to transmit facts and information; establish a formal setting for meetings and major decisions; and use rewards to motivate their staff (Bolman \& Deal, 2013; Gamble, 2003; Manning, 2013). 
Collegial. The collegial, or human resource, typology is the original model of higher education as an organization. It focuses on the role of individuals and interpersonal relationships in organizations and leadership. It "centers on what organizations and people do to and for one another" (Bolman \& Deal, 2013, p. 113). Features include the acknowledgement of human needs and investing in those needs to motivate employees and move the organization forward by empowering and rewarding them, providing job security, promoting from within, sharing responsibility for the organization's performance, and emphasis on expert power rather than positional power (Birnbaum, 1988; Manning, 2013; Bolman \& Deal, 2013).

In stable environments, there is a strong fit between the individual and the organization, allowing the individual to find meaning in and be satisfied with their work and contribute talent and energy to the organization (Bolman \& Deal, 2013; Manning, 2013). Weick's (1976) loose coupling model reflects the strength of the collegial typology because the approach to leadership preserves the unique and separate identities of individuals within the organization and allows capacity for self-determination of the participants in the organization. However, when this typology does not fit the circumstances of the organization, neither the organization nor its participants can reach their full potential.

The collegial typology is seen in higher education leaders when they approach planning with events to promote participation; allow decision-making to be an open process; seek balance between informal and formal roles in their reorganization; use evaluation to help their staff improve; resolve conflict through relationship-building and encouraging confrontation; encourage open communication, regardless of hierarchy; welcome emotion and feeling in communication lines; consider meetings to be an informal place for participation and 
contribution; and use growth and self-actualization for motivation (Bolman \& Deal, 2013; Gamble, 2003; Manning, 2013).

Political. The political typology evolved out of a lack of fit with the collegial and bureaucratic typologies in some instances of organizational change in higher education. It reflects how higher education can be a contested political ground characterized by power, conflicting priorities, and strategic maneuvers as well as how relationships can be the key to understanding these organizations. The political typology represents how individuals and groups navigate these power dynamics, and gaining power is the source for making things happen (Birnbaum, 1988; Manning, 2013). It views organizations as "rolling arenas, hosting ongoing contests of individual and group interests" (Bolman \& Deal, 2013, p. 188). Masten (2006) argues that higher education organizations are naturally political because of the opportunities for mutually beneficial trade-offs and cooperation, and because the costs and benefits for these bargains and trade-offs occur non-simultaneously, they are more susceptible to negotiations and conflict.

Two major features of the political typology are management of scarce resources (i.e. deciding who gets what) and enduring differences, which "make conflict central and power the most important asset" in this typology (Bolman \& Deal, 2013, p. 189). The slow pace of decision-making also characterizes this typology, as well as the continued visibility, salience, and value of higher education in the political arena (Pusser, 2003). Negotiation and bargaining are other important features, which means leading from this typology places conflict at the center of the organization's day-to-day operations.

The political typology is seen in higher education leaders when they use planning as a way to address conflict and realign power; see decisions as an opportunity to gain or exercise 
power; reorganize to redistribute power; evaluate to exercise power; approach conflict by bargaining or manipulating; set goals to make interests or intentions known; communicate to influence others; view meetings as an opportunity to get points across and compete; and motivate through coercion or manipulation.

Symbolic. The symbolic, or cultural, typology postulates that what happens in an organization is not as important as what those happenings mean for the organization (Bolman $\&$ Deal, 2013). It reflects the performance, dynamism, transformation, and ever-changing nature of higher education organizations (Manning, 2013). In the symbolic typology, culture is the bond or superglue that unites people and holds an organization together, especially during times of change, and uncertainty and ambiguity are overcome with symbols that provide direction and hope (Bolman \& Deal, 2013; Manning 2013).

The features of this typology are its symbols, or the mission, vision, values, stories, myths, and legends that comprise the culture of the organization. These are developed over time and bring a sense of community, connection, purpose, and direction as well as guidance for the future. "Managers who understand the significance of symbols and know how to evoke spirit and soul can shape more cohesive and effective organizations — so long as the cultural patterns align with the challenges of the marketplace" (Bolman \& Deal, 2013, p. 264). Meyer and Rowan (1977) also posit that the structure and ceremony of an organization is a symbol in and of itself and reflects the culture of the institution.

The symbolic typology is seen in higher education leaders when they use planning to negotiate meaning; make decisions to provide comfort and support; reorganize to demonstrate accountability and responsiveness; see evaluation as an opportunity to share a ritual; approach conflict with shared values and attempt to negotiate a shared meaning; aspire to develop symbols 
and shared values across the campus; communicate through story-telling; identify meetings as sacred places to develop culture and to celebrate; and motivate through tangible imagery, such as t-shirts or plaques (Bolman \& Deal, 2013; Gamble, 2003; Manning, 2013).

Transactional verses transformational verses servant leaders. Three leadership styles that span the other leadership typologies are transactional leadership, transformational leadership, and servant leadership. Transactional leaders typically lead from a highly structured, authoritative, and top-down management structure that is focused on providing rewards or other resources to their subordinates in return for task completion (Basham, 2012; Stone, Russell, \& Patterson, 2004). They often recognize their staff's needs and find ways to meet them in exchange for something to help reach their goals (Stone, Russell, \& Patterson, 2004). They often have a very narrow focus from the perspective of their discipline specialty, and, as a result, they may not recognize or understand the consequences for complacency (Basham, 2012). On the contrary, transformational leaders provide a vision and have the capability to reframe and learn beyond their specialization (Basham, 2012). They are characterized as charismatic, values-driven heroes who promote engagement in the organization through a shared vision and strive to bring out the best in people. They seek to overcome complacency and identify change as central to progress and survival of the institution and encourage others to be a part of those goals to move the organization forward (Basham, 2012). Servant leaders are similar to transactional leaders in that they seek to meet the needs of others, and they are similar to transformational leaders in that they, too, are focused on bringing out the best in people, but their ultimate focus is service to others (Stone, Russell, \& Patterson, 2004).

Reframing. The leadership typologies are seen as tools for leaders to manage their organizations and make decisions. While leaders may primarily identify with just one typology, 
they are encouraged to reframe depending on the circumstances and environments they face to process what is occurring and inform their decisions. The right frame helps leaders "know what (they) are up against and, ultimately, what (they) can do about it” (Bolman \& Deal, 2013, p. 10). It also allows leaders to better understand their institutional missions and culture and adapt them over time (Gayle, Tewarie, \& White, Jr., 2003).

\section{Mission-Building and Strategic Planning}

"In order to secure their place in the modern, knowledge-based economy, universities everywhere are being forced to carefully reconsider their role and the relationships with their various constituencies, stakeholders, or communities" (Jongbloed, Enders, \& Salerno, 2008, p. 303). The creation of this purpose, often reflected through the mission, vision, values, and strategic plan for a higher education institution, is often the responsibility of not only that institution's president but other leaders across the institution. The mission statement provides a nuanced understanding of the institution's ideology and purpose; helps leaders set goals, prioritize and plan; and provides a shared vision to engage all the individuals connected to the institution, including faculty, staff, students, alumni, and donors, as well as prospective members of those populations (Morphew \& Hartley, 2006). While most universities incorporate some combination of research, teaching, and service into their mission, land-grant universities also have the added responsibility of carrying out the engagement mission of the Morrill Act, which spans all three of the other areas, as depicted above.

Jongbloed, Enders, and Salerno (2008) explore the role of the higher education mission further: "Universities are expected to be excellent and relevant (in their teaching and research); to be entrepreneurial and caring (in their approach to students, communities), to be competitive and collegial (in dealing with other knowledge providers); and to be local and international in 
focus (in teaching and research) at the same time" (p. 318). As changes take place in society, the mission of higher education and specific institutions are also often called upon to change with it. The changing environment of higher education in the United States is also reflected in other areas of the world as globalization spreads, the knowledge economy becomes a reality, and universities everywhere are forced to meet the challenges of information technology and distance education, resource allocation and accountability, and the need for reassessing the teaching and learning environment. (Gayle, Tewarie, \& White, Jr. 2004, p. 3)

Gioia and Thomas (1996) considers how economic, political, demographic, and other environmental issues have influenced higher education as an industry, causing it to change in response to become more competitive in the marketplace. This competition is not just with other colleges and universities, but with other organizations and industries as well as public and private funding. Their case study of a large, public research university follows its executive leadership team as it implements a new strategic plan with a goal of becoming a top-10 university while attempting to navigate these changing environmental contexts. Gioia and Thomas (1996) found that the leadership team members' interpretation of the institution's future identity, image, and mission that it aspired to reach through the new strategic plan was key in creating organizational change and helping the organization to become more nimble and flexible to respond to these environmental changes.

As a result of this multifaceted mission, higher education institutions serve and seek to engage a variety of audiences and stakeholders, which impact the direction of leadership decisions related to strategic planning. "Universities these days have very many stakeholders and potential partnerships. Thinking in terms of partnerships with stakeholders has a number of important repercussions on the university, its governance, and the way in which it fulfills its 
accountability requirements" (Jongbloed, Enders, \& Salerno, 2008, p. 318). Stakeholders often influence the research agenda and curriculum and the culture of universities as well as how missions and strategic plans evolve over time. "Present day universities are forced to be in constant dialogue with their stakeholders in society. This may lead to a number of fundamental changes in the relationship between the universities and their environment" (Jongbloed, Enders, \& Salerno, 2008, p. 306).

Place, specifically the community and the state in which institutions are located, also plays a role in mission. This impact is particularly true with the engagement mission of landgrant universities.

Some higher education institutions are particularly committed to the goal of reducing social and spatial inequalities...how the institution relates to its stakeholders, is never shaped entirely by its communities, but also very much path dependent. History and geographyin other words, institutional contingency and regional contingency — will also shape the relationships a university has with its stakeholders. (Jongbloed, Enders, \& Salerno, 2008, p. 308)

The impact of place will be further illuminated in the next section on the history of higher education and higher education governance in West Virginia as well as the WVU history section.

\section{History of Higher Education Governance}

Higher education governance is the "structure and process of authoritative decision making across issues that are significance for external as well as internal stakeholders within a university" (Gayle, Tewarie, \& White, Jr., 2003, p. 1). Despite the conservative, slow embedded organizational culture of higher education institutions discussed above (Bolman \& Deal, 2013; Manning, 2013; Pusser, 2003), for public institutions, states have a tendency to revamp their 
higher education governance structure about every 15 years (Corder, 1992). While only two state coordinating boards for higher education existed prior to 1950 , through a survey of 49 states about proposals made for governance changes from 1989 to 1994, Marcus (1997) found that by 1972, 47 states had some sort of governing body for their higher education institutions. As of as of 1979, 26 states had boards of higher education with a broad range of coordinating authorities, and 21 other states had governing boards just for public higher education (Academy for Educational Development, Inc., 1979). The changes in governance of higher education reflect the growth of institutions and student enrollment and overall diversification of higher education since World War II as well as a desire by the state governments to be more efficient with their use of appropriations (Machesney, 1971). These shifts indicate trends toward more centralized coordination and governance of higher education and away from the decentralized autonomy and flexibility institutions enjoyed in previous decades. However, these trends were most salient in regional pockets, demonstrating the role of place in structural and policymaking choices (Marcus, 1997; Garraway, 1996).

Governance structures also impact the management and performance of higher education institutions, particularly administrators' decisions relating to research, teaching, service, mission development, and distribution of research. In their study of 48 states, Knott and Payne (2004) found that resource distribution and research productivity were higher at universities with a more decentralized statewide governing board. Marcus (1997) found that the state legislators were most accountable to public interests, and that while legislators were the most frequent source of proposals to change governance structures, the proposals by state governing boards were more likely to be passed. 
Uncertainty of political power also influences leadership and organizational design choices. There is a continued dissonance surrounding the value of higher education: universities are frequently criticized by the public and state legislatures for increasing tuition, which is often the universities' responses to decreased state appropriations from the state government. Simultaneously, universities are also criticized of wasting taxpayers' money on basic research that is not applicable to local issues, as well as bloated administrations and overlapping degree programs with other state institutions (Knott \& Payne, 2004). This debate demonstrates the ultimate trade-off in public higher education: declining state appropriations and public support combined with increased oversight from the state government results in an institutional desire for more institutional autonomy and flexibility; subsequently, changes in activities that reflect the behaviors of private institutions (e.g. fundamental research activities and increased reliance on student tuition) reflect less focus on student access and a broader public mission. As a result, increased reliance on revenues other than state appropriations is altering how institutions are budgeting and how their revenues are impacting their expenditures, ultimately altering who they are accountable to and whether they are fulfilling their original missions (Fowles, 2014), which is a continued debate in the land-grant saga, described above.

\section{Higher Education History and Governance in West Virginia}

Like various other states and higher education overall, West Virginia has also experienced this dichotomy of education as a public versus private good as it negotiates various higher education governance structures over time. This section of the literature review will begin with a broader and more historical focus on how West Virginia's higher education system developed, then lead into recent legislative and economic events that have provided a foundation for the research questions. 


\section{Origins}

Higher education governance resides at the state level; consequently, American public higher education reflects the individuality of each of the 50 states. "Higher education in the United States has never been compelled to conform to any one pattern of organization, administration, or support. The vast size of the country and the heterogeneous composition of the population have precluded the establishment of uniformity in higher education" (Cavins \& Kirby, 1939, p. 4). As a result, individual institutions have had the freedom to develop their own missions, recruit students, create curricula, and shape their progress within the direction of their own governing bodies. That variety of responsibility and mission has led to a "vast and confusing array of institutions, both public and private, each with its own traditions, history, and goals" (Jackameit, 1973, p. 4; Woodring, 1968, p. 3). Just like with institutional types, goals, and missions, the governance by the states over higher education has varied as well.

West Virginia's public higher education system is no different. When West Virginia seceded from the Commonwealth of Virginia in 1863, nearly all educational activities were put on hold. However, the new government quickly established free education, allowing for the creation of a state normal school (now Marshall University) and an agricultural college (now West Virginia University), the first two public higher education institutions in West Virginia.

\section{Institution Types}

"Many changes took place in the early years of West Virginia higher education; some as a result of the process of natural evolution and as a reaction to the educational needs of the state, others as a result of educational planning, and some because of political maneuvering" (Machesney, 1971, p. 73). According to Cavins and Kirby (1939), higher education institutions in West Virginia in the early $20^{\text {th }}$ century could be classified into four categories: normal schools 
(i.e. teachers colleges), including Bluefield State Teachers College, Concord State Teachers College, Fairmont State Teachers College, Glenville State Teachers College, Marshall College, Shepherd State Teachers College, and West Liberty State Teachers College; denominational institutions (i.e. private institutions), including Alderson-Broaddus College, Bethany College, Davis and Elkins College, Morris Harvey College, Salem College, and West Virginia Wesleyan College; junior colleges including Beckley College, Greenbrier College, Kanawha College, New River State College, Potomac State College, and Storer College; and other miscellaneous institutions. The latter category represents two institutions that did not fall into any other category and should be considered separately: West Virginia University (the state's only landgrant, flagship, research university with a comprehensive medical center) and West Virginia State College (the historically black land-grant college). By 1971, all major institutions had been established in one form or another (Machesney, 1971).

While the various normal schools were founded for a specific purpose, the development of educators in their local regions, they quickly became an arena for the expansion of higher education all over the United States through the addition of liberal arts curricula. "Their geographic dispersal, less than selective admissions standards, and low tuition attracted local students of average ability and moderate income whose primary interest was not becoming a teacher but earning a (bachelor's) degree" (Jackameit, 1973, p. 21).

\section{The Influence of the World Wars}

The most significant changes (especially those most transformative in a short amount of time) to higher education in West Virginia occurred post-World War II. The world wars completely altered the populations attending West Virginia's higher education institutions and their overall missions, cultures, and activities. Nationally, higher education institutions 
"unreservedly lent their intellectual and physical resources to the effort" (Hennen, 1996, p. 24), and West Virginia's institutions followed this trend. The governor at the time, Matthew Neely, used his inaugural address to pose a call to action to improve the quality of education throughout the state and specifically targeting the flagship, replacing five of seven members of the West Virginia University Board of Governors (BOG) and threatening to fire then-president Charles Lawall, which was approved by the BOG (Machesney, 1971).

In the post-World War II era, technical training was funded and conducted by West Virginia University engineering faculty. Normal schools transitioned their curricula to emphasize patriotism and loyalty. Public and private institutional resources alike were used for food production, scientific investigations and research for the federal War Department, and curricula focused on war propaganda (Hennen, 1996). Post-World War II, public officials "believed that educational leaders were positioned to match West Virginia's impending commercial development, which had been enhanced by wartime productivity, with educational progress" (Hennen, 1996, p. 70). This direction led to further centralization and consolidation of educational governance for both K-12 and higher education, matching national trends.

The nation was also taking on an attitude of directing youth to their "social destiny," encouraging students to pursue the professions and service areas most appropriate to them. "To the $95 \%$ of West Virginia students who were not destined for professional occupations, teachers imparted more drill on the facts needed to back up our theories and practices in government and in life" (Hennen, 1996, p. 74). Simultaneously, higher education institutions were receiving an influx of students as soldiers returned from the war and were making use of the G.I. Bill, leading to an increasing college-going rate and institutions' enrollments (Thelin, 2011). 
After that brief increase in higher education enrollment with the return of veterans following World War II, enrollment declined with the transformation of the coal industry in the 1950s and the development of the chemical industry (Thomas, 2010). Curricula in the colleges with close proximity to the coalfields began to transition their curriculum to focus on vocational and technological subjects (Thomas, 2010).

\section{Governance of West Virginia Higher Education}

Also during the post-World War era, the West Virginia State Legislature created an interim committee to evaluate higher education. Six separate boards of regents for higher education existed in 1901, and all of public higher education was governed simultaneous by a single State Board of Education in 1919 (Machesney, 1971), making planning and coordination unwieldly and inefficient. Their Strayer Report found that "the state had assumed responsibility for a number and variety of institutions of higher education beyond the apparent disposition and policy of the state to provide for adequate support and development” (Machesney, 1971, p. 79), which led to a State Council of Higher Education to bring representatives from all institutions together to evaluate and share best practices. The report also recommended that the institutions be removed from the State Board of Control in favor of relying on their individual governing boards for fiscal and academic responsibility (Joint Committee on Government and Finance, 1956). Later, the state legislature's Brewton Report proposed separating all higher education institutions from the State Board of Education, which oversaw K-12 as well as higher education, in favor of a streamlined governing board (Machesney, 1971). While it did not pass at the time, it was a significant move because it was the first time higher education was emphasized in this way as well as the need for streamlining. Another failed attempt was made in 1961, but the same failure to move beyond the education committees in either house was the same as 1957 
(Machesney, 1971). Creating a Board of Regents for higher education finally passed in both houses in 1969, an evolution from three separate governing structures (Corder; 1992;

Machesney, 1971). "The impact of overwhelming enrollment growth and increasing demands on the financial resources of state governments made it imperative that education at all levels be an orderly, planned, and coordinated program" (Machesney, 1971, p. 116).

While the state-based governing structures ebbed and flowed with the changing political powers throughout the history of higher education in West Virginia (experimentation with governance and educational structure was common all around the country in the $20^{\text {th }}$ century), all of West Virginia's public higher education institutions were placed under control of the consolidated Board of Regents on July 1, 1969 by the state legislature for economic and administrative efficiency (Corder, 1992). It was the first time all governing, policy, and financial matters of the public higher education institutions were placed under the control of one entity. This step abolished WVU's Board of Governors and removed the other public colleges and universities from under the jurisdiction by the State Board of Education (Hoblitzell, 2000; Acts of the Legislature of West Virginia, 1969). The change was due to the State Board of Education's emphasis on K-12 education and a need for higher education support. "A bumpy history of administrative arrangements and the vagaries of West Virginia politics with regard to public higher education rendered as anticlimactic the creation in 1969 of a consolidated governing board" (Jackameit, 1973, p. 22).

This change was motivated by concerns to insulate the State Legislature from lobbying by the institutions, improve operational and budgetary efficiencies, and encourage statewide planning (Academy for Educational Development, Inc., 1979). The new Board of Regents was also an attempt to bring consistency to a diverse array of institutions in terms of their geography, 
accessibility, culture, and populations served. However, within 20 years of the governance change, higher education budget allotments by the state legislature dropped from $20 \%$ to $12 \%$ (Hoblitzell, 2000). "This decline in revenue share reflected a state whose economy was largely stagnant in the 1980s. Inflation and continued declines in the coal, chemical and steel industries left the state with few new tax resources. Tight budgets fueled the dissatisfaction of public higher education institutions with the Board of Regents" (Hoblitzell, 2000, p. 2).

In addition to the budget challenges, there was an obvious split between the two largest institutions, West Virginia University and Marshall University, and the rest of the institutions. The tensions were mostly due to budget allocations, enrollment differences, research agendas, and types of programs offered (e.g. graduate and professional education).

The geography of the state tends to divide the southern and northern parts from each other. The two great trunk lines of railroad make communication across the state from east to west easy while travel north and south is difficult. Not only so, but a number of towns in which state institutions of higher education are located in regions not easily accessible because highways are determined in their courses by the necessity of avoiding, as far as possible, the mountains which break up the state into a number of comparatively distinct areas.

The location of the majority of the state institutions was determined by historical accident and by political determinations rather than as the result of any carefully formulated plan. For example, the normal school at Shepherdstown is located on the site of an academy, the junior college at Keyser is on the site of a state secondary school which was founded at the time when local districts in that part of the state had no high schools. 
Seven of these institutions are located on the extreme borders of the state, and are, therefore, less accessible to the people of the state than is desirable. If we add to what has been said regarding the location of institutions on the borders of the state, the fact that three of the institutions for white students are in towns which are off the railroads, it will be seen that access to West Virginia's higher institutions is very difficult. The institutions referred to are the normal schools at West Liberty, Glenville, and Athens. (Brown, Dearborn, Reeves, Works, Zook, \& Judd, 1928)

In 1979, the Academy for Educational Development, Inc. submitted a report to the West Virginia State Legislature's Joint Committee on Government and Finance and The Joint Subcommittee on Higher Education assessing the state of the Board of Regents in terms of "management, control, and supervision of all public higher education institutions; management of state-wide higher education activities, budgeting, and planning" as well as making recommendations for future governing structures for higher education in the state (p. 16). While the Academy for Educational Development, Inc. (1979) shared that the motivation for the study was their "conviction that a strong, purposeful system of higher education is critical to the societal and economic development of the citizens of West Virginia" (p. 2), the assessment does not specifically state what individual or entity called for the assessment or how it was funded. The recommendations included two options. The first recommended replacing the Board of Regents with a coordinating board, which would focus more on state-level planning and activities rather than governance of the individual institutions, and transition those responsibilities to three governing boards, one for the state universities, the School of Osteopathic Medicine, and the College of Graduate Studies; one for the four-year colleges; and one for the community colleges. The second recommendation involved maintaining the Board of 
Regents but in a substantially expanded approach that better incorporated the individual institutions in decision-making and planning processes to "reduce campus and constituent isolation from decisions" (Academy for Educational Development, Inc., 1979, p. 27).

Ten years after the Academy for Educational for Education Development was released, the Board of Regents was dissolved in 1989 after 20 years of governance. Frequent turnover by chancellors and other personnel challenges created some instability coupled with dissonance surrounding calls for different governing structures based on institution type, creating the foundation for an environment ready for change (Corder, 1992).

Through Senate Bill 420, West Virginia's higher education governance structure shifted to a two-board system to focus governance but maintain the centralization of structure and policymaking, which also gave a new governor an opportunity to appoint new members rather than keeping on the previous members of the Board of Regents (Hoblitzell, 2000; Corder, 1992). The University System Board of Trustees served the four-year colleges and universities and the College System Board of Directors served the two-year community and technical colleges. The most significant improvement seen from this restructuring was the college-going rate, which improved 20\% in a decade (Hoblitzell, 2000).

Today, each four-year institution has its own Board of Governors and the West Virginia Higher Education Policy Commission, established in 2000, provides oversight and develops policy agendas. Following the passage of HB 2542 during the 2017 legislative session, more autonomy in human resources-related issues was given to WVU and Marshall University, allowing the institutions more flexibility in personnel decisions, including considerations of skillset and experience (beyond seniority and years of experience) for regulations involving job position classification and compensation (West Virginia University Bureaucracy Busters, 2017). 
Any other four-year college and university within the state can also apply to the Higher Education Policy Commission to receive the same right.

The West Virginia Community and Technical College System oversees the two-year community and technical colleges. Though most of the state's community and technical colleges were established as branches of four-year institutions, the structure of the four-year and two-year institutions recently shifted as national trends in both education and industry evolved. In 2008, the West Virginia Higher Education Policy Commission led a statewide separation of the twoyear community and technical colleges from the four-year institutions (Mountwest Community and Technical College, 2016).

While some of the challenges discussed in the State Department of Education survey (Brown et al., 1928) were addressed over time, such as the modernization of transportation to increase access around the mountains, many of the same challenges still exist today. Limited access to broadband internet continues to separate communications across the various regions of the state. Reliance on fading natural resources in failing local economies continues to take precedent over opportunities for continuing education. Individuals struggle to overcome cultural barriers and norms to move beyond the only homes they have ever known for opportunities outside those communities. Continually increasing statewide budget cuts, including spending 21.6\% less per student in FY2014 than in FY2008, a \$1,800 per student reduction (Mitchell, Palacios, \& Leachman, 2014), hinder the institutions from creating opportunities to overcome these challenges.

Governing boards play an important role in higher education policymaking because they serve in not only an advocate capacity but as a buffer to inquiries from external populations (Academy for Educational Development, Inc., 1979). That advocate capacity also extends to 
being accountable to all the institution's relevant constituent groups (e.g. students, faculty, staff, alumni, donors, the community, policymakers, etc.) and maintaining mission, values, and social goals (Martin \& Samels, 1994).

\section{Economic Climate}

"The nation has the economic ability to provide adequately for higher education ... the problem of financing the public institutions of higher learning does not stem from a lack of financial ability, but rather from a lack of public understanding of the financial needs of higher education, and lack of modern and effective tax structures" (Joint Committee on Government and Finance, 1956). West Virginia's state government has grown $24 \%$ over the last 10 years while population and revenue streams decreased (Gaunch, 2016). However, only 11\% of the state's base budget, or about $\$ 497$ million, is appropriated for higher education (O’Leary \& Boettner, 2016). In fiscal year 2015, West Virginia cut higher education more than any other state except Wyoming, decreasing the per-student funding by more than $20 \%$ since the 2008 recession (Mitchell, Palacios, \& Leachman, 2014). This cut resulted in the state's public higher education institutions decreasing their budgets by three percent, or by $\$ 9.6$ million overall, equating to about $\$ 330$ per student (Mays, 2014). This ultimately means personnel cuts for the higher education institutions as well as tuition increases to decrease costs and increase revenue, respectively. For example, West Virginia University responded by eliminating 13 employees and leaving more than 100 positions vacant, while Marshall University eliminated 36 positions and left 17 unfilled to reduce their respective workforces in 2014 (Mays, 2014).

Despite these ongoing cuts to higher education by the state government, the state's public higher education institutions continue to generate revenue, making one of the largest economic impacts of any state agency or entity. In 2014, the state's public colleges and universities spent 
$\$ 1.5$ billion, which generated another $\$ 1.2$ billion in additional revenue, making public higher education's overall economic return to the state $\$ 2.7$ billion (Bowen \& Meszaros, 2016). This effort also supported approximately 24,000 in-state jobs (Bowen \& Meszaros, 2016). WVU has contributed significantly to this total, generating nearly $\$ 1.3$ billion while directly employing 6,600 (with another 4,600 jobs supported through its spending efforts) (Bowen \& Meszaros, 2016).

\section{WVU History}

West Virginia University's history as a higher education institution has been captured comprehensively via two books: William Doherty and Festus Summers's (1982) West Virginia University: A Symbol of Unity in a Sectionalized State and Ron Lewis's (2013) Aspiring to Greatness: West Virginia University Since World War II. David Hardesty's (2007) memoir of his presidential administration also situates his administration's role in the history through his own perspective while also serving as a source of speeches and commentaries for document analysis.

A prominent theme of these histories is how WVU sought to fulfill its goal of becoming a Carnegie Foundation Highest Research Activity institution (i.e. R1). While WVU achieved that classification in 2015, a premise in these histories, especially Lewis's (2013), is the process of reaching that goal and challenges the University faced in reaching it. Three overarching obstacles include the lack of sufficient financial resources due to the state's perpetually weak economy and declining financial commitment to the institution; persistent and corrosive intra-state regionalism and geographic divide, particularly in public attitudes, state and local politics and the media due to the small state's mountainous terrain and poor infrastructure; and continual shifts in higher education governance systems and state processes. While these challenges were identified early 
in WVU's history, they are themes that continue to shape WVU's mission and policy agenda today.

\section{Research}

Following World War II, WVU lost many opportunities to expand its footprint in higher education, including its research agenda and subsequent funding structure due to financial and governance restrictions from the state of West Virginia. State code prohibited West Virginia's public colleges and universities from accepting federally funded research grants and projects unless they could fund the contract up front. Because the federal government only reimbursed the research projects once they were complete, it was not financially feasible for WVU to fund these expensive research projects. WVU President Irvin Stewart explained in 1950, "Unfortunately, we cannot participate to any extent in such a program because of the fiscal limitations within which we must operate... We were forced to lose the opportunity to climb quickly up the path to doing more research, upgrading its laboratories, and providing opportunities for graduate students" (Lewis, 2013, p. xi). In addition, because the state, and subsequently the University, followed the fiscal calendar (i.e. July 1-June 30), it did not have the legal authority to commit beyond the funds currently available or carryover unspent balances into the next fiscal year because any available budget not spent was returned to the state treasury at the end of the current fiscal year (Stewart, 1958; Lewis, 2013). Any federal grants coming to WVU were routed through the state treasurer's office, making any resources property of the state rather than the University (Lewis, 2013). Simultaneously, the state called on its public universities during this time to increase their research productivity because in 1954-1955, they only allocated $16.5 \%$ of their expenditures to research, compared to the national public university average at 24\% (Joint Committee on Government and Finance, 1956). These 
limitations hampered WVU from pursuing top-tier federal research funding, setting the institution back following World War II when other universities were gaining ground.

While WVU's development and increasing enrollment mirrored national trends of postwar expansion toward massification during this time, a simultaneous trend was the separation between the research universities and the undergraduate-focused colleges (Geiger \& Sorber, 2013). With its research goals in place, WVU was caught in the middle of this separation. It sought to be among the major research universities but failed to make it into those ranks because of its inability to fund federal research grants and the lack of state support for those endeavors. 'Since WVU occupied a 'muddled middle ground,' not inconsequential but yet not among those institutions now 'knocking on the door of greatness,' competitors Penn State and Pittsburgh among them, the central issue facing WVU was how to position itself closer to that door of opportunity" (Lewis, 2013, p. 74; Miller, 1964). The competition, particularly for research status and funding, is not unlike the competition seen in the higher education marketplace today not only for research status and funding, but enrollment and value in the public's view (Duderstadt, 2012).

United States Senator Harley Kilgore believed it was Congress's responsibility to set the nation's federal research agenda (Lewis, 2013; Kleinman, 1994). Because he represented the entire state of West Virginia, that influenced him to support a federal science agenda that benefitted the state in general rather than a specific institution (i.e. WVU). WVU President Paul Miller "reorganized the University in hopes that it would become the leading partner on federally funded projects in Appalachia. That strategy also failed to attract federal revenues to the University. Miller's successor, James Harlow, abandoned the Appalachian focus almost entirely" (Lewis, 2013, p. 5). In the midst of such ongoing research funding challenges, these presidential 
administrations' perspectives on research and how research should be focused reflects a change in the land-grant saga and mission directives at that time because of the initial state focus and subsequent transition away from it.

"To become a research university, WVU had to escape from some state-imposed controls and restrictions" (Lewis, 2013, p. 63). In the mid-20 $0^{\text {th }}$ century, research activity was demonstrated by the amount of private and government funding specifically for that purpose in West Virginia. "During a period when research was receiving the greatest amount of federal funding it ever had, only two of the state's institutions received such funds. During the 19651966 college year, Marshall University received approximately $\$ 6,000$ for contract research and services, while (WVU) received \$2,542,000" (Lewis, 2013, p. 75).

This policy changed for the first time under Stewart's leadership when the West Virginia State Legislature allowed WVU to use $\$ 100,000$ in excess collections as a revolving fund to pursue federal research contracts (Lewis, 2013; Stewart, 1958). Coupled with more similar opportunities and an emphasis on private funding for research support, WVU's research efforts continued to expand under Stewart (Stewart, 1958). By 1990, WVU's research productivity had grown to unprecedented levels, ranking the University for the first time among the nation's top 100 research universities. President Gene Budig emphasized increasing federal research grants, with a goal of increasing revenues from energy prices that would encourage the state to invest in WVU (Lewis, 2013). As a result, major research areas included clean fuels, mine reclamation, cancer research, computer-based technologies, wooden and composite materials for bridges, poultry, economic and population growth patterns in West Virginia, low cost sheet metal coating, and improvement of social services in southern West Virginia counties, leading to increased job opportunities for thousands of West Virginians (Lewis, 2013; The Dominion Post, 1985). 
These disciplines exemplified how WVU began to operationalize its land-grant mission through its research agenda in the late $20^{\text {th }}$ century. WVU also began to move ahead of the curve in terms of technology, research equipment, facilities, and tech-transfer through an early partnership with Siemens. That grant provided computer-based training courses in cooperation with faculty from engineering, computer science, and extension (Lewis, 2013). President Neil Bucklew explained that the grant was an "example of how the state's comprehensive research institution can apply its expertise in response to an economic development need" (Lewis, 2013, p. 229; Toren, 1987), setting the tone for WVU's research agenda as a part of its land-grant mission in subsequent administrations.

\section{Regionalism}

Resulting from its geography and subsequent poor economy and infrastructure, the state of West Virginia's politically, economically, and socially corrosive founding led to regionalism from the very beginning of its history, perpetuating to its higher education institutions and governance of those institutions. "The mountains created a beautiful landscape, but they also divided the state into distinctive regions and spawned an intense sectionalism that only began to break down with postwar improvements in transportation and communications. Competition among institutions for limited resources, reinforced by sectional interests, also played a significant role in the search for orderly governance" (Lewis, 2013, p. 357).

WVU regularly faced criticism for being so far out of the way geographically and culturally from the "greater part of the state's people" (Lewis, 2013, p. 12) and its close proximity to the Pennsylvania border. An early regional fight involving WVU included attempts to relocate its medical school to West Virginia's capital, Charleston. While the move was logical for serving a larger patient population, it contained significant consequences for advancing 
science and the development of modern medicine and new technologies that needed a connection to its Health Sciences Center's home base on campus in Morgantown, which ultimately determined that the medical center would remain in its original location. During a 1951 debate to move the WVU medical school to Charleston, West Virginia, Governor Okey Patteson opted to main the entirety of the state's flagship university in Morgantown. "The governor's closest advisers were convinced that the governor knew he was committing 'political suicide' by choosing Morgantown, but that he believed he had made the right decision for the entire state" (Lewis, 2013, p. 58; The Morgantown Post, 1951).

Changes in governance to the state's other four-year colleges, beginning in the mid- $20^{\text {th }}$ century, redefined the identity of higher education in West Virginia as several West Virginia colleges received permission to rename themselves as universities. WVU President Elvis Stahr noted, "Over the ensuing decades many of the state colleges would be allowed to take the name 'university,' thereby denuding any specific meaning of the term. WVU would have to choose another avenue to defend its status as the state's land-grant public university" (Lewis, 2013, p. 52). This shift resulted in a new regionalism challenge for the state's flagship for years to come.

\section{Regulation}

The aforementioned discussion of how policies relating to research funding and institutional governance are just two examples of how state regulations hindered WVU from reaching its goal of becoming a premier research university. The West Virginia State Legislature had a tendency to pursue a traditional role of centralized governance (modeled after the state's K-12 education system), which resulted in a homogenous approach to treating all higher education institutions the same, regardless of their mission, structure, enrollment, endowment, or 
other defining characteristics. This demonstrated the state's struggle to differentiate research institutions from state colleges.

From 1967 to 1995, state regulation, protest, and reform defined WVU as it struggled politically for less regulation and more autonomy while facing national pessimism about the efficacy of higher education. The movement toward massification after the post-World War II baby boom followed by stagnating enrollments resulting in revenue declines and consideration of reductions in employees and programs only added to the negative attitudes toward higher education nationally (Geiger \& Sorber, 2013) as well as in West Virginia.

(WVU) evolved into a mature institution during this period not only in size but also in its mission as a comprehensive land-grant university. While its mission became more complex, and its impact on the development of the state more widespread, the University's ability to meet its obligations was severely constrained by political controls imposed from the state capital. Sectionalism and the tension between whether political power should rest with central or local authorities have always been destabilizing forces in West Virginia politics. Confined within this context, WVU has always fought for independence in administering its own internal affairs. In retrospect, it would seem that WVU matured as an institution despite the loss of self-governance to a centralized Board of Regents, which controlled higher education during most of this period. (Lewis, 2013, p. 135)

The state Board of Regents, established in 1969, included a Board of Governors for the state colleges, a Board of Governors for Marshall University, and a Board of Governors for WVU. Within a year after this reorganization, state support for WVU decreased 6\% (Doherty \& Summers, 1982; Lewis, 2013; Corder, 1992). Twelve years later, President E. Gordon Gee’s first action as WVU's new president in 1981 was a comprehensive external review of WVU as part of 
his plans for modernization and to establish WVU's efficacy and independence as the state's flagship. He considered the Board of Regents a flawed system and sought to establish ways WVU could distinguish itself from the other public colleges and universities in West Virginia while also demonstrating its investment in the state (The Dominion Post, 1985; Lewis, 2013). He noted, "to be successful, a university must push the 'frontiers of knowledge' in all kinds of research" (Lewis, 2013, p. 169; The Dominion Post, 1985).

(Gee) insisted that legislators had not been willing 'to make the tough kinds of decisions' about higher education and had treated WVU as a drain on the state rather than as a major investment. Unlike a highway department or a department of social services, the University is a catalyst for economic development, and legislative support for the institution was vital for the future of the state. When legislators imposed salary caps, developed centralized classification systems, opposed attempts to implement merit incentives, and imposed overly burdensome regulatory controls on the University, they were not acting in the best interest of the institution. Gee urged legislators to "stop or we are going to have a university only in name and not in reality." (Lewis, 2013, p. 169; The Dominion Post, 1985)

The Board of Regents expired on June 30, 1989, and was subsequently abolished by West Virginia Governor Gaston Caperton. Through Senate Bill 540, the state replaced the governance system with a Board of Trustees to oversee WVU's system, Marshall University, and the state's Graduate College, and a Board of Directors to govern all other state four-year colleges and universities and the two-year colleges (Lewis, 2013; West Virginia University, 2004; Corder, 1992). WVU president Neil Bucklew supported the change in governance, and he nominated WVU alumnus and prominent lawyer David Hardesty to chair the Board of Trustees, who would later serve as WVU's $21^{\text {st }}$ president. 
In 1991, more changes came to the governance of West Virginia's four-year public colleges and universities. The West Virginia State Legislature mandated that each public fouryear institution prepare a report card with data that was comprehensive but easy to read (Lewis, 2013; Manning, 2000). Simultaneously, Caperton established a Higher Education Advisory Team (HEAT) to identify goals and plans for overcoming challenges faced by higher education institutions in West Virginia, including employee accountability, maintaining institutional autonomy and flexibility, open access to higher education, affordability and student financial aid, and economic and workforce development, which demonstrated a view of higher education as a public good (Lewis, 2013; Manning, 2000). While WVU's leadership was cautiously optimistic about HEAT because of the prospect for improving its relationship with the state government and gaining access to resources, "WVU administrators believed that the financial difficulties confronting the University were rooted in a political culture that did not perceive education as an agent of change" (Lewis, 2013, p. 361). Just five years later, through Senate Bill 547, the public colleges and universities were instructed to eliminate weak programs and focus on developing programs of strength that had the potential to contribute directly to West Virginia's economy (Lewis, 2013; West Virginia University, 2004). During this same period, WVU managed to enhance technology, expand libraries, develop student-centered approaches to teaching and learning, and extend services with a direct impact on economic development (Lewis, 2013; West Virginia University, 2004). Senate Bill 547 was replaced by Senate Bill 653 in 2000, through which the state's public universities and colleges were asked to demonstrate their goals and strategic planning through a compact, and WVU's covered a six-year strategic plan, including a facilities master plan and engagement plan for outreach in the state through 2007 (West Virginia University, 2004). 


\section{Budget Limitations}

WVU has experienced a perennial struggle to convince legislators that increasing appropriations is necessary. Because of the institution's ongoing budget challenges, particularly post-World War II, “'Good and able people’ at the University were questioning whether West Virginia could 'afford a first-rate university in all of its modern complexities"' (Lewis, 2013, p. 77).

Over the years, WVU presidents shared varying responses to diminishing state appropriations, how they defined education as a public good, and how they perceived the public's value of higher education. Irvin Stewart believed public money should be devoted to instruction and private funds for living space (Lewis, 2013). Elvis Stahr reflected, "The public simply was not aware that education was "the goose that lays the golden eggs"" (Lewis, 2013, p. 48).

In the 1960s, WVU's requests for increased appropriations to provide faculty with secure jobs and pay raises to help with retention were seen by the state legislature as "selfish" and "uncompassionate" (Lewis, 2013, p. 75), a tension and challenge the University continued to face throughout its history. Faculty salaries in $1957-1958$ to $1967-1968$ ranged from $\$ 4,200$ to $\$ 15,000$ (Lewis, 2013), resulting in significant faculty turnover. Following President Paul Miller's sudden departure in 1966, taxpayers questioned if the move was proof of the state's inadequacy and inability to retain quality faculty and administrators and compete with other states (Lewis, 2013).

Persistent state budget challenges in the 1980s involved the intersection of diminishing funding and increased regulation. "It was the persistently inadequate level of appropriations that the University received from the state, as well as the limitations imposed by that level of 
funding" (Lewis, 2013, p. 203). Simultaneously, the University faced other related challenges: noncompetitive faculty salaries and graduate student stipends, high student-faculty ratios, lack of support for faculty development, inadequate library resources, deteriorating facilities, lack of computers for instruction and modern research equipment, underdeveloped information systems and databases, and declining current expense funding (Doherty \& Summers, 1982; Lewis 2013). Despite these overlapping challenges hindering its ability to carry out its land-grant mission, WVU achieved remarkable success in increasing enrollment, expanding its research agenda, and extending service around the state, which is attributed to the dedication, loyalty, and commitment of the institution's faculty and staff, including the leadership of presidents E. Gordon Gee and Neil Bucklew (Lewis, 2013).

The budget challenges continued into the 1990s, negatively impacting the state's economy and WVU's operations. The restrictions ultimately resulted in a 1990 hiring freeze. The administration responded with a plan to "get smaller and better" (Lewis, 2013, p. 224), ultimately with a goal of improving efficiency. Because the institution was losing more and more state support, it became increasingly dependent on student tuition funds, a trend that has continued for more than two decades.

\section{Evolving Land-Grant Leadership}

Despite all of the challenges related to funding and regulation, WVU nevertheless pursued strategic goals post-World War II that emphasized its land-grant mission by expanding opportunities for access to higher education throughout the state. President Irvin Stewart championed access as part of his administration: "The only 'honorable' course was 'to provide an opportunity for higher education to every West Virginia boy or girl capable of meeting University requirements...We cannot fail them. Common decency dictates that we must do our 
job" (Lewis, 2013, p. 30; Stewart, 1946). Stewart recognized the state's needs and the University's role in providing them, particularly the shortage of doctors, dentists, and nurses in West Virginia and the role the University's medical school could play in meeting that need. He also saw increasing enrollment as an opportunity to expand the University's service mission to the state, reflecting that each graduating class elevated the University (Lewis, 2013; Stewart, 1947).

Similarly, WVU President Paul Miller saw himself as a leader of the national land-grant movement. He "believed that the transforming influence of education should be open to every citizen according to talent rather than social or economic status. Instead of trying to be a liberal arts college, the University should be the catalyst for solving the problems that had shackled West Virginia's development. Miller's avowed purpose was to transform the institution into an agent of change" (Lewis, 2013, p. 72). Miller's principles for expanding WVU's role in the state's social and economic development included strengthening academic disciplines; implementing comprehensive, institution-wide planning to avoid duplication of effort and act efficiently; and finding new ways to coordinate efforts with the state's other colleges and universities. "Higher education should be reconceptualized in order to more efficiently train the state's future leaders, with WVU in the leading role and the colleges serving as regional centers" (Lewis, 2013, p. 80).

Miller's leadership as a land-grant president energized the institution's administration and organizational culture, and he helped to better distinguish what WVU was already doing well, while setting the institution apart from its competitors by being more efficient. For example, due to lack of funding for quality faculty, Miller established interdisciplinary positions for mutually supportive research so he could hire fewer faculty but ones of top quality with better pay and 
benefits. He also established the Appalachian Center as a way of bringing the University to the people of West Virginia (Lewis, 2013; West Virginia University, 2004).

Not unlike other land-grant presidents during the 2012 sesquicentennial of the Morrill Act, Miller took advantage of celebrations of the 1962 Morrill Act centennial and West Virginia's 1963 statehood centennial to focus the attention on WVU's role as the state's landgrant institution because conditions for land-grants had changed substantially.

The old boundaries between rural and urban life had dissipated, and regional communities now formed around large central cities. Consequently, rural and urban problems, agricultural and industrial problems, and community and state problems had become increasingly interlocking. Technology had increased the rate of obsolescence for institutions, tools, and occupational skills. Knowledge was therefore increasingly more complex and uncertain. In this emerging world, continuing and life-long education were essential, and it was now more vital than ever that WVU help people 'to make intelligent adjustments to the changing requirements of occupations, ideas, and institutions'. (Lewis, 2013, p. 80; Miller, 1963)

WVU President Gene Budig also brought a unique approach to leading a land-grant university. He was the youngest executive officer at a land-grant university when he began his administration in 1977 (West Virginia University, 2017). He took a pay cut to accept the position, despite the role being more complex than his presidency at Illinois State University. One way Budig approached operationalizing WVU's land-grant mission was recreating the Committee of 55. Composed of alumni from each county in West Virginia who provided guidance and ideas, this strategy demonstrated his interest in hearing from individuals with "boots on the ground" in every corner and hollow of the state. 
Candidates for WVU's presidency were evaluated based on their connections to the state of West Virginia (i.e. residency), including loyalty toward and affection for the University, the state, and the people (Lewis, 2013). President Neil Bucklew is remembered as a favorite for this qualification because "far more than any previous president, (he) focused on educating the public about the University's role as an engine for economic development" (Lewis, 2013, p. 253). Bucklew demonstrated research as a key component of the land-grant mission, reflecting "The impact of WVU's research reaches deep into the state's economy and far into the future" (Lewis, 2013, p. 255).

\section{Summary}

To prepare for studying West Virginia University's changing land-grant mission in the $21^{\text {st }}$ century, this chapter has examined various characteristics of West Virginia University as a land-grant, flagship, Carnegie Research 1 university as well as the historical aspects of those characteristics as a foundation for interpreting its more recent history. This chapter considered the history of Morrill Act and the resulting saga created and experienced by land-grant higher education institutions as well as the challenges faced by leaders of those institutions and higher education leaders broadly. It has defined higher education as an organization and the approaches leaders take to management within that function, including the role and responsibilities of higher education leaders in institutional mission-building and strategic planning. It explored the history of higher education in West Virginia, including governance and the impact of state policy on the purpose of higher education, which demonstrated how strongly tied West Virginia's history is to that of West Virginia University's. Finally, it highlighted key elements in WVU's history that have influenced its mission today, including research aspirations and reaching the Carnegie 
Research 1 classification; regional influences and the importance of place; state regulation and policy; budget limitations; and the evolution of land-grant leadership on campus.

While all of these areas may appear as independent constructs in the literature, each area is crucial to understanding WVU's past, how it reached its present position, and how its leaders are positioning the institution for the future. That relationship simultaneously presents the gap in the literature and the importance of this study - it demonstrates the opportunity for an institution to serve as a case for understanding the changing land-grant saga and how the land-grant mission can be operationalized through leadership decisions and strategic planning. 
Chapter 3: Methodology 
The purpose of this study was to examine West Virginia University's changing mission and strategic plan over the course of five presidential administrations from 1995-present. I also considered how those changes have influenced the institution's positionality within the landgrant saga and how that shifting positionality subsequently influenced the operations of the institution during these time periods. This study was addressed through the following three questions:

4. How has West Virginia University's mission and strategic plan changed across the presidential administrations of David Hardesty (1995-2007), Mike Garrison (2007-2008), C. Peter Magrath (2008-2009), James Clements (2009-2013), and E. Gordon Gee (2013present)?

5. How did those shifts in mission and strategic plan influence WVU's positionality within the land-grant saga?

3. How did this shifting positionality influence the work of the institution across these periods?

\section{Pilot Study}

To prepare for this dissertation, I conducted a pilot study on this topic in 2017. While the purpose of the study has remained the same, to examine how WVU's mission as a land-grant university and its resulting strategic plans have shifted in the $21^{\text {st }}$ century from one presidential administration to the next, I originally began with two research questions in the pilot study:

1. How has West Virginia University's policy agenda changed across the presidential administrations of David Hardesty (1995-2007), Mike Garrison (2007-2008), C. Peter Magrath (2008-2009), James Clements (2009-2013), and E. Gordon Gee (2013-present)?

2. How did those shifts in policy impact WVU's mission, strategic plan, and positionality within the land-grant saga?

The study featured two data collection methods, document analysis and interviews, to practice and test both types ahead of the dissertation. For document analysis, I focused on the presidential State of the University address transcripts across all administrations identified in the research questions because those offered a finite sample spanning each case. For interviews, I 
chose one participant to interview who was directly involved in strategic planning, missionbuilding, accreditation, academic affairs, assessment, and other aspects of university planning with three of the presidential administrations (i.e. Hardesty, Clements, and Gee) and had strong familiarity with the other two. Her broad and varied experiences provided good starting points for data collection via interviews because our conversation spanned all the presidential administrations and a variety of topics and issues. The pilot study also helped with snowball sampling for the dissertation because of her widespread knowledge of key officials and their roles at the University.

This pilot study informed the current dissertation study through refinement of my research questions, theoretical framework, and interview protocols. I first reassessed the original research questions and added a third for clarity and to further connect them to both the land-grant saga as well as the theoretical framework, organizational saga. In particular, I determined the word "policy" was too broad and didn't fully represent the study's purpose. Next, when reflecting on analysis of the State of the University addresses, one finding was the importance of considering the motivations behind why certain stories, research, programs, and ideas are featured in the transcripts; what the motivations are behind those examples; how they are funded; and the audiences to whom they are targeted. This finding helped to refine the approach to coding as I learned more about those strategies as well as the interview protocols for gathering first-hand information about what was shared in the transcripts. The interview illuminated another possible document analysis strategy_reviewing the mission statements themselves in conjunction with the strategic plans, speeches, and other official documents. 
Overall, the pilot study was a helpful first step in exploring the original research questions and narrowing the purpose and scope of the study. It also illuminated the value of multiple methods and how they intersect in analysis for providing the richest data possible.

\section{Qualitative Inquiry}

A qualitative, inductive methodology was used to explore and address the research questions. Qualitative methods assume that "reality is socially constructed, that is, there is no single, observable reality. Rather, there are multiple realities or interpretations, of a single event" (Merriam, 2009, p. 8). Qualitative research asks questions that interpret individuals' understandings of their world (Merriam, 2009).

The purpose of this study was to examine how a university's mission, vision, values, and strategic plans have changed over time and to position those changes within its identity as a landgrant institution through the documents that represent those changes and the individuals who contributed to their inception. The influence of these details and individual construction of these realities and experiences cannot be fully captured or expressed in a quantitative study, which is why a qualitative methodology was chosen. Qualitative researchers "are interested in understanding how people interpret their experiences, how they construct their worlds, and what meaning they attribute to experiences" (Merriam, 2009, p. 5). As a result, a qualitative approach provided the flexibility as well as a vessel to gather and synthesize the robust, rich detail needed to effectively address the research questions.

\section{Research Design}

The research design used for this study was a qualitative multi-case study. Because of the complexity and variability of this research design type, Merriam (2009) devotes an entire chapter to this type of research design, unlike the other five broad design categories, which are grouped 
into a single chapter. She defines a qualitative case study as an "in-depth description and analysis of a bounded system," or single units "around which there are boundaries" (Merriam, 2009, p. 40). Creswell's (2007) definition of case study is also fitting: "Case study research is a qualitative approach in which the investigator explores a bounded system (a case) or multiple bounded systems (cases) over time, through detailed, in-depth data collection involving multiple sources of information" (p. 73).

Unlike other qualitative research designs, case study does not require particular data collection methods, giving the researcher added flexibility to pursue the data collection methods that best fit the research questions and the theoretical framework (Merriam, 2009). It is also characterized by providing thick description; being grounded, lifelike, and anchored in real-life situations; illuminating meaning; and communicating tacit knowledge (Merriam, 2009).

This study met the parameters of this type of research design because it examined five different bounded systems in WVU's history, or presidential administrations, which contain clearly defined timeframes set by start dates and end dates. This research design was also appropriate for the study because its bounded systems provided finite approaches to data collection, or specific limits to who could be interviewed and which documents should be pursued.

\section{Site Selection}

This study took place on the main campus of West Virginia University (WVU), located in Morgantown, West Virginia. Founded in 1867, WVU is the state's land-grant, flagship, research university with an enrollment of 28,488 students on its main campus and 31,287 students across all campuses. It is accredited by the Higher Learning Commission and is classified as "R1: Doctoral Universities - Highest research activity" as described by the Carnegie 
Classification of Institutions of Higher Education. In terms of athletics, WVU is classified as Division I by the National Collegiate Athletics Associated and is a member of the Big 12 Conference. Because WVU's Morgantown campus is the location of the institution being studied, it was appropriate to conduct interviews here where most participants currently work and reside. There were some recommended participants from past presidential administrations who were no longer employed at the institution and/or living on or near the campus, and I was flexible to conduct their interviews via phone based on their convenience and preference.

\section{Data Collection}

To examine how WVU's mission as a land-grant university and its resulting vision, values, goals, and strategic plan have shifted in the $21^{\text {st }}$ century from one presidential administration to the next, this study used document analysis and semi-structured interviews to understand how those changes have positioned the University within the land-grant saga. This approach to data collection was appropriate to the nature of the study because it combined investigation of the official documentation representing the missions, visions, goals, values, and strategic plans of the presidential administrations in question with a discussion of how they came about with the individuals who were a part of the planning and implementation, providing a more robust approach than any one single method of data collection.

Document analysis. Document analysis is the systematic process of identifying and locating relevant artifacts, assessing their authenticity and accuracy, and developing a system for coding and cataloging them using content analysis, or describing the content of the materials (Merriam, 2009). It is useful for incorporating historical and literary works as well as modern media, speeches, policies, and planning documents into qualitative research designs (Merriam, 2009). 
This study used document analysis to understand how the changes in presidential administrations have positioned the University within the land-grant saga as reflected through each presidential administration's State of the University address transcripts. They also enabled me to observe the presidents' publicly shared perspectives and messages. WVU presidents traditionally present one or two State of the University addresses per academic year. This timing is mostly consistent with the data collected in this study with few exceptions. President Michael Garrison was not in office long enough to present a State of the University address prior to resigning. As a result, the documents collected for his administration included his inaugural address as well as news stories and press releases related to his hiring and resignation as well as a report on his first 100 days as president.

To better balance the focus across each presidential administration, additional institutional documents incorporated included inaugural address transcripts, the 2004 and 2014 accreditation self-study reports prepared for the Higher Learning Commission, related news releases, and strategic planning documents spanning the five administrations, West Virginia University's 2010 Plan: Building for the Future and the 2020 Strategic Plan for the Future. Finally, I collected and analyzed each of the University's official mission statements during these presidencies to observe how they have changed over time and how those decisions connect back with the other documents as well as the information shared in the interviews.

The following 62 documents represent a complete list of the documents referenced or cited directly in the study. An additional 76 documents were reviewed during the analysis process for a total of 138 .

\section{Hardesty}

- Administration Organization Initiatives Brochure (July 27, 1995) 
- New Student Convocation speech (August 20, 1995)

- Inaugural Address (September 8, 1995)

- 1996 State of the University Address (January 16, 1996)

- 1996 Student Affairs Task Force Report (January 16, 1996)

- "West Virginia Higher Education and West Virginia University: Driving Forces that Propel the Development of West Virginia" (Remarks delivered at "Executive with Executive" conference sponsored by the West Virginia Council for Community and Economic Development, April 11-13, 1996)

- Memo regarding the Kellogg Commission's “Returning to Our Roots: The Student Experience" (May 7, 1997)

- $\quad$ Spring 1997 State of the University Address (February 10, 1997)

- “Building a High-Performance Organization at West Virginia University” (March 5, 1997)

- Fall 1997 State of the University Address (September 8, 1997)

- $\quad$ Spring 1998 State of the University Address (February 1998)

- Fall 1998 State of the University Address (October 1998)

- 1995-1999 Presidential Assessment

- Overview of West Virginia University for the New Members of the University System Board of Trustees (August 1999)

- 2001 State of the University Address (September 2001)

- 1999-2003 Presidential Assessment

- 2004 Accreditation Self-Study Report

- 2005 State of the University Address

- 2010 Strategic Plan (September 30, 2005) 
- Leading the Public University (2007)

\section{Garrison}

- West Virginia U. Ignores Controversy and Picks Garrison as New President (News Article, Chronicle of Higher Education, April 13, 2007)

- WVU's next president (News Article, Times West Virginian, April 14, 2007)

- Garrison's path 'home' complete as he is formally installed as WVU's 22nd president (October 19, 2007)

- Inaugural Address (October 19, 2007)

- Transition Issues (First 100 Days Report, December 2007)

- West Virginia U. Roiled Over Alleged Transcript Rewrite for Governor's Daughter (News Article, Chronicle of Higher Education, January 3, 2008)

- Presidencies Derailed: Why University Leaders Fail and How to Prevent It (2013)

\section{Magrath}

- State of the University Address (October 13, 2008)

- Being a Mountaineer in a Spirit that Envelopes You (WVU Commentary, January 8, 2009)

- Inefficient Record-Keeping System to be Corrected through Adopting Best Practices;

Degrees Will Stand (News Release, February 2, 2009)

- One City, One University - and One Strong Local Economy (Guest WVU Commentary with Morgantown Mayor Ron Justice, March 17, 2009)

- The Challenge of an Interim Presidency After a Scandal (Commentary, Chronicle of Higher Education, February 7, 2010)

- Magrath's Account of Presidency at West Virginia U. is 'Self-Serving' (Letter to the Editor, Chronicle of Higher Education, March 21, 2010) 
- The Land-Grant Faith and Its Practice (Speech, WVU's Morrill Act Sesquicentennial Celebration, September 12, 2011)

\section{Clements}

- Summer 2009 State of the University Address (June 17, 2009)

- Fall 2009 State of the University Address (October 12, 2009)

- Summer 2010 State of the University Address (June 23, 2010)

- Fall 2010 State of the University Address (October 11, 2010)

- Fall 2011 State of the University Address (October 10, 2011)

- Fall 2012 State of the University Address (October 8, 2012)

- 2020 Strategic Plan for the Future

- 2020 Strategic Plan for the Future: Lifelong Learning Progress Report (October 2012)

- 2020 Strategic Plan for the Future: Economic Well-Being and Engagement Progress Report (December 12, 2012)

- 2020 Strategic Plan for the Future: 2013 Progress Report

- 2014 Accreditation Self-Study Report

- 2020 Strategic Plan for the Future: Quality of Life Progress Report (December 2014)

- WVU Extension Service strategic plan

\section{Gee}

- Gee Returns to WVU as President (Video, January 2014)

- "Rules of Engagement" (Memo to Executive Leadership Team, January 6, 2014)

- Gee Appointed West Virginia University President—for a Third Time (News Release, March $3,2014)$

- 2014 State of the University Address (October 6, 2014) 
- At 100 years old, WVU Extension still puts knowledge in practice (Commentary, Charleston Gazette-Mail, October 26, 2014)

- 2015 State of the University Address (October 5, 2015)

- West Virginia University offers hope (Commentary, Charleston Gazette-Mail, February 19, 2016)

- Spring 2016 State of the University Address (March 1, 2016)

- Built on Resiliency (Commentary, Charleston Gazette-Mail, July 3, 2016)

- Fall 2016 State of the University Address (October 10, 2016)

- The Role of the University in Promoting Community Resiliency (President2President Blog, December 8, 2016)

- Celebrate WVU's legacy by imagining the state's future (Commentary, Charleston GazetteMail, March 11, 2017)

- Spring 2017 State of the University Address (March 22, 2017)

- Spring 2018 State of the University Address (February 27, 2018)

- Fall 2018 State of the University Address (October 8, 2018)

Interviews. Kvale and Brinkmann (2009) describe interviews as an "active process where the interviewer and the interviewee produce knowledge" (p. 21), the purpose of which is to "understand themes of the lived daily world from the subjects' own perspectives" (p. 27). Semi-structured interviews "seek to obtain descriptions of the life world of the interviewee with respect to interpreting the meaning of the described phenomena, yet at the same time there is openness to changes and of sequence and forms of questions in order to follow up on the specific answers given and the stories told by subjects" (Kvale \& Brinkmann, 2009, p. 150). 
In this study, the semi-structured interviews illustrated the behind-the-scenes feelings, thoughts, intentions, behaviors, and emotions that led to what was published in the documents and illuminated what was learned from the foundational information provided by the document analysis. Because these activities have already taken place and cannot be observed in real-time, interviews provided a reflection on past occurrences that cannot be replicated (Merriam, 2009). Interviewing is also the best practice when conducting an in-depth study with a few selected individuals or cases, which is the structure of this study (Merriam, 2009). As a result, the interviews provided first-hand knowledge about the strategic planning process from the individuals who led it, including how and why decisions were made about the mission statement, vision, values, and goals of the institution. Documents only provide the final and official reflection of the institution at the time; interviews provide insight into how those final decisions and messages were reached.

The semi-structured style of interviewing allowed for that knowledge to arise from the contexts and narratives shared by the interviewees because I was prepared with the public knowledge that resulted from these documents, but not the procedures and processes that were taken to arrive at that point. Semi-structured interviews were also particularly appropriate because while a basic interview protocol was established, the context of some questions varied depending on the individual who was being interviewed as each stakeholder held or have held a different role or set of responsibilities in each administration, providing them varying contextual experiences. See Appendix B for the interview protocol.

\section{Participants}

A very narrow and specific population of potential participants fit the study's criteria. These included individuals who have been involved in past and/or present strategic planning on 
behalf of WVU. They were contacted via email and/or phone to participate in interviews to describe their experiences as part of the strategic planning process and how WVU's mission, vision, values, and strategic plan have changed over time.

Participants were first determined through purposive sampling, or identifying key administrators who could provide insights into the strategic planning and policymaking process based on the literature and documents. Ten participants were identified through the pilot study and literature review and have past and/or present roles in strategic planning, accreditation, government relations, extension, and academic affairs, among other, which grew during document analysis and once interviews began as recommendations made through snowball sampling.

Additional participants were recruited using a snowball sampling approach by asking each participant if they had any recommendations of individuals who would be a good fit. After creating a literature review and conducting initial document analysis, that preparation informed a list of relevant individuals who have been involved with WVU's past and/or present strategic planning to initially recruit for interviews. However, I was also open to additional suggestions to individuals to interview and incorporated that inquiry in each interview to encourage recommendations from the participants. The participant list was focused on gaining the greatest depth and breadth of insider knowledge from institutional leaders, past and present, on the topic at hand. While I was informed of who the best individuals to contact are to some extent based on the aforementioned literature review and previous pilot study, I was flexible about receiving recommendations of others to include (or even some to exclude) based on recommendations of those directly connected to the topic, who can provide that first-hand insight and awareness of how those behind-the-scenes processes work. This sampling and data collection approach 
resulted in 17 interviews. Most of the interviews lasted approximately 60 minutes, but some only lasted 30 minutes due to scheduling restrictions for some of the key officials.

Potential participants were contacted via email about the study and received the cover letter (see Appendix A) in that communication. If they did not respond within two weeks, I followed up with a second email. Outreach via phone calls to their office phone numbers was deemed necessary for follow-up for some participants who were unable to be reached via email. In the email, I introduced myself as a doctoral candidate collecting data for a dissertation, explained the purpose of the study and the data collection process, shared why the individual made sense for an interview, and asked them if they would be willing to participate in a 60minute interview in-person or via a video conferencing platform or phone, if necessary. I also directed them to the cover letter (which was attached to the emails) for more information about the study, the Institutional Review Board approval, and information about confidentiality and privacy.

Participants scheduled an interview directly through me by replying to that email communication. Consent was garnered through the same cover letter provided at the time of the initial email and shared via hard copy at the time of the interview so the participants had access to the document in both print and digital formats. To ensure privacy and confidentiality, all participant names and titles were granted pseudonyms maintaining the same level of power as their current titles or those they held during the administration. All interviews were audio recorded and transcribed. Interviews were conducted in spaces on campus with doors to ensure privacy. Interview participants were reminded of the necessity of confidentiality before, during, and after the interview. Data were and continue to be stored on my password-protected computer for 10 years to allow for the possibility of longitudinal data comparison through a later study. 
Data collected from these participants via interviews were analyzed inductively and compared and contrasted to document analysis.

The participants included:

\begin{tabular}{|l|l|l|}
\hline Table 3.1 & \\
\hline Participant & Role & Administrations \\
\hline Danny & Health Sciences Center & Gee \\
\hline Eddie & Governance & Hardesty, Garrison, Magrath, Clements, Gee \\
\hline Edith & Faculty & Hardesty, Garrison, Magrath, Clements, Gee \\
\hline Frank & Academics & Hardesty, Garrison, Magrath, Clements, Gee \\
\hline Henry & Retired (Faculty) & Hardesty, Garrison, Magrath, Clements, Gee \\
\hline Jackson & Extension Service & Hardesty, Garrison, Magrath, Clements, Gee \\
\hline Jameson & Academics & Gee \\
\hline Joseph & Retired (Academics) & Hardesty, Garrison, Magrath, Clements, Gee \\
\hline Linda & Academics & Hardesty, Garrison, Magrath, Clements, Gee \\
\hline Lou & Retired (Faculty) & Hardesty, Garrison, Magrath, Clements, Gee \\
\hline Mary & Academics & Clements and Gee \\
\hline Nicole & President's Office & Hardesty, Garrison, Magrath, Clements, Gee \\
\hline Samantha & Academics & Garrison, Magrath, Clements, Gee \\
\hline Sean & President's Office & Magrath, Clements, Gee \\
\hline Sidney & Academics & Hardesty, Garrison, Magrath, Clements, Gee \\
\hline Vincent & Academics, President's Office & Hardesty, Garrison, Magrath, Clements, Gee \\
\hline William & Academics, President's Office & Hardesty, Garrison, Magrath, Clements, Gee \\
\hline
\end{tabular}

\section{Data Analysis}

The data from both the documents and the interviews were coded using first-level and second-level coding. The software NVIVO was used for coding, analysis, and analytic memos. The first-level coding strategies originate from three of Saldana's (2015) coding categories: descriptive, versus, and evaluation. The speeches in the collection of documents were also coded with a fourth coding type, in vivo. The second-level coding strategy followed Saldana's (2015) longitudinal coding. Rigor was demonstrated through robustness of using several different coding approaches as well as the integration of Clark's $(1971,1972)$ organizational saga theory, as discussed in the theoretical framework section in Chapter 2. 
First-level coding strategies. Descriptive coding comprised the initial first-cycle coding method used for analysis. Also called topic coding, it identifies and makes meaning of the topic being discussed in a particular passage, to articulate and give context to what is happening in a passage (Saldana, 2015). Descriptive coding can also be used across time periods to show longitudinal change over time, which will be helpful for comparing and contrasting within and across presidential administrations.

Next, versus coding identifies conflict and discourse occurring between multiple entities, whether they be individuals, organizations, ideas, goals, or other phenomena (Saldana, 2015). This coding method is ideal for studies involving organizational theory, like this one, because of its ability to identify differences, including differences in power. When conducting versus coding, Saldana (2015) recommends organizing versus codes into three categories initially: stakeholders, perceptions/actions, and issues. This approach allowed me to observe any conflicts or discourse while still being open to other themes.

Third, evaluation coding is used to consider and determine the quality and merit of particular entities, including policies, programs, organizations, and plans (Saldana, 2015). These codes describe, compare, and predict what is happening in the data and help determine whether whatever entity is being considered meets its goals or ideal standards and allow for recommendations of change. This coding approach was particularly helpful in answering the second research question, which is determining how changes in mission and strategic plan have impacted WVU within the land-grant saga.

Finally, in vivo coding, also known as literal coding and verbatim coding, uses codes pulled directly from the data collected, or terms originating directly from the participants themselves (Saldana, 2015). This coding strategy was helpful for analyzing the speeches from 
the documents collected in this study because it allowed their words to be prioritized and authentically represented the messages they are sharing.

Second-level coding strategy. The second-level coding strategy used was longitudinal coding, which is appropriate to this mission and strategic planning-focused study because it explores how entities, particularly groups or organizations, change and/or develop over time (Saldana, 2015). This coding strategy considers what increases and emerges over time as well as what decreases and ceases; what accumulates over time; any epiphanies or turning points; what remain constant or is consistent; and what is missing (Saldana, 2015), providing a comprehensive way to synthesize the first-cycle codes. It was helpful in answering both the first research question, or comparing and contrasting the differences in mission and strategic plan across the five administrations, as well as the third research question, or identifying how the shifts in land-grant mission and saga positionality are operationalized within the institution.

\section{Role of the Researcher and Positionality}

Taking a constructionist epistemology, or the idea that meanings are constructed based on individuals' social contexts and environments and their engagement with the circumstances around them, this study recognizes that individuals make meaning and understand situations in different ways (Crotty, 1998; Manning, 1997; Broido \& Manning, 2002), another motivation for selecting a qualitative methodology. This approach reflects the motivation and importance of identifying many different individuals in various aspects of each presidential administration studied (e.g. Office of the President, Office of the Provost/Academic Affairs, academic colleges and schools, Health Sciences Center, Extension, etc.) to learn and understand their roles and perspectives of how the University's mission, goals, values, and strategic plans were determined. 
Beyond my epistemology, I possess a strong connection to the phenomenon I studying as well as the setting where it takes place. I am a two-time graduate of the institution and am currently enrolled there as a doctoral candidate in higher education administration. Also in my seventh year of full-time employment as an administrator at the institution, I am very familiar with the institution's missions, vision, values, and goals; its culture; its organizational structure, governance, and strategic plan; and its leadership. In my professional capacity, I am currently an interim director of communications and marketing for an academic college, and my daily work reflects regular interaction with messaging, strategy, speech writing, and the like, which ultimately influences how I think about higher education initiatives broadly. As an undergraduate student, I also worked for the West Virginia State Legislature, for a U.S. congressional office, and as a journalist covering state and local government beats, all of which directly shaped my understanding of the relationship between higher education and government and other key stakeholders.

\section{Trustworthiness and Credibility}

All of these connections to the study and the study's setting had the potential to influence my perspectives as a researcher. To keep these biases in mind, I conducted regular memoing to ensure I remained aware of my close connections to the study and reflected on when it is necessary to acknowledge these, particularly during the coding and analysis processes as well as writing. These memos were created using the Evernote app, which allowed me to access the memos on any of my devices and keep them organized chronologically in a central place. These memos provided an ongoing record of any moments or situations where I should note in my analysis that I have a view or experience that is very similar to or very different from what is presented in the data collection. 
While I have never reported directly to or worked under any of the individuals interviewed or those who composed the documents analyzed in this study or have not interviewed them in any other research study, I have met, participated in meetings with, and/or had conversations with some of them in contexts beyond the focus of this study. Those experiences informed my perspective as a researcher in a way that prepared me to interact with individuals in leadership roles while also building a rapport with them and gaining their trust to allow for an interview that takes the shape of a conversation, resulting in rich detail and descriptions in their accounts. I also recognize that I have a responsibility to best represent and interpret what they have been willing to share as individuals in power with access to confidential or privileged information about how decisions were made and the processes that led to those decisions. I genuinely aim for their stories, accounts, and recollections to guide the research as to represent their experiences as accurately and authentically as possible. However, a challenge I faced with the study was maintaining the authenticity of the participants' stories shared through their interviews while also not revealing so much information that their identities were compromised. That required a balance and thorough contemplation of what information should be shared without compromising their identities. While it is vital to maintain their anonymity and protect their identities as human participants, it is just as vital to ensure that their experiences and reflections are represented accurately in depicting the institution's history and changing mission and strategic planning.

The credibility of this study was further pursued through data triangulation, or "comparing and cross-checking data" collected from different data collection methods at different times (Merriam, 2009, p. 216). This approach to trustworthiness, credibility, and internal validity is appropriate for this study because it uses both document analysis and 
interviews. Merriam explains that "with regard to the use of multiple methods of data collection, for example, what someone tells you in an interview can be checked against . . . what you read about in documents relevant to the phenomenon of interest (Merriam, 2009, p. 216).

\section{Ethical Considerations}

The ethical considerations for this study shaped the methodological decisions made from the beginning of this study's inception. From my first dissertation planning meeting with my committee, we discussed the vulnerability of not only the participants but also other key administrators being discussed throughout the course of the study, including the presidents themselves. That is what makes this study so humanizing - it is a reflection of and by the leaders who have shaped the last five presidential administrations at West Virginia University. Their reputations as higher education administrators - and their supervisors, the presidents themselves - are at stake based on how this study and its findings will be interpreted. To ensure comprehensive understanding by the University's institutional review board, I completed a phone conversation and email correspondence with a representative of the institution's Institutional Review Board (IRB) and discussed the importance of maintaining confidentiality after receiving IRB approval.

One of the most vital decisions made in the research process based on ethical considerations was who to interview. While one of my committee members and a few participants encouraged me to reach out to the presidents themselves for interviews, I opted to not do so at this point because it would be impossible to mask their identities in compliance with protecting the confidentiality of human sources without masking the institution. Instead, I have chosen to focus on the administrators and staff who were part of the presidents' administrations individuals, while in the public eye, are less so than their presidential public figure counterparts. 
There are also broader ways to mask their identities and positions through appropriate pseudonyms. One of, if not the most, important parts to the context and authenticity of this study is place - the institution at which and the state in which this study is occurring. For example, Marek (2005) chose to not identify institution type in a dissertation considering how college and university missions are portrayed in the media, which greatly limited the findings from textual analysis of media clips. At this point in the study, I am not willing to compromise the authenticity and richness of the context that place provides.

\section{Limitations}

The most significant limitation to this study is the participants themselves, which is directly tied to the ethical considerations above. The participants identified in this study for interviews are considered what Kvale and Brinkmann (2009) identify as elites, or individuals of power. There are many challenges associated with interviews involving this type of population, including access, bias, confidentiality, and authenticity.

With regard to access, some limitations included locating their contact information, successfully contacting them, and actually finding a time to meet and scheduling the interview. Kvale and Brinkmann (2009) recommend being flexible with the timing (e.g. giving several interview time options to work around their busy schedules) as well as with the formats (e.g. not only offering the option for in-person interviews, but also video conferencing), which I employed regularly.

Bias can be a limitation for the participants because of the possibility of "talking tracks," or agendas presented by the participants. They are accustomed to being asked and subsequently sharing their opinions and thoughts, and they may try to tell the interview what he or she wants to hear or drive the conversation by shaping their own agendas or promoting their own 
perspectives. Kvale and Brinkmann (2009) encourage interviewers to use a semi-structured interview format to have a plan going into the interview (including a pre-established direction of what should be accomplished) as well as questions to fall back on if "talking tracks" do appear, which I relied on as needed.

As discussed in the ethical considerations section, ensuring participants' confidentiality was a potential limitation because elites' identities are more difficult to mask than most participants'. Kvale and Brinkman (2009) encourage use of strong pseudonyms for both names and titles to best maintain this confidentiality and privacy. Similarly, authenticity can also be difficult to maintain due to this same reasoning. Because they are in the public eye so often, elite participants are well aware of how what they say can be perceived, which could influence the authenticity of what they chose to share in the interview.

A separate limitation beyond the interview participants involves the representation of the available strategic planning documents as well as speeches. Each presidential administration does not contain the same quantity of speeches or strategic planning documents because of the duration of their administrations and/or because of their approaches to strategic planning and giving the State of the University address. As a result, it is possible for some administrations to have more documents available for analysis than others. 
Introduction to the Findings 


\section{Introduction}

The following six chapters of synthesized findings and themes from the document analysis and semi-structured interviews are organized chronologically by each case: David Hardesty, Michael Garrison, C. Peter Magrath, James Clements, and E. Gordon Gee. Each of these cases is organized to first discuss how the land-grant mission was operationalized through strategic planning, major goals and initiatives, and the work of the institution, followed by how the land-grant mission was envisioned, defined, and described by each of the presidential administrations. The concluding chapter will feature a synthesis of themes across the five cases and discussion of how the land-grant mission has changed over time.

Before moving into a discussion of each case and its respective findings, I open first with a brief overview of the process of and purpose behind strategic planning broadly through the voices of three participants. They provide perspectives of how WVU's early approach to strategic planning fit into what was taking place historically in higher education.

Strategic planning became a more common tool for university presidents and their administrations in the 1970 s as the external competition for students became fiercer. Higher education institutions borrowed ideas and strategies from industry, healthcare, and government to create their own plans and models for planning ahead. Thoughts about strategic planning in higher education in general were shared in the interviews by William, Frank, and Linda.

William $^{1}$, a retired faculty member and administrator who served in leadership roles in strategic planning during his career, presented perspectives on the history of strategic planning not only at WVU but in higher education as an industry. In his view, universities began to seriously use strategic planning in the 1970s. By that time, "business had already determined that

\footnotetext{
${ }^{1}$ Pseudonyms have been assigned to all participants.
} 
there was value in focusing on certain directions, broad themes, and then to create a structure that allowed you to do two things." William went on to describe the strategic planning structure in the following sequence and how it could relate to or be a model for strategic planning for higher education.

One, analyze your external competition. From that analysis, determine what you needed to do to position yourself as a more competitive and effective organization. And then two . . . use those insights to create a sense of direction with enough specificity that you could . . . It could influence and guide your decisions. So, external analysis led to internal guided action, smarter action.

Strategic planning has also given institutions the opportunity to include the greater campus community into the decision-making process, allowing for input, feedback, and ideas. This approach allows higher education leaders to gain buy-in and support from their constituents for carrying out the plans, giving them the chance to be more useful and relevant. According to William,

When universities plan well, incorporate the community in thinking through and working in concurrence on where they are trying to go, you've got a much better chance of getting there. When you make decisions and implement decisions. When you spend money where your mouth is. When you say this isn't just hollow rhetoric, ... Those who help us step up [will] be particularly supportive because it's a priority.

Strategic plans can also be used to leverage accountability for results later on, even when transitions and leadership changes occur, according to William. "When a president leaves and a next president is selected, you've got that momentum and you can build on it." Thus, he argued, 
it is critical to "think and act and implement strategically . . it's not some small group top exercise. It's an institutional exercise. And it doesn't stop."

Strategic planning became more a commonly used tool by university presidents in the 1970s and 1980s. By the mid-1990s, the timeframe for which this study begins, strategic planning was already a common tool for university presidents and their staffs to employ (Sullivan \& Richardson, 2011). As William related, "By the time you're starting your study, universities understood the advantages of acting that way. It was part of good executive management." However, he cautioned, not everyone in the role of the presidency utilized that approach. "When I think of Hardesty to Gee, I think that people came with different styles and personalities that reflected their own personal experience and, to some extent, strategic analysis and action was more [sic]. Some had that in their tool chest better than others."

Yet, each president has brought his own approach to strategic planning and missionbuilding. Frank, a key official from the Office of the Provost, explained, "Each president wants his or her stamp on the university. So, if you're at the tail end of the last strategic plan, you let it finish. If you're at the beginning of somebody else's strategic plan, you probably shelve it and move into something different that has your imprint on it." Linda, another administrator with a leadership role in writing strategic plans, has also observed this desire for a fresh start from the administrations in which she worked. "Any time a president comes in, they're going to have their own priorities and goals for their administration. And we're seeing that now." She gave the example of President Gee.

When [Gee] came in ... You know, it wasn't that the goals of the 2020 plan weren't great, but . . . because they are so inclusive, we could continue on with that plan. But at the same time, [Gee's] agenda wasn't [Clements's] agenda. So, every time a new 
president comes in, I think that change in leadership does mean that there's going to be a change in the course of the University.

Over the course of the next six chapters, each of the five presidents' strategic planning, goalsetting, and mission-building approaches and messages are examined, followed by a synthesis across the five as to how those approaches, processes, and messages have changed.

First, we will explore the presidency of David Hardesty. A nontraditional president with a background in law, business, and state government, his presidency was initially characterized by his lack of experience in higher education. After working diligently to overcome early critiques of his nontraditional path to the presidency, he pioneered several innovative initiatives focused on students, improving organizational efficiencies, and building community engagement across the state with a reorganized Extension Service while navigating several changes in higher education governance and appropriations cuts that impeded the work of the institution along the way. His administration began to look more nationally toward the end of his tenure as it developed goals related to developing excellence in all areas of the institution, including students, faculty, teaching, research, and service, which were captured in a formal strategic plan requested as part of accreditation from the Higher Learning Commission.

After Hardesty's retirement, Garrison was chosen by the Board of Governors as WVU's next president. An even more controversial selection due to his close ties to state politics and lobbyists and even less higher education experience, Garrison's administration was nearly doomed from the start because of the deluge of criticism and doubt from faculty. Despite some quick gains of political capital through morale-building staff pay raises and a childcare center, his administration was over nearly as quickly as it began following an academic recordkeeping scandal that resulted in a high-profile graduate student receiving a degree she had not met the 
requirements to earn. This resulted in a purging of the University's leadership team and the resignation of Garrison himself, leaving little time or capital to begin any long-term planning process.

Next, Magrath was brought in as an interim president tasked with healing, restoring, and rebuilding the campus community and the University's state and national reputation as a landgrant university. Rather than pursuing any new goals and initiatives or embarking on a long-term strategic planning focus, his task was "righting the ship" and laying the foundation for his successor, the next permanent president, to have a clean slate from which to plan and lead. He used his experience and network as a prominent national leader in higher education, specifically of land-grants, to help restore the University's commitment to the land-grant mission and national presence with broad calls to action focused on community engagement, rallying the campus community and key stakeholders like alumni, donors, and state government around the land-grant mission of service to West Virginia.

Clements was the permanent president selected following Magrath's interim term. A traditional president coming up through the academic ranks as a faculty member and provost, he immediately earned respect and buy-in from the campus community even though he was young and this role was his first presidency. A collegial leader intent on uniting the campus, Clements came in with immediate intentions on pursuing a strategic plan, both for his own learning and acclimation but also to bring the campus together under unified goals. He is remembered for his focus on research and aspirations for reaching the Carnegie Foundation's esteemed Research 1 status as well as his external, outward-facing engagement with alumni and donors and pursuits toward a more diverse, globalized, and welcoming campus. In contrast, he is simultaneously critiqued for the generic, safe, and unassuming goals he pursued and his "cheerleader" approach 
to leadership, a leader who stayed within his comfort zone. After nearly five years in the role, he left to take over the presidency at Clemson University.

Following Clements' departure, E. Gordon Gee returned for his second tenure as WVU president in an interim capacity and to lead the search for the permanent replacement. However, after just two months in the role, the Board of Governors invited him to stay on permanently. He has since returned the University's focus on the state. He unofficially laid Clements' 2020 strategic plan to rest while pursuing his own strategy of fulfilling the University's obligation to the state by seeking ways to improve citizens' education, health and well-being, and prosperity, three pillars he has used to guide all of the work of the institution during his administration thus far. However, with no formal conclusion to the 2020 plan or introduction to the planning process for its successor, it is unclear what strategy is in place for the future. 
Chapter 4: David C. Hardesty Jr.'s Administration 


\section{Figure 4.1 Hardesty Presidency Timeline}

\section{July 1, 1995}

- First day of presidency

- Launched "student-centered" initiative

\section{July 27, 1995}

- Launched "Administrative Organization Initiatives"

\section{August 1995}

- New Student Convocation created, a welcome event for all new students

\section{5-2000}

- Senate Bill 547 active, calling for West Virginia colleges and universities to focus resources on programs and courses that offered the greatest opportunities for students, maximize technology, and provide competitive salaries to all employees. As a result, WVU required to reallocate $\$ 32$ million of its existing budget over five years to meet legislative mandates.

\section{6}

- WVU acquires West Virginia Institute of Technology, which is renamed to WVU Institute of Technology.

1997

- Facilities Management Plan launched

- Integration 2000 announced, a plan to unify and modernize technical operations across the entire campus prior to $\mathrm{Y} 2 \mathrm{~K}$

- WVU Research Corporation established

- WVU Hospitals formed partnership with United Health Center in Clarksburg, which eventually evolved and expanded to be part of what is known today as WVUMedicine

\section{8}

- WVU Extension restructured with new focus areas on workforce education and job accommodation, sustainable agriculture and agromedicine, food safety and nutrition, and child care

\section{9}

- Office of Technology Transfer created

- Requests-for-proposal period opened for new research park (but never materializes)

\section{0}

- Senate Bill 653 implemented, requiring an assessment of the state's colleges and universities to determine state appropriations and be used for planning from 2001-2007. In response, WVU publishes, "The Compact Between West Virginia University and the State of West Virginia." 
2004

- 2010 Strategic Plan announced in response to requirements from the Higher Learning Commission following the 2004 Accreditation Self-Study.

2007

Hardesty retires as president and returns to the faculty at the WVU College of Law.

\section{Figure 4.2 Hardesty's Organizational Saga}

\section{Stage 1: Initiation}

- July 1, 1995: Hardesty begins tenure as president of WVU amidst tumultuous tension and criticism from the faculty as a nontraditional candidate who was not deemed their first choice in the search process

- Kicks off student-centered initiative on first day of presidency with a press conference

- Follows up at the end of July 1995 with second major initiative "Administrative Organization Initiatives," focused on improving operations in response to cuts to state appropriations

\section{Stage 2: Fulfillment}

- President from 1995-2007

Personnel (Faculty and Staff)

- Calls for culture change focused on quality, greatness

- Improved internal communications

- Responds to Senate Bill 547 with mandated salary increases, operational efficiencies, and investment in campus infrastructure and related resources

- Hires new leadership for social justice

- Establishes professional development efforts (e.g. LEAD program for mid-level managers)

- Revisions to promotion and tenure guidelines

- Launches Research Task Force, which eventually establishes WVU Research Corporation

Programming (Visible practices; mission, vision, and values)

- New vision statement

- Focuses on four goals: teaching, research, service, technology

- Integration 2000

- Facilities Master Plan

Social Base (Alumni, donors, community)

- Rapport as an alumnus and West Virginia native (wife Susan contributed to this area, too)

- First capital campaign in history 
Student Subculture (Students)

- First major initiative was becoming student-centered (i.e. created Student Affairs Task Force)

- Increased engagement with student government

- Established Mountaineer Parents Club

- Ended Grant Street block party to establish a culture of student safety; launched FallFest as an alternative

- Created New Student Convocation

- Created WVUp All Night

- Resident Faculty Leader program

- Operation JumpStart (new approach to orientation and retention; revamped orientation course; more efficient processes for advising, registration/scheduling, financial aid, and student accounts)

- Established a student advocacy program that helps traditional students and their parents solve problems and helps nontraditional students negotiate child care and welfare problems

Imagery (Symbols, traditions, culture, events)

- New taglines and marketing campaigns

- Relaunched Festival of Ideas lecture series

- Ended Grant Street block party to establish a culture of student safety; launched FallFest

- Created New Student Convocation to welcome new students to campus

- New facilities through Facilities Master Plan 


\section{Operationalizing the Land-Grant Mission: Strategic Planning and the Work of the Institution}

David C. Hardesty Jr., WVU's $22^{\text {nd }}$ president, was hired following long-time president Neil Bucklew, who rejoined the faculty ranks of the College of Business and Economics after his retirement as president. A nontraditional president who did not follow the typical academic administrative path, Hardesty came into the role after a distinct career as an attorney at Bowles Rice in Charleston, West Virginia. He had also served as the West Virginia State Tax Commissioner during Senator John D. Rockefeller IV's first term as governor. Prior to being named president of WVU, Hardesty's only previous higher education experience was as an instructor at the WVU College of Law and as a member of WVU's governing board. He was also a WVU alumnus, having graduated with a bachelor's degree in 1967. While an undergraduate, he served as student body president and won the Rhodes Scholarship, known as the world's most prestigious scholarship, which included an opportunity to study abroad at Oxford University in the United Kingdom. He earned both bachelor's and master's degrees in philosophy, politics, and economics. He later went on to earn a Juris Doctorate from Harvard Law School. Hardesty also had the experience of being the parent of a legacy student as his daughter enrolled at WVU while he was president (West Virginia University College of Law, n.d.).

From the moment he was hired, Hardesty faced a tumultuous interpersonal environment because of his status as a nontraditional president. Before he ever arrived on campus, he faced critiques and doubts about his qualifications and his intentions from the campus community, especially faculty, as well as concerns about his political aspirations. Many individuals did not have confidence in or support the hiring decision because he came from a legal and political background rather than a traditional career trajectory in academia. One faculty member went as 
far as to file a lawsuit against Hardesty, which was eventually dismissed by the Kanawha County Circuit Court (Lewis, 2013). Eddie, who served on WVU's Board of Governors, remembered this dissent: "In some ways, David Hardesty became an academic. He didn't start off as an academic. [Hardesty] was a lawyer when he was hired ... There was very a lot of consternation when [Hardesty] became president from the faculty because he was not an academic." This lack of confidence and support, especially from faculty, meant Hardesty started off his presidency with tensions and challenges that he had to overcome before his first day in the role, and Hardesty continued to face these critiques of being in the pocket of the politicians and the legislature for several years into his presidency.

Recognizing these tensions from the get-go, even in preparation for his interview for the presidency, Hardesty studied the situation he was entering and began conducting research and gathering feedback about what was taking place. This research and preparation would become the foundation for his approach to goal-setting, mission-building, and strategic planning as president. Henry, a retired faculty member and advisor to Hardesty, explained that Hardesty's strategic planning began before he was ever selected for the position, during the time period between deciding to apply for the role and the on-campus interview: "[Hardesty] asked several people that he knew in one capacity or another to help give him a sense of the on-campus situation. I was one of those that he called on to do that. He reached out to them ... basically as part of his preparation for his on-campus interview process." This style reflected Hardesty's preparation for reaching stage one of organizational saga, or initiation, despite the criticism he received.

Hardesty himself acknowledged the uphill battle he faced from the time he was hired and the strategies he pursued to overcome it in his 1995-1999 presidential assessment, a document he 
wrote and published as a performance assessment tool for the Board of Trustees. "As a 'nontraditional president' I needed to meet constituent expectations with regard to consultation and shared governance. I began by arranging a series of meetings with the various faculties on the Morgantown campus ... These meetings represent a significant commitment, given the number of campuses and colleges ${ }^{2}$ within the University" (Hardesty, 1999).

That proactive information-gathering was an approach Hardesty took throughout his presidency — consistently learning, seeking information, and researching trends. Hardesty's researched approach to leadership was a characteristic that Nicole, a staffer in the Office of the President, remembered, saying,

Hardesty loved to use those sorts of think-tanks to stimulate thinking. He read; he always read. And sometimes when he had like a Saturday where he would just say he was going to take it to read. We would always be like, 'Ugh, he's going to come in Monday with some big ideas.' He read everything he could about organizational development and planning. Hardesty also described this information-gathering style himself in his book written with his wife Susan, Leading the Public University. "I constantly seek information that can help me do my job better. When I find it — whether in books, in journal articles, in reports from other universities, in news items, or just from insight-I make a point of sharing it with appropriate members of my management team" (Hardesty, 2007, p. 43).

\section{Hardesty's Approach to Determining Presidential Initiatives: The "Kitchen Cabinet"}

To support this research, input and feedback gathering, and subsequent planning, Hardesty put together a "kitchen cabinet" — a small group of advisors to which Hardesty reached out individually for advice, both during his interview for the position and after he was hired. This

\footnotetext{
${ }^{2}$ At this time, WVU's organizational structured included three regional campuses (i.e. Potomac State College, WVU Institute of Technology, and WVU-Parkersburg), as well as 12 academic colleges and schools.
} 
step was another example of his administration's quick work toward reaching organizational saga's beginning stage, initiation. It was also a strategy on Hardesty's part to quickly learn to navigate the unfamiliar aspects of the organizational structure and the internal politics of the University, especially faculty. Vincent, one of these advisors, remembered, "It was people who believed deeply in [WVU] and wanted to help him. And what happened is it didn't have any institutional bias ... they would ask questions, and they would say well there's this issue and there's that issue and there's this issue." The "kitchen cabinet" would collect additional information and conduct research to see how the issues presented in the information gathering were making an influence elsewhere in higher education and how other universities navigated them. Vincent recalled how Hardesty would introduce possible issues to pursue with the "kitchen cabinet" and how the work on those issues would subsequently occur. He said, "[We] would put together a task force of stakeholders that inform people. [We] would go away, and [we] would really work on different ideas that the president had independently. [We] worked on the best findings in the field. And we'd come back, and [we'd] say here's the things we can do."

After the "kitchen cabinet" returned with its findings, they would determine what issues to pursue. Those issues were, more often than not, addressed by task forces, a structure that allowed the administration to tackle issues as they occurred. Vincent explained that this model gave WVU the capacity to address issues that spanned the various administrative units of the University, saying, "They were burning problems. They were problems that didn't belong to a single dean, vice president, director, or some chief official ... And what happens is no one really owned it."

The issues addressed by the task forces did not necessarily have to connect or relate to each other, nor were they all presented comprehensively in one document or location. Instead, 
WVU'S LAND-GRANT MISSION

100

they were addressed as problems arose. However, that lack of connection or comprehensive approach was often evident to the campus community, and the strategy or reasoning behind why certain issues or initiatives were pursued were often questioned by both faculty-at-large and the Faculty Senate. Vincent recalled, "It was very much driven by a very strong-willed president, which in my mind was good. But if you were sitting on the outside you would say, 'I don't understand how those initiatives link together.'" Hardesty used his executive power to carry those initiatives through despite the questions and critiques. His strong-willed personality and approach to leadership reflected the "strong purpose" criteria in the initial stage of organizational saga while simultaneously suggesting a lack of understanding or disregard for the traditional dual governance structure of higher education, a common challenge for nontraditional presidents not familiar with the organization of higher education.

Frank had a similar recollection to Vincent in terms of the organization and operation of the task forces. He described the task forces as SWAT teams specifically charged with addressing major issues happening across the University, which totaled about four or five per year.

You assembled people to address that issue quickly, and then come up with a report and hopefully make changes in the University. So rather than trying to step back and bring all the pieces together and come up with a larger comprehensive plan, you took one little piece and said OK ... let's do a quick [study], let's figure out what are the two or three things we can do to make some improvements, and let's get them out there.

The task forces were typically led by a facilitator, usually a member of the "kitchen cabinet." This individual's role was to listen, observe, and help keep the conversation going. Then, he or she would bring the findings back to the "kitchen cabinet" to inform strategic planning. 
WVU'S LAND-GRANT MISSION

101

Joseph, another retired faculty member and advisor to Hardesty, reflected on the task forces' processes and approaches to problem-solving: "One of the critical things is putting together represented a group of stakeholders ... And I insisted that the people that were put on [the task forces] were people that had working knowledge of those issues." Joseph often served as a facilitator for the task forces, organizing the meetings, taking notes, and keeping the participants engaged. He recalled, "It's a very fast-paced kind of an effort ... And my role [was] being neutral in terms of my own personal opinions. And there are times when you do that that you want to ask prompting questions to them that maybe things that they haven't thought about." Many of the initiatives that were tackled by task forces followed a formula-"kitchen cabinet" research, a speech and a press release announcing the initiative, the task force's work on it, and a follow-up report assessing that work.

One of the critiques of the "kitchen cabinet" model that arose from the interviews is that it did not often incorporate the academic colleges and schools and their leadership in the planning process. An example of this approach was the creation of WVU's Leadership Studies Program, a curricular change Hardesty pursued out of his passion for leadership development. When the program was first established, it did not have an academic home, belonging to no college or school, William explained. He recalled,

That may be a good example of how it was hard for [Hardesty's] model to work as effective as it needed to in a university ... Not a good formula for a curricular change to really take hold. It had trouble finding a home that would love it. But it was politically very attractive . . I I think the leadership program was a good example of a good idea not effectively implemented because, in part, of the inexperience in dealing with how a university effectively implements and nurtures a change. 
WVU'S LAND-GRANT MISSION

102

The previous paragraphs describe the Hardesty administration's intentional approach to strategic planning. By having a process and formula to follow in place with buy-in from the leadership team, his administration had a foundation for quickly reaching the initiation phase of organizational saga before they even began honing in on specific issues. While the "kitchen cabinet" itself was not representational of the University as a whole, just including five or six hand-picked faculty and/or administrators, and, occasionally, Hardesty's wife, Susan, the "kitchen cabinet" did attempt to be as representational as possible with the task forces, including different levels of faculty, staff, and students as appropriate to match individuals with the issues that directly affected them. However, where this process was often challenged was at the executive leadership team level — the "kitchen cabinet" itself. Because that group was so small, concerns arose that the University's day-to-day operations were not always addressed as quickly, strategically, or comprehensively as possible because there was so much focus on special, signature projects or "niche" activities, which are discussed in the subsequent sections. This lack of comprehensive planning ascribed to decision-making was rejected in favor of more one-off, targeted victories for the majority of Hardesty's presidency until his administration was required to take a more comprehensive approach by its accreditors, discussed later in this chapter. The approach implies that the choice reflects not only Hardesty's nontraditional background outside of higher education but also his need to overcome the early criticism he faced by obtaining quick successes to gain more political capital and credibility among the campus community for future decisions.

\section{Hardesty's First Major Initiative: The Student-Centered University}

On the first day of his presidency, Hardesty followed this task force formula to announce his first major initiative. In his inaugural speech and subsequent press conference on July 1, 
WVU'S LAND-GRANT MISSION

103

1995, he kicked off a student-centered initiative to transform WVU into a "student-centered" university. By working so efficiently, this initiative helped the administration quickly reach stage one of organizational saga, initiation. This initiative was also an example of the administration's first step toward reaching the student subculture phase of the second stage of organizational saga, fulfillment.

Nicole recounts how Hardesty placed a podium on the lawn in front of E. Moore Hall, a campus building located in a highly trafficked area of campus, and declared that WVU was to become more student-centered and announced plans for a student affairs task force. She reflected, "[Hardesty] basically put his flag in the ground that we want to become more studentcentered. And he laid out some things that he was going to do to set that in motion ... So, he elevated that." Linda also remembered this immediate focus on student-centeredness, saying, "[Hardesty] was very concerned with students, not only the academic side, but the more domestic side and that balance."

The Student Affairs Task Force aspired to exceed students' expectations by improving their living and learning environments, treating them with respect, and investing in their academic success (West Virginia University Student Affairs Task Force, 1996). They began with a redesign of the first-year experience. Dubbed "Operation Jump-Start," it included a comprehensive set of programming focused on student learning and retention with initiatives like intensified academic advising, increasing technology resources for students, and making student services more efficient (e.g. advising, scheduling, registration, financial aid, and student accounts), all elements that contributed to student subculture in organizational saga. In his inaugural speech, Hardesty charged that all WVU employees would play a role in retention, and that was the foundation that would help WVU "become one of the leaders in 
WVU'S LAND-GRANT MISSION

104

retention among land-grant universities" (Hardesty, 1996a). Looking back on the initiative nine years later in the 2004 Accreditation Self-Study Report, he claimed, "This student-centered philosophy now permeates the campus and includes a focus on critical inquiry in the classroom as well as an emphasis on responding to student needs in WVU's service units" (West Virginia University, 2004). By including a call to action for all employees, Hardesty was striving to gain buy-in from all across campus to engage with students, another attempt toward fulfilling the student subculture phase of organizational saga that was not immediately reached. However, he didn't gain buy-in, especially from faculty. Faculty questioned the emphasis placed on students, not only because the focus took away from other more faculty-centric priorities, like research, but also because of the expectation placed on them to support retention initiatives and work more closely with students beyond their standard teaching responsibilities. Some faculty believed Hardesty did not understand their responsibilities as not only teachers, but scholars, and that the scholarship and research aspects of their roles were devalued because of the additional expectations placed on them to more regularly interact with students (Associated Press, 1998; Lewis, 2013).

One of the ways Hardesty attempted to carry-out this initiative was adding staff specifically with the responsibility of working with students. Beyond the "kitchen cabinet" described previously, Hardesty made several changes and additions to the executive leadership team. One new role was a dean of students who reported directly to him, a progressive type of position at the time when university administrations were still relatively small and most administrative work was still decentralized in the hands of the faculty-at-large and the faculty senate. This role had previously served as an associate provost reporting up to the provost, which Hardesty believed made it a forgotten or "lesser" position, according to Vincent. He said, "There 
WVU'S LAND-GRANT MISSION

105

were conversations about it and there were also faculty that [questioned], 'What is this?'” Many faculty reacted negatively to the administrative changes, questioning the purpose of the dean of students position in particular and the "administrative bloat" from the new positions and the costs of salaries and benefits associated with them.

During this time, Hardesty also launched, in partnership with his wife Susan, a Mountaineer Parents Club to connect the parents and families of WVU students to the campus community and to each other. This part of the initiative also included a toll-free "Parents Helpline" that students' parents and families could call with questions, and on-campus fall and spring parents' weekends to engage families in activities on campus and around Morgantown. “The Parents Club, which has over 12,000 families, and toll-free Parents Help Line also speak to our commitment to student-centeredness. Student-centeredness extends to our research commitment. Both McNair and Honors Program undergraduates have programmatic opportunities to engage in rigorous research to prepare them for graduate education" (West Virginia University, 2004). This initiative expanded the student subculture phase to also embrace students' primary opinion leaders, their families.

This programming reflected Hardesty's desire to improve the experience he had as a WVU parent for other parents. He knew the administration must navigate the limitations in place with the Family Education Rights and Protection Act, a federal policy that protects the privacy of student records. Both the Mountaineer Parents Club and the Parent Helpline were intended to support this effort. Vincent recounted an early conversation with Hardesty that reflected his and Susan's inspiration for the Mountaineer Parents Club, which came out of an experience they had when their own daughter attended WVU and they couldn't determine the balance due on her student account, an obstacle students and their families often experienced. 
WVU'S LAND-GRANT MISSION

106

He wanted parents to be more invested and more knowledgeable about how their children were doing ... When he became president the year after his daughter attended her orientation, his wife comes in with her bill. He said, 'She and I are fairly sophisticated people. Been here a long time. Neither of us could tell what the balance due was.' And she says, 'I have a check. How much should I make the check out for?' You started going like, 'Are you kidding me?' So, you call the chief financial guy, and he goes, 'That's the damnedest thing.' [Hardesty] would say, 'That's what I'm talking about.'

The Hardesty administration also sought to create a sense of belonging for new students by personalizing the first-year student experience. He created the Resident Faculty Leader Program, living-learning communities that featured a faculty member residing in each residence hall to facilitate programming and offer mentorship, inspired by his time at the University of Oxford in the United Kingdom as a Rhodes Scholar, where a similar program existed. This initiative demonstrated his aspiration to weave students' residential experiences with their academic experiences, connecting students with well-respected faculty who could serve as resources and mentors.

Throughout Hardesty's presidency, these living-learning communities also evolved to include interest groups, where floors in the residence halls were dedicated to specific disciplines like engineering, nursing, and creative arts, where students took a course or courses together as a group. However, faculty in general were not on board with the idea because of the extra time, responsibility, and interaction with students that would be required. Nicole recalled some complaints Hardesty received after introducing the idea in a faculty meeting:

They were pushing back and grousing about the role of faculty and no business talking to the students and all that. And he said, 'How many of you are parents of college students?' 
WVU'S LAND-GRANT MISSION

107

So, some hands go up. And he said, 'How many of you are parents to students who go to WVU?' Some hands go down, some stay up. 'How many of you have a student at WVU who lives in a residence hall?' And the way he tells the story, all but one hand goes down. This one person had their hand up. And he said, 'What do you think?' And that person ... said, 'Implement this as fast as you can.' And so, I think that gave him the perseverance and had that real effect on folks that you may not think we need to do anything about this ... He felt like dorms were like warehouses where students were between classes.

While faculty in general did not support the Resident Faculty Leader program, Hardesty was able to gain enough interest and participation from influential faculty and administrators to launch it in some of the residence halls, and it grew over time. For example, Hardesty notes in his book (2017) that he was greatly assisted in the residential education initiative by English professor and global affairs administrator David Stewart (a former Oxford professor and tutor), who Hardesty describes as someone who "understood and shared [his] vision and helped to develop it. Although skeptical when he came to [Hardesty's] first focus group on residential education, he became champion of the program" (Hardesty, 2007, p. 364). Hardesty also credits then-Provost Gerald Lang and then-Vice President for Student Affairs Kenneth Gray for their leadership in the effort.

This personalization to the student experience was also seen through New Student Convocation, launched in August 1995, a welcome event for all new WVU undergraduate students. At this event, Hardesty spoke on why he created the event and the goals he had for all WVU students, including embracing technology, learning communication skills, acquiring leadership skills, valuing diversity, preparing students for society, making new friends, and connecting with the campus community, especially faculty and staff. He said, "At WVU, most of 
WVU'S LAND-GRANT MISSION

108

you will begin a journey through the world of ideas. Your journey will truly transform you, and this convocation, this day, this event, reaffirms both our intent to help you make this journey and your commitment to make it through diligent study, exploration, and investigation" (Hardesty, 1995b).

In 1998, three years after the student-centered initiative was implemented, Hardesty established a Commission on Academic Standards and Expectations to review the work of the student-centered university initiative and the goals and expectations WVU had set for undergraduates as part of it. Led by the provost and the student body president, the commission was composed of faculty, students, and administrators, as well as members of the general public, parents, public school teachers and administrators, and a member of the West Virginia Office of the Secretary of Education and the Arts. The group conducted a study of undergraduate education literature and administered surveys to WVU faculty and students to assess the state of undergraduate education at WVU as it related to national trends. The Commission's most significant finding was that much more work needed to be done to revamp the first-year experience, and it recommended a required University orientation course for all new first-time freshmen. The one-credit course, University 101, was intended to offer students resources and tools to aid their transition from high school to college. Other programming that resulted from the Commission's work included the addition of freshmen interest groups to the Resident Faculty Leader program mentioned above, required capstone courses as the culminating academic experience to reflect the comprehensive knowledge gained by each student prior to graduation, and initiatives to help students writing and math skills, including the establishment of a Center for Writing Excellence and Institute for Math Learning. 
WVU'S LAND-GRANT MISSION

109

Hardesty came into the presidency with an immediate focus on the student subculture phase of organizational saga, with aspirations of increasing access to student experiences like he had in his own undergraduate career, from serving as student body president to winning the Rhodes Scholarship and studying at Oxford. This motivation is reflected through not only his immediate focus on student initiatives but the way he approached them-by hearing from the students - and their families - directly. Vincent reflected,

[Hardesty] came with some preconceived notions and some ideas, and that's not bad. If I'm interviewing you for a job, we hope you come with some ideas. We don't just come and say wow, here, just lay here and grab the sun. What happened is [Hardesty] had an outstanding undergraduate career. His undergraduate experience was extraordinary for a lot of different reasons. What he tried to do was say how can every student at [WVU] have that same [experience].

Though it evolved over time as seen later in this chapter, the student-centered initiative continued to be a priority for Hardesty and his administration throughout this time as president, even at the expense of other parts of the mission and University operations, including faculty and research. This change in University culture reflected Hardesty's desire to emulate his unique undergraduate experiences and replicate those for as many students as possible and that his priority was on the student subculture component of organizational saga, even if that meant placing less emphasis and resources on other parts of the organization.

\section{Administrative Organization Initiatives}

Later in July 1995, the same month that the student-centered initiative began, Hardesty, with contributions from the "kitchen cabinet," followed up with his second major initiative, which he described as "administrative organization initiatives." An element of the programming 
WVU'S LAND-GRANT MISSION

110

phase of organizational saga, this initiative was focused on making the day-to-day operations of the University more efficient, especially in the context of preparing for the next millennium technology-wise and navigating public funding challenges. This emphasis reflected his businessoriented and legal background, which was often characterized by navigating situations with scarce resources, a characteristic of the political leadership framework (Manning, 2013; Bolman \& Deal, 2013). Launched via an internally distributed brochure on July 27, 1995, Hardesty called for higher education leaders in West Virginia and administrators at WVU to meet the "challenges of change" through intentional, flexible, collaborative, and efficient leadership and organizational decision-making.

To insure WVU will be poised to serve the state and nation in the next millennium, we must continue to invest in our future ... During this time of rapid change, West Virginia University must remain an agile, responsive, and flexible institution which views these challenges as opportunities to increase its role and maximize its contribution to the everchanging needs of society ... During this time of change, it will be important for those of us at West Virginia University to establish clear priorities and focus our resources on meeting objectives which directly reflect these priorities . . . If WVU is to remain a strong and healthy institution, we must manage and administer, efficiently and effectively at every level. Institutions which continually evaluate their administrative performance and identify opportunities for improvement will be better prepared to face the challenges of change. (Hardesty, 1995a)

The "challenges of change" Hardesty acknowledged (Hardesty, 1995a) included decreasing federal and state appropriations; the decreasing West Virginia population, including high school enrollment; changes to technology, especially in preparation for the year 2000; state mandates 
WVU'S LAND-GRANT MISSION

111

for salary increases; the increasing number of nontraditional students; increased calls for accountability (from students, parents, and government officials); and ongoing changes to the global economy. To address these obstacles, he made the following recommendations for administrators:

- Administration should be open: that is, honest, fair, and collaborative.

- The reason administrative units exist is to provide decisive leadership and to support and facilitate the work of the faculty, staff, and students. The role of central administrations should be leading, facilitating, and empowering the University community.

- Operational functions should be at the lowest effective administrative levels.

- Administration at WVU should be adaptive and flexible to ensure rapid response to the changing environment.

- Administrators should continually seek to reduce the cost of administrative activity.

- Administrative units should establish and monitor measures of performance.

- Administrative units should foster continuous quality improvement.

- Administration at all levels of the University should be attentive and responsive to those the University serves.

- Administrators should be entrepreneurs, team players, and faithful stewards for the taxpayers of West Virginia.

- Administrative units should embrace diversity, respect the individual, and practice tolerance in both words and deeds.

- WVU administrators should seek new opportunities to collaborate with West Virginia citizens for the betterment of our State. 
WVU'S LAND-GRANT MISSION

112

- Creativity and efficiency in WVU administration should be valued and rewarded. (Hardesty, 1995a)

These recommendations demonstrate how Hardesty incorporated both his business and legal backgrounds in his leadership style, attempting to make the University more customerservice oriented and efficient. For example, the recommendations "creativity and efficiency in the WVU administration should be valued and rewarded" and "WVU administrators should seek new opportunities to collaborate with West Virginia citizens for the betterment of our State" both represent the political model of leadership, which focuses on scarce resources and partnerships; "the reason administrative units exist is to provide decisive leadership and to support and facilitate the work of the faculty, staff, and students" reflects the structural model of leadership; and "Administrative units should embrace diversity, respect the individual, and practice tolerance in both words and deeds" comes from the collegial model, while the recommendation "Administration at WVU should be adaptive and flexible to ensure rapid response to the changing environment" reflects the principle of reframing across all leadership models to best approach the situation at hand (Manning, 2013; Bolman \& Deal, 2013).

Hardesty reflected that this more customer-centered approach to leadership and organization reflected the University's striving to flatten layers of the administration and consolidate overlapping units for consistency (Hardesty, 1996b), an example of his political leadership style in this period of scarce resources for the University. This initiative also highlighted how Hardesty's business and legal background influenced his leadership choices in higher education, a reflection of the structural and political frames of leadership (Manning, 2013; Bolman \& Deal, 2013). The following quote from a Fairmont Times-West Virginian (Hardesty's 
WVU'S LAND-GRANT MISSION

113

hometown newspaper) editorial was also included in this brochure, which further describes his leadership style:

West Virginia University's new president is giving every indication that he will act rather than react. David Hardesty, Jr., criticized by some before and after his appointment because he was the only candidate for the position who was not a career academic, is using his business background to the University's advantage. A former state tax commissioner with a background in tax law, Hardesty has established the second major initiative of his short administration — one geared to respond to what he terms "external factors" that are shaping the environment of higher education. (Hardesty, 1995a) Though not included in this brochure, two major organizational changes occurred at the University within two years of this initiative's release. The acquisition and merger of West Virginia Technical Institute in Montgomery, West Virginia, to become part of the WVU system was completed in 1997, which was met with significant discontent from that institution and community (Owston, 2009). This effort was also managed by a task force approach, which Joseph was a part of. He reflected on the experience, "I would honestly say I don't think that the implementation was very successful because I don't think the Tech people were willing to make the commitment that needed to be done. It was a very unfriendly student environment, and they were not willing to make it more student friendly.” Also in 1997, WVU formed a partnership with United Hospital Center in Clarksburg, West Virginia, which eventually evolved and expanded to what is known today as WVUMedicine. Hardesty reflected on the latter in his Fall 1997 State of the University Address as an opportunity to increase access to healthcare for more West Virginia residents: "We are better serving West Virginians through access to higher education and healthcare while bolstering our support around the state" (Hardesty, 1997c). 
WVU'S LAND-GRANT MISSION

114

The "administrative organization initiatives" represented Hardesty's infusion of his nonacademic legal and business background, characterized by organizational and operational efficiency, into the traditionally decentralized organization of higher education. In response to ongoing cuts to state appropriations for higher education by the West Virginia State Legislature, he tried to frame WVU as a leader and model in business practices by sharing recommendations with not only leaders on the Morgantown campus but higher education leaders across the state about how to restructure their operations to be more flexible and adaptable and, simultaneously, less bureaucratic. These recommendations offer a curious contrast to some critiques of his administration, which focused on the growing size of Hardesty's own leadership team and increasing reporting lines to the presidency from positions that traditionally did not report to the role. Similar recommendations would continue to be presented and employed throughout Hardesty's presidency as the University faced continued cuts to its state appropriations, requiring more resourcefulness in budget management.

\section{Other Early Goals and Initiatives}

Hardesty continued to follow this task force approach to strategic planning throughout most of his presidency, using the following vision statement as a guide, which also contributed to the programming phase of organizational saga: "West Virginia University is a premier studentcentered, learning community meeting the changing needs of the people of West Virginia and the nation through teaching, research, service, and technology."

After the initial two initiatives discussed above, Hardesty announced five goals in his February 1997 State of the University Address (Hardesty, 1997a) that would guide the next seven years of his presidency: remain student-centered and foster student success, a continuation of the first major initiative discussed above; engage society; focus research; implement the 
WVU'S LAND-GRANT MISSION

115

Facilities Master Plan; and improve communications. An additional goal, lead in technology, was added in the Fall 1998 State of the University Address (Hardesty, 1998b). In spring 1999, the goals were morphed back into four: foster student success, focus research, serve West Virginia and the nation, and model innovations in uses of technology. These goals spanned the phases of the fulfillment stage of organizational saga and continued to be the guiding framework for all of Hardesty's major speeches and task force initiatives leading up to the re-accreditation process in 2004, discussed later.

\section{Remain student-centered and foster student success/Foster student success.}

Encompassing the student subculture phase of fulfillment in organizational saga, the studentcentered approach to leadership was the hallmark of Hardesty's presidency from the beginning, and he continued to highlight progress throughout his major speeches. Hardesty shared in the February 1997 State of the University Address (Hardesty, 1997a): "We must always remember

to look to those we serve for guidance - students. Above all, we must remain student-centered. If we are to preserve the public trust, students must remain our primary focus.” In the October 1998 State of the University Address, Hardesty shared some academic successes from the task force's work: the retention rate from freshman year to sophomore year retention improved to $80 \%$, and academic suspensions decreased by $40 \%$. From a campus culture perspective, he noted that residence hall occupancy was up from 80\% in 1993 to full in 1998 and that the University dropped out of the Princeton Review's top 10 party school ranking after being ranked first the previous year. In terms of campus safety, total incident reports were down by $23 \%$ and vandalism reports were down by $30 \%$ in comparison to 1995 when his presidency began. Emergency room admissions of students during football weekends had also decreased by more than $50 \%$ in a year's time (Hardesty, 1998b). 
WVU'S LAND-GRANT MISSION

116

New academic and student life initiatives during this time included the relaunch of Festival of Ideas, a series bringing nationally known speakers to campus that was held in the 1960s when Hardesty served as student body president. According to the 2004 Accreditation Self-Study Report, recent speakers in the series at that time included Maya Angelou, Spike Lee, Kareem Abdul-Jabbar, Cornel West, David Halberstam, Michael Beschloos, and F. W. DeKlerk. WVUpAllNight, a weekly on-campus event for students on the weekends with free food and activities, was launched by Student Affairs in 1998 as a healthy entertainment option. In collaboration with the Student Government Association, the Mountaineer Maniacs was created as a student organization to promote positive school spirit and attendance at all University sporting events. The University also began a study of a long-term concern of addressing faculty, staff, and student day care concerns, and plans for a student recreation center were announced. An initiative was launched to address the needs of the University's growing nontraditional student population. The University also started collaborating with fraternities on national policies of their houses "going dry." In addition to being part of the student subculture phase of fulfillment in organizational saga, these programs and activities represented imagery as they all shared goals of elevating the University's scholarly reputation and overcoming its negative party school image, which is also engrained and celebrated in the University's tradition and culture by students and alumni alike, despite the negative publicity that abounds from the image it portrays. As a result, the decisions by the Hardesty administration to take steps to challenge the party school reputation represent either decisions made as part of the symbolic leadership model (Bolman \& Deal, 2013; Manning, 2013; Meyer \& Rowan, 1977) or working directly against it, depending on one's perspective. 
WVU'S LAND-GRANT MISSION

117

Engage society/Serve West Virginia and the nation. In his State of the University addresses, Hardesty frequently quoted former WVU President Irvin Stewart, saying "The state is our campus." For example, in his February 1997 State of the University Address (Hardesty, 1997a), Hardesty remarked, "We must demonstrate to all of West Virginia our clear intention to view the state as our campus and to become more valuable to our state and the nation." He also said the following year in the February 1998 State of the University Address (Hardesty, 1998a), "In a state where mountainous terrain creates formidable natural barriers between regions, the concept of remoteness is very real. Yet WVU serves all the people of West Virginia, not just those living in a particular region or a few population centers." These quotes reflect his motivation behind the second long-term goal, "engage society" as well as his work toward reaching the social base phase in organizational saga.

The first major initiative under this goal was an Extension Task Force. Hardesty brought in Lawrence Cote from Pennsylvania State University to lead WVU Extension Service, who introduced new focus areas in October 1998: workforce education and job accommodation, sustainable agriculture and agromedicine, food safety and nutrition, and child care. Nicole reflected on the work of the task force and its efforts to improve Extension's operational efficiency and communications. She shared that one of the most significant changes was reorganizing the infrastructure in the WVU Extension Service from a regional office format to focus more on programming in specialized subject matter areas, particularly after the advent of email connected the county offices with the Morgantown campus more than ever before. Nicole explained,

If I work in [agriculture], I'd rather have a really good subject matter expert that I can call upon. Youth development and health. Whatever their areas are. I'd rather call upon that 
WVU'S LAND-GRANT MISSION

118

and not have this money spent in the bureaucratic infrastructure. And so that was one of the bigger recommendations was that those offices went away. And they did try to create some more specialists in those areas.

While the reorganization was intended to save money and improve the efficiency of WVU Extension's operations, the decision to eliminate the regional offices was met with criticism because there were fewer leadership positions around the state, which was a step background of reaching the social base component of fulfillment in organizational saga as the Extension Service is an initiative directly charged with reaching the University's social base of state citizens. This change is also a direct contradiction to some recommendations found in the literature for how land-grant universities can continue to engage with their communities, such as the campus doing more than sharing "physical space" with the town by meeting with community leaders to identify their needs (Gavazzi, 2015). The decision to move personnel out of communities has also been seen as what McDowell (2001) describes as abandoning the social contract with the communities.

According to Hardesty's 2003 presidential assessment, 90\% of the task force's 95 recommendations were accomplished by 2000. By 1998, 4-H, the Extension Service's youth development and leadership program, was serving more than 40,000 youth around the state annually, and that number grew to more than 56,000 by 2003 (Hardesty, 1998a). In 2003, Extension introduced a Youth Entrepreneurship Program for elementary school-age 4-H members, which was facilitated by elementary school teachers (Hardesty, 2003). During this time, WVU Extension increased its sponsored research funding from just under $\$ 1$ million in FY 1998 to $\$ 5.3$ million in FY 2003, which featured a tourism project linked to forest heritage assets 
WVU'S LAND-GRANT MISSION

119

across the state, flood recovery and disaster prevention efforts, and risk management strategies for farmers (Hardesty, 2003).

In 1998, WVU received a W.K. Kellogg grant to establish the WVU Expanding Community Partnerships Program, which featured collaborations between the WVU Health Sciences Center and Kellogg Foundation to support community development in West Virginia. Through this $\$ 1.25$ million grant, more than 2,000 WVU students participated in communitybased learning through 43 partnerships with communities in 25 West Virginia counties (Hardesty, 1998b; Hardesty, 2003). According to Hardesty's 2003 presidential assessment, the initial program also generated more than $\$ 2$ million in follow-up projects and grants to sustain the University-community partnerships.

WVU pursued external partnerships with other organizations during this time, many of which were to find new ways to increase economic development in the state. The University formed partnerships with major employers in the region, including Polymer Alliance, the FBI, and NASA. WVU leaders also began exploring the possibility of a science and technology park in Morgantown, and an executive MBA program was launched to educate business leaders (Hardesty, 1998a).

The University also teamed up with other educational institutions. WVU partnered with then-West Virginia State College in Institute, West Virginia, to form the West Virginia Association of Land-Grant Institutions. WVU also formed the Alliance for Ventures in Education with the state government as well as WVU Tech and the University of Charleston. Through the Benedum Center for Education Reform, WVU strived to increase its collaboration with the state's elementary and middle schools. 
WVU'S LAND-GRANT MISSION

120

To open the campus to outside groups and continue efforts to increase the state's collegegoing rate, WVU hosted the state's Governor's Honors Academy, Health Sciences Technology Academy, Energy Express, and other summer campus and programs. Energy Express, which was first piloted at two sites in 1994, grew to 90 sites in 43 West Virginia counties by 2002 (Hardesty, 2003). According to the 2003 presidential assessment, the program employs 500 college-age mentors and uses 4,769 volunteers to help more than 3,800 elementary school children develop their reading skills during the summer months, totaling approximately 75,000 service hours. The program was selected as one of eight national innovation award winners by the Council on State Governments (Hardesty, 2003).

Healthcare around the state was another way the University "engaged society" during this time. According to the 1998 State of the University Address, tens of thousands of patients are served annual through WVU's hospitals, regional campuses, and the United Hospital Center.

All of these partnerships and collaborations reflected the Hardesty administration's work toward reaching the social base phase of fulfillment in organizational saga in the early part of the administration. The definition of social base was expanded beyond just the traditional definition of just engaging with alumni to also include West Virginia citizens, local businesses, nonprofit organizations, other higher education institutions, and government entities. These activities were also part of imagery because of how the partnerships and collaborations continued to change perceptions of the University in a positive way.

Focus research. Hardesty viewed research as the foundation for carrying out the tenants of the land-grant mission and stressed the importance of connecting research's relevancy to state and national issues: "WVU's research mission cuts across every segment of the University and has increasingly been at the core of our land-grant institution's activities. It is our mechanism for 
WVU'S LAND-GRANT MISSION

121

learning and developing our knowledge base" (Hardesty, 1997a). He established a research task force to review how WVU could continue growing and producing research focused research programs that aligned with and contributed to the "intellectual, social, cultural, and economic benefit of all West Virginians" and better integrate students into the research process (West Virginia University, 2004).

The idea of focusing the University's research came about as a finding from the task force because "WVU can't be all things to all people" in its research efforts (West Virginia University, 2004). which is a stark contrast to the expansion of programming identified in the previously discussed goal of "engaging society and serving West Virginia and the nation," demonstrating how Hardesty prioritized each of these early goals. The research task force recommended that the University specialize in niche areas and target resources to those areas. The following focus areas were selected based on the University's existing strengths and resources, potential for funding, state industry needs, and potential for statewide economic and community development:

- Advanced Materials

- Energy and Environment

- Human Development and Culture

- Information Technology

- Local and Regional Economic Development

- Molecular and Biomedical Sciences

These focus areas were also an opportunity to target specific research activities in ways that had an opportunity to influence economic development, similar to the goals presented by Klein and Woodell (2015). "Our efforts are making WVU a preferred economic development partner and 
WVU'S LAND-GRANT MISSION

122

will lead to broader commercialization of WVU faculty research and a stronger economy in West Virginia" (Hardesty, 1998). However, as with any time research areas are narrowed, Hardesty's administration faced critique from faculty researching in disciplines not directly represented in the focus areas.

Other goals included maintaining the University's status as a top 100 research university (West Virginia University, 1999) and, as of 1997, doubling research funding over five years to ensure that continued designation. In 1997, WVU Research Corporation was established to streamline the University's research operations. Frank recounted, “The Research Corp. was set up as a way to quote circumvent state policies. It was a way to get more . . f flexibility with regard to our ability to hire ... The Research Corp. was set up as a way to provide greater flexibility for our research faculty and the research projects and so it became the repository for grants and so forth." The creation of WVU Research Corporation contributed to the programming phase of fulfillment in organizational saga as a new organizational structure intended to make processes related to research more efficient.

A request-for-proposal was initiated in 1999 for a research park along Route 705 in Morgantown to support entrepreneurship and technological development. Its first phase was intended to have infrastructure for a 25,000 square foot business incubator to promote entrepreneurialism and provide services to small businesses, but it never materialized. The University's library repository and a federal building are currently located on the site. Frank discussed the delays in implementing the research park,

So, it never really took off . . . We had many stops and starts with people who were going to help build the building. We were going to set up something, but we never got at the park initiated. It still sits there, and we've got money in the ground in terms of having all of the 
WVU'S LAND-GRANT MISSION

123

utilities and stuff ready to go. At some point in time somebody is going to figure out what to do with it. Right now, there's just no capacity to invest into it.

Because the research park never materialized, it is a missed opportunity for the personnel, programming, and imagery phases of the fulfillment stage of organizational saga.

Despite the setback, research continued to grow in other ways. As of Hardesty's 2003

presidential assessment, the following increases had occurred in sponsored funding and research expenditures:

- $123 \%$ growth in total sponsored funding from 1999-2002

- $148 \%$ increase in funding from federal sources since 1998

- $53 \%$ increase in Health Sciences Center research expenditures from 1998-2002

- A research and development expenditures ranking of 121 out of 500 universities in 2000

- Retention of the Carnegie Doctoral/Research University Extensive classification In 1999, the University created an Office of Technology Transfer office staffed by business professionals. In four years, tech transfer activities on campus increased by $300 \%$ and two startup companies were founded (Hardesty, 2003). A director of economic development role was added that same year. All of these tactics are comparable to the recommendations presented by Klein and Woodell (2015). These achievements reflect the personnel phase of organizational saga because of the new opportunities they created for faculty and staff to contribute to the University's research mission. They also contributed to the imagery phase because the rankings that came with them are characteristics of the University's reputation and status.

Forming partnerships and collaborations, one of the initiatives under the "engage society" goal, also trickled down to research. The University collaborated on interdisciplinary research 
WVU'S LAND-GRANT MISSION

124

activities with several research centers during this time: Blanchette Rockefeller Neurosciences

Institute, Center for Identification Technology Research, Biometrics Knowledge Center,

Industries of the Future-West Virginia, a virtual medical campus, and two Centers of Biomedical

Research Excellence as designated by the National Institutes of Health (i.e. Sensory

Neuroscience Research Center and the Signal Transduction and Cancer Center at the Mary Babb

Randolph Cancer Center). Other partnerships included the National Guard Bureau, West

Virginia National Guard, Department of Energy's National Energy and Technology Laboratory, Polymer Alliance Zone, NASA, Diabold, Inc., SAGEM Morpho, Inc., and U.S. Department of Justice.

Implement the Facilities Master Plan. An element of the imagery phase of fulfillment, the Facilities Master Plan reflected the University's need for increased capacity to match its growth in students and programs, but also the need for modernization. The plan was also a response to requirements of Senate Bill 547, which required modernization and upgrades to facilities. The plan initially announced four major building renovations for teaching research, a new 180,000 square-foot building (that would eventually become the Life Sciences Building), \$30 million for overhauling the libraries, and plans for a new Student Recreation Center. A partnership with the City of Morgantown was integrated for recreational and riverfront development, which is currently known as the Wharf District. From 1995 to 2003, more than \$286 million was invested in campus facilities, which increased campus space by $12 \%$ (West Virginia University, 2004). These included:

- Downtown Library Complex

- Student Recreation Center

- Life Sciences Building 
WVU'S LAND-GRANT MISSION

125

- One Waterfront Place (including Visitors Resource Center)

- White Hall Computing Center

- Stalnaker Hall renovation

- Eiesland Hall renovation

- Evansdale Library renovation

- Libraries depository

- Resident Faculty Leader facilities

- WVU Eye Institute

- Rosenbaum Family House

- Armstrong Hall renovation

- Boreman South renovations

- Distance learning infrastructure and classrooms

- Health Sciences Center renovations

- Student Financial Aid Office relocation

- Blaney House

- Coliseum abatement and renovation

- Lewis Cottage at Jackson's Mill

- Mountaineer Field renovation

- Caperton Indoor Facility

- Cary Gym-women's gymnastics center

- Parking lot additions and improvements

- Pedestrian walkways and roadway maintenance 
WVU'S LAND-GRANT MISSION

126

As of the 2003 presidential assessment, other ongoing facilities projects included a Health

Sciences Center campus master plan, construction of the Blanchette Rockefeller Neurosciences Institute, Creative Arts Center renovation, athletics master plan, Engineering Sciences Building renovation, and Jackson's Mill master plan. Other planned renovations included Oglebay Hall and Brooks Hall as well as several other residence halls.

While the University faced criticism for the new facilities and renovation as expensive undertakings during a time of scarce resources, one (now retired) faculty member, Lou, who was involved in the composition of the strategic plan during the Hardesty administration, described the infrastructure improvements as what put WVU on the national stage and retained him for 38 years despite intending to only work at the University for a few years and subsequently "move on to greener pastures." He recalled, "I looked upon [the campus] as being a rusty Chevy attempting to be Cadillac. But with the outstanding development of the campus facilities, ... I think the stability on the faculty is much improved. Morgantown is a place to live with quality of life. It is a thousand percent better than 1980 when if you wanted to have a decent meal or buy anything, you went to Pittsburgh [, Pennsylvania]."

Improve communications. Hardesty’s administration pursued several efforts to improve both internal and external communications throughout this presidency, which encompasses the personnel, student subculture, and imagery phases in the fulfillment stage of organizational saga. One of the motivations behind this goal was to differentiate WVU in the increasingly competitive higher education marketplace. He shared in the 1997 State of the University Address: “As we strive for quality, we must explicitly differentiate WVU's strengths and attributes from those of our competitors. With increasing competition for students. research dollars and other resources, we can no longer afford to be misunderstood, overlooked, or 
WVU'S LAND-GRANT MISSION

127

confused with others. We must have a unified and distinguishable message, supportive of our overall vision."

In terms of recruitment, one of the strategies was to improve the University's reputation and image among prospective students, particularly as it related to campus culture and safety. During this time, the recruitment communications were redesigned, and University messages avoided reference to being a large university or party school in favor of "high quality," "academically distinguished," "caring," "innovative," and "cost-effective." Unified websites for all the colleges and schools were also created. Internally, a Key Communicators group was formed to bring all communications and marketing professionals together on a regular basis to discuss goals, plans, and challenges related to their day-to-day work. An internal Mountaineer ENEWS email, campus-wide event calendar, and University intranet were launched to keep the University community up-to-date on news and events around campus. All of these efforts reflect work toward the imagery phase of fulfillment in organizational saga.

Lead in technology/Model innovations in the uses of technology. A fifth goal, "Lead in Technology," was added to improve businesses practices and data processing across campus and how those efforts were organized, including the Health Sciences Center and regional campuses, another strategy influenced by his business and legal background. These efforts for unity across campuses reflected movement toward the programming phase of fulfillment because of the changes in University operations and day-to-day work. The plan pursuing this goal, "Integration 2000," also reflected technical upgrades in preparation for the new millennium. Edith, who worked on this plan, shared how the plan operationalized the land-grant mission by connecting all parts of the University across the state. She recollected, 
WVU'S LAND-GRANT MISSION

128

It was really the first effort to say WVU needs to think of itself as a national player ... And that instead of being very strong regional presence, which certainly is part of the land-grant mission, that we should also be part of the sort of land-grant consortium and we should be a member at that table. That we as an institution were becoming more involved in that group that we wanted to see more of a network so that we weren't just the flagship university in this upper corner of the state but that we were really serving the entire state. And one of the ways we could do that would be by strengthening our connections with Keyser, Beckley, Parkersburg, and one of the things that made those connections more possible in the 1990s was technology so that it wasn't sort of a natural alliance to think about technology and a stronger alliance among regional campuses ... We've got these new technologies; we need to be embracing them. We need to be connecting as a whole network of campuses to serve our students.

This effort included email accounts for every student, library software updates, and the addition of Oracle software for all data processing, including payments. BANNER, a student information system, was implemented, which allowed for telephone registration and early work on web-based registration. All residence halls were wired for computer access, and various laptop computer programs were launched in academic units and the libraries. An interactive video network was added for remote classrooms to allow virtual students to communicate with their professors.

However, Edith is not confident Integration 2000 reached all of its intended goals due to budget challenges. She said, "But with the budget getting cut and cut again, it was hard to balance all those things. And it I don't know if the Integration 2000 project really achieved some of its goals. And I think part of the reason it may not have was that it was getting so hard to 
WVU'S LAND-GRANT MISSION

129

move forward on one front as the ground was getting undermined in terms of budget." The financial strains placed on the University by the state's decreasing appropriations were just beginning. While the Hardesty administration attempted to move the University forward in terms of $21^{\text {st }}$ century technology and business practices across all campuses while navigating the scarce resources available, it came at a cost. The University began to turn to out-of-state student recruitment for a larger student population and their accompanying greater tuition revenue, which directly resulted in critiques from in-state residents who eventually became nearly outnumbered in terms of enrollment. Simultaneously, that enrollment growth placed a strain on the one campus population that was not growing in size or in compensation-faculty. That would change, to a point, following more governance changes and mandates from the state government, discussed in the next section.

\section{Senate Bill 547}

The goals and operations pursued by Hardesty's administration up through 2000 were dominated by the University's response to Senate Bill 547, one of the many changes in higher education governance in the state's history (Machesney, 1971; Corder, 1992). With objectives of developing high quality and relevant educational opportunities statewide, focusing resources on programs and courses that offered the greatest opportunities for students, maximizing technology, and providing competitive salaries to all employees, this legislation called for the University to reallocate $\$ 32$ million of its existing budget over five years to meet legislative mandates (West Virginia University, 2004). The legislation also required WVU to invest in crucial facilities upgrades, including its libraries and technology. Nicole reflected on the resource challenges during Hardesty's presidency: “It's all of a sudden we get hit again, and we're like, 'Ugh.' We had already done some of what you call the low hanging fruit and some of those 
WVU'S LAND-GRANT MISSION

130

things. So that became difficult ... We just had cuts and cuts.” Many of the cost-savings

initiatives were met with dissent from faculty, staff, and students who felt that the decisions were made from the top-down rather than with input from the campus community. A faculty senator was quoted to this effect in WVU's campus newspaper, The Daily Athenaeum, "The tradition at the University is that they make the decision with the input of faculty, staff, and students. In this process, people felt left out” (Seracki, 1995, p. 1; Lewis, 2013).

The biggest "loser" in the budget cuts may have very well been one of the most famed traditions in WVU history - the national championship rifle team. The sport was celebrated as a reflection of the state's rural, pro-Second Amendment heritage and further espoused by the Mountaineer mascot image. One of five Division I-A athletic teams to be cut in 2003 as a costsavings due to the athletic department running on a deficit (Anderson, 2003), the elimination of the sport tarnished Hardesty's otherwise "heroic" presidency (Basham, 2012). While the rifle team was restored in 2009 during James Clements' presidency with support from a line item in the state's budget (Clark, 2009) and has since produced an Olympic gold medalist in Ginny Thrasher, its initial disbanding wreaked havoc across the state of West Virginia, causing an outcry from alumni, donors, and fans alike from Wheeling to Welch and everywhere in between. The backlash was immediate. Students fired off e-mails. Alumni collected 9,000 signatures on a petition demanding the team's return. The National Rifle Association wrote letters disputing the university's claim that the sport was too costly. (The team's $\$ 163,000$ budget accounted for less than 1 percent of the athletic department budget.) And most team members refused to stop practicing and formed a club instead. (Clark, 2009)

This was just one example of the Hardesty administration's strategies for cost-savings. Because of the pressures from the purse-strappings of the state government, the idea of "focus" 
WVU'S LAND-GRANT MISSION

131

introduced earlier in the "Administrative Organization Initiatives" brochure (Hardesty, 1995a)

permeated this period of Hardesty's presidency, reflecting the strategy of focusing the

University's operations as a way of navigating through the budget challenges, part of the

programming phase of fulfillment in organizational saga. The University responded by

establishing Executive Business Offices to streamline financial operations, reorganizing human

resources, combining food operations in the residence halls and Mountainlair Student Union, merging the facilities planning and physical plant units, merging computer science and computer engineering programs, and refinancing auxiliary bonds.

This idea of focus was also addressed in the 2004 Accreditation Self-Study, a report for the Higher Learning Commission of the North Central Association of Colleges and Schools, WVU's accrediting body.

Record enrollment, record high research dollars, and record private support clearly demonstrate that WVU's planning structures are working. However, ongoing reductions in state funding pose challenges of an unprecedented scale. In such an environment, effective planning becomes more important than ever. Thus, President Hardesty suggests that 'the one overarching strategy that we will need is focus. We will need to focus on our core mission and weigh our decisions against it.' (West Virginia University, 2004)

The responses to the legislation changed management and organization of the University in a way that made it more flexible. However, the University still recognized the impact of decreasing state appropriations on maintaining competitiveness with peer institutions, as reported in the 2004 Accreditation Self-Study.

Compared to ten years ago, WVU now can be more flexible in allocating resources to respond to challenges while remaining committed to its core values of research, service, 
WVU'S LAND-GRANT MISSION

132

and outreach within a student-centered learning community. Budget shortfalls and state legislation to improve efficiencies have forced WVU to evaluate how resources are used. We continue to face a decrease in our state budget allocation as a percentage of our overall operating dollars. We substantially raised salaries for staff and faculty, but continue to struggle to keep up with our peers in these areas. (West Virginia University, 2004)

This dichotomy between public funding decreases and maintaining competitiveness in the marketplace continued to complicate the desire to make WVU a nationally recognized university.

The 2004 Accreditation Self-Study Report reflected how management of resources had framed much of the decision-making and strategic planning during this time. In the report's passage on finances and organization, the following details were shared:

The past decade has presented numerous challenges for West Virginia University in the management of resources. To paraphrase historian Arnold Toynbee's evaluation of civilizations, 'Now universities . . . come to birth and proceed to grow by successfully responding to successive challenges. They break down and go to pieces if and when a challenge confronts them which they fail to meet.' West Virginia University has responded effectively to challenges posed by inadequate funding and has thrived, with the assistance of dedicated faculty and staff, committed administrators, and generous donors. (West Virginia University, 2004)

All sections of the 2004 Accreditation Self-Study Report (i.e. resources/organizational/financial, strategic planning, students/teaching, and campus culture) reflected the administration's awareness of the potential for ongoing budget cuts and how continued cuts would impact the operation of the University over time. "In the future, we will need to answer the following question: How can WVU, as a doctoral research-extensive, land-grant institution with a 
WVU'S LAND-GRANT MISSION

133

comprehensive health sciences center, continue to accomplish its educational and other purposes when facing a future of potentially reduced state funding?” (West Virginia University, 2004). Navigating the budget cuts and governance expectations were part of the steps taken toward reaching the programming phase of fulfillment in organizational saga, which also reflect Hardesty's continued reliance on the political leadership model (Bolman \& Deal, 2013; Manning, 2013) as he navigated decisions based on scarce resources.

\section{Senate Bill 653}

In 2000, the West Virginia State Legislature passed Senate Bill 653 as a form of assessment of the state's colleges and universities to determine state appropriations. The policy, another change relating to governance activities (Machesney, 1971; Corder, 1992) required the state's higher education institutions to submit their goals in the form of a compact to be used for strategic planning over a six-year period, July 2001-June 2007. Through its compact, “The Compact Between West Virginia University and the State of West Virginia," WVU presented goals of developing stronger relationships with its constituents (i.e. students, research sponsors and organizations, federal and state government, and the state's citizens), an example of the student subculture, personnel, and social base phases of the fulfillment stage in organizational saga. Hardesty discussed the Campus Compact in his 2001 State of the University Address:

In addition to taking good care of our students, we will make certain that we continue to be good stewards of the public's investment in us through state appropriations. I should note here that, since state appropriations and tuition account for only about half of our revenues, we have built the magnitude of this university largely by earning the confidence of external sponsors, donors, and others. However, being accountable to the state remains vitally important. In fact, it is now required of us through mechanisms such as the campus 
WVU'S LAND-GRANT MISSION

134

compact we presented to the Higher Education Policy Commission earlier this year. (Hardesty, 2001)

\section{Strategic Plan}

Until 2004, strategic planning was decentralized other than the Campus Compact. Individual colleges, schools, and divisions were responsible for composing their own strategic plans in consultation with the administration. According to the 2004 Accreditation Self-Study Report, the University felt that "this form of planning is an effective way to respond quickly to changes in the state that affect the University" (West Virginia University, 2004). However, it was not necessarily on the radar of the broader campus community. Eddie recalled, "I think it would be fair to say [the strategic plan] was not even on their radar. I'm sure it was referenced in board meetings, but it was not necessarily a document that for which they grasped what, what need it was out of it. It just was a reporting document more than anything else."

Hardesty's administration continued with the decentralized task force approach to strategic planning up through the 2004 re-accreditation process. During this process, the accreditors asked for the administration to begin creating a comprehensive strategic plan that documented all of its goals and initiatives in one place. That resulted in the 2010 strategic plan, “West Virginia University’s 2010 Plan: Building the Foundation for Academic Excellence.”

The 2010 strategic planning efforts were led Provost Gerald Lang and Faculty Senate Chair Larry Hornak, co-chairs of the plan. They brought together a 100-person strategic planning and assessment committee to brainstorm initial ideas, many of whom were part of the previous task forces. Over the course of what Frank described as two-day "marathon session," the committee decided on the following five overarching goals for the plan:

1. Attract and Graduate High-Quality Students 
WVU'S LAND-GRANT MISSION

135

2. Recruit and Retain High-Quality Faculty Committed to the Land-Grant Mission

3. Enhance the Educational Environment for Student Learning

4. Promote Discovery and Exchange of Knowledge and Ideas

5. Improve West Virginia's Health, Economy, and Quality of Life

This plan was an incredibly comprehensive, featuring a paragraph describing each goal, guiding principles describing the motivations for why each goal was included, and bulleted objectives for reaching each goal. Nine implementation teams were tasked with making the strategic plan a "living" document by Hardesty, and their nine sub plans were included as appendices: enrollment, student affairs, research, economic development, finance, capital, fundraising, information technology, and Health Sciences Center. This style reflected the University's steps to engage faculty and staff as well as students in the plan, highlighting work toward the personnel, student subculture, and programming phases of organizational saga. Sidney, a professor and member of the Faculty Senate at the time, remembered, "I will say that when most people that looked at the plan, it was understandable. It was who we were, you know. Maybe you could have parsed out some of the bullets in different ways. But essentially, it was saying who we were."

In terms of assessment, each goal had a list of key indicators that would show whether or not the goal had been met. The overarching theme, as described by Hardesty's opening of the plan (West Virginia University, 2005), was student-faculty engagement and interaction. He indicated that fulfilling that goal encompassed the five formally articulated goals in the plan.

The goals also encompassed all phases of the fulfillment stage in organizational saga. Goal one, "Attract and Graduate High-Quality Students," incorporated student subculture as it focused on programming to recruit and retain students. Goal two, "Recruit and Retain High- 
WVU'S LAND-GRANT MISSION

136

Quality Faculty Committed to the Land-Grant Mission," incorporated personnel because of the focus on faculty but also programming because of the potential of what they contribute to the University as well as imagery because the messaging connected back to the land-grant mission. Goal three, "Enhance the Educational Environment for Student Learning," included both student subculture because of the experience it focused on for students as well as personnel because of the expectation of the faculty's role in reaching that goal. Goal four, "Promote Discovery and Exchange of Knowledge and Ideas," encompassed both personnel and student subculture because of both faculty and graduate student expectations for research as well as programming and imagery because of the activities associated with research and the reputation that comes with prominent research and its potential for economic development. Goal five, "Improve West Virginia's Health, Economy, and Quality of Life," incorporated social base because of its focus on community but also programming because of the activities that were part of reaching that goal as well as imagery because of what reaching that goal would represent for the University's relationship to the state.

Overall, the plan demonstrated a rigorous focus on research and economic development in the state while continuing its commitment to students, for which by that point the University was known for broadly through initiatives like WVUp All Night and the Mountaineer Parents Club. The role of service and engagement in the life of the campus was also stressed in addition to the research and economic development goals as avenues for carrying out the land-grant mission: "As a land-grant institution, our mission is to serve the citizens of West Virginia. As we connect students to these efforts, we advance the concept of civic engagement in our future citizens and provide invaluable practical experience for our students" (West Virginia University, 2005). 
WVU'S LAND-GRANT MISSION

137

What is not apparent in any of the documents at hand is whether these goals were met. The plan was still ongoing at the time of Hardesty's retirement from the presidency in 2007.

\section{Summary}

What Hardesty lacked in traditional higher education or academia experience, he made up for with his familiarity and comfort in navigating state politics and governance issues, a major part of the responsibilities for any land-grant leader, as seen in Chapter 2. William reflected on Hardesty's leadership style as coming from the political frame (Manning, 2013; Bolman \& Deal, 2013), saying,

I think [Hardesty], by style, is influenced and informed by what I'm going to call the political model. He had no higher education administration experience. In the big law firm, he was the managing director of, he had been part of the higher education scene in the state in various ways from the governing board to his work in private education structures in the state. Thoughtful guy. But when he came as president, I think that the political model is the one he had some of his most vivid experiences in. He had no formal preparation about strategic planning.

The political frame of leadership (Manning, 2013; Bolman \& Deal, 2013) was also reflected in the types of initiatives Hardesty chose to pursue. William described these initiatives as political choices designed to give the University character or special, niche qualities, but at the risk of taking time away from focusing on other responsibilities, especially considering the small size of his executive leadership team.

I don't think that the Hardesty years were grounded in a strategic management approach. I don't think the deans were major players. And I think that the leadership team was relatively tight - a lot of energy and resources. And there's only so many resources that are 
WVU'S LAND-GRANT MISSION

138

discretionary for you to use, were not aimed at what curricular changes are we trying to pursue ... [He] was a very smart man but just came with a different style. A University of the type can take strategic steps but, if it's to influence the University, it requires an analysis that is clear to people that they are involved in. The themes are clear. The major operating administration, the deans and major directors, understand it, are a part of it, and see it on their agenda. That's the characteristics that makes the place hum strategically. And, if you have super bells and super bells, I think the public probably says, 'Wow, wow,' but I don't think it strategically is likely to take you in a direction that moves the institution.

This reflection shows that while Hardesty's administration was intentional in its strategic planning initiatives, that they did not necessarily gain buy-in from the campus community as a whole at the time, especially early on in his presidency.

\section{Defining the Land-Grant Mission: Vision and Messaging}

\section{Becoming a National University}

From the beginning of his presidency, Hardesty believed that the "greatness" of a comprehensive, land-grant university was its ability to constantly be connected to the state's citizens through research and service, similar to recommendations illustrated by Reilly (2003) and Peters (1998). He shared in his inaugural address: "The citizens of our state and region are touched daily by our service and research. This is the true greatness of the comprehensive university. This is the historical significance of land-grant universities. Since 1867 West Virginia University has served society, especially West Virginia and the region of which it is a part" (Hardesty, 1995c).

Throughout his public talks and speeches, Hardesty regularly incorporated the University's pursuit of "greatness," or the idea of constantly working to improve on its quest to 
WVU'S LAND-GRANT MISSION

139

become a national university, as part of the responsibilities of being a land-grant university.

Samantha, a faculty member at the time, remembered this quest:

I remember ... [Hardesty's] focus on helping everyone both on-campus off-campus and the world to understand that WVU was a place of excellence and a place that wanted to focus on preparing students to be leaders. And so, the motto at the time is 'where greatness is learned.' And I always thought that that very much reflected [Hardesty's] passion about leadership, the idea that each one of us can be great. And that was something that that really, I think, spoke to a lot of people.

However, Samantha also recalled negative reactions by faculty and staff as well as state government officials to the goal of becoming a national university. This criticism was often in response to the tension that arose from focusing on national goals and developing a national reputation for the University during a time when the state was calling for more of a local focus, especially during reforms such as Senate Bills 547 and 653, discussed above. Samantha continued,

There were also a lot of people who were cynical about it because that was a period of transition from being sort of WVU's identity as a strong regional university as opposed to a strong national and international university. And it was also a time where [Hardesty] knew that with legislative budget cuts the way that we were going to be able to maintain and grow was going to be through additional student enrollment. So, it was a period where that identity shift from a state or regional school to one that served to the world. There was a palpable shift in focus. [He] had to walk a tightrope in that period of shift from how do you talk about serving the state which obviously is the land-grant mission and then 
WVU'S LAND-GRANT MISSION

140

expanding the concept of the land-grant mission to include what we could do as a nationaland world-recognized university.

\section{Navigating External and Environmental Issues}

In his "Building a High-Performance Organization at West Virginia University" speech (Hardesty, 1997b), Hardesty identified several issues impacting leadership decisions made at higher education institutions, especially WVU: the globalizing economy, increasing job market competitiveness for college graduates, communications and technology revolution (e.g. internet, email, cell phones, etc.), erosion of social responsibility and loss of civic responsibility among young adults, emergence of educational competitors (e.g. for-profit institutions, industry, etc.), and healthcare reform costs. These challenges were many of the same ones Duderstadt (2009) acknowledged, as described in Chapter 2. In response to these issues, Hardesty called for WVU to become a "high-performance organization," identified characteristics of high-performance organizations, and made recommendations for how leaders should act on them. The characteristics included becoming other-centered, or focused more on the campus community that the University serves (e.g. students, customers, patients, clients, community members, and research sponsors); engaging with and continually learning from society (through areas like job creation, economic development, welfare reform, healthcare, education, and technology); narrowing research focus to areas that reflect the University's strength and opportunities for research development; placing a premium on human development and teamwork (through initiatives like improving internal communication and organizational structure and encouraging collaboration and appreciation); and differentiating from the competition. Frank recalled how Hardesty's experience in law and business framed his motivations for efficient management of University operations: "I think that the effort there was to try to get us to sort of think outside the 
WVU'S LAND-GRANT MISSION

141

box about how we can become more efficient and more effective. And I think those words efficiency and effectiveness have, have just ridden through the change of time because we still talk about it today." These operational changes were a step toward reaching the programming phase of fulfillment in organizational saga.

Hardesty often spoke of how engaging with the land-grant mission could help WVU navigate these external and environmental challenges facing higher education, similar to Crow and Dabars' (2015) perspective in their conceptualization of the "New American University," as discussed in Chapter 2. In his inaugural address, Hardesty said, "It has always had the same mission: teaching, research, and service. The manner in which it has met its mission, however, has in large measure been determined in the context of events influencing it at various times in its history. Our generation of leadership at West Virginia University is challenged today, just as prior generations of leadership have been challenged" (Hardesty, 1995c). He took a similar approach in his first State of the University Address (Hardesty, 1996), sharing observations of the University's current situation while discussing major issues affecting higher education. In this speech, Hardesty offered ideas for how WVU can navigate and respond to the rapidly changing higher education landscape by adapting its land-grant mission.

We now must operate in a different era. Federal funds are shrinking. State funds are limited. Enrollments are declining. And we are expected, in the midst of all of this, to adjust to what amounts to gigantic shifts in our economy. The impact of all of these forces is to create a swirling sea of change upon which we must navigate. As good stewards of this institution, we must strengthen WVU in the midst of today's significant challenges. We cannot lower our standards! We cannot accept less than high quality. We cannot stop investing in the 
WVU'S LAND-GRANT MISSION

142

future! We have no choice but to change ourselves. And we are charting a new course. (Hardesty, 1996)

This speech also included a continued call for the University to focus on quality and greatness. Simultaneously, Hardesty asked the University community to become a more service-oriented university in all areas of its mission, including expanding its service activities to encompass the entire institution, not just the Extension Service and Health Sciences Center. To do so, he asked the audience to consider the following questions in how they approach for teaching, research, and service: "Whom do we serve? What are their needs and expectations? How we can exceed their expectations?" (Hardesty, 1996). These ideas were similar to those called for by the authors of the Association of Public and Land-Grant Universities" "The Centrality of Engagement in Higher Education" report, which shared strategies of how public research universities had revamped their missions to engage with their communities over time to address similar challenges, such as informing economic development.

In 1999, a document was published for new Board of Trustees members to educate them about WVU's history, its missional responsibilities, and what it means to be a land-grant university. The opening section focused on WVU's importance to the state and nation as a research university. This section highlighted that even though the fundamental mission of the University has not changed, that WVU still needs to adapt to changing environmental, social, cultural, and economic influences, another step toward reaching the programming phase of the fulfillment stage in organizational saga.

West Virginia University is an engaged, student-centered, land-grant university with the traditional threefold mission of instruction, research, and extension. Land-grant institutions were established in each state by the Morrill Act passed in 1862 to create universities with 
WVU'S LAND-GRANT MISSION

143

the mission to support agriculture and mechanical arts through teaching and research. Although the fundamental mission has not changed, land-grant institutions are embracing considerable changes in how they carry out their missions to meet the challenges brought about by rapid advances in information and other technologies, globalization of our economy, and the increasingly fast pace world in which we live. (West Virginia University, 1999)

This passage reflects the Hardesty administration's work toward reaching every aspect of fulfillment in organizational saga - faculty responsibilities of quality research and teaching (i.e. personnel), the student experience (i.e. student subculture), connecting with communities through service (i.e. social basis), addressing challenges like technology and the economy through the mission (i.e. programming), and how all of this work reflects the institution (i.e. imagery).

Research, in particular, was emphasized as the arm of the University that has most potential to make a difference in citizens' lives and in the economy. "The need for research has become more important to our security and economy. Therefore, WVU must be increasingly aggressive to maintain a competitive edge in its research programs" (West Virginia University, 1999). Research was also emphasized in Hardesty's inaugural address as a source for economic development in the state. "We will extend the frontiers of knowledge. Our research will be meaningful, competitive, useful, and relevant. Our more than 20 centers and institutes that now return over $\$ 10$ to our campuses for every $\$ 1$ provided by our state, will continue to work to expand our understanding of our environment, our natural resources, our bodies, our minds, and worlds both past and future" (Hardesty, 1995c). Vincent also reflected on Hardesty's emphasis on research as part of the land-grant mission: 
WVU'S LAND-GRANT MISSION

144

So, it's that kind of thing that now there's ways that we really can be more active. We can do things like that ... To publish papers. To do research. When you start to look at . . robotics and math and STEM and getting kids involved. That's the kind of thing that is a real bridge builder. But we wouldn't have done that in the past. We would've said, 'That's not our problem.' So, we have changed a lot more. And we do a whole lot more different things ... We do more, more differently now. Hardesty was one of the ones that started it ... He started that conversation.

Vincent's recollection demonstrates how the Hardesty administration used research to operationalize the land-grant mission and continue to reach the personnel, programing, and imagery phases of fulfillment in organizational saga.

In his inaugural address, Hardesty also identified the service mission as an avenue for addressing the needs of the state of West Virginia, specifically in the areas of education, healthcare, the economy, and community development.

We will vigorously serve our state, our region, our nation and our global community. We care about those we are charged to serve. As a land-grant institution and as a comprehensive research university, we are supported by the people of our state and nation. They expect us to serve and we will meet their expectations. We will provide exceptional rural health care, we will foster community development, we will look for ways to assist our public system of education, we will address the quality of life of those around us, we will continue the education of professionals, we will provide useful and practical knowledge to the people of West Virginia through our extension service, we will foster new industries and revitalize older ones in order to provide meaningful work for future generations, we will assist our governments and we will help those whose circumstances require helping hands. We will, 


\section{WVU'S LAND-GRANT MISSION}

145

every day, make service a priority and by so doing, we will earn the respect of those we serve. We will enter into partnerships with those we serve to help make their dreams come true. (Hardesty, 1995c)

This aspiration demonstrated the administration's focus on the social base phase of fulfillment because the goals and messages discussed emphasized the University's responsibility to not only address state needs but care for its citizens.

This service focus continued in Hardesty's 2005 State of the University Address, though taking on an economic development standpoint as he called for WVU to become more innovative to continue navigating the challenging economic landscape for higher education. "In this climate, we must make sure that as a land-grant institution, we are part of a culture of innovation. We must ask ourselves hard questions challenge the status quo and truly assess whether we can do more in or, to adapt to world changes" (Hardesty, 2005). Hardesty also revamped the University's vision statement during this time to reflect the aspiration to become more innovative in how WVU carries out the land-grant mission, including an emphasis on technology.

Because the perceived quality of our institution is so important to the future, our immediate goal is to not only adapt to the challenges that lie ahead, but also to advance our national reputation. Our newly revised vision statement asserts not only that we will be student centered and meet society's changing needs but also that we will be an institution with a national reputation for excellence while doing so. We aspire to be nationally recognized for excellence in teaching, scholarship, discovery, performance, service, healthcare, athletics, and every other area of our collective endeavors. (Hardesty, 2005) 
WVU'S LAND-GRANT MISSION

146

This strategy and discussion of a culture of innovation is an example of what Klein and Woodell (2015) called for in their economic development framework, which demonstrated how research and innovation, human capital and talent development, and stewardship of place all intersect to inform the most potential for economic development activities between land-grant universities and their home communities.

\section{Students and the Land-Grant Mission}

Hardesty believed the University would continue to carry out its land-grant mission during his presidency because of the focus on students and teaching. He shared in his inaugural address:

We always have and we still do care deeply about students, teaching, and learning on our campuses. We want our students to have rich and rewarding experiences while they are with us. We want them to learn about the world of ideas and how to think, to communicate, to respect others who are different from them, to participate in the international community, to lead, to serve, to address ethical problems, and to accept civic responsibility. And, we want our students to have bold dreams and to believe that they too can make a difference.

We believe we will prepare them to do just that. (Hardesty, 1995c)

Hardesty's focus here on students and their experiences shows how much his administration emphasized not only the student subculture phase of fulfillment in organizational saga but also the role of teaching and student learning in the land-grant mission.

Vincent and Nicole acknowledged that the focus on the student experience and how student culture fit into and operationalized the land-grant mission because the way the University approached the campus culture, campus safety, and student experience was a strategy for increasing access for students, especially those from southern West Virginia and other more rural 
WVU'S LAND-GRANT MISSION

147

parts of the state. Vincent remembered how WVU's Morgantown campus struggled to recruit instudents living distances away, such as from Kanawha County in the southern half of the state where the state capital is located, because of the party school reputation and other safety concerns, such as living off-campus in dilapidated housing.

[Hardesty] would say we're not getting the [George Washington High School] kids; we're not getting the Kanawha Valley kids. They're afraid of us . . . He said when the kids come from the Kanawha Valley, what they're telling their parents has to be: the dorms are fine. I'm safe. The food is better. Things are structured. They're making me study. I'm having a great time, but I'm also working hard. I feel safe.

Nicole also noted, "I think a huge part of what he wanted to do was to change the image and student culture ... [He] worked hard to change the student behavior." These anecdotes reflect not only the student subculture phase of fulfillment in organizational saga, but also imagery and the role reputation plays in influencing students' college-going decisions, an element of the symbolic leadership framework (Bolman \& Deal, 2013; Manning, 2013; Meyer \& Rowan, 1977).

Improving campus safety and the overall atmosphere on campus, especially new students and their families, was a significant part of this outlook. One of the ways Hardesty tackled that challenge was eliminating an annual block party on Grant Street, located near the downtown campus, in favor of a University-sponsored campus-wide welcome back celebration, known today as FallFest. Similarly, he took on "The Pit," a parking lot near WVU's football stadium known for heavy partying leading up to home football games. Vincent remembered, "[Hardesty] and I go to 'The Pit,' and it's debauchery, drunkenness, hideous behavior. And he's going, 'What do you think?' And I'm like, I mean, what can I say. So he would say things like, 'OK, get that 
WVU'S LAND-GRANT MISSION

148

fixed." Nicole also recounted how much Hardesty cared about students and their safety and experience.

[Hardesty] felt the student life aspect really had been neglected ... And in fairness to neglect, he said there was this period where you had the 1960s, you had all this protest on campus ... I think he felt that we were ready to go from rejection of that to really focusing again on supporting our students and being partners with them and involving their parents. Hardesty also demonstrated the connection between the student experience and the landgrant mission when he charged Provost Gerald Lang with distributing a memo (Lang, 1997) along with the Kellogg Commission on the Future of State and Land-Grant Universities' report on "The Student Experience" to WVU's academic leadership. This report called for all landgrant universities to refocus their missions on the student experience. The memo from Hardesty's administration did just that - calling WVU to become a more student-centered university in conjunction with the work of the Student Affairs Task Force. This strategy further strengthens Hardesty's student-centered initiatives and new vision statement while exemplifying a way to reengage with the land-grant mission. The memo notes, "as a land-grant institution, WVU is a public trust, existing to create a learning environment for our State's citizens." To meet this call of becoming more student-focused, the memo highlighted five goals and examples of how the University was working toward that call or could work toward that call:

1. Revitalize partnerships with public schools: Benedum Collaborative in College of Human Resources and Education, college courses for high school students, BOT initiatives 7-1 O; Honors Academy 
WVU'S LAND-GRANT MISSION

149

2. Reinforce commitment to undergraduate instruction: Emphasis on teaching as cornerstone mission, new library/modernization, e-mail accounts for students, teaching professorships, STEP, STAY, new academic building

3. Development of students in holistic way: Operation Jump Start, enhanced advising, service learning, Student Recreation Center

4. Link education and career: Career Success Academy, Parents Club

5. Link discovery and learning: Study abroad, independent research, Honors Program, Festival of Ideas

Frank recounted the motivations behind sharing this report and memo with leadership and what the administration hoped to accomplish.

What we tried to do with those memos was contextualize those reports. One, talk about them and then showed how WVU was actually working to move in that direction. It was an effort to align the institution with the activities of the Kellogg Commission and to suggest to our faculty for those that were on board were doing the right things. And for those that we still needed to move along, to give them the encouragement to make some of the changes because this is where the future of land-grant university was going. So, it provided us with the opportunity to communicate with the campus.

The use of this memo as part of the administration's early leadership strategy reflected both work toward the student subculture phase of fulfillment in organizational saga as well as the imagery phase.

\section{WVU Extension Service's Role in the Land-Grant Mission}

Hardesty identified WVU Extension Service as the primary outlet for operationalizing the land-grant mission, and he worked to streamline and expand its activities to target the needs of 
WVU'S LAND-GRANT MISSION

150

West Virginia residents. He often highlighted it in his speeches to educate the public on not only WVU Extension Service's role in the community but affiliation with WVU, an example of carrying out the social base phase of fulfillment in organizational saga. Vincent shared how WVU's land-grant mission has changed through WVU Extension Service's operations, which has expanded beyond more traditional agriculture offerings of the county Master Gardener position and 4-H to economic development, similar to McDowell's $(2001,2003)$ calls for innovating the mission of Extension. Vincent shared, "Since the Hardesty era, we have been more intently focused on the needs of the state and the appropriate role of [WVU] in the state ... We didn't, we weren't able to do a lot of the other kinds of stuff. So, one of the things that happens is in the Hardesty era was how can we actively help the state."

During Hardesty's presidency, WVU Extension Service combined its field operations and campus-based programming divisions into one cohesive program center concept with three areas: Agricultural and Natural Resources Development; 4-H and Youth, Family, and Adult Development; and Community, Economic, and Workforce Development. As a result, WVU Extension faculty were given a primary assignment in one of those three areas.

From the beginning, Extension personnel took the results of Agricultural Experiment Station research directly to the people who most needed them-farmers and their families. Extension defines its mission as 'Taking the University to the People.' This first venture into the community with practical knowledge of benefit to people in their everyday lives has blossomed into the wide array of public service activities offered today by many of West Virginia University's schools and colleges. The growing need to provide lifelong learning experiences is leading WVU to extend itself even more than it has in the past. Changing career patterns and new demands for updated knowledge have made it essential 
WVU'S LAND-GRANT MISSION

151

that higher education institutions offer an increasing number of opportunities for adults. (West Virginia University, 1999)

This restructuring reflected Extension Service's attempt to redefine its mission in a way that best positions its resources for serving West Virginia communities, which aligns with McDowell's (2003) recommendations for Extension.

\section{Partnerships, Collaboration, and Engagement}

Despite the emphasis on WVU Extension Service's role in operationalizing the landgrant mission, the above-mentioned document for new Board of Trustees members also stressed the importance of creating partnerships with community groups and organizations to continue engaging with the land-grant mission, demonstrating steps toward the social phase of fulfillment in organizational saga.

While celebrating its past success in bringing the benefit of new knowledge to millions of people, land-grant universities are recommitting themselves to do more and to do it better. West Virginia University is embarking on a campaign of improving engagement with its citizens. Engagement emphasizes partnerships-mutually beneficial, two-way collaborations with business, industry, school systems, the health and social service sectors, and government. The two-way interaction occurs to define problems, goals, and agendas together. As WVU President David C. Hardesty Jr. noted in his February 1999 State of the University Address: 'West Virginians will come to know their state's flagship University as one that commits to society, learns from it, serves it, educates it, and contributes to it.' It is all about responding to the most critical social and economic concerns of our communities. (West Virginia University, 1999) 
WVU'S LAND-GRANT MISSION

152

To work to identify those community concerns and needs, WVU embarked on a county program forum in all 55 counties in fall 1999 to identify the high-priority issues and make recommendations for ways the Extension Service can address them through collaboration partnerships, another engagement strategy similar to those seen in Fitzgerald et al. (2012) and Gavazzi (2015). However, no documentation could be located that demonstrates the results of those forums.

\section{The Changing Land-Grant Mission}

In his 2001 address, Hardesty acknowledged how the land-grant mission had changed so far in his six years as president. He observed the focus on student-centeredness and the role of technology in society as two major sources of that change. He also described how the institution had continued to adapt its mission to meet the needs of the people it serves, a reflection of reengaging with its mission in the land-grant saga, similar to the mission recommendations from Jongbloed, Enders, and Salerno (2008).

We have transformed WVU into a stronger university with new and updated facilities; a focused and balanced vision; a commitment to core values, including student-centeredness; and a clearer view of the present and future needs and goals of the people we serve. We are in a period of accelerated change that is strengthening and improving university in many important ways. The result of our work is a new West Virginia University. Yet, our traditions are intact. Our history remains that of land-grant university fulfilling its mission to serve the people of our state. Things are happening at WVU now that will benefit individuals and society in ways never imagined in 1895 or 1995 - and in many ways we cannot imagine today. The University, of course, is older than any of us will ever be. It is probably wiser than any of us, and it will outlive every one of us. Everything we do to 
WVU'S LAND-GRANT MISSION

153

advance the institution helps to guarantee the advancement of generations to follow. Ours is a noble cause, and a vital one. (Hardesty, 2001)

All of the elements in this passage show how Hardesty's administration made consistent progress to each of the phases of the fulfillment stage in organizational saga: personnel, student subculture, social base, programming, and imagery.

\section{Summary}

Coming into the presidency as an outsider, someone whose curriculum vitae did not reflect that of what was typical or expected of a university president, Hardesty faced challenges from the start. His recognition of this status and the criticism he faced, especially from faculty, was important for his navigation of the initiation phase of organizational saga, characterized by a strong purpose in a short time-frame, as he kicked off a major initiative (i.e. becoming a studentcentered university) on the first day of his presidency, and then followed that up with a second major initiative (i.e. "administrative organization initiatives," also referred to as a highperformance organization later in his administration) later that same month.

Despite the transitional challenges, Hardesty was able to use his nontraditional business and government background to shift the institution's focus to pursuing "greatness" in the tripartite land-grant mission, which reflected steps toward both the programming and imagery phases of stage two of organizational saga, fulfillment. However, these efforts were still met with criticism, especially from faculty who were expected to do "more" beyond the traditional workload as the University shifted to a more student-centered culture. The new student-focused initiatives made improvements to retention, safety, and processes like financial aid, advising, and registration while building relationships with parents and improving WVU's reputation for prospective students across the state, a step toward the student subculture phase of stage two of 
WVU'S LAND-GRANT MISSION

154

organizational saga. The establishment of WVU Research Corporation gave faculty the flexibility to pursue major funding opportunities from the federal government and national organizations, making WVU a research competitor in the national marketplace for the first time and working toward the personnel phase of stage two of organizational saga. Organizational changes to WVU Extension Service helped identify needs and focus priorities in West Virginia communities, making WVU a more familiar partner and working toward the social base phase of stage two of organizational saga. Simultaneously, a comprehensive strategic plan featuring innovations to technology and facilities and a focus on efficient business operations reflected a modern university becoming a player in the national arena while being more engaged with its state than ever before, another reflection of the programming phase. All of these efforts and those described in the section above demonstrate how the Hardesty administration reached the second stage, or fulfillment, or organizational saga, over the course of his 12-year presidency, more than twice the duration of the average higher education presidential tenure. While his presidency was initially framed by significant criticism and doubt, Hardesty is remembered today by many of the participants interviewed in this study as a heroic leader, someone who persevered and overcame much conflict as he sincerely attempted to modernize WVU and put the University on the national map, particularly in the wake of declining state support. These recollections are also consistent with how the media viewed Hardesty by the conclusion of his presidency, with headlines like "Hardesty Gets High Marks at WVU”; "WVU Must Build on Hardesty Legacy"; "Hardesty Has Strengthened WVU”; "Hardesty’s Decision to Step Down at WVU Exemplifies Leadership Skill”; "He'll Be Missed”; among others (Lewis, 2013, p. 409). This heroic leadership style (see symbolic leadership frame: Manning, 2013; Bolman \& Deal, 2013; Meyer \& Rowan, 1977; Basham, 2012) reflects how Hardesty’s leadership has evolved 


\section{WVU'S LAND-GRANT MISSION}

155

over time, not only in his 12 years as president, but how the campus community views his presidency more than a decade later. 
WVU'S LAND-GRANT MISSION

156

Chapter 5: Michael Garrison's Administration 
WVU'S LAND-GRANT MISSION

157

\section{Figure 5.1 Garrison Presidency Timeline}

\section{Earlier in 2007}

- Search process for new president; faculty voted "no confidence" in Garrison's candidacy

July 2007

- Presidency began

\section{August 2007}

- Employee pay raises approved

\section{September 2007}

- Campus safety initiative announced

October 2007

- "WE CAN" sustainability initiative announced

- "Coming Home" inauguration week/formal celebration

$\circ$ Inaugural speech

- "Join the Conversation" town halls

- Announced plans for construction of child care center

- Record-setting \$25 million private gift

\section{December 2007}

- New residence hall announced

- Research Trust Fund implementation shared with Board of Governors

\section{Spring 2008}

- Degree scandal

June 2008

- Resignation

\section{Figure 5.2 Garrison's Organizational Saga}

\section{Stage 1: Initiation}

- Followed a 12-year president (i.e. David Hardesty) who retired in a positive light and modernized the institution

- Wrought with criticism (because of lack of qualifications, political background, lack of higher education experience) even before he was hired

$\circ$ Faculty Senate vote of no confidence

- Many comparisons to Hardesty because of their similar backgrounds

- Within six months: wave of optimism 
- Increases in state budget

- Salary increases

$\circ$ Largest gift in University history

- Media gave the administration an "A"

\section{Stage 2: Fulfillment}

- $\quad$ N/A; president from July 2007-June 2008

Personnel (Faculty and Staff)

- Gathering input via "Join the Conversation" initiative

- Employee pay raises

- New childcare center

Programming (Visible practices; mission, vision, and values)

- Research Trust Fund: Public-private partnership for research and faculty recruitment

$\circ$ Externally funded research increased by $7 \%$ in Garrison's year as president.

- New childcare center

- New student housing

- "We Can" green footprint initiative

- Safety initiative

Social Base (Alumni, donors, community)

- Rapport as an alumnus and West Virginia native

- Relationship with state government and politicians with legal, government, and lobbyist background

- Former policy commissioner

- \$25 million private gift, largest in WVU history (at the time)

Student Subculture (Students)

- Gathering input via "Join the Conversation" town hall initiative

- Built rapport with students because of his perspective as a first-generous college student and past experience as Student Government Association president

Imagery (Symbols, traditions, culture, events)

- "Come Home," week-long event for inauguration (tied to Homecoming, Diversity Week, other events on campus, etc.)

- Degree scandal worked against this area

- Pursued lawsuit against then-football coach Rich Rodriguez when he left his contract early for head coaching job at University of Michigan. 
WVU'S LAND-GRANT MISSION

159

\section{Another Tumultuous Beginning}

Following a president who served more than twice the average tenure of university presidents and, as a hero figure to the organization (Basham, 2012), was considered to have put West Virginia University on the map of the national higher education landscape, Michael Garrison's start as president of WVU was not unlike that of David Hardesty's: wrought with criticism and doubt. Just 38-years-old when he assumed the presidency, Garrison's only higher education experience prior to becoming WVU's $23^{\text {rd }}$ president was as an adjunct instructor in WVU's Department of Political Science and chairing the state's Higher Education Policy Commission. Instead, Garrison, who was a lobbyist with the "longest client list in West Virginia" (Fain, 2007), brought experience in law, business, politics, and government to the role. A former secretary of tax and revenue under West Virginia Governor Cecil Underwood, Garrison emphasized his experience navigating the state funding model to demonstrate his ability to manage inefficiencies in how the University is organized and bureaucratic processes with his business background.

Garrison believed his presidency represented a "distinct change from the WVU and higher education status quo" (Trachtenberg, Kauvar, \& Bogue, 2013), despite his experiences and qualifications being parallel to that of Hardesty's when he began his presidency. This belief implied that he aspired to emulate the transformational leadership framework (Basham, 2012). Nicole, a staffer in the Office of the President, recalled how Garrison's background shaped his presidency, saying,

He had the benefit, like [Hardesty], that he had been . . . a policy commissioner. So, he had seen the University. He was a student like Hardesty. He had been a student body president. 
WVU'S LAND-GRANT MISSION

160

He had his own observations, his own direct experiences. When he came in, he had a number of things he wanted to do that he thought were important to address.

Several faculty and administrators described Garrison as too political or too young and inexperienced to take on the role of the presidency at a large, public, land-grant, research university, demonstrating their lack of confidence in his ability to be a successful president and understand the role of faculty and proactively work with them. Garrison himself reflected on these characteristics in the book Presidencies Derailed: Why University Leaders Fail and How to Prevent It (Trachtenberg, Kauvar, \& Bogue, 2013, p. 82).

The faculty forum was marked by contradictions. I was too young to handle the job, but needed 'enough energy to take us to the next level.' I needed to know how to navigate the state funding process to win increases in faculty salaries, but my background was 'too political.' I would have to be able to tackle bureaucracy and inefficiency on campus, but my business background was suspect because 'a university cannot be run like a business.' Several administrators during Garrison's tenure recall this dissent. Henry, a retired faculty member, commented on Garrison's nontraditional background. He indicated that Garrison's minimal higher education experience influenced his leadership style, which was the opposite of the traditional collegial model in higher education (Manning, 2013).

There was a lot of opposition on campus to him. I think a part of it was that he was coming from outside the education system even more so than [Hardesty] had been from outside. He tended to approach things more from the partisan politics of the West Virginia tradition than the academic politics of a campus. From pretty much day one, there was just an opposition to [Garrison's] presidency and a desire for his presidency to end as soon as 
WVU'S LAND-GRANT MISSION

161

possible. I think he approached it pretty much from the rough and tumble world of West Virginia politics.

In addition to the minimal higher education experience in his background, opposition came from beliefs that the presidential search process was too "insulated and political" (Wilson, 2007), making Garrison immediately distrusted. Following interviews with three candidates, Garrison; Daniel Bernstine, president of Portland State University; and M. Duane Nellis, provost of Kansas State University and former dean of WVU's Eberly College of Arts and Sciences, the faculty endorsed Nellis, while the Student Government Association endorsed Garrison (Wilson, 2007), making the campus severely divided in their support.

Joseph, a faculty member and academic leader, recalled the faculty's distrust in Garrison's ability to keep the University's best interests in mind because of his experience in state government and politics, expressing concerns about the political sway that could be held over WVU's presidency. "Coming from a Charleston background ... he was very astute in the ways of the legislature and positioning us well for that ... I think he was ill-equipped to be a university president. But he knew the politics part." William, a faculty member and former administrator, remembered concerns about Garrison's minimal higher education experience.

And I liked [Garrison] and admired his tenaciousness and was pleased to see his early career. But I think he was not ready for the role he was asked or pursued and got. There was little in his background that prepared him for that role, whether it was to be the CEO of this organization or another. So, I don't think that strategic assessment as a management tool was on his plate or used. And the turmoil that developed overwhelmed he [sic] and his administration. 
WVU'S LAND-GRANT MISSION

162

During the interview process, Garrison attempted to strategically compare himself to Hardesty because of their similar backgrounds as a way to leverage his experience, an example of how he used the political leadership framework as a strategy for trying to gain buy-in (Manning, 2013; Bolman \& Deal, 2013). Edith, another faculty member, remembered these comparisons vividly.

The fact that Garrison was chosen without a comparable level of experience and the fact that he was comparing himself very directly to [Hardesty] when he really didn't have the credentials that [Hardesty] brought. He didn't have the scholarly background . . . He had a degree from WVU. He really hadn't seen other institutions. He didn't bring that perspective. So, I think that's part of why the faculty, and I would include myself in that, were so resistant to Garrison, and I was someone who respected and continue to respect [Hardesty] because he did bring an outside perspective but with a very solid academic grounding and with a real focus on students. So, [Hardesty], I think, quickly demonstrated that he was going to share institutional values in common with the faculty whereas we didn't have that same sense from Garrison. And Garrison, by trying to draw comparisons between himself and Hardesty, was almost setting himself up for more resistance because faculty know how to read a [curriculum vitae], and there were big, big differences.

Joseph also observed Garrison's attempts to compare himself with Hardesty as a strategy for earning political capital among faculty, staff, alumni, donors, and state leaders as he was beginning his presidency, another strategy of his that reflected the political leadership framework (Manning, 2013; Bolman \& Deal, 2013).

[Garrison] saw himself as very similar to [Hardesty]. But on campus, for some reason or another, it was not as being very similar to [Hardesty]. I think most people on campus felt 
WVU'S LAND-GRANT MISSION

163

that his being selected was more of a true political process in the West Virginia sense than what [the Board of Governors] thought would be appropriate. They felt that they needed somebody from academe as opposed to somebody who was well-connected in politics. The Faculty Senate eventually voted no confidence in Garrison's candidacy for president, making him the "runner up" in the faculty's eyes in what became a two-person contest that he won, which made it even more difficult for him to gain rapport and buy-in. Edith remembered this decision.

Out of a large field of candidates that we came down to finally, . . one person dropped out, and the other person was Duane Ellis, who a lot of the faculty knew and respected because he'd been the dean of the [Eberly College of Arts and Sciences] ... He seemed to bring both an outside perspective and experience, a really good blend.

However, the Board of Governors ultimately selected Garrison for the role in a search that was seen as "rigged in his favor" and immersed in "political favoritism" by critics (Fain, 2007; Fain 2008) because politics weighed heavily on the search process.

William recalled when Garrison's hiring was addressed at a faculty meeting, which was hosted in the University's 1,412-seat concert theatre to have the capacity for the anticipated crowd. He remembered,

The buzz, the mood was not good. This is not the way leadership is selected at an institution ... And, my summary of it, blunt as this is: He could not have been in the final three to five candidates in any other land-grant university in the United States. None. He did not have the experience, background, credentials for that. This was a fashioned appointment done poorly. My assessment was that he got used and just didn't have the capability of not being used. He was dead in the water. I wouldn't have invested a penny in his future. As 
WVU'S LAND-GRANT MISSION

164

much as I liked him on a personal basis, he just shouldn't have ever been appointed as president. I think it was predictable on his appointment.

William believed that the Board of Governors' "used" Garrison as a political player, likely to give the state legislature more power and oversight over the University, and that their decision to hire Garrison and the resulting dissention about the decision set him up for failure on the spot.

It was only a matter of time and probably a short time until he was not going to be president of the University. And it was just a matter of what would bring him down. And it didn't take a lot or a long time. Now, in that context where you are fighting animosity—I just don't think you are allowed, almost. Even if he had been articulate and able to talk about what the strategic future and needs of the University, the audience wasn't listening or available.

In the media, Garrison attempted to play this in his favor, describing WVU as a "quasigovernmental entity" and declaring that his political background had prepared him to lead a university that "relies on and interacts with the state on a number of fronts, such as funding, legislative initiatives and purchasing issues" (Stump, 2007). Comments like these continued to show Garrison's leadership from the political frame (Manning, 2013; Bolman \& Deal, 2013).

In the midst of this turbulent beginning, what the Garrison administration attempted to present externally and publicly was celebration and pomp and circumstance, attempting to create or even force an image of Garrison as an organizational "hero" (Manning, 2013; Basham, 2012) to overcome the criticism. A formal approach was taken to his inauguration with a week of celebratory events connected with the University's traditional homecoming events framed by a "Coming Home" theme, a much larger and grander inauguration event than any other president included in this study (West Virginia University University Relations, 2007). A welcome 
WVU'S LAND-GRANT MISSION

165

reception in the Mountainlair Student Union featured students celebrating WVU as their home and how they serve the state and teach other through the University. Garrison, along with some of the University's influential professors and student researchers, discussed what motivated them in the classroom and the laboratory. Alumni visited Garrison's political science class to share how WVU changed their lives. The week culminated with a webcasted inauguration ceremony in Woodburn Circle.

This formal and celebratory approach to the presidency demonstrates Garrison's use of the symbolic leadership frame (Bolman \& Deal, 2013; Manning, 2013) as well as his administration's attempts to reach the initiation phase of organizational saga by seeking to overcome the turbulent beginning and distrust, especially with faculty, through events, messaging, and celebrations seeking to unify the campus. In particular, the divided campus preferences and opinions about who was the preferred candidate set up a limiting initiation phase of organizational saga for his administration.

\section{Operationalizing the Land-Grant Mission: Strategic Planning and the Work of the}

\section{Institution}

Following his week-long homecoming celebration and inauguration, Garrison began his administration with an input and feedback-gathering process coined as "Join the Conversation." A divergence from predecessor David Hardesty's initial strategy of gaining input through a small, targeted, hand-picked "kitchen cabinet," Garrison's initiative of town hall-style meetings allowed Garrison to hear from various constituents across campus, including students, faculty, staff, and alumni. "As we listened to the campus constituencies, a desire for more radical change became palpable and we worked hard to deliver" (Trachtenberg, Kauvar, \& Bogue, 2013, p. 83). He expressed this desire for change in his first meeting with the Board of Governors, sharing his 
WVU'S LAND-GRANT MISSION

166

"commitment to serious change rather than the status quo" (Trachtenberg, Kauvar, \& Bogue, 2013, p. 82), discussing issues related to faculty and staff salaries, stability, morale, and retention. Eddie, who served on WVU's Board of Governors, reflected, "[Garrison] truly believed that there needed to be a new generation of outlook on things. He believed that controversy was not a bad thing that he thought you had to sometimes stir things to make them better." This anecdote also reflects how Garrison tried to emulate the political and transformational leadership models (Basham, 2012; Bolman \& Deal, 2013; Manning, 2013).

Early on, Garrison expressed a goal of making some of those radical changes in his first 100 days, not unlike the approach made by new public officials in their first terms in office. Nicole remembered this strategy, which featured work on a childcare center for students, faculty, and staff as well as employee raises and health insurance improvements. "[Garrison] was very mindful of the window of opportunity to make some changes in 100 days. You hear those sort of things about the first 100 days. We did a first 100 days report. So, I remember the Dominion Post did an article on it. These are some of the different things he's been able to launch in that 100 days."

The child care center was one of Garrison's signature initiatives from the first 100 days plan (Garrison, 2007b) and one of the few things he is remembered positively for doing among those interviewed. Nicole recalled,

That's something he had been hearing in the community. He was hearing it from campus, and he said, 'We're going to put a group together and figure out how we can have childcare here.' And we have a childcare center now. We put together [a request for proposal]. His wife chaired the group. They had young children. They got the issue. They were hearing a lot about it from students, faculty, and staff. 
WVU'S LAND-GRANT MISSION

167

The facility was the result of ongoing studies for more than three decades. Eddie remembered it coming to fruition: "He was very adamant about daycare, that there needed to be a daycare center ... And it'd been in the works for many, many years and discussed, but never happened." This strategy reflected a step toward the personnel phase of the fulfillment stage in organizational saga. Samantha, an academic leader at the time, shared, "[Garrison] was very sensitive about the responsibilities that come with child-raising and how for many of our families that was very difficult to find quality child care. And so that was when he launched the process of building the new childcare facility. And he was very committed to that facility being excellent and providing very high-quality childcare." This strategy appeared to be an attempt by Garrison's administration to quickly gain some political capital among the campus community since the child care center was already in-progress and an initiative that could be completed reasonably quickly. It also demonstrated that his focus early on was on faculty and staff issues, in contrast to Hardesty's prioritization of students.

As another morale booster, another one of Garrison's first initiatives was a faculty and staff salary increase, the largest in 15 years. This move helped address a long-standing issue with the state's classified staff funding schedule, which had not been fully funded for a decade, relying instead on earmarks. Several of the key officials interviewed recalled this initiative. Eddie remembered, "He was very adamant about increasing salaries for classified staff. He felt that their salaries were inadequate." Sidney, a professor and member of the Faculty Senate, recalled that while the raises were an effective morale booster, that they came as a cost to the budget, which subsequently became under pressure as a result of the initiative. He said, "I've had several people observe to me that they received the largest salary raise they ever received because he walked in and gave a salary raise, which was something of a morale booster, but 
WVU'S LAND-GRANT MISSION

168

perhaps ate some seed corn at that time." Samantha saw the raises as a step toward making the University more competitive in the marketplace for prospective employees and retaining talented individuals.

[Garrison] did a couple of things very quickly, which I think spoke loudly about his priorities. He managed to work with the board to have a very large increase salary program ... It was a lot and, and it was very welcome because we had gone for a number of years without raises, and it was, I think, a recognition of the excellence of the faculty and that we were becoming more competitive in the market and he wanted to stabilize our competitive position.

Yet another attempt at boosting morale, especially for faculty, was a public-private partnership for matching research funding with the state of West Virginia, which resulted in a 7\% increase in externally-funded research (Trachtenberg, Kauvar, \& Bogue, 2013). This was another initiative already ongoing that Garrison received credit for even though it was initially started during Hardesty's presidency, which reflects the fluid nature of strategic planning across administrations. Garrison shared in his inaugural address, "We look forward to partnering with the state of West Virginia - as other states partner with their research universities - to develop a system of support that maximizes private investment, rewards discovery, and contributes to the growth of science-based economic enterprises" (Garrison, 2007a). Frank explained how the initiative came to fruition: "We did that entire initiative at the end of the Hardesty era, the beginning of the Garrison year. So, it finished up. We actually finished a plan under Hardesty, had it approved, and then in the first year of Garrison, we were out there trying to bring the money in to get the matching funds from the state." This effort, which was one of Hardesty's later initiatives coming to fruition, demonstrated another step toward the personnel phase as well 
WVU'S LAND-GRANT MISSION

169

as the programming phase of the fulfillment stage in organizational saga. It reflected an attempt by Garrison to build relationships with the faculty in an attempt to overcome the tension and disapproval they expressed toward his candidacy during the presidential search and hiring processes. It was also another opportunity for Garrison's administration to complete an initiative relatively quickly as his administration was just beginning and attempt to increase the University's standing.

\section{Consumed by Crisis}

All of these reflections demonstrate that Garrison not only had an uphill battle to overcome from the beginning of his presidency because of how his experience was characterized by faculty, but any progress made was quickly overwhelmed by crisis. Any progress made by the Garrison administration discussed previously was interrupted by scandal just a few months into his tenure.

A routine fact-checking phone call to the Office of Admissions and Records by the media to confirm U.S. Senator Joe Manchin's daughter and Mylan Pharmaceuticals CEO Heather Bresch's Executive Master of Business Administration degree led to the uncovering of falsified academic records, including Bresch receiving a degree without completing requirements for graduation. The actions were taken nearly a decade after she was a student, according to the Pittsburgh Post-Gazette (Sabatini \& Boselovic, 2007). At the time, University leadership blamed the College of Business and Economics for its failure to transfer the records to the WVU Office of Admissions and Records, but a further investigation by a panel put together by the faculty senate determined that Bresch's records had been falsified (Boselovic \& Sabatini, 2008a). From that point until his resignation, Garrison's administration was consumed by the issue. Several University leaders resigned, including WVU Provost Gerald Lang and College of Business and 
WVU'S LAND-GRANT MISSION

170

Economics Dean Stephen Sears, and Garrison himself resigned in June 2008 following a

resolution from the faculty senate calling for his resignation (Boselovic \& Sabatini, 2008b).

Later, during subsequent Interim President C. Peter Magrath's tenure, the American Association of Admissions and Collegiate Registrars was brought in to audit the University's recordkeeping processes (West Virginia University University Relations, 2009).

In response to the situation, key officials reflected that Garrison's administration did not last long enough to make a difference in the University's mission-building or strategic planning efforts. Joseph recalled, "Garrison was not here long enough to even make an impact on [strategic planning]." Frank added, "I think with most first years in a presidency it's trying to get a handle on the institution. You're spending a lot of time learning about things and putting together your team." Henry remembered, "The Heather Bresch situation certainly created a situation that caused the support that [Garrison] had on campus to further erode and the support that he had from the Board of Governors to basically disappear." Sidney noted that "it didn't take long before [Garrison] was in a survival mode." William added that Garrison never even got his administration off the ground, due in part to the divided search process described earlier, which kept WVU's "major players" from being "engaged" in his presidency and "frustrated" the faculty, who felt "disconnected." Referring back to the criticized hiring process, William said, "My assessment is he never got that done. He never had a chance to do [strategic planning]. He was wounded on appointment ... I think that the administrative leadership across the University was often chagrined by what looked like a tainted appointment process."

The degree scandal, which was ultimately the demise of Garrison's administration, consumed the time, energy, and focus for the remainder of his presidency, leaving little room for 
WVU'S LAND-GRANT MISSION

171

other initiatives. As a result, it completely disrupted any potential development for organizational saga.

It also had major consequences for the University has a whole. It resulted in the removal of several key administrators, including a provost, leaving the University leadership with many gaps. The value of degrees were questioned, ultimately tainting the national reputation of the University that Hardesty had worked to elevate nationally, impacting student and faculty recruitment, and dampening campus morale. It left the University in peril, with many questions remaining as to its future and how it would recover.

\section{Conclusion}

Despite his administration's rocky beginnings, Garrison was able to gain some momentum early on his presidency with the salary increases, the completion of the day care center, and the implementation research trust initiative, though most of those initiatives have their roots in Hardesty's administration. However, that momentum quickly faded in the wake of the Bresch scandal. Eddie described Garrison's intentions, which reflected his leadership style, primarily emulating the political frame (Bolman \& Deal, 2013; Manning, 2013).

[Garrison] truly believed that there needed to be a new generation of outlook on things. He believed that controversy was not a bad thing that he thought you had to sometimes stir things to make them better. And he also believed that the University could be but a much bigger player in the state. He believed that we were not doing what we needed to do in research and that we needed to be a bigger player on that stage. Now, as you know, all of that did not come true because of the controversy he got into. But, he did that. He is the reason the day care center is sitting there, and he is the reason that the classified staff 
WVU'S LAND-GRANT MISSION

172

got some pay raises. He found the money for that. So those two things he did do. The rest of his tenure was basically mired in controversy and issues that we had to deal with.

Garrison's presidency had barely gotten started before it ended, attributed to his political appointment by the Board of Governors, setting him up for difficulty from the start. Coupled with the fact that his tenure was mired with conflict and controversy, Garrison's administration did not even reach the first stage of organizational saga, initiation. He presented a few examples that could be elements of the personnel and programming phases of the fulfillment stage, including the child care center, employee pay raises, and research trust fund initiative, but these efforts were not substantiated enough to move him past initiation.

\section{Defining the Land-Grant Mission: Vision and Messaging}

In his brief time as president, there were not many opportunities for Garrison to discuss the land-grant mission publicly. His inaugural address was his primary platform for introducing his ideas and plans for the University prior to the Bresch scandal. In this speech, he stressed service to the state for the public good as the University's primary purpose, an element of the social base phase of fulfillment in organizational saga.

This University was destined to be, in the words of our first president, Alexander Martin, West Virginia's 'brightest ornament and crowning glory.' Let us never lose sight of the fact that West Virginia University is held in trust for the people of West Virginia. Each of us here are here to serve. We serve our students. We serve the world. And, most importantly, we serve the state of West Virginia. (Garrison, 2007a)

Garrison defined service in terms of initiatives related to economic development, education, and healthcare, common areas of focus across all the administrations studied here. 
WVU'S LAND-GRANT MISSION

173

Today, West Virginia University is fulfilling the commitment of 1867 to serve our state with campuses across the state and a robust and meaningful presence in each of our 55 counties. We lift up the health of children and adults; We drive economic and social development; and We take education to people in their own homes and in their own communities. (Garrison, 2007a)

Garrison also emphasized the educational access component of the land-grant mission, his first major reference to student issues in his public messaging. He believed WVU was created to change lives through education and to serve as many West Virginians as possible by encouraging all students who had a desire to attend college to do so. This discussion reflected a step toward the student subculture phase of fulfillment in organizational saga.

Our founders saw to it that the sons and daughters of coal miners and factory workers would walk side by side with the sons and daughters of bank presidents and corporate leaders - all entitled to the honest pursuit of their own ambition and all contributing to the advancement of our state and our nation. Because of this, the diversity of our University community is one of our greatest strengths. We are enriched by the cultures, the languages, and the spirit of the people who make up WVU. We will always hold open the doors of this university to all who dream of a better life. Opportunity is here for all. Success is here for those who earn it. (Garrison, 2007a)

One of his interpretations of the land-grant mission was access to higher education. He often highlighted the educational access mission of land-grant universities, especially for firstgeneration students. Romanticizing the opportunity to pursue a college education, he described first-generation students as having the unique opportunity to share their experience with their family, friends, and hometowns and introduce them to the opportunities of higher education. 
WVU'S LAND-GRANT MISSION

174

We must never forget that one of five of our students will be the first in their family to graduate from college. We celebrate and acknowledge this fact because it reflects the true embodiment of the mission of West Virginia University. Each of those students represents a family that will be changed - perhaps for generations - by the experiences that student is having at WVU. (Garrison, 2007a)

Though he did not do it often, when Garrison did take the time to reflect on the land-grant mission in his public appearances, he did so in a way that attempted to appeal to West Virginians, by sharing messages of WVU's connection to the state. He focused mostly on West Virginia residents, first-generation students in particular, and the opportunities they would have at WVU for a college education. More often than not, he spoke in platitudes and romanticized language that could be celebrated and embraced by a broad population, referencing the state's rural heritage and humble industrial economic upbringing. This more generalized style of messaging reflected what Garrison knew, making a political appeal, as well as his inexperience in higher education.

\section{Conclusion}

By following a 12-year president coupled with entering the presidency amidst significant criticism about the search process and his qualifications, Garrison's administration had to work to overcome significant distrust and animosity to have a chance at reaching the initiation stage of organizational saga. However, within six months, there appeared to be a wave of optimism with a slight increase in the state budget for higher education, employee salary increases, the largest private gift (at the time) in University history, the opening of the childcare center, and the media giving the administration an "A" grade (Trachtenberg, Kauvar, \& Bogue, 2013), there was 
WVU'S LAND-GRANT MISSION

175

enough momentum to have the potential to reach that first stage of organizational saga. That optimism was short-lived.

These statements about the land-grant mission offered a romanticized and celebratory view of the role and purpose of the land-grant mission rather than discussion of tangible examples of how it would frame the work of the institution. Because of the brief nature of Garrison's presidency and its abrupt and scandalous conclusion, there were not opportunities for follow-up in speeches, plans, or other documents to reflect on if the mission changed, and, if so, how, during his tenure. Instead, what remained was a question of where the University would go from this point and whether it would recover. These examples demonstrate that the Garrison administration did not reach the second stage of organizational saga, fulfillment.

Garrison is ultimately characterized as the villain to Hardesty's figure in this narrative, a reflection of how higher education leadership not only emulates organizational saga but a theatrical model of leadership (Manning, 2013; Meyer \& Rowan, 1977). There was not enough time or progress made in the short time-frame of his administration to do so, which was immediately followed by an interim president who was tasked with healing the campus and restoring WVU's reputation to a national, research university focused on its land-grant mission, a president described by many officials interviewed in this study as a hero (Basham, 2012) in his own right. 
WVU'S LAND-GRANT MISSION

176

Chapter 6: C. Peter Magrath's Administration 


\section{Figure 6.1 Magrath Presidency Timeline}

\section{8-2009}

- August: Appointed as interim president

- Uses engagement strategies and messages from Kellogg Commission's "Returning to our Roots" report (1999) in State of the University address to unify campus

- Visits state legislature, Chamber of Commerce, County Commission, etc. to rebuild relationships with state and local government officials

- Teams up with Morgantown Mayor Ron Justice to renovate Sunnyside neighborhood

- Brings in American Association of Collegiate Registrars and Admissions Officers (AACRAO) to conduct academic recordkeeping audit and make recommendations

- Works with athletic department to navigate search for head football and basketball coaches

- Oversees search for permanent president

- June 2009: Steps down after James Clements is selected as permanent president

\section{Figure 6.2 Magrath's Organizational Saga}

\section{Stage 1: Initiation}

- Appointed with a clear mission: overcome the degree scandal from Garrison's presidency and recover WVU's reputation while leading search for permanent president

- Highly qualified, respected national leader with extensive experience at land-grant universities

- Came in with a lot of public support from WVU administrators, faculty, alumni, state leaders, and former WVU presidents

\section{Stage 2: Fulfillment}

- N/A (Interim president from August 1, 2008-June 2009), but made progress toward reaching a long-term organizational saga

Personnel (Faculty and Staff)

- Creation of new University Registrar position

- Improvement of faculty morale following the degree scandal

- Gained buy-in from unstable administration (many individuals in interim appointments at the time)

Programming (Visible practices; mission, vision, and values)

- Internal and AACARO audit of academic recordkeeping and implementation of subsequent recommendations and additional policies to overcome decentralized recordkeeping challenges 
Social Base (Alumni, donors, community)

- Limitations with fundraising due to both Bresch scandal and unexpected departure of head football coach

- Restored certain donations that had been pulled by the time his interim tenure was complete

- Halted capital campaign previously begun under Garrison

- Used community engagement strategies and messaging to rally campus together around service to state

Student Subculture (Students)

- Improvements of recordkeeping and degree processes

- Increased value of degrees

Imagery (Symbols, traditions, culture, events)

- Wrote commentary piece after the Meineke Car Care Bowl victory based off long-time commentator Tony Caridi's infamous "Once a Mountaineer, Always a Mountaineer"

- Celebrated the Mountaineer spirit and the culture of the state, the University, and its fan base

- Attempt to boost morale across all campus audiences 
WVU'S LAND-GRANT MISSION

179

\section{Operationalizing the Land-Grant Mission: Strategic Planning and the Work of the Institution}

\section{Becoming an Engaged Institution}

To lead West Virginia University through the controversy of Michael Garrison's administration, the Board of Governors looked to a renowned land-grant leader with extensive presidential experience - C. Peter Magrath, former president of University of Minnesota, the University of Missouri system, and the National Association of State Universities and LandGrant Colleges as well as an advisor to the College Board. He was appointed as WVU's interim president from August 2008 to June 2009.

Edith, a faculty member, remembered when the decision was announced, describing the hire as a strategic move for gaining faculty support. She said, "I can't speak for all the faculty, but my sense was that [hiring Magrath as interim president] was a very strategic move on the part of the University because it gave us someone with experience, and experience in a couple of different contexts. To come in immediately so we weren't rushing to the next president because that was part of the controversy over Garrison." Because Magrath came up through the traditional faculty and academic leadership ranks and had presidential experience at many different institutions, he brought the balanced background faculty had demanded when Hardesty and Garrison were hired.

In his State of the University Address, Magrath did not introduce any major goals or initiatives; rather, he took a more collegial leadership approach (Bolman \& Deal, 2013; Manning, 2013), a stark contrast to predecessors David Hardesty and Michael Garrison. He celebrated WVU's purpose and identity as a land-grant university and stated that reengaging with that land-grant mission is what it would take for WVU to overcome the Heather Bresch 
WVU'S LAND-GRANT MISSION

180

scandal and Michael Garrison's controversial year as a president: "Universities have a broad commitment to being of use and value to their society" (Magrath, 2008). This statement reflected his focus on the more humanistic elements of organizational saga, including social base, student subculture, and personnel. Based off the Kellogg Commission on the Future of State University and Land-Grant Colleges report, "The Engaged Institution" (1999), Magrath recommended the following steps for WVU to take to become a more engaged institution and fully embrace its land-grant mission to move forward beyond the scandal:

1. It must be organized to respond to the needs of today's student and tomorrow's, not yesterday's.

2. It must enrich students' experiences by bringing research and engagement into the curriculum and offering practical opportunities for students to prepare for the world they will enter.

3. It must put its critical resources (i.e. knowledge and expertise) to work on the problems the communities it serves faces.

Magrath emphasized the importance of a mutually beneficial relationship between the University and its home community, as discussed in Chapter 2 (Gavazzi, 2015; Reilly, 2003). This strategy also reflected a commitment to the social base phase of fulfillment in organizational saga because of this focus on community-building and building external relationships.

What ultimately counts is the concept of a major state university being in partnership with its community, its state and region, and, yes, the wider world with which we are inextricably involved in this new globalized environment. Ultimately, all that counts is what we actually do in effective working partnerships with businesses, civic organizations, government agencies, and other universities. Everything we do in the future which is right now must involve the 


\section{WVU'S LAND-GRANT MISSION}

181

fundamental responsibility of educating men and women of all ages from our diverse populations (we can call this learning); discovering new knowledge and applying it (typically labeled research); and serving society. (Magrath, 2008)

He went on to describe this kind of partnership as the core responsibility of land-grant universities. The philosophy of the $21^{\text {st }}$ century engaged university is clear: it is an educational enterprise that has great talents - brains if you will - within its faculty and staff. These educational talents must serve society by providing a variety of learning opportunities for students; by discovering new knowledge and applying it for the good of America; and by partnering with social and economic interests in its state and region in ways that meet not university needs, but community needs. This, of course, is the core land-grant mission, and so it must forever be. (Magrath, 2008)

This partnership-forward call-to-action for WVU and all land-grant universities was consistent with his vision for land-grant universities broadly, shared earlier with the Kellogg Commission on the Future of State and Land-Grant Universities in their 1999 "Returning to Our Roots: The Engaged Institution" report and more recently in his foreword for Gavazzi and Gee's (2018) book with recommendations for leaders of land-grant universities.

Magrath recognized that WVU already had a history and tradition of engagement and successful partnerships in the community. He highlighted the work of the Center for Service and Learning, including 182,000 service hours accumulated in 2007 to 2008; the Community Design Team, which brings volunteer professionals together with people in West Virginia communities to share ideas for building on their communities' strength and improving their economies; WVU Healthcare's efforts to bring resources to rural citizens, including screening children for heart disease risk factors and assisting low-income patients in obtaining medication; and energy 
WVU'S LAND-GRANT MISSION

182

research. The inclusion of all of these efforts show how Magrath strived to use the symbolic approach to leadership (Bolman \& Deal, 2013; Manning, 2013) by celebrating positive, familiar traditions while intersecting the programming phase with the social base phase of fulfillment in organizational saga.

WVU is already an engaged university. We have an emerging culture of engagement. But we can and must do more. We need to reach out to collaborate even more effectively and intensively with citizens on social, economic and community interests. We need to do a better job of quantifying and publicizing the services already provided through the state and engaging with our states' citizens in partnership ways. This kind of engagement is not only the right thing to do, it is also the smart way to build political support and attract the financial resources we need to do our vital work of serving people in our state, the region and the nation. (Magrath, 2008)

Though he did not set specific goals in this area, Magrath also identified how WVU's identity as a student-centered university and resulting initiatives contributed to its engagement mission, a reflection of the student subculture phase of fulfillment in organizational saga. It was another way of bringing together areas of the University that were already successful, recognized, and/or celebrated in an attempt to bring unity and positivity to the campus culture.

This is a student-centered university, a place of opportunity for countless people seeking a better life-including many first-generation college students. And this university is the pride of an entire state and a passionate worldwide alumni family. We are and will continue to be engaged with education and learning for students from all kinds of circumstances in life. Universities must put students first, because if they do not do that, they are neglecting one of their fundamental purposes. (Magrath, 2008) 
WVU'S LAND-GRANT MISSION

183

This statement was consistent with the messages shared by Hardesty throughout his administration. It celebrated a major accomplishment by Hardesty, who was still seen as a hero figure (Basham, 2012). It gave the University community something to rally around by providing a reminder of what was positive from the past, which was a step toward healing the campus following the turmoil of the Garrison scandal as it looked to the future.

\section{Healing a Campus in Turmoil}

Magrath recognized that his responsibility as an interim president was not to introduce numerous new programs, goals, and initiatives. Key officials working at the University during this time recognized the importance of Magrath's healing approach for the environment encompassing the campus community at this time, reflecting his commitment to the social base, student subculture, and personnel phases of fulfillment in organizational saga. Linda, a key official in Academic Affairs, described this responsibility as being a healer and a caretaker.

[Magrath's] job was not to implement policy or changes. His job was to steer the institution through this difficult time and reestablish it so that someone else could take over and then start their policy. Now, not that he didn't. He did what needed to be done during that time. He wasn't absentee, but in some ways when you're an interim, your role is more of a caretaker. You might be doing clean up during that period of time. Sometimes if there are issues, you want to take care of those things before the new person arrives so that the new person can arrive with as clean a slate as possible and isn't stuck doing cleanup during the first six months of their administration.

Joseph, a faculty member, saw Magrath's leadership as calming and stabilizing for the campus community. He said, "It was a sort of a stabilizing, calming kind of thing from all the turmoil that occurred during Garrison ... I think it was mostly just recovery." This quote reflects 
WVU'S LAND-GRANT MISSION

184

that Magrath achieved what he was brought to the campus to do-be a healer; nothing more, nothing less. Sean, a staffer in the Office of the President, also shared this sentiment, saying that Magrath's leadership was "reactive and tactical, [with] not a lot of strategy, not a lot of long-term thinking, just reacting to the day-to-day things that came up in the wake of the MBA scandal. With that said, the longer [Magrath] was here and the more things just settled down and people started to feel good about the University again, and then we were able to turn a little bit to longterm strategy." That long-term strategy is discussed next.

Beyond stabilizing the institution as a whole, Magrath also focused on re-centering the senior leadership of the University. Sean also described Magrath's role as bringing stabilization to the University's leadership team, which had several vacancies at this point.

[Magrath's] approach really was twofold. On the one hand, the University was in a lot of turmoil at that point. Coming out of the eMBA scandal and a lot of turnover in key leadership positions. So, a significant part of what [Magrath] did was less about long term goals and strategic planning and thinking, and it was more about tactics and how to just keep things together and keep things moving forward from day to day week to week month to month because it was a pretty delicate time there.

Eddie, who served on WVU's Board of Governors, also commented on the support Magrath provided to the existing University leadership. "He didn't come in and try to change a bunch of stuff immediately, but he tried to get everything back into a very calm situation. He gave me great advice, wonderful advice as I moved forward trying to figure out how do I help be a part of that and that calming and getting us back on the right track."

Magrath also focused his efforts on strengthening the University's standing nationally to attract high-quality presidential candidates and locally in order to repair town-gown relations in 
WVU'S LAND-GRANT MISSION

185

the wake of the failed Garrison presidency. Nicole, a key official in the Office of the President, viewed the healing strategy as a way to regain the University's relationship not only around the state but nationally.

I think his initial goal was to simply try to have the University positioned so that when it started the search [for the next president] it would be viewed as an attractive place that good candidates would be willing to consider as opposed to someplace to be avoided ... All of what he was wanting to do was to position the University to be in as strong a position as possible for this presidential search for the next president ... I think he believed in [the land-grant mission], supported it, recognized it, all those things.

Sidney, a professor and member of the Faculty Senate at the time, shared an anecdote about how Magrath's experience, especially with town-gown relations, helped the University regain trust with the city of Morgantown, where the main campus is located. "I was very fond of [Magrath]. His role was to repair, heal, move ahead. He understood the land-grant. He understood big universities. He understood simplicity and communication."

Sidney illustrated this quality through an anecdote involving a local Chamber of Commerce meeting they attended while Magrath was still new to the University.

He leaned over to me. And he said, 'Am I allowed to say bull shit to this audience?' And I said, 'Sure, Peter; that's not a problem.' And he stood up and he spoke, and I forget his exact words, but he spoke about all the ways we're demeaned. People say we're a backwards state. People say, and you know, you could see the audience warming up. And then suddenly he paused, and he just screamed and said that's a bunch of bullshit. And they all rose, and they ate out of his hands. And in a similar way, I would see him pound the lectern and say this is a great institution and his foot would be stamping a little bit, and so 


\section{WVU'S LAND-GRANT MISSION}

186

he just pumped out that we were a good institution. We were strong. We were stable. And that was his job. And he did it admirably. And, of course, he had the contacts, right? He had a fine Rolodex to work from.

This anecdote demonstrates Magrath's comfort with interacting with political and governmental officials, a strength reflecting his long tenure as a higher education leader that also shows his ability to lead from the political frame (Manning, 2013; Bolman \& Deal, 2013). It also illustrates his leadership capacity to reframe his approach to leadership and decision-making depending on the audience with whom he was communicating, particularly in contrast to his collegial interactions with faculty and staff described above. These characteristics exemplify Magrath's attempt to reach the social base stage of fulfillment in organizational saga because of the influence government leaders have in the local area near campus as well as region and state.

William, a faculty member and former administrator, believed Magrath's extensive presidential leadership experience was the foundation for his calming approach and exactly what WVU needed to move forward. He shared that Magrath was "a very experienced person for whom these would not be strange approach to executive leadership. But again, he was faced with a world that had gotten torn up, and I think rather than strategic assessment for the institution, I think he saw his role and performed his role as a calm these waters. Bring this place back to a functioning University." This statement highlights Magrath's range of experience in higher education administration, specifically as a president of different higher education institution types, in contrast to the minimal experience both of his predecessors, Hardesty and Garrison, brought to the role.

However, not all assessments of Magrath's role as healer were positive. Vincent, a former academic leader, thought the University took steps backward during Magrath's year as president. 
WVU'S LAND-GRANT MISSION

187

He said, “So, you brought in [Magrath], who didn't do anything, wouldn't do anything. And it was this holding period that, I think, harmed the institution more than anything. Because part of it got to be is nobody wanted to do anything. I mean everyone was afraid to do everything." This recollection highlights how the traditional route to organizational saga was not prioritized in Magrath's administration because of his role as interim. Similarly, a letter to the editor by WVU alumnus Zenovy Wowczuk (2010) in the Chronicle of Higher Education, a response to Magrath's own guest commentary (2010) in the same publication summarizing his contributions to WVU during his year as president, argues that Magrath took credit for several progressive initiatives that were initiated during Garrison's presidency instead of pursuing new initiatives on his own.

Magrath ultimately did not want to introduce any long-term activities that his successor would have to take over upon arrival. By choosing to not do so, it limited his contributions toward the programming phase of fulfillment in organizational saga. Sean explained,

He really didn't try to start very many new things. He really was very respectful of, 'I'm here for a short time,' and he didn't want to create anything that his successor would inherit and have to deal with. So, he was careful not to. But there were some things that have been started both under [Garrison] and under [Hardesty] that [Magrath] wanted to see through. But in terms of in terms of new initiatives ... by and large [Magrath] wanted to take care of the basics and let the long-term fall to his successor.

Instead, Magrath arrived with a goal of stabilizing the institution and providing leadership.

The challenges at WVU were obvious. I would have to help organize a credible search process for a permanent president, stabilize a shell-shocked administration laden with many interim appointments, and improve low faculty morale . . . I also hoped that, while 
WVU'S LAND-GRANT MISSION

188

avoiding the trap of trying to begin lots of new programs — especially inappropriate for an interim president-I could try to push a handful of objectives. (Magrath, 2010)

Even if efforts on healing the campus held Magrath's administration back from reaching organizational saga, most key officials concluded that he tried to do what was needed to set the next president up for success, discussed in more detail in the next section.

\section{Regaining Trust}

Fostering credible presidential search. One of those objectives was contributing to the organization a credible and accountable search process for a permanent president. James Clements, the former provost at Towson University, was selected within eight months. Edith recalled the search process for Clements and why a sound, accountable one was needed following Garrison's hiring following the politically tainted processes for selecting Hardesty and Garrison.

That whole search that ended up selecting Garrison felt fraught, and that it wasn't really clear what the criteria were. I think having an interim for sort of kind of making sure we had someone who was experienced at the helm of this big ship to steer us through some pretty rocky waters was a good move. It gave us stability. It gave us legitimacy nationally. Because not only was Garrison coming in without the credentials that Hardesty had then established, there was also that whole cloud of scandal. So, we really needed someone who was well-respected nationally so that WVU could be seen in good hands. And you can't find a good presidential fit quickly. So, an interim was a very strong move I thought.

Nicole concurred with this assessment, saying, "I think [Magrath's] major attention was to try to basically stabilize WVU so that it would be in as good a position as possible to start the search for a successor." Sean also described Clements' search and hiring process as part of the 
WVU'S LAND-GRANT MISSION

189

University's healing and restoration process. He saw it as an opportunity to "restore confidence" and help the campus community "feel good" about WVU's future. He said,

He very much wanted that to be a seamless process, transparent, something everyone could have a lot of confidence in. So, he worked very closely with the Board of Governors on that search process and on that selection process for, for the president. [Magrath] was so wise because he had so much experience. As a president in higher [education], he knew that his biggest long-term legacy would be to make sure that that the process by which a successor was selected had everybody's confidence ... I think [Magrath] felt like as long as the process was respected, and people have confidence in that, that the outcome was less important what name came up. Just as long as the process was done right.

All of this effort toward conducting an objective search for the new president reflected Magrath's commitment to both the personnel and the imagery phases of fulfillment in organizational saga.

Rebuilding academic accountability. Another immediate need was bringing in the American Association of Collegiate Registrars and Admissions Officers (AACRAO) to provide consultation on the institution's approach to record-keeping to avoid any similar issues to the Bresch scandal in the future (West Virginia University University Relations, 2009). Nicole remembered,

Magrath focused a lot on how we addressed the issues that came out about with recordkeeping and what the University as a whole needed to do to really get more into the $21^{\text {st }}$ century with record keeping and electronic shadow systems. And the actual public side of the controversy is what people remember, but there were things that come out of that were we said we need to change. And we need to take more advantage of modern technologies 
WVU'S LAND-GRANT MISSION

190

and ways that we can do things ... So, they brought AACRAO in, and they worked with a group.

Part of this overhaul of the recordkeeping process was an opportunity to redeem the University's reputation nationally across all of higher education by demonstrating its accountability to fixing the issues. Nicole continued, And I think one of the things [Magrath] also focused on was this is a good institution. Don't let something that happens define us. These things happen, and you just you don't pay. It's a big deal here, but in the grand scheme of higher [education], we've got a lot going on that's good. Let's focus on that. I think in that interim role, he was just trying to transition people from kind of going down the rabbit whole of a controversy to there's this greater University and it does great things.

Improving internal morale. Another objective was improving faculty, staff, student, alumni, and donor morale in light of the Garrison scandal, a reflection of the student subculture, personnel, and social base phases of fulfillment in organizational saga as well as one of the motivations for the engagement strategy Magrath pulled from the Kellogg Commission on the Future of State and Land-Grant Universities (1999). He wrote in a commentary piece (2010) for the Chronicle of Higher Education,

Throughout that time, it was important to remind those within the University, alumni and supporters, and other people throughout the state that they were part of a good publicserving university that, as happens at other places, had momentarily stumbled but was again moving forward. One should never underestimate the value of a university president presenting a positive, uplifting message that is based on the facts. I reminded people that WVU had a good historical record, excellent faculty members, hard-working students- 


\section{WVU'S LAND-GRANT MISSION}

191

and a great future of service to its state and nation. I made the point that I would have not have taken the job were it not at a credible, exciting land-grant institution. All that helped, to use information-technology jargon, to reboot faculty, staff, student, and alumni morale and reassure disaffected donors that their institution was a solid investment. (Magrath, 2010)

Samantha, an academic leader at the time, reflected on how Magrath worked to regain the trust of faculty and staff, another example of his focus on the personnel stage of fulfillment in organizational saga, which was part of his strategy for healing the campus — working from the inside out.

Internally . . . the alleged activity that the leadership at that time and [Garrison's] administration had engaged in had really, really rocked the confidence of a lot of faculty members. And they were they were angry, they were embarrassed, they thought it not only reflected on the organization but really impacted their individual reputations as scholars and teachers. So, it was very deeply felt. And [Magrath] was able to come in and stabilize and to a certain extent heal, to really be a healer in saying you're right, these things happened, and we've now come through that and now we're all going to work together and we're going to elevate this place and the way that it should and, and, and deserves. And so, he was able really remarkably to take people from that place of kind of anger and grief and, and move them to a place of hope and, and collaboration and a sense that the institution will remain true to its mission and will continue. And so, he was a very, very effective leader for that time. And then, in addition, because he was so experienced and so wellconnected throughout the United States and the world, I think people felt like with his 
WVU'S LAND-GRANT MISSION

192

relationships, his deep knowledge of other places that he knew a path forward for us to reposition ourselves.

Repairing relationships with state and federal leaders. Magrath also dedicated time to conversations with governors and legislators to work on improving the University's relationship with state government and then-West Virginia Governor Joe Manchin, the latter of whom was also caught up in the degree scandal as Bresch's father. This strategy showed Magrath's commitment to the social base as well, especially later in his interim year as president. "I spent time listening to the governor and key legislators - something a university president can never overdo" (Magrath, 2010). A partnership with the city of Morgantown to develop the Wharf District and renovate the Sunnyside neighborhood, known as desolate, off-campus student housing celebrated for its social gatherings demonstrated efforts to establish positive town-gown relations while also reflecting the programming, social base, and imagery phases of fulfillment in organizational saga. Magrath and then-Morgantown Mayor Ron Justice wrote in a commentary, These kinds of collaborative efforts form a foundation for economic growth. They are examples of a city and a university with a clear focus on creating a strong local economy that also facilitates future growth. So, while WVU and Morgantown currently offer a diversity of employment opportunities from teaching to health care, from hospitality to manufacturing there is also a clear focus on the future with new jobs in emerging fields such as alternative fuels, biometrics and nanotechnology ... We believe that the partnership between Morgantown and West Virginia University can serve as a model for similar size communities across the country. We have created a wealth of opportunities with projects and initiatives that support our growth. We have been and will continue to be focused on creating a strong future together. (Magrath \& Justice, 2009) 
WVU'S LAND-GRANT MISSION

193

Sidney reflected on Magrath's ability to navigate the state politics and build relationships with West Virginia public officials. "He was remarkably capable of dealing with people on an individual basis. He just went out he met them ... And my impression was that although he could be very firm, he did not go in with a preconceived plan dealing with people who had authority." This anecdote demonstrated Magrath's capability of leading through the collegial frame (Bolman \& Deal, 2013; Manning, 2013).

Magrath worked on initiatives related to the University's organization, revamping the reporting structure of the research vice president, adding a research office in Washington, D.C., as a strategy for improving federal relations, and adding engagement strategies beyond the WVU Extension Service to include partnerships in the academic colleges and school and Health Sciences Center. These strategies reflected the programming, social base, and imagery phases of fulfillment in organizational saga as well as his ability to lead from structural leadership frame (Bolman \& Deal, 2013; Manning, 2013).

Reenergizing the fan base. Athletics was another area of the University plagued by criticism and disapproval during this time. Both the head football and basketball coaches, celebrated for major wins, conference championships (in football), and post-season success, departed for the University of Michigan. Though Garrison was initially involved with navigating the head football coach's departure and initially pursued a lawsuit over contractual issues, Magrath was tasked with smoothing over these unexpected and devastating departures with the fan base and donors. He was tasked with finding replacements under tight deadlines, elements of the social base and imagery phases of fulfillment in organizational saga because of the central role college athletics plays not only on campus but with alumni, donors, and state citizens, but all fans alike. 
WVU'S LAND-GRANT MISSION

194

\section{Summary}

Magrath was brought in as the interim president with a clear purpose - to use his seasoned experience as a leader in higher education, specifically of land-grant universities and organizations, to heal the WVU campus following a major scandal with political implications. He used his own experiences and expertise to help rebuild WVU's reputation both internally among faculty, staff, alumni, and current donors as well as externally in the national higher education environment. This meant bringing a sense of stability to the campus without introducing any major goals or strategic planning initiatives, which some key officials saw as a limitation to WVU's progress, possibly holding it back in the higher education marketplace. Instead, Magrath's areas of focus were maintaining the day-to-day operations of the University with many vacancies or interim individuals in leadership positions, initiating an audit of the institution's record-keeping process, and supporting the search for the permanent president.

\section{Defining the Land-Grant Mission: Vision and Messaging}

Framing his administration with a focus on engagement (Kellogg Commission on the Future of State and Land-Grant Universities, 1999; Brackmann, 2015; Reilly, 2013) was Magrath's strategy for reestablishing a positive reputation and support for WVU. This was a way to reunite the broken University through its common thread - the original land-grant mission. Magrath celebrated the way the land-grant mission could rally every area of the university and connect pure learning and the liberal arts and sciences with generating economic development in many different industries. In his State of the University address, he shared,

Though some may disagree, universities are a part of society even as they need a certain level of independence for their creativity to blossom in order to serve society effectively. This, to use a familiar phrase, involves learning for its own sake, which is of estimable 
WVU'S LAND-GRANT MISSION

195

value. But that objective in no way conflicts with the absolute imperative that universities and most especially land-grant universities serve economic development needs. We have always done this, going back to the early years of the land-grant movement after the enactment of the 1862 Morrill Act. (Magrath, 2008)

He also believed that with an engagement focus WVU was in a stronger position to generate political and public support for its work and the resources it needs to serve society: "We are an engaged university with our state and its people; but we can be more engaged and more helpful as a critical partner in the social and economic development of West Virginia” (Magrath, 2008). Magrath saw the engagement focus as an opportunity to work toward the imagery and social base aspects of organizational saga on the way toward healing the campus and improving the University's reputation simultaneously.

Magrath's engagement approach to defining and operationalizing the land-grant mission was viewed as a balanced interpretation of the land-grant mission. Nicole explained, [Magrath] said WVU is one of the most balanced land-grant institutions. So, it's not like your research just overshadows. It's not like you're all about only service with expensive research. But that you also have this incredible educational, you know, manifestation. And he just said you're just so balanced ... He just carried that message forward about you have great balance. You have this great research we need to really push this. We've got great Extension and outreach and healthcare and colleges that are doing all of these things. And then educationally. And not only do we do it here on campus, but we have programs where we're getting into online programs. We've got continuing education. We teach the firefighters. We educate [teachers]. And he was just really focused on that in his year. 
WVU'S LAND-GRANT MISSION

196

Many of the key officials interviewed recognized Magrath's engagement strategy right away and the way he used it to rebuild the University's reputation in the state and nationally. Eddie reflected on how his experience leading land-grant universities made him the "right person" to heal WVU and provide stability during this tense time. "He came in and immediately started talking about the land-grant and what our mission was and how we needed to do that. And that changed the tone of what we had been having, that changed the tenor. It calmed everybody's fears that we were going to go off in a way we shouldn't." Samantha described Magrath's familiarity with land-grant mission as reassuring for both faculty and administrators during this time, especially coming from the president. "Leadership could change, but the institution would go on with its central mission ... that was true to the land-grant mission that embraced people from all over the world ... He was in command, and everyone knew it. In terms of experiencing leadership, it was really quite extraordinary to watch him."

\section{Summary}

Because Magrath came into the presidency as a highly qualified, respected national leader with a land-grant background and was appointed with a clear mission (i.e. overcoming the Bresch scandal, healing the campus, and recovering WVU's reputation while searching for a permanent president), he quickly reached the first stage of organizational saga, initiation. He also came into the role with substantial public support from WVU administrators, faculty, staff, alumni, state government leaders, and former WVU presidents because of his traditional higher education leadership background, which also helped him reach initiation.

Since Magrath was only in the role for one year and it was intended that his time would be limited, he did not have a chance to fully reach the second stage of organizational saga. 
WVU'S LAND-GRANT MISSION

197

However, during that time he did make substantial progress toward several of the components of that fulfillment stage.

In the personnel phase, he worked to gain buy-in from an unstable administration, with many vacancies and individuals in interim appointments while improving faculty morale. As part of the audit of institutional record-keeping and consulting process, a new University registrar position was created. The internal and American Association of Collegiate Registrars and Admissions Officers audit of recordkeeping and subsequent implementation of recommendations and additional policies to overcome decentralized recordkeeping practices reflected the programming phase. These improvements of recordkeeping and degree processes also increased the value of degrees, a tenant of student subculture. In terms of programming, though, he was extremely limited because he intentionally did not introduce many new ideas or strategies. In terms of social base, there were many limitations with fundraising due to both the Bresch scandal and unexpected departure of head football coach Rich Rodriguez, and Magrath worked to restore certain donations that had been pulled by the time his interim tenure was complete. Finally, Magrath's efforts to publish op-eds and other commentary pieces reflected the imagery stage as he attempted to boost morale across the entire campus community. For example, his article (2009) after the Meineke Car Care Bowl victory based off long-time commentator Tony Caridi's infamous "Once a Mountaineer, Always a Mountaineer" tagline celebrated the Mountaineer spirit and the culture of the state, the University, and its fan base, bringing together many different stakeholders. 
WVU'S LAND-GRANT MISSION

198

Chapter 7: James P. Clements' Administration 


\section{Figure 7.1 Clements Presidency Timeline}

\section{Fall 2009}

- Presidency begins

- "Share Your Vision" survey implemented

- Filling vacant leadership positions (e.g. provost, Health Sciences chancellor, etc.) and creating new ones

- Announces Carnegie Foundation Research 1 aspirations

- Announces student retention blueprint plan

2010

- Begins 2020 strategic plan preparation process

- Convenes strategic planning council

- Organizes subgroups

○ Launches website

- Research goals, called "Mountains of Excellence," introduced

2011

- WVU receives Carnegie Foundation's Community Engagement Classification

- WVU celebrates $150^{\text {th }}$ anniversary of the Morrill Act

2012

- Launches “A State of Minds: The Campaign for West Virginia's University"

- WVU receives record \$45 million gift from Ben and Jo Statler, renaming the College of Engineering and Mineral Resources

- Division of Diversity, Equity, and Inclusion established

2013

- New associate vice provost of engagement and outreach position created

- November: Announces departure for Clemson University

Figure 7.2 Clements' Organizational Saga

\section{Stage 1: Initiation}

- First permanent president after Garrison-Bresch scandal; enters a university searching for stability

\section{Stage 2: Fulfillment}

- President from Fall 2009-December 2013 
Personnel (Faculty and Staff)

- Addition of 100 new faculty lines

- New leadership positions: associate vice provost of outreach and engagement; vice president for diversity, equity, and inclusion; assistant vice president for scholarly and creative activity

- Leadership development training requested by staff and presented to the administration by Staff Council

- Added efficiencies in sponsored research program processes, including new digital records system

Programming (Visible practices; mission, vision, and values)

- New 2020 strategic plan

- Focused on research, student retention and graduation rates, diversity and culture on campus, globalization, improving technology and facilities on campus, and engagement and outreach in the community

- New Division of Diversity, Equity, and Inclusion

- New University College, which centralized student support services and other resources

Social Base (Alumni, donors, community)

- Record giving

$\circ$ Ben and Jo Statler gave \$45 million, renaming Statler College of Engineering and Mineral Resources

- Launched A State of Minds: The Campaign for West Virginia's University capital campaign

- Regularly gave State of the University address in Washington, D.C. to alumni and public officials in addition to campus-based address

Student Subculture (Students)

- Focused on graduation rates and retention

- Recruitment of graduate students

○ New Provost Michelle Wheatly and new Health Sciences Chancellor Christopher Colenda both brought backgrounds in graduate recruitment

- Health and wellness plan (e.g. WELLWVU, construction of Health and Education building, etc.)

- Encouraging international student recruitment and study abroad participation

- As a first-generation student himself, Clements was passionate about expanding access for this population.

- Opened HomeStart Closet, coordinated by the Office of Social Justice, to provide international students with furniture and supplies to make their Morgantown apartments feel more like home. 
Imagery (Symbols, traditions, culture, events)

- Beginning of new construction on Evansdale (e.g. Health and Education Building)

- Leaves Big East Conference and joins Big 12 Conference

- Emphasis on athletics in speeches

- Significant wins during this time-Final Four and conference championship in men's basketball, football's Orange Bowl victory gave the campus community something to celebrate

- Sent annual New Year's letters to campus community

- New facilities: Honors Hall, Child Learning Center, WVU Nursery School, (renovated) Summit Hall dining facility, (renovated) White Hall 
WVU'S LAND-GRANT MISSION

202

\section{Operationalizing the Land-Grant Mission: Strategic Planning and the Work of the \\ Institution}

James Clements, West Virginia University's $25^{\text {th }}$ president, came to WVU from Towson University, where he served as provost. A first-generation college student with four young children, he brought a sense of family to the campus and a familiarity with student needs, which was part of Towson's career-readiness mission as an urban, public university in an industrial region. An accomplished scholar in the computer science discipline with a published book, Clements brought the research background so many faculty were seeking in their new president. What his experience ultimately demonstrated was a balanced background that followed the traditional academic path toward the university presidency.

\section{'A Shared Vision'}

As a brand-new college president, Clements began his tenure at WVU in 2009 with an exercise in learning the institution's culture and gathering input from constituents across the campus. Recognizing the 2010 strategic plan he inherited was on the cusp of expiring, he launched a survey with a theme of "Share Your Vision" to begin preparing for the planning process, similar to previous President Michael Garrison's town hall approach to gathering feedback at the beginning his administration. In his first State of the University Address, coined "A Shared Vision," Clements discussed the results of the survey, which featured words describing WVU collected from the survey responses. A few examples included: life-changing, innovative, visionary, affordable, resilient, capable, committed, and empowering (Clements, 2009b). This strategy demonstrated his administration's early commitment to the initiation stage of organizational saga because he moved forward so quickly in learning about the institution and planning for the future. 
WVU'S LAND-GRANT MISSION

203

In this speech (Clements, 2009b), Clements also introduced guiding principles for the University to follow as it embarked on creating a new strategic plan:

- Ethics and integrity must permeate everything we do

- All employees are valuable

- Our campus culture is defined by respect and creativity

- Diversity is valued and celebrated

- Globalization is pursued

- Stewardship of resources is everyone's responsibility

- Student success is our highest priority

- State service across teaching, research, and service is our core mission

- Partnerships will enable us to be more effective in the future

Meanwhile, Clements began filling various administrative positions, an immediate step toward the personnel phase of fulfillment in organizational saga. However, this was not overtly stated in any of the official documents or speeches; rather, it was done gradually.

Clements highlighted several areas of focus for his first year as president, including research, student retention, diversity, globalization, and engagement. Because he began his public messaging by emphasizing the University's strengths and celebrating successes, these efforts were immediate commitments to the programming phase of the fulfillment stage of organizational saga as well as student subculture, social base, personnel, and imagery. This strategy of uplifting the campus and celebrating collective successes and showing appreciation for individual achievements reflected how he led from the collegial framework early on (Manning, 2013; Bolman \& Deal, 2013). He shared successes already occurring in these areas to celebrate the quality of the institution and gain morale while simultaneously setting goals to 
WVU'S LAND-GRANT MISSION

204

build upon WVU's preexisting strengths. These areas were a reflection of the "Share Your Vision” survey responses, conversations with interim president C. Peter Magrath, and other research leading up to his administration. According to several of the interviews with key officials in this study, faculty were more supportive of him than other recent presidents from the get-go, especially in contrast to the respective beginnings of Hardesty and Garrison's administrations because of his traditional pathway as a scholar and academic administrator. He also demonstrated that he studied and prepare diligently for the role of leading a major, landgrant, research university, learning as much as he could before arriving on campus. Sidney, a professor and member of the Faculty Senate, recalled,

Clements knew everything about this institution before he arrived because the first time he was exposed to the faculty, he did a presentation on Evansdale campus, and there were several hundred faculty, and I asked him a question and he said, 'I know who you are.' So, it was just kind of interesting how much homework he had done ... I think [Clements] had read everything he could online. And now, [Clements] was quite intentional about his career pathway. So, when he was, I forget whether he was a division director or a chair or something like that, but early on in his life, he and [wife] Beth had decided that he would go on an academic administrative career and so very intentionally he'd done that and so he knew the methods and he knew what he wanted to do. And I think that the other thing for the strategic plan, aside from the fact that he knew we needed one, was that he needed to be informed. And one of the easiest ways to be informed was actually to start a strategic planning process.

Sidney's anecdote shows that Clements was precise and thoughtful in his approach to not only his career trajectory, but his self-imposed training for the presidency and decisions made once he 
WVU'S LAND-GRANT MISSION

205

was in the role. This style reflects his leadership from the structural framework (Manning, 2013; Bolman \& Deal, 2013).

Research. In his first State of the University Address, Clements shared several examples of research strengths, a reflection of both the programming and personnel phases of fulfillment in organizational saga and his continued leadership style as a cheerleader working from the collegial frame (Bolman \& Deal, 2013; Manning, 2013). Overall, he announced an 8\% growth in all sponsored research programs from Fiscal Year 2008 to Fiscal Year 2009, or \$140.7 million to \$152.3 million, and another 29\% increase from Fiscal Year 2009 to Fiscal Year 2010. Federal funding for sponsored programs had simultaneously increased $34 \%$, from $\$ 66.0$ million to $\$ 88.2$ million. On a related note, he announced that The Chronicle of Higher Education Almanac reported that WVU was among the "Biggest Gainers in Federal Funds for Academic Research and Development" from 2000 to 2007, with an increase of $135 \%$ in federal research funding. This ranked WVU $12^{\text {th }}$ in research growth for the time period. The successes were attributed in part to the Research Trust Fund efforts from the Hardesty and Garrison administrations, which combined private donations with matching funds from the state, translating to approximately \$6.5 million (Clements, 2009b).

Some specific areas of strength highlighted included child obesity, a multidisciplinary effort from WVU Extension Service, Davis College of Agriculture, Natural Resources and Design, School of Medicine, and Regional Research Institute supported by a $\$ 5$ million U.S. Department of Agriculture grant to address one of Appalachia's biggest health threats; responding to national needs of new, clean energy resources, including receiving the "Oscar of Innovation" for the National Energy Technology Laboratory's development of a new technology that could be a source of clean electricity; the West Virginia Dialect Project, a recipient of three 
WVU'S LAND-GRANT MISSION

206

National Science Foundation grants to document language variation in Appalachia while teaching school children, healthcare providers, and other community members about dialect diversity in the state; and the Center of Biomedical Research Excellence in Signal Transduction in Cancer, which received three phases of funding from the National Institutes of Health for cancer research (Clements, 2009b). Several of these community partnerships demonstrated how research not only reflected work toward the personnel and programming phases of fulfillment in organizational saga, but also social base because of the focus on building relationships in the community beyond the campus.

With these successes in mind, the first research goal Clements introduced in this speech to grow the University's research efforts was doubling the number of sponsored research programs to continue to compete with peer institutions in the marketplace, a commitment to both programming and personnel elements of fulfillment in organizational saga as well as the imagery element because of how this growth could elevate the University's reputation.

We value all academic scholarship and creativity, in its many different forms across all of the disciplines. Since almost every index of a university's national standing includes significant attention to its sponsored research portfolio, we need to focus on funded research as a specific strategic area for development. Over the past decade, we doubled sponsored research and programs. We will need to double it again to be on average with our mission peers. (Clements, 2009b)

Clements recognized that processes, reward structures, and other systems related to research needed to embrace interdisciplinary opportunities, community partnerships, and other collaborations to reach this goal, which is why it touched both the programming and personnel phases of fulfillment in organizational saga. Some efficiencies gained in processing during this 
WVU'S LAND-GRANT MISSION

207

time included the introduction of the Electronic Research Administration system, eliminating paperwork (i.e. "blue sheets"); creating a Grants Budget Office as part of the Office of Sponsored Programs to offer assistance with budgeting for large, multidisciplinary projects that spanned programs, departments, colleges, and schools; and establishing a mentorship initiative for faculty to help with identifying grant opportunities, developing proposals, preparing budgets, navigating compliance issues, and exploring technology transfer opportunities.

In the 'Share Your Vision' survey, the issues most cited as the state's, nation's, and world's greatest challenges were the economy, technology, education, healthcare, energy, and the environment. All of these cross traditional academic departmental boundaries - and so must we if we wish to leverage WVU's strengths in these areas. (Clements, 2009b) This work toward improving processing efficiencies reflects Clements' leadership from the structural framework (Manning, 2013; Bolman \& Deal, 2013). While his predecessors, Hardesty and Garrison, came from legal and business backgrounds, Clements brought an engineering background to the role, and this example highlighted how he used his disciplinary training, which was focused on efficiencies, to influence decisions relating to University operations.

The second research goal was attaining the Carnegie Very High Research Activity, or Research 1 or R1, classification, a goal directly tied to the first and one that reflected a focus on the imagery phase of fulfillment in organizational saga because of the prospect of what reaching the classification would do for the University's reputation. This goal was built upon predecessor Hardesty's focus on developing the University's national standing as a whole as well as how he often included the arts and creative scholarship as part of his research goals. To reach this goal, Clements emphasized a diverse approach to research efforts, ranging from not only sponsored research in the sciences, but also the humanities and other non-STEM fields. He said in his Fall 
WVU'S LAND-GRANT MISSION

208

2009 State of the University Address, "We must recognize that the value of a higher education lies in the diversity of the curriculum. A strong foundation in critical thinking, arts, humanities, and the social, physical, and natural sciences is the hallmark of any great American university."

Student retention. Clements aspired to build upon Hardesty’s student success initiatives with a renewed focus on retention, a contribution to the student subculture and programming phases of fulfillment in organizational saga. In his 2009 State of the University addresses, Clements introduced a goal of creating a blueprint focused on retention and graduation rates as well as support services, advising, and financial aid.

We'll make sure the students that come our way are successful. We'll work on increasing scholarship and financial aid programs. And well make sure that every student that goes through our great academic programs is successful ... We must make a serious effort to put in place the support systems and structures to help improve retention through the sophomore, junior, and senior years. We have room for improvement in our retention and graduation rates. (Clements, 2009b)

This message highlighted a transition to a more specific student success strategy, focused on retention initiatives. This focus was more targeted than Hardesty's student initiatives, which focused on changing the University culture to be more student-centered in a variety of areas.

Part of Clements' blueprint included creating a plan for improving student health and wellness. He introduced a partnership with Student Government Association to encourage participation in student organizations, club sports, and other activities, which helped him build a rapport with students. These efforts demonstrated his commitment to the whole student and how holistic student development impacted their entire experience at WVU. It also highlighted another example of his leadership from the structural framework in the way he described creating 
WVU'S LAND-GRANT MISSION

209

infrastructures and systems to support students (Bolman \& Deal, 2013; Manning, 2013). This commitment to the whole student simultaneously paralleled his commitment to the whole University in his focus on reaching R1 status and a broader national reputation.

Diversity. Clements announced an effort to increase diversity among the student, faculty, and staff populations on campus in his Summer 2009 State of the University Address for Washington, D.C. alumni: "We will work on diversity. We will increase our diversity. And I can tell you that as we work in a global environment, were going to reach out, to make sure our students jump on those new opportunities that exist."

This effort demonstrated a commitment to both the personnel and student subculture phases of fulfillment in organizational saga, particularly because Clements was the first WVU president, at least among those discussed in this study, to actively pursue diversity initiatives. Several examples reflect how this effort was operationalized early on in Clements' presidency. To increase student success and promote diversity, the Center for Black Culture and Research launched the Academic STARS Program, which was focused on recruiting and retaining African American freshmen and helping them build a solid academic foundation at WVU while developing their leadership potential. Another program that reached out to underrepresented youth is the Health Sciences and Technology Academy (HSTA). HSTA's goal is to increase the college-going rate of minority, rural, and underrepresented youth. The program is a statewide partnership among educators, community leaders, health professionals, and colleges and was one of five finalists nationwide for the 2010 C. Peter Magrath University Community Engagement Award. Similar to the discussion in the student retention section above, the efforts with diversity, especially HSTA, were another representation of Clements' commitment to holistic student 
WVU'S LAND-GRANT MISSION

210

development, even for students not yet enrolled at WVU, and how he valued every facet of the University.

Globalization. Clements' focus on becoming a more globalized University was partly motivated by the push to make the University more visible on both a national and international scale and to expand the work of the land-grant mission beyond the state's borders, demonstrating how Clements embraced the "world-grant" concept in the land-grant mission (Hudzik \& Simon, 2012). Sidney remembered this strategy and how it was a change from the previous administrations he'd been a part of, dating back to Hardesty's administration.

In the strategic planning, there was a lot of discussion about national and international outreach and how we needed to be nationally visible and internationally visible and how we needed to really be engaged with the growth of the world and have a global vision. And someone shouted out, 'We're not even south of Route $60^{3}$,' right, which was the whole, the land-grant mission was very cloistered in the north of the state.

This anecdote highlighted a distinct shift during the Clements' administration of not only expanding outreach to the southern part of the state, but beyond the state's borders to around the nation and around the world, which was a shifting geographic definition of social base in organizational saga during this time.

This goal was also inspired by the international nature of the University's alumni network. Clements shared in his Summer 2009 State of the University Address: “As I look around WVU, we have an alumni network that's global. It's not just West Virginia, it's not just D.C., it's not just Maryland-it's everywhere. People keep WVU close to their hearts no matter

\footnotetext{
${ }^{3}$ U.S. Route 60 is a major roadway in southern West Virginia that connects through the Kanawha Valley, home of the state's capital city, Charleston.
} 
WVU'S LAND-GRANT MISSION

211

where they live, no matter where they work, no matter where they travel. There is a true love for this institution like no other I have seen." This statement reflected the administration's focus on the student subculture phase of fulfillment, in terms of the growing emphasis on international student recruitment, but also social base because of the increasing diversification of the University's alumni network. Though Hardesty did lead a capital campaign and Garrison had talked of one (which never materialized due to the scandal), Clements was the first president in this study to place a continued emphasis on alumni engagement in his strategic planning efforts. Some examples of how this goal was operationalized in Clements' first year included HomeStart Closet, coordinated by the Office of Social Justice to provide international students with furniture and supplies to make their Morgantown apartments a home away from home; roundtables with leaders in Academic Affairs and Student Affairs to initiate strategies to maximize WVU's integration of international experiences at home and abroad and to strengthen the appreciation of the diversity that defines campus culture; the launch of the-then College of Human Resources and Education Office of Diversity and Global Initiatives; and a new a dual-degree master's program in history focused on central and eastern European studies in partnership with universities in Poland and Estonia. "It's clear to me that people really understand the mission of the institution. We're entrusted to make a difference every single day a positive difference and these are some examples of people who are doing that in West Virginia, in Washington, and around the globe" (Clements, 2009a). These examples also demonstrate how the globalization goal expanded to the programming phase of fulfillment in organizational saga because of the additional programming and initiatives needed to support a diversifying and increasingly global campus community, another example of Clements' holistic focus for all 
WVU'S LAND-GRANT MISSION

212

WVU students as well as his expansion of the University's activities to include national and international perspectives.

Engagement. In his 2009 State of the University addresses, Clements described several examples of WVU's engagement efforts in the community, ranging from economic development to healthcare to education, a commitment to the social base phase of fulfillment in organizational saga as well as examples in the literature (Kellogg Commission on the Future of State and LandGrant Universities, 1999; Brackmann, 2015; Reilly, 2013). This approach reflected how Clements incorporated both local and global audiences in his strategy, striking a balance between these two stakeholders in organizational saga. These strategies varied from identifying the economic return invested in the economy by the University to coursework offered to healthcare provided by WVU physicians and dentists to a free rural literacy program to coursework offered online and in West Virginia high schools to expand students' access to higher education. His emphasis on these activities in major speeches like the State of the University Address represented Clements' early understanding of the land-grant mission and how he valued activities already in place at the University related to service to the community.

Because of the varied depth and breadth of the University's engagement activities already in place, Clements announced plans to apply for the Carnegie Classification in Engagement to demonstrate the University's commitment to public service and to organize the institution's engagement efforts toward a common goal. WVU received this classification in 2011. This represented both Clements' attention to the social base and imagery components of organizational saga because it highlighted WVU's work with the community as well as a ranking that elevated WVU's reputation nationally, in conjunction with the work toward the R1 aspiration. 
WVU'S LAND-GRANT MISSION

213

\section{Preparing for the 2020 Plan}

To begin developing the 2020 strategic plan, Clements brought together a 45 -member strategic planning council, composed of representatives from all major administrative units of the University. Unlike Hardesty's large strategic planning group, which only met at one retreat, this group met regularly throughout the planning process. Prior to that group there were also several working groups that informed the later work of the council, according to Linda, a key official in the provost's office. She explained that the council was incredibly large, both in size and complexity.

Honestly, when you're working with a 45-person group, there's just so much. Coordinating electronically with different levels of technological comfort is just impossible. So, what we would do is actually put pieces of paper in front of them. If they had edits, they would hand them back to me at the end of the meeting. [We] would also take notes on the conversation as it evolved and make changes to a document. So, in terms of information gathering for us, it was better to have pieces of paper in front of people during the meeting and then we would send out updates.

The intent of the large group was for it to be as representative and inclusive as possible, a representation of the imagery phase of fulfillment in organizational saga. Sidney explained the large size as unwieldy but that it provided diversity of representation.

The large group also may have been emblematic in that there were so many [oxen] to gore if you didn't invite the constituencies by discipline, by employment level, by seniority. It really required a pretty big mix, as representative as possible . . . The idea of it really was bring together that large strategic planning council with really broad representation and actually do a whole lot of brainstorming. So, we did not go down the pathway of doing a 
WVU'S LAND-GRANT MISSION

214

SWOT analysis and all of these traditional things. It was like, what do you think's important at WVU ... There was a lot of who are we, what would we like to be? And we weren't much interested in what was possible, that's impossible. And it got a lot into the land-grant mission. It got a lot into the involvement with state. And Health Sciences was certainly represented pretty well.

Because of the group's large size, the meetings of the main planning body were an opportunity more for reporting and discussion rather than tangible progress, which mostly happened at the sub-committee level. Since the group's composition was based on a representational model, many different representatives of various constituencies from on- and off-campus were included. Samantha, an academic leader, described the model as a paradox because of the roles of the representatives, comparing the campus community to a democracy where the general public does not feel as engaged in the process as legislators or that their representatives are best suited or prepared to meet their needs in Congress. She said,

On one hand, you have all these representatives, but you have all these constituencies that may not realize the extent to which their representative is or is not best representing their interests. And while you have really firm buy-in from your representatives, you don't necessarily have buy-in or engagement at a deeper level, but then you have this paradox of representation.

Sean, a key official in the president's office, attributed the group's large size to a decision from Clements to help with his on-the-job training. He described the strategic planning exercises as Clements' own introduction to WVU and content preparation for the presidency.

[Clements] wanted it for his own benefit. He wanted the strategic planning process to be as much about his listening and his learning so that whatever plan ultimately emerged from 
WVU'S LAND-GRANT MISSION

215

the process would be well grounded in reality. He just didn't want to do it to be doing it to be going through an empty exercise or worse yet go through an exercise that would produce something that would be counterproductive. And he wanted to make sure he had a good understanding of what the University's identity was and what its, what its mission was.

Like Hardesty, Clements aspired to learn as much as he could and to go into any major meeting or project prepared. However, Clements' approach differed from his predecessors in that he aspired for his own learning process about the University to be included in the strategic planning exercises on a much larger scale, while Hardesty's learning happened behind-the-scenes and on a smaller scale with the "kitchen cabinet." That broad learning was part of Clements' motivation for the plan itself and the process he used for creating it.

The representative nature of the group was also motivated by the need to reunite the campus following the Bresch scandal and Garrison's brief tenure as president. Linda explained, "I think that coming off the trouble, all of the changes in leadership that happened in 2007-2008 that people felt [sic]. I think that this document and this strategic plan was a way to try to bring everyone together and do a little bit of healing and sort of 'let's chart a new course together' since it had been such a divisive and difficult time."

Once the large group as a whole determined the overarching goals of the plan, they were divided into subgroups to develop actionable tasks to implement the goals. Led by Provost Michele Wheatly and Faculty Senate Chair Nigel Clark, this structure was seen as a "more traditionally academic approach to strategic planning" by participants like Nicole, a staffer in the president's office. She explained how the sub-committees worked together across groups: "It was what you would kind of more traditionally think of in terms of how do we have the mission . .. what are some of the goals, and so forth." 
WVU'S LAND-GRANT MISSION

216

The subgroups not only came together in regular meetings to check in and give updates to the overarching council, but the vice presidents provided regular updates in their executive leadership team meetings to show how the plan was materializing. Sean remembered, "[Clements] would have what he called big three-big three items that each member of the senior leadership team would need to report on. And most of those big three items were strategic planning items." He explained that these items shifted throughout the strategic planning process from "the development of the strategic plan" to "a lot of input from a lot of constituencies" once the plan was developed, and the clear objectives helped leaders make the plan a living document. Another way the plan was considered a living document was the intent for all of the administrative units and academic colleges and schools to develop and carry-out their own complementary plans. Nicole described the plan for implementation.

The idea was that it would cascade, if you will. Once the central goals were established, then colleges would do their plans and units like Student Life and so forth would do their plans. And they would say how are we going to propagate these goals? And so, you had the main plan, and places like Student Life would have concomitant strategic plans that followed or tracked those five major goals in the 2020 plan.

Sidney also elaborated on the plan for implementation, describing the 2020 strategic plan as something that could not only be used at the University level, but by colleges and schools, departments, programs, and even individuals.

It was expected, but no obligation, that colleges would take that and have a down flow and have a college plan. And the college plan did not have to adopt all of the University's goals, but at least not be oppositional to them and adopt perhaps a few more succinct goals relevant to that college ... And that was then meant to trickle down to the departments, 
WVU'S LAND-GRANT MISSION

217

and it was then meant to trickle down to the individual. And it was perhaps the first time for myself that I realized that I hadn't had a strategic plan in my life, ever.

The 2020 strategic plan was intentionally written, organized, and presented in a way that could reach the entire campus in an inclusive way. The content was broad and flexible enough to be inclusive, which was a strategy for gaining buy-in across all constituencies. This approach demonstrated Clements' ability to lead from both the collegial and symbolic frames (Manning, 2013; Bolman \& Deal, 2013) because of the way he went about the planning process and what it represented for the campus - an indication of unity.

One example of a divisional unit that followed this lead was WVU Extension Service. Its leadership, in particular, embraced this call to action of creating and implementing a complementary plan to the 2020 strategic plan. Jackson, a staffer in the unit, described Extension Service's approach to strategic planning as part of the University's 2020 plan, which was taking the initiative to be a part of the plan beyond just Extension's traditional role of service.

It's been my experience that typically there's about four or five goals . . . And service from the University always seems to be goal five . . . It just runs in my mind that service is always goal five. In the past, it has been given less emphasis than the other strategic goals because I think land-grants and the land-grant mission, particularly with Extension's mission, a lot of faculty are still confused about the land-grant mission and what their responsibility and role in service should be . . but part of what we've done for Extension this last decade in the strategic plan that came out with five other goals and the fifth one was service and we said, 'Okay, we'll be, we'll be part of the fifth goal in service. But what is it that we can do in the first four?' ... We actually have goals in all five of the strategic 
WVU'S LAND-GRANT MISSION

218

plan goals. Because we said we part of this University. We're going to be part of that student experience. We're going to be part of the research agenda.

Jackson's statement showed that the WVU Extension leadership not only bought into the inclusive and comprehensive nature of the goals presented in the 2020 plan by finding ways to be a part of it, which emulates what McDowell $(2001,2003)$ calls for in his own reconceptualization of Cooperative Extension Service nationwide, as discussed in Chapter 2. WVU Extension's leadership also tried to use the 2020 plan to guide their own planning and include their constituencies in the planning process, which was the ultimate goal of the design of the plan.

These various subgroups and units were key to meeting one of the strategic planning council's intents for the plan — for it be actively used and incorporated into the life of the University. That is one of the reasons why the plan itself was so short, as discussed in the next section. Sidney described its simplicity as intentional: "The strategic plan as you have seen it is remarkably simple, right? It's this little flier. This is what we want to do [with] the idea." The reason behind that simplicity and conciseness was the intention for it to be used regularly. Nicole explained, "One of the things that was interesting about that plan, though, was that there was a consensus among the group that it shouldn't be a plan that sits on a shelf and that it should be something that you can put on a card so that people do understand what our goals are. And then, whatever they do at the institution can plug into those goals."

\section{Introducing the 2020 Strategic Plan}

The five focus areas introduced in the 2009 State of the University Address were the foundation for the content in the 2020 plan, the 2020 Strategic Plan for the Future: "the success of our students; the excellence of our research; the diversity of our culture; our engagement with 
WVU'S LAND-GRANT MISSION

219

the world; the coordination of our outreach in West Virginia." The 2020 plan was kicked off during the 2010 State of the University Address with a new vision statement, which offered a broad interpretation of the land-grant mission: "By 2020, West Virginia University will grow in national research stature, thereby enhancing educational attainment, global engagement, diversity, and the vitality and well-being of the people of West Virginia." This element, along with the values introduced in the Fall 2009 State of the University Address, were the foundation of the 2020 strategic planning process and demonstrated a comprehensive approach to reaching the programming phase of fulfillment in organizational saga. "We must prepare our students to succeed in a complex and competitive $21^{\text {st }}$ century worldwide workplace. We must create a rich fabric of diversity on our campus to ensure that the best mix of the best minds produces the best outcomes. We must provide life-changing outreach for the people of West Virginia, through education, healthcare, and economic development" (Clements, 2010b).

As mentioned in the section on preparing for the strategic planning process, the 2020 plan was incredibly concise, offering five goals with recommended objectives and action items for reaching them that totaled just two pages:

1. Engage Undergraduate, Graduate, and Professional Students in a Challenging Academic Environment

2. Excel in Research, Creativity, and Innovation

3. Foster Diversity and an Inclusive Culture

4. Advance International Activity and Global Engagement

5. Enhance the Well-Being - and the Quality of Life - for the People of West Virginia These goals, which built upon the focus areas Clements first announced in his Fall 2009 State of the University address, discussed previously, were put in place to reach the following aspirations 
WVU'S LAND-GRANT MISSION

220

by 2020: attaining Research 1 status, the highest Carnegie research ranking; doubling the number of nationally ranked programs; and graduating students who are among the nation's leaders in career readiness. The following sections with examine these five goals, including the objectives and action items from the original plan as well as updates and descriptions of how they were addressed and implemented during Clements' tenure per subsequent documents, speeches, and interviews.

\section{Implementing the 2020 Strategic Plan}

\section{Engage undergraduate, graduate, and professional students in a challenging}

academic culture. The objectives set in the 2020 plan for reaching this "Students" goal were as follows: educate, retain, and graduate the leaders of tomorrow at the undergraduate, graduate, and professional levels; transform the curriculum and encourage innovation in teaching to provide students with the skills that they need to succeed in a rapidly changing society; and strengthen relationships with the state and with regional primary and secondary education systems to facilitate a seamless, lifelong learning process. This goal primarily targeted the student subculture and programming phases of fulfillment in organizational saga because of its focus on student development initiatives, including improving retention and graduation rates; recruiting a more diverse student body, which a focus on international recruitment; and improving advising. To achieve these objectives, Clements' administration aspired to weave more critical and creative thinking into the curriculum and student engagement activities as well as a culture of lifelong learning, career readiness, wellness, and sustainability.

As introduced in 2009, Clements continued to emphasize efforts to improve student retention and graduation rates and promote critical thinking. The Blueprint for Student Success, first mentioned in the Fall 2009 State of the University Address, was implemented in fall 2010. It 
WVU'S LAND-GRANT MISSION

221

created a robust first-year student experience through connecting programs designed to help students transition smoothly from high school to college. Students could learn about expectations in higher education, develop critical thinking and analysis skills, explore major and career pathways, gain a greater understanding of diversity and inclusion, and become aware of the University's administrative structure. Programs included a first-year seminar, the First-Year Academy; themed living/learning communities in residence halls; and an online orientation available during the summer.

Academic Affairs invested resources in supporting students who were determined to be "not yet ready for the rigors of college work" (Clements, 2011). They reinvigorated the Resident Faculty Leader program developed during Hardesty’s presidency, a competency-based orientation class, and a cross-college retention graduate council using predictive modeling to improve retention. A Center for Seamless Student Success was established to provide additional advising resources to students in STEM and pre-health majors as well as to graduate and professional students aspiring to obtain prestigious fellowships and grants. A Mountaineer Success Academy was created for incoming undecided students with low high school GPA and SAT/ACT scores, which featured early move-in in a living-learning community, one-on-one academic coaching, and a specific curriculum. An Early Alert Program for advisors and supporting Mid-Semester Help Center helped identify students at-risk for being placed on academic probation and/or dropping out. Simultaneously, Career Services also launched an outcomes-focused strategy during this time. Its " $>$ (greater than) A Four-Year Plan" was created in response to feedback from prospective and current students and their families about preparing students for the job market after graduation. Together, these retention and career-readiness goals 
WVU'S LAND-GRANT MISSION

222

were intended to work together to fulfill Clements' intentions of developing the whole student, as discussed previously.

The next effort to further streamline student success resources was establishing a new academic unit where they were housed: University College. The primary purpose of the academic unit was to program to support students who have not yet declared a major or who were admitted to pre-majors as well as nontraditional students. Several academic units were reorganized under University College: academic and developmental advising, programs for academic advancement, the First-Year Experience program, ASPIRE, Center for Service and Learning, Ronald E. McNair Achievement Program, Honors College, and Career Services Center. This reorganization is another example of Clements' leadership from the structural frame (Manning, 2013; Bolman \& Deal, 2013) as he attempted to streamline student services and help students access all the resources they needed in a convenient location.

The "Students" goal was expanded beyond student subculture to the social base component of organizational saga through an action item of engaging with the state's preK-12 education system and community and technical system to support training of STEM educators. An initiative already in place at this point was 4-H, whose camps, which feature STEM activities, reach 16,000 kids around West Virginia. To expand efforts across the University, four new faculty positions were created in education, science, and technology to strengthen and expand STEM education opportunities around the state. In addition to the student subculture phase, this tactic also reflected the social base phase of fulfillment in organizational saga because of its focus on higher education access and a source of economic development support because of the job training, an example of what Klein and Woodell (2015) called for in their talentinnovation-place model of economic development. 
WVU'S LAND-GRANT MISSION

223

Another tactic that expanded this goal to the social base component of organizational saga involved additions to the University's online and distance learning programming, which had the potential to increase educational access. A new Division of Academic Innovation was charged with developing new techniques in the classroom, expanding educational access for students, and providing a place for faculty to experiment with emerging educational technologies and tools. This division also began exploring the use of massive online open courses, or MOOCs, to allow faculty to teach a broader, more expanded audience. Like the pre-K STEM initiative, this tactic reflected the social base phase of fulfillment in organizational saga in addition to the student subculture phase because of its focus on access for diverse populations of students, including those around the state and not just local to the Morgantown campus.

The efforts that were part of the "Students" goal demonstrate that Clements first used his structural leadership style to bring together, organize, and streamline student development programming and resources already in existence so students could access them in one convenient place. That reorganization also gave him an opportunity to identify what was missing and add new initiatives to meet those gaps, including in the areas of retention and career readiness. He also looked outward to the state beyond the campus to see what educational initiatives could meet a broader goal and added programming to support STEM teacher education as well as distance learning, which was a new perspective for carrying out the land-grant mission.

Excel in research, creativity, and innovation. In the Fall 2010 State of the University Address, Clements referred to this "Research" goal as the most critical goal in the strategic plan and the one that ties the entire plan together.

Our research and scholarship make us a better institution in all ways, for all of our stakeholders. They add vitality to campus, enriches our work environment, and creates 
WVU'S LAND-GRANT MISSION

224

opportunities to transform — and even save-lives. A campus steeped in a research culture attracts the very best students and the very best faculty and staff. It expands the curriculum and helps develop the critical thinking skills of our students in all disciplines. It builds bridges for West Virginia's advancement in the nation and the world, and it creates portals for others to invest in West Virginia. (Clements, 2010b)

In this speech, Clements explained why improving research will help the University and carry out the land-grant mission: by promoting national and international visibility and enhancing WVU's reputation; expanding the institution's global footprint; contributing to a vibrant curriculum and helping to better educate students; attracting diverse and high-achieving students, faculty, and staff; enhancing graduate education and strengthening it to support research; advancing the state's economy; and enhancing the quality of clinical healthcare. As a result, this goal reflected the personnel, programming, social base, and imagery phases of fulfillment in organizational saga because research incorporated so many different facets of the Universitythe work of faculty and students, the individuals in the community aided by the research, and the reputation and responsibility that aspiring to reach the goal placed on the institution.

Jameson, a key official in an academic college, reflected on the decision to lead with research as the goal that takes priority in the plan, which he described as "really bold," especially in contrast to other land-grant universities' strategic plans that place equal weight on all goals. He said,

WVU actually said, 'No, no, there's one among equals here, and it's going to be research.' I think, to that effect, it was one of the reasons why President Clements, when the budget allowed, sought to hire 100 additional faculty. And lo and behold, some years later, we 
WVU'S LAND-GRANT MISSION

225

became an R1 university. Now, can you draw a straight line between those two? I don't know, but it's an imaginary line.

This exemplified Clements and his leadership team taking a risk in placing so much emphasis on one goal, especially early on in the presidency.

The objectives set in the 2020 plan for reaching this research goal were as follows: increase scholarly activity and research that addresses the challenges faced by the state of West Virginia, the nation, and the world; improve and expand graduate education and strengthen its connection to the University's research enterprise; and encourage interdisciplinary activity in research, scholarship, and creativity.

The first action item Clements' administration pursued to reach this goal was establishing an effective research infrastructure that facilitates the pursuit of research, which emulated his continued leadership from the structural framework (Manning, 2013; Bolman \& Deal, 2013). This infrastructure included linking research with education, global engagement, and economic development throughout the state, which encompassed elements of organizational saga's student subculture and social base because it showed how student learning can be a part of the research process as well as how research can contribute to the state's economic development.

To facilitate the development of this infrastructure, the strategic planning council established a research roundtable as one of its subgroups. The roundtable was charged with conducting a study of WVU's research resources, strengths, and the national research climate to ultimately advance the University's research agenda. The roundtable's charge included establishing an infrastructure and practices to facilitate research; identifying initiatives and fertile research areas; and creating a permanent leadership structure to replace the roundtable at its conclusion. The roundtable determined that it would be efficient to merge offices administering 
WVU'S LAND-GRANT MISSION

226

state and WVU Research Corporation business where appropriate. The University Strategic Research Council (USRC), established in May 2012 and replacing the roundtable as a permanent leadership structure, became the new manager of the investment of research resources. The charges to the USRC, outlined by the research roundtable, include the following: develop and pilot evaluation processes for areas of research emphasis; leverage existing mechanisms to develop, support, and retain scholars; and create and maintain effective communication channels to support research and scholarship. These charges also included coordinating research activities of main campus colleges and divisions with those of the Health Sciences Center and pursue alignment of the University's research financial plan with its strategic initiatives.

Several process-based changes to the University's research infrastructure were made during this time. In preparation for developing an electronic paperwork process to make that process for more efficient and less bureaucratic, the University reviewed all internal grants supporting faculty development and scholarship. Additional budget allocations were made to the funding that supports research, scholarship, professional development, and other activities. Funding and support for graduate and professional students were also reexamined as part of this process. These process-based changes were part of the programming and personnel phases of the fulfillment stage of organizational saga because they emphasized efficiency and other similar operational improvements while also supporting faculty and staff. These changes were also a nod from Clements to the structural leadership framework (Manning, 2013; Bolman \& Deal, 2013) because he used his computer science experience to find ways to make University processes and operations more efficient. 
WVU'S LAND-GRANT MISSION

227

Five research focus areas, called Mountains of Excellence, came out of the research roundtable's efforts to guide strategic investment to research, including private giving. The focus areas were:

- Achieving international leadership in radio astronomy

- Utilizing shale gas

- Promoting stewardship of water resources

- Improving STEM education and scientific literacy

- Addressing health disparities in Appalachia

These represented strengths identified by University leadership in the existing faculty and as well as potential growth opportunities for the state's economy, which intersected both the personnel and social base components of organizational saga. They also exemplify what Klein and Woodell (2015) call for in their talent-innovation-place model for research leading to economic development, as discussed in Chapter 2.

Several interdisciplinary research efforts reflect the changes in research infrastructure and how it is applied locally, regionally, and globally through the Mountains of Excellence: a National Science Foundation award used to establish an international research and education program that included high school and college student researchers to detect gravitational waves; creating a clearinghouse to help the state manage the challenges and opportunities of natural gas extraction; an investigation of the interactions between industry and the state's water supply to develop techniques for water management and remediation; the establishment of an interdisciplinary center for bio-nano-technology, funded by an EPSCoR grant, which supports research access; an interdisciplinary project in the P.I. School of Journalism resulted in the nation's first and only World War I memorial of its kind in McDowell County, honoring the 
WVU'S LAND-GRANT MISSION

228

service of African American veterans, which featured an interactive display with a mobile app that made the exhibit available worldwide; a new $\$ 5$ million award in neuroscience from the National Institutes of Health supporting new laboratory facilities; and a \$19.6 million grant from the National Institutes of Health to the West Virginia Clinical and Translational Science Institute to address health issues most commonly affecting West Virginians, including cancer, heart disease, stroke, and obesity.

The second "Research" action item Clements' administration pursued was investing in the hiring and retention of high-quality faculty and research staff committed to research success while mentoring staff and faculty to a high level of achievement, an immediate step toward the personnel element of organizational saga. Specifically, Clements announced in his 2009 State of the University Address a plan to add 100 new faculty positions, a study directly supporting the personnel phase of fulfillment in organizational saga. The first 30 focused on supporting general education teaching loads. The next 30 focused on strengthening areas related to the State's Research Trust Fund. As of fall 2013, WVU was making 24 new hires in areas that support the Mountains of Excellence, outlined above.

Samantha recalls working within the Mountains of Excellence and the competition for the new hires among deans and other academic leadership. She described them as a shift in response to the economic upturn and enrollment increase following the Great Recession, a contrast to the economic challenges faced by Hardesty's administration. She said, “There was some extra money to invest, and so, the president allocated 100 new faculty lines, but the faculty lines could only be allocated along these research excellence areas." Because the research areas were so specific, the Clements administration expected the deans of the academic colleges and schools to 
WVU'S LAND-GRANT MISSION

229

collaborate to determine the most strategic and collaborative ways to fill the multidisciplinary positions. Samantha continued,

I called the process the deans' 'Hunger Games' because we were all trying to, even though we were collaborating, and, we do continue to. The whole thing worked actually, but at the time, it would be something like, okay, we're going to be able to have five lines for shale gas, where are they going to go, and then the deans would get around the table and say, 'Well, you know policy really matters, and so I should get one for policy, and someone else would say, yeah, but hard science research really matters, and petroleum and gas engineering, so I should get all five,' and that's why I call them the deans' 'Hunger Games.' But, in fact, I really believe that it was a process that some of them have been more successful than others.

Clements reflected on why his administration pursued an expanded, but targeted hiring of research faculty in the 2012 State of the University Address and how he intended for it to help reach the research goals set forth in the 2020 strategic plan.

We put faculty innovation front and center in our strategic plan to enhance educational delivery and to create a more vibrant research enterprise. Turning innovation into impact requires analytical ability, critical thinking, communications, design, and many other skills that are the hallmark of a liberal arts education. This is why academic excellence, across the board, is also front and center in our strategic plan. (Clements, 2012)

This statement demonstrated commitment to the personnel phase of fulfillment in organizational saga because it indicated the Clements' administration was willing to make budget allocations for its research goals, showing that hiring talented researchers and faculty support in general were a priority. 
WVU'S LAND-GRANT MISSION

230

The efforts that were part of this "Research" goal reflected Clements leadership from both the collegial and structural frameworks (Bolman \& Deal, 2013; Manning, 2013). His collegial approach stemmed from the faculty support and budget prioritization for new faculty hires in the targeted research areas, highlighting that he was willing to invest financially where necessary to support this goal. His structural approach was seen in the organizational and operational changes he pursued to make the process of applying for and receiving sponsored research funding more streamlined. His research efforts made a major contribution to the fulfillment stage in organizational saga as well, as a new research infrastructure and foci areas supported the programming phase; the partnerships formed and economic development-focused research areas supported social base; the budgetary support for new faculty lines supported personnel; and the new research status aspirations and the reputation that came with them supported imagery.

Foster diversity and an inclusive culture. The objectives set in the 2020 strategic plan for reaching this "Diversity" goal are as follows: become a model institution for the attraction and inclusion of diverse groups; incorporate diversity broadly into the curriculum; and create an integrated administrative infrastructure to promote diversity, inclusion, equality, and intercultural and intercommunity outreach. This goal encompassed all phases of fulfillment in organizational saga: personnel, programming, student subculture, social base, and imagery. It intersected new curriculum, events, and other activities, many with a global theme, for faculty, staff, students, and community members alike while also expanding the University's worldview, an attempt by the Clements' administration to change the culture by shaping the campus to be more welcoming and open-minded. 
WVU'S LAND-GRANT MISSION

231

The first action item put in place to reach this "Diversity" goal was to deploy best practices to promote inclusive searches for staff and faculty, diverse hiring, and retention. The first step in operationalizing this action item was creating a University-wide structure to promote diversity, inclusion, and equity and to explore new ways to integrate diversity into the University's curriculum and research agenda. This organizational structure eventually became the Division for Diversity, Equity, and Inclusion in Clements' administration and is another example of Clements' use of the structural leadership framework (Bolman \& Deal, 2013; Manning, 2013) in his decision-making. During this time, the University was awarded a $\$ 3.2$ million grant from the National Science Foundation to create an ADVANCE Center at WVU to promote women in the STEM disciplines. The grant supports the University to address programs, policies, and activities that improve the work-life conditions of both male and female faculty both inside and outside of the STEM fields.

Both of these tactics are examples of how the Clements' administration took steps toward the personnel component of organizational saga because these initiatives focused on diverse hiring practices and employee retention and engagement. They are also examples of the imagery component of organizational saga because they both reflect foundational steps toward culture change among University employees.

The second action item Clements' administration pursued toward the "Diversity" goal was utilizing assessment tools to evaluate the impact of diversity practices and institutional climate, focusing on access and success, intergroup relations, curriculum, education and scholarship, and institutional viability and vitality, and use the findings to advance diversity at WVU. The strategic planning council's diversity roundtable, another one of the previously mentioned subgroups, was tasked with carrying out this action item. The purpose of this group 
WVU'S LAND-GRANT MISSION

232

was to promote a more inclusive culture on campus, a more respectful workplace, and ways to advance the recruitment and retention of minorities in all constituencies. In the plan's overarching 2013 progress report (West Virginia University Strategic Planning Council, 2013), one of their recommendations was the hiring of a chief diversity officer. David Fryson was brought on in 2012 and tasked with leading the Division of Diversity, Equity, and Inclusion, assessing recruitment and retention initiatives for African American and Hispanic students, exploring the possibility of an office for the University's LGBTQ community, and leading community development efforts in at-risk communities around the state.

Some culture change initiatives more focused on students were also implemented during this time. The Office of Graduate Education and Life launched an initiative to provide underrepresented minority graduate students with academic and career resources and mentorship opportunities. These included a graduate student orientation, a dissertation writing retreat, the Faculty and Alumni Mentoring for Excellence Program, a diversity-focused professional development series, and the My Brother's and My Sister's Keepers Peer Academic Support Program. The Center for Black Culture and Research developed the STARS program for incoming African American freshmen, including a single-credit course in African American literature, relevant workshops and study tables, and extracurricular and service activities.

As announced in the Summer 2010 State of the University Address (Clements, 2010a), the Education Trust ranked WVU among the best public institutions in the country for attracting and graduating academically qualified low-income and minority students. WVU was one of four institutions in the country with the highest marks for overall performance on educational access. Clements shared in that speech: "Today, as we have throughout our history, WVU is opening the doors of opportunity to people from all backgrounds." 
WVU'S LAND-GRANT MISSION

233

Clements continued to lead from the structural framework (Manning, 2013; Bolman \& Deal, 2013) as his administration worked toward this "Diversity" goal in the 2020 strategic plan. The structural framework was seen through the new infrastructure put in place, i.e. the Division of Diversity, Equity, and Inclusion. Simultaneously, the symbolic framework (Meyer \& Rowan, 1977; Manning, 2013; Bolman \& Deal, 2013) was introduced for the first time in the 2020 strategic planning process as he worked to shift the culture of the campus to a more welcoming and open-minded one. The tactics under this "Diversity" goal also contributed to nearly every phase of the fulfillment stage of organizational saga: the resources in the new Division of Diversity, Equity, and Inclusion and the staff and leadership that accompanied it supported personnel; the new activities and curriculum supported programming; the focus on diversifying student recruitment supported student subculture; and the shifting campus culture and resulting Education Trust ranking supported imagery.

Advance international activity and global engagement. The objectives set in the 2020 plan for reaching this "Globalization" goal are as follows: promote international partnerships in education, research, outreach, and economic development that benefit our constituents and the state; integrate global themes broadly into the curriculum; and create an integrated administrative infrastructure to promote global engagement and awareness. This goal reflects the programming and imagery phases of fulfillment in organizational saga because it combined new curriculum and activities on campus with a change in culture to shift the campus's focus to be more outward-looking and global.

A global engagement roundtable was one of the subgroups created out of the strategic planning council. It was charged with pursuing four action items: expose all students to a global experience, with opportunities for study abroad, global service learning, on-campus activities, 
WVU'S LAND-GRANT MISSION

234

and a curriculum that incorporates international vision; promote and support international research and professional development opportunities for all faculty; facilitate the exchange of knowledge, perspectives, and commerce between the state of West Virginia and its global partners; and enhance the University's efforts to recruit international students. This group worked to connect all the international activity and global engagement related-initiatives already happening to streamline those efforts, including recruitment, student exchange programs, economic development, research partnerships, and alumni relations, another reflection of Clements' leadership from the structural framework (Manning, 2013; Bolman \& Deal, 2013).

The global engagement roundtable recommended that WVU double its international student enrollment. In their progress report, they found that WVU had fewer international students and a less mature infrastructure to support them than do leading institutions. They also determined that the University's global engagement and outreach efforts are organizationally and physically decentralized and indicated that one key to success will be to coordinate the University's global engagement efforts through one administrator in a single physical location with a new organizational structure under a senior international officer, all of which highlighted Clements' continued leadership from the structural framework (Bolman \& Deal, 2013; Manning, 2013).

The global engagement roundtable also recommended an expansion of alumni chapters around the world that provide linkages with graduates and potential new students. One example resulting from this effort was a partnership with a university in Bahrain to offer joint degrees in fields such as leadership, science, engineering, banking, and women's studies (Clements, 2010a). These efforts highlight an intersection between the student subculture and social base phases of 
WVU'S LAND-GRANT MISSION

235

fulfillment in organizational saga because students were given more opportunities to expand their own networks and gain international career experience as a result of the work of alumni.

The global engagement roundtable reported in the strategic plan's 2013 progress report (West Virginia University Strategic Planning Council, 2013) that international first-time freshman population grew by $60 \%$ for a total of 136 students in 2012 , more than double that of the freshman class in 2010, and triple that of the freshman class of 2009. In fall 2013, international first-time international freshmen increased, and overall undergraduate international enrollment grew by $26 \%$. As of fall 2013 , total international enrollment totaled more than 1,800 , an increase of $36 \%$ from about 1,300 in 2009.

The "Globalization" goal continued to showcase Clements' leadership from the structural framework (Bolman \& Deal, 2013; Manning, 2013) as he worked to streamline all of WVU's activities and initiatives related to international students and international opportunities. With regard to organizational saga, the efforts that resulted from this goal brought together student subculture with the focus on international recruitment and resources; programming with the newly restructured activities and others that were newly introduced; and imagery as all of these efforts reflected a shift in the culture of campus to be more global and welcoming to individuals from different cultures.

\section{Enhance the well-being - and the quality of life - for the people of West Virginia.} The objectives set in the 2020 plan for reaching this "Community Engagement" goal are as follows: create an academic health system and health professions programs that enhance the well-being of West Virginians; increase opportunities for the citizens of the state through workforce education, lifelong learning, and outreach to every county; promote sustainable economic development and a cultural environment that improve the quality of life throughout the 
WVU'S LAND-GRANT MISSION

236

state. This goal demonstrated a commitment to the social base and programming components of fulfillment in organizational saga because it identified new activities and strategies for engaging with the community. It also took on the imagery component because of the way the messages discussed the University's service to the state—statements about enhancing and improving wellbeing and quality of life for all people.

Three roundtables, focused on economic well-being and engagement, lifelong learning, and quality of life, respectively, were created to implement this goal. They were tasked with connecting WVU's campuses to citizens and communities throughout the state by providing resources and information to equip West Virginia University Extension agents and other personnel engaged in outreach and care for a broader role as "ambassadors" for the institution. A new structure for engagement activities, including WVU Extension Service, was the beginning of the efforts to reach this goal, another example of Clements' leadership from the structural frame (Bolman \& Deal, 2013; Manning, 2013). The move is intended to give the service part of the land-grant mission more prominence and infuse it more into strategic discussions that connect the teaching and research facets of the land-grant mission. The intent was for the Extension Service will be connected more closely than ever before with the deans and the colleges with more opportunities for collaboration and partnership. An associate provost for engagement and outreach position was created to lead this effort. In addition to being a structural shift, this change was also a component of personnel in organizational saga because of the added responsibility placed on Extension agents as "ambassadors" and a component of imagery because it represented a very visual shift in priorities.

The lifelong learning roundtable completed and published an inventory of 111 activities already taking place at WVU that offer learning opportunities for West Virginians in its 
WVU'S LAND-GRANT MISSION

237

concluding report (West Virginia University Lifelong Learning Roundtable, 2012). They

recommended that the new associate provost for engagement and outreach be responsible for maintaining this inventory and overseeing an advisory committee to determine programmatic needs and interests in lifelong learning. They also recommended that WVU should become more active in the Association for Public and Land-Grant Universities and that the associate provost for engagement and outreach be WVU's official delegate to the council, which was another step toward the imagery component of organizational saga because it contributed toward the continued development of the University's national reputation. Mary, a representative on that committee, noted:

It was the vision of [Clements] and Provost [Michele] Wheatly who wanted to provide coordination and leadership to the 15 colleges and schools regarding our land-grant mission, outreach, and community engagement. And, it was really to bridge health sciences and the main campus. So, the idea was that there was need for coordination and leadership to get people to partner, to have more success stories to share with donors and policy stakeholders . . . Connect people for grant-writing purposes . . . Everything from the impact of Extension Service to the clinics out at the School of Medicine to [the School of] Social Work's footprint. Just having those stories of impact and evidence of the University's impact, the impact of its footprint across the state.

In its fall 2012 progress report (West Virginia University Economic Well-being and Engagement Roundtable, 2012), the economic well-being and engagement roundtable completed an audit of economic development activities, structures, and assets at the University. They identified approximately 32 programs and more than 100 full-time employees engaged in economic development in six colleges, WVU Extension Service, WVU Research Corporation, 
WVU'S LAND-GRANT MISSION

238

and the National Research Center for Coal and Energy. The roundtable also identified seven areas of strength that the University could continue to focus on and made subsequent recommendations for increasing economic development and forming collaborations and partnerships around the state. These areas included talent and workforce development, a continuation of the career readiness tools and the preK-12 and community and technical college partnerships developed under the "Students" goal; innovation and commercialization, a continuation of the Mountains of Excellence priority areas in research and development; community development, a continuation of the "Community Engagement" strategies discussed above; technical support for businesses, industries, and government; leadership development; and global engagement, a continuation of strategies discussed above in the "Globalization" goal.

In its fall 2014 progress report, the quality of life roundtable reviewed ways to communicate with the legislature and the public regarding University outreach initiatives related to quality of life. Regarding the legislative audience, the roundtable concurred that messages would be best framed to highlight the short-term impact that WVU has on quality of life of West Virginians because a "focus on long-term impact could inaccurately imply a sense of delayed interest or involvement” (West Virginia University Quality of Life Roundtable, 2014, p. 3). They suggested that gathering community input could be helpful to learn more about audiences and their interests and needs, similar to Gavazzi's (2015) town-gown relationship model discussed in Chapter 2, as well as targeting strategies to individual communities rather than adopting a homogenous, "one-size-fits-all” approach.

The tactics under the "Community Engagement" goal highlighted Clements' leadership from both the collegial and symbolic leadership frameworks (Manning, 2013; Bolman \& Deal, 2013). The collaboration by the three roundtables represented collegiality because they 
WVU'S LAND-GRANT MISSION

239

highlighted diverse groups of representatives around campus coming together to solve problems, while the messaging of the goal as a whole, working to improve the "quality of life" and "wellbeing" of West Virginians was an example of an attempt to change culture in the state through the work of the University through the land-grant mission. Several components of fulfillment in organizational saga were also supported through the tactics in this goal. Social base permeated all of the tactics as they were designed to support the citizens of West Virginia. Personnel was supported with the creation of a new associate vice provost role to support the University's engagement efforts. Imagery was also prominently supported because of the message portrayed across the state through the service completed by roundtables.

Summary. Clements and his leadership team, particularly Provost Michele Wheatley and Faculty Senate Chair Nigel Clark, continued work on the 2020 Strategic Plan for the Future up through his announced departure for Clemson University in November 2013. As seen in the above sections, updates were regularly shared about the action items and work toward the five goals in the State of the University addresses, an overarching progress report and individual progress reports from the roundtables, and a (now defunct) website, making the process transparent for the campus community to observe.

Clements' approach to the goal-setting for each of the five areas of 2020 strategic plan was consistently derived from the structural leadership framework (Manning, 2013; Bolman \& Deal, 2013). Whether it was creating a unified structure for student resources, research operations, diversity initiatives, international activities, or community outreach, Clements always sought to organize what was already taking place at WVU, identify the gaps, and create or merge activities to fill the gaps. He also recognized the power of reframing (Bolman \& Deal, 2013), often code-switching to utilize different frameworks depending on the goal. For example, the 
WVU'S LAND-GRANT MISSION

240

collegial frame was seen prominently in his work with the "Research" and "Community

Engagement" goals, while the symbolic frame arose in the "Globalization" and "Community Engagement" goals, discussed above.

The 2020 strategic plan thoroughly contributed to fulfillment stage of organizational saga. While the plan's broad goals may have made activities that much more nimble for drawing parallels, it is evident that each of the five goals contributed to many of the components of fulfillment. The tactics in the "Education" goal naturally supported student subculture, but it also expanded to social base as many of the new activities (which also support programming) were implemented in the community through preK-12 and community and technical college partnerships as well as through WVU Extension and 4-H. The "Research" goal was accompanied by a new research infrastructure that supported programming but also resulted in many new faculty lines and other resources, a contribution to personnel. The tactics in "Diversity" and "Globalization" goals both came with new activities that not only supported programming and student subculture but also imagery as they began to shift the campus culture. The "Community Engagement" goal is a direct connection to social base as all of its tactics are in direct support of the state's citizens, including their well-being, lifelong learning, and economic development. Finally, the aspirations of reaching Research 1 status as well as earning the Carnegie community engagement classification both heavily contributed to imagery because those rankings helped to weather the storm of the Garrison scandal and support the University's growing national reputation.

Before moving into a discussion of how the land-grant mission was messaged and shared through the work of the strategic plan, another subsection will synthesize across both the 2010 
WVU'S LAND-GRANT MISSION

241

strategic plan from the Hardesty administration and the 2020 strategic plan from the Clements administration.

\section{From the 2010 Plan to the 2020 Plan}

While the approach to creating the 2020 plan was to be as comprehensive and inclusive as possible, some key officials interviewed indicated that the strategic planning council had a head start because of the work done on the 2010 plan during Hardesty's administration. Edith, a faculty member, relayed her perspective,

While Clements had a more ... comprehensive strategic plan, he also had something to build off of . . When Clements created the 2020 plan, it built on many of the same points because in a sense almost any strategic plan nationally is going to have something about faculty, something about students, and something about you know the, the land-grant mission. So those three pieces remain constant. And I think what the strength was that it continued the [2010] plan and it continued that process of being forward in a purposeful way. What it lost, I think, was that engagement with a broader set of voices . . I don't know that he to my mind really had a clear vision. And part of the reason I say that is because there had been a strategic plan and it didn't really get taken up, nothing really came of that. There was something in place. There was some momentum building [from Hardesty's 2010 strategic plan], and then he just let it drop. And, you know, maybe he felt he couldn't touch that because it was so connected with previous administrations. But I also didn't see a real push for the same kind of new strategic planning that was going to be as inclusive of faculty in various sectors of the University.

This anecdote from Edith highlights that while Clements' administration introduced goals in many of the same areas that Hardesty's administration focused on in the 2010 strategic plan, they 
WVU'S LAND-GRANT MISSION

242

felt a distinct motivation to move beyond the 2010 plan and start fresh with their own. She also highlights a tension relating to faculty and research stemming from Clements' prioritization of research and the Research 1 aspiration. While his messaging emphasized faculty hiring increases and expanded research productivity, it was targeted narrowly to the five areas in the Mountains of Excellence. Those foci were narrow, in contrast to Hardesty's research goals, which tended to be broader and always encompass the liberal and creative arts.

The symbiotic nature of the two plans was also confirmed in the 2014 Accreditation SelfStudy Report for the Higher Learning Commission, which also described the role the land-grant mission played in developing the content for them.

In 2010, WVU initiated an inclusive planning process that built upon the achievements of the 2010 plan, while charting a new course toward 2020. Planning was framed by the $150^{\text {th }}$ anniversary of the Morrill Act that established WVU's land-grant mission. WVU's 2020 Strategic Plan for the Future was created by the Strategic Planning Council and endorsed in 2011 by the WVU BOG. The mission, vision, and strategic plan clearly articulate the institution's priorities by highlighting its status as the flagship, land-grant institution of higher education in the state. (West Virginia University, 2014, p. 11)

Other key officials believed that the goals determined for the 2020 plan were too generic and broad and not unique to WVU's mission and purpose. Sidney shared this perspective, saying,

[Clements'] background was sort of an organizational structure, and he bridged management, and he bridged business management and engineering, all three. I think he just need he needed the plan, because we needed to have a plan, the 2010 plan was dying, and I think he'd read the 2010 plan. Something that was of interest is that a lot of it came 
WVU'S LAND-GRANT MISSION

243

out very parallel to the major bullets of the 2010 plan. In other words, there really was fairly good continuity there. And that group did not get deeply into implementation.

Henry also commented on the general nature of the goals presented in the 2020 strategic plan, saying, "I think the [goals] were fairly standard. You know, there was nothing earth-shattering, nothing that rocked the boat or anything of that nature just sort of what one would expect the president to be talking about."

Joseph described the generic nature of the plan as a "cop-out" with no strategy involved in the decision-making. He said, "You could have put a different university's name on it, and it would've been the same plan. There was nothing there that was unique. And it really wasn't a strategy. It was just a bunch of [sic]. It was like a Chinese menu." Jameson described the goals as familiar because they were nearly identical to those set that same year by his previous institution, also a land-grant, Research 1 university. He shared an anecdote about the parallels between both institutions' plans.

Right before I came here from [another university] . . . I was on the strategic planning stuff at [that university], which was also a very engaged process with all kinds of committees and subcommittees and supercommittees and committees of committees and so and so on. And I co-chaired the committee on international and global engagement, whatever it was called. And we met with all the other committee chairs and so on. At the end of the day, [we] came up with a nice plan. I don't know how many pages it was. And it had five major goals. And those five goals were launched right before I came here, and they were exactly the same as the five goals WVU came up with, which also launched right before I came here. Because how could you have a university that didn't say we're going to promote 
WVU'S LAND-GRANT MISSION

244

faculty excellence and student achievement? That we're going to promote whatever the five were. Different ways of saying the same thing. These are all important, right?

William, a faculty member and former administrator, shared concerns about the lack of assessment opportunities with the 2020 plan: "[Clements] may have used some words, but he didn't have well-oiled machine that did strategic assessment, kept at it, tried to make sure that that guided the internal decisions or the activities." Like William, Jameson also shared concerns about whether assessment would take place. He continued,

In fact, I joked with some people over time, even with [Clements] at the time, that all these universities could've saved themselves a whole lotta effort and just adopted one strategic plan for all research universities because they all come to the same conclusion about the five, six, or four things that need to be promoted because those are obvious. Jameson described assessment in what sets universities' strategic plans apart from one another because most do not take the time to do so, or intentionally don't out of fear of failure. He said, "Most universities shy away from having metrics like that because you are then subject to evaluating yourself. There's risk there, so you don't do that." Samantha also expressed concerns about minimal opportunities for assessment and evaluation of progress.

If you go around campus and you ask people, they'll tell you two things about the strategic plan itself. They'll say the goals were wide enough to drive a truck through, and there were never outcomes or metrics designated, and so, over the decade, no one can really tell specifically are we making progress in this area or that area.

While the strategic planning council clearly articulated the plans goals, objectives, and action items and made them available on a public website, there were no metrics identified for evaluating the plan. The few documents with assessment information were the progress reports 
WVU'S LAND-GRANT MISSION

245

discussed above. Instead, Clements relied on the State of the University Addresses to provide periodic examples of the work being done within the goals. This lack of assessment strategy was a contrast to Clements' engineering background, which is focused on producing and evaluating efficiencies.

Still others believed that the representative nature of the plan was the fresh start WVU needed to move forward and stabilize after the Garrison crisis, as described in the previous chapter. William reflected,

And Clements was the first person who really now sort of had a fresh opportunity. But, people were still gun shy . . . For however many years that was, the University administrative leadership was either unable to lead and couldn't focus on leading, or they had to focus on something else. Get over the pain. I really think that when [Clements] came, that those years of turmoil and bad feeling and 'Oh my God' was over. And I think he was a fresh appointment made through a good search. He had good academic credentials. He had a fresh start.

Like William, Samantha also saw the 2020 plan as a sign of progress beyond the scandal and a new beginning.

Well, it was a very exciting time right because the, it was a sign of moving forward that the sense of instability that had had been now was going to transition. [Clements] was a very dynamic, energetic leader. I think he was very good at building relationships, convincing people that he cared very deeply about the institution. He had been, even though he hadn't been at land-grant, he had been in public institutions that had played an important role in Maryland, and people really value that, the idea that he understood the role of a 
WVU'S LAND-GRANT MISSION

246

public university to its state. People saw him as fresh and innovative, I think. The campus responded extremely well to him.

Ultimately, for Samantha and others, the 2020 plan represented a fresh start for the University community as it moved beyond the Garrison scandal and looked to reset its reputation on the national stage, another step toward reaching the imagery phase in organizational saga.

\section{Summary}

Clements lead from a traditionally academic approach to strategic planning, bringing together a large, representative group to develop and implement the plan. His most notable initiative, research, resulted an increase in the faculty ranks and laid the groundwork for WVU receiving the Research 1 classification for the first time. While the University did not receive the ranking until several years after his departure, that will be a significant part of his legacy. He was also credited for diversifying WVU's campus culture in terms of international student recruitment, international alumni engagement initiatives, and globalization of the campus community, which was an innovative approach for a WVU president to take during this time. He is also remembered for being a cheerleader, a collegial leader who made positive impressions on students, faculty, and alumni and donors alike, as well as a structural leader for all of the infrastructure changes and operational efficiencies he pursued. Despite these notable pursuits, what most of the key officials remember him for now won't likely be remembered several years into the future - the 2020 strategic plan itself. That is because so many of the individuals interviewed reflected on that plan as well-intentioned with its comprehensive, representative approach, but with messaging that was so generic that it lacked the character and personality of a land-grant university with a unique mission to its state. That messaging will be discussed in more detail in the next section. 
WVU'S LAND-GRANT MISSION

247

\section{Defining the Land-Grant Mission: Vision and Messaging}

\section{Improving the Quality of Life for West Virginians}

Despite arriving as an outsider, Clements immediately identified the relationship between WVU and the states' citizens and the responsibility the University has in serving the public good through its research, teaching, and service mission as a land-grant university, and he recognized the role faculty, staff, students, and alumni have in that responsibility and their loyalty to it. This observation reflects his commitment to the social base phase of fulfillment in organizational saga. It was evident in his first State of the University Address in summer 2009, presented to alumni and donors in Washington, D.C.:

It's clear to me that people really understand the mission of the institution. We're entrusted to make a difference every single day-a positive difference . . . I found in meetings with faculty and staff on the campus that you can't find a more committed or dedicated group. They're committed to making a difference every single day. And I can tell you that they do. They absolutely, completely do. Look at the medical professions. We are literally saving lives. It's a big deal. But were also committed to the state the great state of West Virginia committed to building the economy and strengthening the state as a whole. (Clements, 2009a)

Throughout his State of the University addresses, Clements described several ways WVU could play a role in improving the quality of life for all West Virginians, including investing in the economy and improving healthcare. These two areas are explored next. 
WVU'S LAND-GRANT MISSION

248

Investing in the economy. "It has been said: no state depends more on its land-grant university than West Virginia. WVU provides at least a 20-to-1 return on every state dollar invested in the University" (Clements, 2009b). Clements described how that economic investment has changed throughout WVU's history, from agrarian to industrial efforts, including the role of WVU Extension Service.

In the early days, in what was still a largely agrarian society, land-grant universities developed new farming techniques, and they created Cooperative Extension Services to disseminate those techniques. Today we apply knowledge from nearly every field of human endeavor to improve lives in West Virginia and throughout the world. The land-grant system was a catalyst for our nation's industrial revolution, propelling us to world leadership in less than a hundred years. Today, land-grant universities are vital to ensuring that all 50 states participate in the information age. And, since land-grant institutions were originally established in every state to focus on education, research, and service, together, we as the land-grant system form a powerful and important backbone for advancing our nation. (Clements, 2011)

This goal demonstrated the intersection of programming and social base elements of organizational saga in how Clements discussed the land-grant mission because he discussed how the economic investments made by the University directly impact the state's economy and its people, an example of how he continued to interpret and re-envision the land-grant mission in his presidency.

Clements also called for WVU and land-grants across the nation to play a role in diversifying the economy through innovative research and entrepreneurship, a recommendation seen in the literature from Klein and Woodell (2015) and Fitzgerald et al. (2012). "University research and innovation has traditionally been a driver for the U.S. economy. In critical areas 
WVU'S LAND-GRANT MISSION

249

such as energy, health care, and national security, WVU is uniquely positioned to have an impact" (Clements, 2010a). He continued this messaging in the Fall 2011 State of the University Address, which acknowledged the $150^{\text {th }}$ anniversary of the Morrill Act, through a discussion of innovation.

Not since the era of the Morrill Act has the need for land-grant leadership been so urgent. Today, as we honor our heritage, WVU is ready to lead the country in redefining land-grant innovation in the $21^{\text {st }}$ century. So, how do we define innovation? Innovation starts with creativity, but it doesn't end there. Innovation results in finding practical solutions to the problems we are facing. It often starts as basic research and results in amazing discoveries. Throughout history, innovation has pushed the frontiers of knowledge, fueling economic development, curing diseases, protecting our environment, meeting our energy needs, and making a better future for our children. Innovation is research-research applied for the common good. Linking fundamental discovery to real-world advances is perhaps the strongest contribution of the land-grant institution to society. Because innovation is so important to the future of our state, we have placed a high priority on growing our research program.

These statements continue to demonstrate how Clements redefined the land-grant mission through discussions of innovative research and how research has the potential to contribute to economic development. His messaging, such as this example, bring together the motivation behind his emphasis on research goals in the earlier section on strategic planning and how they materialized through his discussions of mission.

Clements also pushed the idea of innovation as a way to reengage with the land-grant mission in his Fall 2012 State of the University Address. 
WVU'S LAND-GRANT MISSION

250

Land-grants and other major research universities have produced some of the greatest advances in society, including computing, the fundamentals of GPS, laser technology, the genomic revolution, and nearly all breakthroughs in modern medicine. And, it is land-grant and research universities across all 50 states that will again lead the next generation of innovation. (Clements, 2012)

Clements recognized the challenges land-grant universities continue to face with disinvestment from state governments and simultaneous public critiques of the value of higher education, similar to Duderstadt's $(2009,2012)$ observations described in Chapter 2. These include "keep[ing] tuition affordable, respond[ing] to demographic shifts and globalization, compet[ing] with universities from around the country and the world, and engag[ing] more thoughtfully with community" (Clements, 2012), all consistent with the goals his administration introduced in the 2020 strategic plan. Clements went on to say that WVU must "reimagine" its mission to respond to these challenges (Clements, 2012).

Clements also considered what higher education institutions, specifically land-grant universities, can do to improve the value proposition, especially for first-generation students, saying, "Everything we do at WVU has a common goal: making sure that the American dream is not just a dream but a reality within the grasp of every student who is willing to study and work hard" (Clements, 2012). He indicated that "promoting access for more first-generation college students will be one of the keys to increasing the country's overall educational attainment levels." He also celebrated that recruiting and enrolling first-generation students "is a strength at WVU" because "more than one in five, or 22\%, of [WVU] students are first-generation college students" (Clements, 2010a). Similar to predecessor Garrison's earlier advocacy for firstgeneration students, Clements demonstrated through this messaging the importance of access to 
WVU'S LAND-GRANT MISSION

251

higher education in the land-grant mission. This messaging is consistent with the way his administration operationalized this goal through its work on retention and student success initiatives, online learning, HSTA, and partnerships with the state's preK-12 and community and technical college systems, discussed above under the "Students" goal.

With continued questions of what the future of modern American higher education would look like, Clements shared his vision for why WVU will continue to compete in the increasingly competitive higher education marketplace.

We are one of only 11 schools in the country that are land-grant, doctoral research universities with a comprehensive health sciences. I have said on many occasions that WVU means more to West Virginia than any other university means to its state. I truly believe this is true! From the roughly $\$ 200$ million WVU receives from our state, we create more than $\$ 8$ billion in business volume for the state's economy. This is a 40 -to-1 return on the state's investment. (Clements, 2010a)

This statement showed his outlook on differentiating WVU as a leading land-grant university, similar to Gavazzi and Gee's (2018) calls for organizational heterogeneity in the higher education marketplace by land-grant university presidents.

Improving healthcare. Clements believed expanding WVU's healthcare system was one of the ways the University could continue to innovate in the changing higher education and reengage with its land-grant mission by expanding its contributions to West Virginia citizens, another example of how he intersected the programming and social base elements of organizational saga.

One of the ways WVU has been able to fulfill its land-grant mission is with its enormously successful health care enterprise. It has experienced unprecedented growth in size, 
WVU'S LAND-GRANT MISSION

252

complexity, and specialization. Our faculty, staff, and students have improved the quality of life for West Virginians in very tangible and measurable ways. From free community health clinics to a sophisticated nuclear medicine imaging device that can give a 3-D look at otherwise undetectable breast tumors. From the engineering and dentistry researchers who are working together to develop a better tool for the early detection of periodontal disease to a $\$ 9$ million expansion of the WVU Stroke Center. From the School of Medicine's $100 \%$ pass rate on medical exams to the creation of a groundbreaking and unprecedented partnership that could lead to a cure for Alzheimer's disease. (Clements, 2009b)

\section{Preparing Students for a $21^{\text {st }}$ Century Workforce}

Clements described a tenet of WVU's land-grant mission as preparing students for what life would be like after graduation, including how to compete in the workforce. This showed his commitment to the student subculture phase of fulfillment in organizational saga. He brought experience in this area from his role as provost of Towson University, an institution highly focused on workforce development for students.

We must prepare our students to succeed in a complex and competitive $21^{\text {st }}$ century worldwide workplace. We must create a rich fabric of diversity on our campus to ensure that the best mix of the best minds produces the best outcomes. We must provide lifechanging outreach for the people of West Virginia, through education, healthcare, and economic development ... This is our land-grant mission. The importance of a cohesive education system has never been more critical . . . Our University is more than an institution. Our University is the combination of all of us - and each person whose life we improve. (Clements, 2010b) 
WVU'S LAND-GRANT MISSION

253

He continued this messaging a year later in his Fall 2011 State of the University Address, saying, "One hundred and fifty years ago WVU helped students build practical skills that were needed at that time, mainly in farming and mechanics. Today, we are helping our students build the skills they need to succeed in the $21^{\text {st }}$ century and the skills our nation needs them to have" (Clements, 2011).

Like Hardesty, Clements also believed developing an attitude of service was one of WVU's responsibilities to students as they prepared for life after graduation, a reflection of his focus on the student subculture and social base phases of fulfillment in organizational saga. He shared in the Fall 2012 State of the University Address: "That's what being a Mountaineer is all about - community, outreach, service, and making a difference. Step by step, project by project, we are impacting the world. And, we do it best by preparing our students to be agents of change."

\section{Evolving as an 'Engaged' University}

During the sesquicentennial anniversary year of the Morrill Act, Clements centered many of his speeches around a theme of how WVU will continue to evolve as an engaged university in the next 150 years of the legislation, similar to calls for engaged universities seen in the literature (Kellogg Commission on the Future of State and Land-Grant Universities, 1999; Fitzgerald et al., 2012). He tied this statement in with former Interim President C. Peter Magrath's statement at WVU's celebration of the $150^{\text {th }}$ anniversary of the Morrill Act (Magrath, 2011): "Peter Magrath, who has spent his distinguished career as a champion of the land-grant system, returned to Morgantown recently to kick off our Morrill Act anniversary celebration. While he was on campus, he said: 'The $21^{\text {st }}$ century land-grant university must be, at its core, an engaged university,"” (Clements, 2011). 
WVU'S LAND-GRANT MISSION

254

In that same speech, Clements emphasized how innovative research intersects with engagement as part of the land-grant mission and why it was important to pursue the Carnegie Foundation's engagement classification. He said,

Those are just a few examples of the work that is emerging from our campus and changing lives. And they exemplify the importance and the promise of a land-grant university like WVU. In fact, we value outreach so much that we are among only $6 \%$ of institutions in the country who received the Carnegie Foundation's designation of being highly 'engaged' with the community ... Land-grant institutions are the source of a huge amount of our innovation and our economic power. By staying true to our land-grant roots and by becoming agile in a new era, WVU is enjoying unprecedented levels of success." (Clements, 2011)

In this speech, he also celebrated why WVU is an engaged university and shared several examples spanning economic investment, advances in technology, healthcare, and the work of WVU Extension.

Indeed, we are an engaged university. What we do goes well beyond our annual metric that shows for every dollar the state invests in WVU we put $\$ 40$ back into the economy-from helping local newspapers leap into the digital age to helping families access legal help they couldn't otherwise afford; from expanding ultra-high-speed computer networks to involving high school students in astronomy and the search for pulsars ... The clinical, educational, and research missions combine forces in the land-grant vision, and the impact is beyond calculation. (Clements, 2011)

These recommendations were similar to those made by Klein and Woodell (2015) in Chapter 2 and connect back to the original areas of strength and focus he introduced in his Fall 2009 State 
WVU'S LAND-GRANT MISSION

255

of the University Address and subsequent goals of the 2020 strategic plan. They also highlight how Clements' continued to reimagine the land-grant mission: "At a time when some land-grant universities have drifted away from the fundamental mandate to apply knowledge through service, we have embraced it" (Clements, 2011).

Clements continued his commemoration of WVU as an engaged university in his 2012 State of the University Address, celebrating the role of faculty in carrying out the land-grant mission, an example of the personnel phase of fulfillment in organizational saga.

Our students come here with big dreams, and your work is a pivotal part of their journey. Your work changes the world through the students whose lives you touch, and the lives they in turn touch. Your work is changing the world through the innovation that comes from your research and scholarship. It's changing the world through the service you offer to our citizens and the international exchanges you foster. That is what being a land-grant university is all about. (Clements, 2012)

These different examples and speech anecdotes demonstrate how Clements included all campus constituencies, from faculty and staff to students to alumni, in carrying out the land-grant mission and how they can contribute to it in their own manner. This messaging indicated that carrying out the land-grant mission was everyone's responsibility, in some way.

\section{Summary}

Over the course of his presidency, Clements provided a broad interpretation of the landgrant mission, one that was national and even global in scope with his emphasis on research innovation, economic development, and international partnerships. However, at times it came across as so broad that it was generic, safe, and not necessarily connecting with the state of West Virginia or even WVU at times. Similarly, while his approach to strategic planning was 
WVU'S LAND-GRANT MISSION

256

comprehensive and representative, which some key officials saw as a strategy for continuing to heal and unite the campus beyond the Bresch saga, it also resonated as impersonal and too unwieldy and complex with the campus community. What brought his leadership through the land-grant mission back into focus and reconnected with the state was receiving the Carnegie Engagement Classification, a reflection of how the University had worked to bring greater coordination to its service activities and better leverage its outreach capacity in the state.

Clements quickly reached the initiation stage of organizational saga, entering the presidency after climbing the traditional academic ladder and immediately reaching out to the campus community for input through the "Share Your Vision" feedback-gathering process. These efforts brought a further sense of stability as the first permanent president following a major controversy.

While WVU was his first presidency, there are many examples to reflect on across all phases of the fulfillment stage of organizational saga. In terms of personnel, the addition of 100 faculty lines (many focused on targeted research areas), new leadership positions (i.e. associate vice provost of engagement and outreach; vice president for diversity, equity, and inclusion; assistant vice president for scholarly and creative activity), expanded supervisor training, creation of Mountaineer Leadership Academy for current and aspiring leaders around the University, and added efficiencies in sponsored programs processes, including new digital records system all contributed to reaching that phase. The new 2020 strategic plan, with comprehensive goals encompassing the entire university, fulfilled the programming phase. Clements particularly showed a dedication to the social base phase, regularly giving State of the University addresses to the alumni and donor base in Washington, D.C. In 2012, he launched "A State of Minds: The Campaign for West Virginia University," a capital campaign that eventually 
WVU'S LAND-GRANT MISSION

257

included the largest gift to date in University (i.e. \$45 million from Ben and Jo Statler, renaming the Statler College of Engineering and Mineral Resources). In the student subculture phase, there were many different efforts focused on graduation and retention as well as the recruitment of graduate and international students. As a first-generation student himself, Clements was passionate about expanding access for students. Examples include a health and wellness plan featuring the launch of WELLWVU and construction of a new Health and Education Building as well as the opening of HomeStart Closet to provide international students with furniture and supplies to make their Morgantown apartments feel more like home and the establishment of the Division of Diversity, Equity, and Inclusion. The imagery phase was especially celebrated through athletics, as WVU departed from the Big East Conference and joined the Big 12 Conference during Clements' presidency. With many significant wins during this time (e.g. Big East Conference championship in men's basketball and Final Four appearance as well as football's Orange Bowl victory), Clements capitalized on that success by emphasizing athletics in his speeches. New construction on campus also represented this phase, including Honors Hall, WVU Nursery School, renovated Summit Hall dining facility, and renovated White Hall.

All of these examples demonstrate a fairly balanced approach from Clements to both operationalizing the land-grant mission through the work of the institution and the strategic plan. He was the young leader with the traditional faculty upbringing who still gave the fresh perspective the University needed following the degree scandal and a crumbled presidency under Garrison's leadership. Clements brought the familiar academic perspective faculty sought with a focus on research and other faculty issues while also introducing an innovative take on diversifying the student body and globalizing the University's mission, a strategy that had not yet been seen. His unassuming cheerleader persona, which worked to encourage alumni and bring in 
WVU'S LAND-GRANT MISSION

258

several major record-breaking gifts, refreshed engagement in those areas, but also resulted in a lack of substance or defined personality for the institution and its mission. In particular, he was critiqued for playing it too safe with his goals and messaging and that attempts to be as comprehensive and representative as possible in strategic planning resulted in a generic plan that could be applied to any other university at the time.

While many in the University community were disappointed to see Clements and his family depart for Clemson University in late 2013, the president who followed would certainly not receive the same critiques of being too generic or playing it safe. E. Gordon Gee returned to WVU for his second presidential administration in January 2014. 
WVU'S LAND-GRANT MISSION

259

Chapter 8: E. Gordon Gee's Administration 


\section{Figure 8.1 Gee Presidency Timeline}

\section{4}

- January: Presidency begins

- March: Named permanent president

- 55-county tour

- Bureaucracy Busters

- Campus Conversations

- "One WVU" processes

- Policies

- Course harmonization

- Branding and marketing

- Project 168

- Living-Learning Communities

- Monongalia County Ballpark

- Public-private residence halls

2015

- Carnegie Foundation Research 1 ranking

- New Welcome Week

- WVUMedicine

- Dream First campaign

\section{6}

- Three pillars announced

- LGBTQ+ Center opened

- WVU Innovation Corporation created

- Flood relief and recovery efforts in southern West Virginia

2017

- $150^{\text {th }}$ birthday celebration

- New mission statement

- Five values introduced

- West Virginia Forward initiative announced

- WVU Tech move to Beckley completed

2018

- Carnegie Foundation Research 1 ranking renewed

- Gee's work with the Blue Ribbon Commission begins

- Dependent student scholarship announced for employees

- Fraternity and Sorority Life plan announced 


\section{Figure 8.2 Gee's Organizational Saga}

\section{Stage 1: Initiation}

- Appointed initially as interim president

○ News release announcement indicated he would not be considered for the permanent position

- Hired permanently in March 2014, two months after interim administration began

\section{Stage 2: Fulfillment}

- President from January 2014-present

Personnel (Faculty and Staff)

- Distributed Rules of Engagement memo highlighting expectations for leadership team

$\circ$ Encouraged to pass on to their staff to disseminate the expectations

- Renamed and restructured Human Resources to Talent and Culture

- Created coin celebration as part of WVU's $150^{\text {th }}$ anniversary

- Acknowledged 150 individuals who represent WVU's five values

- Culture survey administered to understand challenges facing faculty and staff in terms of work culture and how it can be improved

- Hired new administrators: athletic director, provost, health sciences chancellor, vice president of the Division of Diversity, Equity and Inclusion, "dean of completion"

- Launched Campus Conversations to increase transparency and distribute information about University-wide pertinent issues while gaining input from faculty and staff

○ Recent topics: Tuition discounts for employees, culture surveys, West Virginia Forward, West Virginia State Legislature bills

Programming (Visible practices; mission, vision, and values)

- New mission statement as of spring 2017: As a land-grant institution, the faculty, staff and students at West Virginia University commit to creating a diverse and inclusive culture that advances education, healthcare, and prosperity for all by providing access and opportunity; by advancing high-impact research; and by leading transformation in West Virginia and the world through local, state, and global engagement.

- Introduced five values: service, responsibility, respect, accountability, appreciation

$\circ$ More internally focused; listed on Talent and Culture website

- West Virginia Forward, statewide collaboration with Marshall University and other partnerships to improve the state's economy

- Annual summer 55-county tour

- It's on Us campaign for sexual assault awareness and prevention on campus

- Moved WVU Tech's campus from Montgomery to Beckley

- Rebranded and expanded WVU Healthcare as WVUMedicine around the state and surrounding states

- 12 BIG! Days of Service

- Bureaucracy Busters 
Social Base (Alumni, donors, community)

- Response and aid following June 2016 floods in southern West Virginia

- Million Hour Match program: students challenged faculty, staff, community members/West Virginia residents, and government officials to match their goal of one million hours of service to the state

- Record giving - State of Minds campaign goal reached over a year in advance

- Launched WVU Connect, an internal social media platform

- Started Day of Giving

Student Subculture (Students)

- Abolished University College in favor of Center for Learning, Advising, and Student Success

- Project 168, a student transition and retention initiative

- Student organizations office reorganized

- Fraternity and sorority life plan implemented

Imagery (Symbols, traditions, culture, events)

- Reached Carnegie Foundation R1 designation, highest research ranking possible

- New facilities: Agricultural Sciences Building, Engineering Research Building, Evansdale Crossing, Evansdale Library renovations, Monongalia County Ballpark, residence halls, art museum

- Mountaineers Go First brand

○ Banners on buildings

- New national spots

- Expanded Welcome Week

- "Gee Mail" email series

- Year-long 150th birthday celebration

- Evansdale Crossing

- Physically connected Evansdale Campus

- WVU Day at the Legislature

- Not a new initiative under Gee, but revamped to be more focused on lifelong learning

- "One WVU” mantra

- More united approach to regional campuses

- Five values: service, curiosity, respect, accountability, appreciation 
WVU'S LAND-GRANT MISSION

263

Operationalizing the Land-Grant Mission: Strategic Planning and the Work of the

\section{Institution}

Following the departure of James Clements for Clemson University, announced in November 2013, E. Gordon Gee, who originally served as president of WVU from 1981 to 1985, was asked to serve as the interim president while the University searched for a permanent president. Gee was in the position for about two months when WVU's Board of Governors announced he would be the permanent president. According to the initial news release announcing Gee's placement in the permanent posting (West Virginia University University Relations, 2014), the Presidential Search Committee met in an emergency session on February 28, 2014 to ask the Board of Governors to endorse Gee as the permanent president. However, no other information was shared for the reasoning behind the decision, another example of a nonnormative hiring process in the cases examined in this study.

Gee came into the role with extensive presidential leadership experience. He often jokes publicly that he has been president at nearly all of the U.S.'s higher education institutions. After leading WVU, he was subsequently president at the University of Colorado, Brown University, Vanderbilt University, and Ohio State University (twice), totaling more than 30 years of presidential experience.

\section{'Reaching the State's Fullest Potential'}

Like most of the presidents in this study, Gee began his presidency at WVU with a form of information and input-gathering. Rather than surveys, meetings, panels, or focus groups, though, he looked outward for this input — to the citizens of West Virginia. In 2014, he embarked on a tour of all 55 counties in the state, visiting communities to hear from citizens about their needs and the issues facing their daily lives as well as from prospective students and their 
WVU'S LAND-GRANT MISSION

264

families. For example, he traveled with the Pride of West Virginia: The Mountaineer Marching Band to McDowell Country for a performance at a high school football game. He reflected on this leg of the tour in his 2014 State of the University Address, discussing why having a statewide presence is vital to carrying out the land-grant mission, a commitment to the social base component of fulfillment in organizational saga.

That moment — sitting in the stands - felt like the true culmination of our 55-county tour. And what made that trip even more special was that it had been 26 years since the band played in that county. Twenty-six years. Can you imagine that? Someone was keeping count. But what they need to be counting on is our presence. We need to be present in the communities and the farms and at the gas wells. Present in our attendance. Present in our listening. And present in our actions when responding to their needs. We can never, ever allow another 26 years to pass by again. And it is not big gestures, like bringing in the band, that matter the most. It is the chat over a Diet Dr. Pepper at the local café. It is making a phone call to freshmen parents to assure them their student is doing fine. It is stopping by to see a colleague at another institution. It is being present. It is all of us being present. Let me be clear: The 55-county tour is not a one-time effort. I plan to tour the state again next summer, and the next, and the next. I want to visit with people again - to look into their eyes, to shake their hand, to wrap my arms around them. I want to share with them the soul of our University. I want to explore their needs and create partnerships that embolden them. I want to know West Virginia University is doing all it can to raise this state to its fullest potential. (Gee, 2014b)

These comments highlight Gee's initial leadership from the symbolic framework (Manning, 2013; Bolman \& Deal, 2013; Meyer \& Rowan, 1977) because he regularly used elements of that 
WVU'S LAND-GRANT MISSION

265

framework, symbolism and theatre, to inspire constituents and confirm WVU's commitment to their well-being. From the beginning of his presidency, Gee's messaging was directed outward to the entire state, not just to the internal University community of faculty, staff, and students. This was a change from his predecessors, who were all immediately focused, at least early on in their administrations, inwardly at the beginning of their presidencies, whether it was on students (i.e. Hardesty), faculty and staff (i.e. Garrison and Magrath), or a combination of the two populations (i.e. Clements). As a result, this outward focus on the state exemplified a shift toward early commitment to and prioritization of the social base and imagery components of organizational saga by Gee.

That idea of helping the state reaching its fullest potential carried throughout the 2014 State of the University Address. Gee noted several steps for the University to take to reach this goal, looking inward to the composition of the University to see how changes on campus could influence the institution's external work: (1) Eliminate bureaucracy; (2) Put students first; (3) Build partnerships to overcome challenges of decreasing state and federal appropriations; (4) Invest in faculty and staff; and (5) Create a Center for Big Ideas. These steps represented an intersection of the programming, student subculture, personnel, and social base phases of fulfillment in organizational saga because they focused on using operational efficiencies, student, faculty, and staff issues as well as building relationships with government officials to make an impact on the state's citizens.

Eliminate bureaucracy. The idea of eliminating bureaucracy stemmed from the motivation to create a unified campus culture, termed "One WVU." This idea was not just posed for all the units on the Morgantown campuses, such as the academic colleges and schools, the administrative units, WVU Research Corporation, WVU Extension Service, WVU Health 
WVU'S LAND-GRANT MISSION

266

Sciences Center, WVU Foundation, etc., but also the regional campuses, Potomac State College and WVU Institute of Technology. Gee called for a willingness to "break the rules" (Gee, 2014b) and work together to make processes like travel, hiring, purchasing, and research more efficient across every aspect of the University, which highlighted his transformational, symbolic, and structural leadership styles (Manning, 2013; Bolman \& Deal, 2013). To do so, he initiated an effort called "Bureaucracy Busters" for faculty, staff, and students to provide feedback and ideas on overcoming the institution's efficiency challenges and made the communication of their activities transparent through the addition of Campus Conversations, or town hall-style panels open to all faculty and staff. The processing improvements and efficiencies are tactics seen now across all five the administrations studied here, which shows the pressure of exogenous changes in technology and business practices continued to influence the day-to-day work of the institution. All of these efforts reflected Gee's commitment to the personnel, programming, and imagery components of fulfillment in organizational saga because they used new initiatives on campus, particularly those involving University employees, to begin to shape the internal culture and external perception of the University.

Some key officials in this study reflected on Gee's initial quest for WVU to become "one WVU," with a mix of praise and concern. As Edith, a faculty member, shared, "I admire [Gee] trying to do this 'one WVU.' And I think if I were going to point to a signature thing about his [presidency], it's that." She noted that Gee "also has some very interesting ideas about how to face budget crises by privatizing some things and creating other efficiencies." While she said she does not always agree with his responses to perceived University issues, she thinks "he's got a really innovative approach to thinking about those puzzles." 
WVU'S LAND-GRANT MISSION

267

Danny, a key official in the WVU Health Sciences Center, shared that he has seen the campus be more connected under Gee's leadership than ever before: "At least from what I understand about the place before [Gee] was that we were much less integrated from the Health Sciences [Center] and the bigger University. And, our vision was more Morgantown and WVU as opposed to the state of West Virginia and the land-grant university." As the Morgantown campus became more united and connected, Gee then called on the regional campuses across the state to do the same with each other and the Morgantown campus by collaborating and partnering in areas such as policies, course harmonization, marketing, and recruitment strategy.

Samantha, an academic leader, described the "one WVU" vision as a powerful strategy on the part of Gee and his administration. She said,

[Gee] calls [the regional campuses] our front door to the rest of the state. I think that's very powerful. Rather than just consolidating all of this knowledge and expertise and energy and wisdom in Morgantown, the idea that we can push this out to other areas and state is actually very powerful, and it's a way of extending the land-grant mission throughout the state.

She understood the land-grant mission in terms of serving the state through multiple avenues, including education and postsecondary access close to home, accomplished through the regional campuses, which allow West Virginians to "get a degree, and ... stay in your community ... and be someone who contributes over the long term to the goals of your community." To Samantha, the power of the regional campuses could not be overstated in creating local change agents across the state. "I think that's a powerful identity that we can drive through the land-grant mission, and I actually feel like that's part of what speaks to [Generation] Z, whether it's 
WVU'S LAND-GRANT MISSION

268

returning to your own community or going to another community, but this is a place where you can come and be a change agent.”

In the Fall 2016 State of the University Address, Gee provided an update on the work of the Bureaucracy Busters initiative. Some of the efforts included eliminating the need to encumber requisitions in excess of $\$ 25,000$ in the state accounting system, consolidating five separate business offices into one serving five units, reducing a 14-page job description form, down to two, and implementing a new, electronic hiring process called WVU Hire. These changes reflect the programming phase of fulfillment in organizational saga because of their emphasis on operational efficiencies.

Put students first. Next in his 2014 State of the University Address, Gee announced a focus on both recruitment and retention, demonstrating a commitment to the student subculture phase of fulfillment in organizational saga and prioritization of students similar to that of Hardesty's at the beginning of his presidency. Gee called for an increase in the enrollment of the freshman class from 5,000 students to 5,500 students as well as increased participation in transition and retention activities like Adventure WV and Living-Learning Communities in the residence halls. Project 168 was introduced, an initiative to help students make the most of their time at WVU by finding balance between "working smart" and "playing smart" to have a wellrounded experience. He also announced efforts to simplify the general education curriculum requirements and financial aid resources, continuing his leadership from the structural framework (Manning, 2013; Bolman \& Deal, 2013).

In his Fall 2015 State of the University Address, Gee (2015) followed up on his initial goal of "putting students first” with plans to revamp Welcome Week, not unlike Hardesty’s relaunch of New Student Convocation in 1995. This week-long event included an addition of 
WVU'S LAND-GRANT MISSION

269

service projects and a revamping of the formal New Student Convocation launched in Hardesty's presidency to Saturday Night Lights, an event at Milan Puskar Stadium to introduce students first-hand to favorite campus traditions, including cheers for athletic events, the marching band, singing Country Roads ${ }^{4}$, etc. The Welcome Week schedule was also changed so that the highly anticipated FallFest concert did not interfere with the first week of classes, a common complaint from students and faculty alike. These events, by nature, were intentionally designed to be elaborate, extravagant, and over-the-top to make a memorable first impression on new students in terms of what they could expect from their WVU experience in the future. This celebratory, theatric style reflects Gee's decision-making from the symbolic frame (Manning, 2013; Bolman \& Deal, 2013; Meyer \& Rowan, 1977) and how he incorporated traditions and celebrations into his leadership.

Other initiatives announced in the Fall 2015 State of the University Address included the WVU Foundation's Dream First campaign, which raised over $\$ 50$ million for scholarships, and the hiring of a "dean of completion" to examine the University's retention efforts. The position itself reflects the symbolic frame (Manning, 2013; Bolman \& Deal, 2013; Meyer \& Rowan, 1977) in that it implies a campus-wide focus on retention and persistence, which was strategic in a time period in which greater attention has been placed on student debt. Similarly, the fundraising tactic also reflected Gee's leadership from the symbolic frame (Manning, 2013; Bolman \& Deal, 2013; Meyer \& Rowan, 1977) in how the effort was named, which represented how he viewed scholarships as fostering opportunities for more students to attend college while simultaneously supporting the increased enrollment goals mentioned earlier in the chapter.

\footnotetext{
${ }^{4}$ John Denver's Country Roads, one of West Virginia's state songs, is sung by WVU fans after every home sporting event. It is a favorite tradition among students and fans alike and singing it for the first time is deemed a rite of passage by many WVU students.
} 
WVU'S LAND-GRANT MISSION

270

Mary, another academic leader, shared a perspective on the role of the new dean of completion, welcome activities, and Gee's other student-focused initiatives. She observed that Gee "quickly shifted" his focus to student success and retention efforts, which she described as his administration's attempts to play "catch-up" following previous administrations, causing his leadership to move at "lightning speed" to implement needed retention initiatives that WVU needed to catch up on in contrast to peer institutions. She indicated this response occurred because WVU was "just plain behind on some of those programs and services that universities across the country had been offering for years if not more than a decade." This critique was unexpected because so much emphasis had been placed on student success initiatives in both Hardesty and Clements' administrations, which implies how exogenous factors in higher education broadly continued to influence the administration's priorities.

\section{Build partnerships to overcome challenges of decreasing state and federal}

appropriations. In a time of declining state investment in higher education, Gee proposed a goal of finding new ways to identify revenue in his 2014 State of the University Address. One of those was public-private partnerships, a strategy for addressing facilities needs on campus, including residence halls. A new baseball stadium, in partnership with Monongalia County ${ }^{5}$, was also built during this time. It is a shared facility between WVU's baseball team and Single A short-season Minor League Baseball team, the West Virginia Black Bears. These partnerships demonstrated work toward the programming, imagery, and social base components of fulfillment in organizational saga because they created new activities for the campus, including ones that can engage the community, and represented growth on the campus as new physical spaces were developed to meet the needs of an increasing population.

\footnotetext{
${ }^{5}$ Monongalia County is home to Morgantown, West Virginia, where the main WVU campus is also located.
} 
WVU'S LAND-GRANT MISSION

271

In his 2015 State of the University Address, Gee followed up on this goal by discussing the role partnership and collaboration plays in conducting research that makes a difference in the lives of others and improves the state's economic outlook. This messaging parallels recommendations from both the engagement literature discussed in Chapter 2 (Gavazzi, 2015; Brackmann, 2015; Reilly, 2013) as well as the Association for Public and Land-Grant University's economic development model (Klein \& Woodell, 2015). Some examples Gee shared included launching the Marcellus Shale Energy and Environmental Laboratory in partnership with Northeast Natural Energy, the National Energy Technology Laboratory, and Ohio State University; enhancing the West Virginia and Regional History Center to preserve the state's heritage with collaborative initiatives based on collections from Pearl S. Buck, Nick Rahall, and Jay Rockefeller; establishing a Humanities Center to position WVU as a leading voice on the value and necessity of humanities education; and reorganizing WVU Healthcare and the WVU Health Sciences Center into one unified entity, "WVUMedicine."

Danny described why this unification across WVU's healthcare system has been valuable for both the University and the state, including opportunities for economic investment and expansion of healthcare opportunities across the state. He shared that $\$ 1.5$ billion has already been invested in the state's economy between the hospital system and the University, and that they plan to invest another $\$ 1.5$ billion in the future. "We have invested a tremendous amount of money, but this is money that doesn't just get invested and didn't do anything, but actually regenerates more revenue so that we can reinvest and build even more and build better programs, more access points, etc." Danny also explained that as part of Gee's administration WVUMedicine has hired about 400 faculty, making it a "critical part of the University" and "the biggest part of the University." He noted that the health system and WVU Health Sciences 
WVU'S LAND-GRANT MISSION

272

Center combined are nearly $\$ 3$ billion per year operation. When combined with WVU, that total grows to $\$ 4$ billion, which is comparable to the West Virginia state government's overarching budget size. These comments demonstrate the role WVUMedicine's reorganization has played and continues to play in the programming, social base, and imagery components of organizational saga, from adapting healthcare delivery methods to best fit those most needed by citizens to expanding access to healthcare with a greater geographic presence across the state.

At the Spring 2018 State of the University Address, Gee further emphasized the importance of partnerships, especially in the current budget climate facing continued decreasing appropriations. This messaging is similar to the recommendations shared by Duderstadt (2009, 2012) for responding to challenges with disinvestment from state governments and simultaneous public critiques of the value of higher education, as discussed in Chapter 2. Gee shared that the University was making progress on moving the WVU Institute of Technology from Montgomery, West Virginia, to Beckley, West Virginia, and that the transition was "continuing to grow WVU Beckley to increase higher education access in southern West Virginia where employers have 20,000 jobs they cannot fill due to lack of qualified applicants" (Gee, 2018a). At both WVU Beckley and WVU Keyser, the University is in the process of establishing two-, three-, and four-year programs that are pathways to graduate programs in healthcare, engineering, and other fields.

Beyond the work of the regional campuses, Gee noted that WVU received the Heiskell Award for innovation in international partnerships with a strategic partner in the Middle East, the Royal University for Women in Bahrain. He announced a collaboration with China Energy that is expected to bring more than $\$ 83$ billion to West Virginia and make investments in the state and region's petrochemical industry. Finally, he recognized the naming of four IDEA Fellows, 
WVU'S LAND-GRANT MISSION

273

faculty members who have received extensive training to develop and teach courses with an entrepreneurial theme. These partnerships are example of the Association for Public and LandGrant Universities model (Klein \& Woodell, 2015) for engaged economic development, discussed in Chapter 2, because they connect University initiatives with resources available in the places where they are situated and they focus on talent development already in those places.

Invest in faculty and staff. Under this goal, which reflects the personnel component of fulfillment in organizational saga, Gee expressed a need to improve compensation to faculty and staff to acknowledge their value and demonstrate appreciation for their contributions to the University in the 2014 State of the University Address. However, no specific initiatives were announced at that time, which held up and hindered any potential progress toward that component of organizational saga. He also stressed the importance of encouraging collaboration, risk-taking, and creative thinking in how faculty and staff approach their work as well as to consider the big picture role they play in carrying out the land-grant mission. It was not until the Fall 2018 State of the University Address that Gee announced plans to make the faculty and staff salary structure more competitive and plans for a dependent student scholarship program.

Create a Center for Big Ideas. Finally, in the 2014 State of the University Address, Gee announced a new Center for Big Ideas, an effort to bring together faculty, staff, and students from across the University to tackle major issues facing the state and nation, such as energy, rural health, STEM education, and arts and culture while repositioning WVU as a national thought leader. This goal encompassed several elements of the fulfillment phase of organizational saga, including personnel, programming, student subculture, and social base. Some efforts from this strategy included establishing the Rockefeller School of Politics and Policy, bringing together the disciplines of political science, international studies, public 
WVU'S LAND-GRANT MISSION

274

administration, and leadership studies under one umbrella, and creating a Business Engagement Center for corporations to collaborate on research, professional development, patenting, and other activities. However, the Center has not been mentioned regularly since early in Gee's administration, and a website for the Center could not be located at the time of this writing, another initiative that has worked against the possibility of reaching the fulfillment stage in organizational saga due to the absence of progress or follow-up.

\section{The End of an Era}

While the 2020 Strategic Plan for the Future is still technically active at the time of this writing, it has been deemed all but defunct in the way the administration has interacted with it (i.e. taking down the website, not referencing the plan in official documents and speeches, etc.) This has also been confirmed by several key officials interviewed who shared the sentiment and has the potential to halt progress toward reaching the fulfillment stage in organizational saga.

Edith attributed some of the movement away from the 2020 strategic plan to the large size of the planning group as well as Gee's disdain for strategic planning processes and documents. She recounted that the strategic planning council under Clements had reached about 80 people in size, “and at a certain point that's too big a group. You don't get anything done out of that. It's just people meeting just for the sake of meeting, in my opinion." Beyond the issue of size, she noted a more impactful impediment to the completion of the plan: Gee's aversion to strategic planning. "I remember one of the meetings of that group when [Gee] was new, he said, 'I don't believe in strategic plans.' Like, okay, then. That's an interesting opening statement to make the first time you meet with a strategic implementation group." However, she explained, this did not mean Gee was without vision. "He said you know you just need to have a clear vision and keep steering towards it ... [Gee] is sort of the master of the ship." She compared his 
WVU'S LAND-GRANT MISSION

275

approach to planning to previous presidents: "I think there's even, maybe less involvement than under Clements across the University. Under Clements there was sort of a token of that enormous committee. Under Gee, I suppose it's more like it was under Hardesty. It's a smaller group but they seemed to be mainly upper administrators."

Edith's anecdote highlights a shift in approach to strategic planning across the administrations studied here. She has observed that Gee's leadership team has returned to a smaller, more exclusive, and less transparent approach to advising the president, similar to Hardesty's “kitchen cabinet," in contrast to Clements' large strategic planning group that published updates and progress reports on a public website.

Mary observed that Gee's administration "immediately" moved away from the 2020 plan and its priorities. She said, "That was a quick change for people because there had been targeted hires and pools of money for start-ups and interdisciplinary funds . . . And then that shifted."

These two anecdotes from Edith and Mary demonstrate another shift in strategic planning at the University. For Gee's administration, a plan has not taken the form of a traditional, stepby-step structure with tangible goals created out of the brainstorming, feedback-gathering, and collaboration from others across the University. Instead, while the 2020 plan has still been technically "active," the vision has organically evolved from the president himself. This style has been an abrupt shift for the campus, especially because changes in the previous research and hiring priorities presented in the 2020 plan were not concluded, addressed, or updated in a tangible way following the transition between the Clements and Gee administrations. This lack of communication or official conclusion about the 2020 strategic plan has the potential to hinder progress toward the fulfillment stage of organizational saga if not addressed or resolved. 
WVU'S LAND-GRANT MISSION

276

However, there have been some hints of planning occurring based on anecdotes from the participants in this study. Linda, a key official in the provost's office, described preliminary discussions she had been a part of about a new strategic plan. "There was a perfectly viable strategic plan in place. There was no reason to up-end that ... And then as the 2020 plan closes out we have been talking about developing a new strategic plan." However, she contended, that process has only involved "some preliminary discussions about what that's going to look like" which she notes is not "anything like the 2020 strategic plan process." She explained that Gee and his leadership had determined a smaller group was needed for developing the next plan, but the process stopped at the early discussion phase. "Right now, we don't have time for that." Similarly, Jameson noted the sunsetting of the 2020 plan, and pointed to the provost's office as possibly spearheading next efforts.

While no formal planning process has been announced University-wide at the time of this writing, the comments shared by the key officials in this study reflect that whatever the next plan will look like has been the responsibility of Provost Joyce McConnell, making Gee very handsoff in the process, a marked change from previous presidents' approaches to strategic planning. The closest comparison was Clements' administration, where the 2020 strategic plan was chaired by Provost Michele Wheatly and Faculty Senate Chair Nigel Clark. However, Clements was very much involved in and a driver of the process as a whole, stemming from his leadership in strategic planning as provost at Towson University, his previous institution.

Receiving the Research 1 classification in 2015, the pinnacle of the 2020 plan, may have also contributed to the movement away from the 2020 plan. Nicole, a staffer in the president's office, recounted the moment when the University received the designation: 
WVU'S LAND-GRANT MISSION

277

I remember that [Gee] gave a speech, we celebrated it, we set our mind to it, [thanked Clements] and all the people who were involved, we achieved it, and then we can almost sort of rest the 2020 plan a little early. That doesn't mean we still don't pursue those goals, but boy, we did it even faster than we thought. And now, let's turn our attention to all of the other things we need to do.

This movement away from the 2020 strategic plan demonstrates a change in the programming phase of fulfillment in organizational saga and a possible hindrance because the transition has not been actively discussed in a public forum. By not formally concluding the 2020 strategic plan from the Clements' administration or introducing a new plan under Gee's administration, there has not been a clear starting and stopping point in the planning process. It is not evident to the campus community what goals are still in place, which is a direct impediment to the development of the fulfillment stage organizational saga.

\section{The Three Pillars}

In the 2016 State of the University Address (Gee, 2016b), the same speech where the Research 1 achievement was celebrated, Gee introduced three new areas of focus for the University. He coined the foci the University's three pillars: education, health and well-being, and prosperity. He intended for these pillars to guide the work of the institution with a goal of improving West Virginia's outlook for the future, becoming the closest iteration of strategic planning pursued by his administration to date.

Education. The first major initiative under the education pillar was moving WVU Institute of Technology's campus from Montgomery, West Virginia, to Beckley, West Virginia, an opportunity to expand the University's access mission in a growing region of the state. The move was met with an outcry from the campus community and citizens in the town of 
WVU'S LAND-GRANT MISSION

278

Montgomery because of the potential for job loss and the long history of the institution in the community, a move that worked against the imagery component of organizational saga. Sidney, an academic leader, reflected, "That was a bold effort on (Gee's) part to finally ... decide it really should be in Beckley ... The regional campuses are very, very grassroots . . if we can provide people with a really solid rudimentary education, perhaps they will become leaders in their community." Despite the ongoing attempts to fully integrate WVU Tech and Potomac State College into WVU's strategic plan, concerns remain that they are still seen as an afterthought.

Eddie, who was previously a staffer at WVU Tech, highlighted some of those concerns. He said that while the land-grant mission and educating students are consistent areas of focus across all the WVU campuses, there should be more differentiation in how those goals are reached to better serve the students enrolled at the communities surrounding each campus. She indicated that it has been "difficult for [the Morgantown campus] to understand" the need for that differentiation because the leaders there are in "their own world." This lack of differentiation is a stark contrast to the push for differentiation that Gee calls for in his 2018 book with Stephen Gavazzi, Land-Grant Universities for the Future: Higher Education for the Public Good, a series of recommendations for land-grant leaders. The discrepancy also shows that despite the 'one WVU' goals introduced early in Gee's presidency, there is still tension among the regional campuses, especially in how each campus should approach contributing to the goals for the entire WVU system. This tension marks a hindrance to the social base component of organizational saga because of the impact it could have on those regional campus partnerships as well as with the communities where they are located. 
WVU'S LAND-GRANT MISSION

279

While the move of WVU Tech's campus was a major undertaking, several other education initiatives were established or expanded as of the 2015 State of the University Address, many of which were focused on STEM education. These included partnerships with pre-K programs, including expanding WVU Extension Service's Energy Express program for literacy and a code camp in 4-H; increasing training opportunities for prospective STEM teachers through the WVUteach program; creating an alliance with 100kin10 to double the number of math and science teachers; adding new STEM courses in the high school ACCESS program, a targeted initiative for increasing access to higher education around the state; and assessing Project 168 and other retention strategies (e.g. Living-Learning Communities, Resident Faculty Leader programs, etc.) to ensure they are meeting the needs of Generation Z, the generation encompassing new first-time freshmen. Many of these initiatives, especially the preK12 initiatives, teacher training, and community partnerships, were continuations of or similar to tactics pursued under the "Education" goal in the 2020 plan under Clements. They represented an intersection of the programming, student subculture, and social base components of organizational saga because they used new activities and curriculum based in various regions of the state to add to and/or improve educational opportunities for current and prospective students. Simultaneously, these efforts also contributed to the imagery component of organizational saga because the work in communities around the state elevated WVU's reputation for those beyond the campus.

Other education efforts during this time focused on lifelong learning efforts, a follow-up to the work of the lifelong learning roundtable from the 2020 strategic plan. Some examples included encouraging literacy through Extension's Energy Express program, improving broadband and other technology infrastructure and resources in rural West Virginia, increasing 
WVU'S LAND-GRANT MISSION

280

participation in the high school ACCESS program, where students can earn college credits before graduating from high school, and continuing to offer MOOCs. These efforts represent both the student subculture and social base components of fulfillment in organizational saga because they bring community members and organizations into the campus realm to offer educational programming for current and prospective students, an element of the access mission of land-grant universities and an example of a community engagement strategy, as discussed in Chapter 2 (Reilly, 2003; Peters, 1998).

The University continued to expand Project 168, including initiatives relating to enrollment, retention, and academic quality. As of the Fall 2016 State of the University Address (Gee, 2016d), the largest and most diverse class had enrolled, totaling more than 6,000 students. The work in Project 168 continued to streamline advising, implemented an early alert system for advisors to reach out to struggling students, and added more tutoring centers. The Alumni Association launched Old and Blue Crew, a student alumni association featuring professional development and mentorship from alumni. A LGBTQ+ Center was also established to support students, faculty, and staff from those populations and connect them with other service around campus. The efforts under the "Education" pillar reflect contributions toward the programming, student subculture, and social base elements of organizational saga as it included innovative approaches to academic advising, curricular changes, and events for current students as well as mentorship with alumni. In the case of the WVU Tech move, the imagery component of fulfillment in organizational saga was an additional element while social base was excluded because the move was a shift in a campus's physical location that had been in place for nearly a century and was an upheaval of a community economic and social well-being as many citizens were forced to move or travel great distances to keep their jobs. 
WVU'S LAND-GRANT MISSION

281

Health and well-being. Under the umbrella of the three pillars, WVUMedicine refocused its efforts on immediate health issues affecting West Virginians. In two of those areas, prescription medicine abuse and heroin addiction, WVUMedicine expanded its efforts in training law enforcement officers to carry and administer Naloxone, a medicine that can reverse the effects of overdose; developed pain management guidelines for the state of West Virginia and conducting medication reviews with patients and prescribers through the School of Pharmacy's Opioid Medication Therapy Management Program; offered a Comprehensive Opioid Addiction and Treatment Program through the Department of Behavioral Medicine, whose leaders are working with the WVU Injury Control Research Center and multidisciplinary experts to predict who is at risk for addiction; and provided more than 6,000 patient visits in rural areas confidential addiction treatment close to home through the telepsychiatry program. The College of Education and Human Services began an addiction studies minor during this time, and WVUMedicine opened new Heart and Vascular Institute with new technologies for heart procedures.

Danny reflected on how WVUMedicine has re-envisioned health and healthcare in the state while also reinvesting in the state since the three pillars were established. He shared that WVUMedicine has changed the way it approaches research and education by not only offering but specializing in healthcare services most needed by West Virginians "so people wouldn't have to leave the state." He indicated that "these are also specialty areas that create the most reimbursement back per patient. And so, that way, we could actually start to reinvest the resources that we're generating in buildings and programs and people." Danny describes this shift as a movement away from decisions based on "quantity and transaction" in favor of 
WVU'S LAND-GRANT MISSION

282

"quality and impact," an example of transformational leadership (Stone, Russell, \& Patterson, 2004). He said,

We really wanted to refocus our research not just on how many grants do we get or how many papers do we publish, but how do we solve important problems and work for real solutions ... And then for education, we really want to start to inspire creativity and inspire people to learn as opposed to regurgitating facts that we are driving into people's brains. As announced in the Spring 2016 State of the University Address (Gee, 2016c), WVUMedicine launched additional efforts through the health and well-being pillar. In partnership with the Blanchette Rockefeller Neurosciences Institute, it consolidated all neuroscience research and education, and, in 2018, began an innovative clinical trial for Alzheimer's research. A biochemistry professor began a study on insulin resistance in diabetes patients. An Autism Services Delivery Clinic was opened to serve West Virginia Children with autism, and a Good Measures program was created to support healthy eating and exercise habits around the state. All of these efforts to date culminated in a national study of major academic medical centers and community hospitals ranking WVUMedicine-West Virginia University Hospitals as the sixth top academic medical center in the U.S. William, a faculty member and former administrator, reflected: "The Health [Sciences] Center believes it can influence the opioid issues, the health areas where we falter and have had trouble grasping as well as to make available throughout the state first-class healthcare. It's not a place where we offer second class, you go elsewhere for your first-class care."

The health and well-being pillar exemplifies work toward the programming and social base components of the fulfillment stage in organizational saga because of the intersection of new healthcare resources specifically aimed at responding to the health needs of the state's 
WVU'S LAND-GRANT MISSION

283

citizens. This strategy is comparable to the community engagement style Gavazzi (2015) calls for between land-grant universities and their communities, as discussed in Chapter 2. The new ranking also contributes to the imagery component of organizational saga because it contributed to how the University's reputation is perceived on a national scale.

Prosperity. One of the first efforts under the prosperity pillar, WVU established the WVU Innovation Corporation, a new tool to increase the amount of contract-based testing and evaluation performed for industry and government agencies, with a special focus on increasing funding from the Department of Defense. WVU also partnered with Gallup, which is interested in working with a few universities on projects impacting the future to reinvent their states. WVU is studying how to restructure the state government to make it effective, efficient, and forwardthinking in response to its current budget climate. Vincent, an academic leader, described how these efforts toward economic development have changed since Gee's presidency began.

We go in and we help with small business with a launch lab that we're trying to help lift people. We're trying to help you actually start businesses, be businesses, and we help with training with executive leadership. And we do a lot more of those kind of things ... I'm working on some things now with shale gas, and different things like that are trying to help with the value-added things, how we get those building.

Additional efforts under the prosperity pillar were announced in the 2016 State of the University Address. New entrepreneurship and economic development initiatives included a new Women's Business Center, funded by the U.S. Small Business Administration; a new Health Sciences Innovation Center, a home for biomedical startup companies; and partnerships with Boeing, the U.S. Army Special Forces, and Pierpont Community and Technical College to build a workforce with in-demand skills. New majors and certificate programs were established to 
WVU'S LAND-GRANT MISSION

284

prepare students for growing career fields: music industry, entrepreneurship, data marketing communications, craft beer tourism, organizational leadership (in partnership with the Boy Scouts of America), and, at WVU Tech, adventure recreation management. As of the Spring 2018 State of the University Address, WVU had also received a \$1 million National Science Foundation grant to develop a next-generation High Performance Computing cluster in the state featuring cybersecurity, cloud services, and a data center. Vincent reflected on these efforts: "Now, we're more active in trying to be part of not the passive part of the economy but trying to be inspirational helpful technical assistance, advice, all that kind of stuff. So, we do a whole lot more of that, and I think we're allowed to do a whole lot more."

In response to the summer 2016 floods spanning many areas in southern West Virginia, the University launched a recovery effort led by the Center for Service and Learning and Student Government Association with support from a \$500,000 gift from alumnus Ken Kendrick. Examples of the efforts included Davis College of Agriculture, Natural Resources, and Design representatives clearing falling trees; WVUMedicine employees administering first aid, vaccines, and other healthcare needs; the football team donating uniforms; Reed College of Media class projects led fundraising campaigns; The Pride of West Virginia: The Mountaineer Marching Band performed at the West Virginia State Fair; and a student recorded a song on Mon Hills Records, WVU's label, with profits going to the recovery efforts.

Many of the examples in the prosperity pillar align with the recommendations shared in the economic development and engagement literature in Chapter 2 (Klein \& Woodell, 2015; Fitzgerald et al., 2012), which calls for intersecting innovative ideas with talented human resources local to campuses. The activities in the prosperity pillar also are examples of contributions toward the social base and programming components of the fulfillment stage in 
WVU'S LAND-GRANT MISSION

285

organizational saga because the University is bringing new activities directly relating to community needs (i.e. economic development) into those communities.

WVU Extension Service and the three pillars. Leaders in WVU Extension Service view the three pillars as an opportunity to reinvent Extension's role in carrying out the land-grant mission as well. With education already a strength through 4-H and other initiatives, WVU Extension is creating additional programming motivated by economic development opportunities, an intersection of the programming and social base components of fulfillment in organizational saga. Jackson, a staffer in the WVU Extension Service, explained,

[The three pillars are] about everything we do. The Extension Service is probably the most selfless institution you will find in the country. Everything we do is to make somebody's life better, happier, healthier, and more prosperous. There's nothing selfish about us. You know we don't get money for a lot of things we do. We don't get a lot of accolades. In all of those, we're working very hard to enhance the education of our state because we are dead last in bachelor's degrees.

To respond to this educational disparity, Jackson described initiatives the Extension Service has been implementing through the three pillars, including K-12 partnerships to encourage students to receive early college credit and programming focusing on STEM skills. He continued, "We're trying to do more to prepare kids for college. All of our STEM programming sparks interest in a lot of studies for kids. A lot of what we do in $4-\mathrm{H}$ is education and personal development to prepare them. We really intimately understand the need for education in this state."

One area the Extension Service hopes to expand through the three pillars is identifying ways to support health and well-being initiatives. Jackson elaborated on some examples and why this pillar is difficult for the Extension Service to reach, including assessing the effectiveness of 
WVU'S LAND-GRANT MISSION

286

programming due to the extreme health problems faced by West Virginians, including obesity, diabetes, heart disease, and hypertension.

We do [programming for] all of this. But how to suggest that we are making a difference is very difficult. And so far, we're not. That's what causes me some concern. So right now, I have the people saying, 'Well, are you going to hire or rehire that families and health agent?' And I'm like, 'Not until we figure this out.' It's really tough. How can you do it? We have an obesity specialist, but how can she do any programming that's going to make a difference in the obesity rate in West Virginia? One person vs. 1.8 million. Probably not a really good strategy there. And it's very difficult. You can't change somebody from being obese just by talking to them. It's very difficult. They have to want to change, and you can help with some support programming, some understanding. But just saying to a morbidly obese person that you are going to die early doesn't seem to be the trick.

Gee discussed how WVU Extension Service's mission has evolved as part of the overarching land-grant mission in an op-ed for the Charleston Gazette-Mail and his Fall 2014 State of the University Address. He shared that the Extension Service has been "keeping pace with change" and "finding new ways to serve citizens" over the course of its 100-year history, which reflects how Extension continues to be a catalyst in WVU's evolving land-grant saga. He described Extension faculty's responsibility as “carry[ing] our gold and blue banner in every corner" of the state and "carry[ing] WVU's ideas into communities and turn[ing] them into big improvements" (Gee, 2014b). Gee shared that, through the work of WVU Extension, WVU is "redefining engagement for the $21^{\text {st }}$ century" and can "serve as a national model for connecting universities and their constituents" (Gee, 2014c), messaging that aligns with the engagement literature discussed in Chapter 2 (Brackmann, 2015; Reilly, 2003; Gavazzi, 2015). Both of these 
WVU'S LAND-GRANT MISSION

287

aspirations for WVU Extension also align with McDowell's $(2001,2003)$ recommendations for cooperative extension nationwide, which calls for land-grant universities to forge a new social contract with their communities by hearing directly from them about their needs and responding accordingly.

\section{A New Milestone and a New Mission}

On February 7, 2017, just five years after the Morrill Act's $150^{\text {th }}$ anniversary, WVU celebrated its own sesquicentennial with a year-long birthday party. The pinnacle of this celebration was the launch of a new mission statement:

As a land-grant institution, the faculty, staff, and students at West Virginia University commit to creating a diverse and inclusive culture that advances education, healthcare, and prosperity for all by providing access and opportunity; by advancing high-impact research; and by leading transformation in West Virginia and the world through local, state, and global engagement. (West Virginia University, n.d.b)

Gee also announced a complementary set of Mountaineer values for the entire University, faculty, staff, and students to follow: service, curiosity, accountability, respect, and appreciation.

Nicole reflected on the new mission and values and how strategic planning evolved under Gee's leadership: "He's doing a lot with culture to try to make what you know because people can be talented and know how to do their jobs. But if the culture is supportive and empowers people, especially those who are closest to those we're serving, we're going to do better, and we can't dictate that from a strategic report centrally." This anecdote shows how Gee's approach to strategic planning exemplifies his leadership from the symbolic frame (Meyer \& Rowan, 1977; Manning, 2013; Bolman \& Deal, 2013), which is heavily focused on culture. These new elements reflected contributions toward the programming, student subculture, personnel, and 
WVU'S LAND-GRANT MISSION

288

imagery components of fulfillment in organizational saga because the celebrations were new activities started on campus that became a tradition celebrated throughout the entire calendar year (not just on the University's actual birthday) and attempted to build morale and community among students, faculty, and staff.

\section{Moving 'West Virginia Forward'}

In response to community conversations that came out of his 55-county tours as well as the continued decline in state appropriations for higher education in the state, Gee announced a state-focused initiative in his Fall 2017 State of the University Address, West Virginia Forward. Some of the challenges and attitudes identified from those community conversations included negative elitism, resistance to change, and unwillingness to try new things because of a fear of failure. The University is attempting to respond to these attitudes through West Virginia Forward by reinforcing the foundation for economic growth in the state, including infrastructure, business client, and talent base, or human capital; identifying potential sectors in West Virginia for diversifying the economy; and helping partners around the state to work together to make the state more prosperous.

In response to the budget cuts, Gee responded that the reductions "merely patch over the problems in our state budget, rather than solving them." Instead, he called for the state and its stakeholders to "enlarge [its] budget pie, rather than fight over the size of our servings as the whole thing crumbles" through collaboration. He charged the state government and other public colleges and universities: "Instead of wringing our hands, we need to stack hands. And instead of slapping Band-Aids on our wounds, we need to heal them once and for all. At West Virginia University, that means taking action, rather than dwelling in the more familiar academic 
WVU'S LAND-GRANT MISSION

289

landscape of words and plans" (Gee, 2017c). West Virginia Forward was that tangible response to the continued decrease in state appropriations.

Through research conducted in preparation for the launch of West Virginia Forward, Gee identified both current industries that could be grown over time (i.e. aerospace maintenance, automotive parts manufacturing, and metals manufacturing) and new industries (i.e.

cybersecurity, cloud services and data centers, and higher-end tourism). These recommendations are similar to those found in the engagement and economic development literature in Chapter 2 (Klein \& Woodell, 2015; Reilly, 2013; Brackmann, 2015) because they identify areas of potential growth already in place that the University can potentially capitalize on through partnership, which is also an opportunity to contribute to the social base component of organizational saga those recommendations are acted upon by West Virginia Forward. Gee spoke of these opportunities for economic growth in the Fall 2018 State of the University Address, saying,

Consistent with the West Virginia Forward findings, the University is helping to build the innovation ecosystem that is so critical to our state's future. Currently, too few businesses are born here, and too many fail or leave. While we are working to empower new investments, start-ups and commercialized technologies, we are also meeting the needs of stakeholders here and now. For the first time, we are creating a guide that will showcase West Virginia's investment opportunities, large and small, in one place. (Gee, 2018b) Because this is intended to be a statewide initiative led by WVU and Marshall University in collaboration with the state Department of Commerce, WVU's intended role in the efforts include innovation and research, local business support, talent expansion, and alumni outreach 
WVU'S LAND-GRANT MISSION

290

under the guidance of the three pillars previously described and the land-grant mission.

Samantha explained the integration,

West Virginia Forward, obviously, is a huge statement about our land-grant mission to the state in terms of health, education, and prosperity, but our vision is very large. It's very globally focused in terms of what kind of businesses and industries can we attract to West Virginia? What kind of preparation can we be giving our students to be global representatives of the state?

The West Virginia Forward initiative reflects the components of social base and programming in the fulfillment stage of organizational saga because it is a new initiative directly responding to community needs. It also contributes to the imagery component of organizational saga because of all the partnerships involved, including with another higher education institution in the state, Marshall University, as well as the state Department of Commerce. However, these steps toward organizational saga can only be fulfilled if there is proven progress made toward reaching the initiatives goals. However, to date, no such metrics for assessment have been published on the West Virginia Forward website. All they have published so far are examples of work being done in each of their priority areas.

\section{Summary}

While the three pillars are not a formal strategic plan, they have been guiding tenets for decision-making for the University since they were introduced in 2016. This approach reflects Gee's disdain for formal strategic planning, especially documents that are not actively used and assessed. He shared this perspective in his Spring 2017 State of the University address:

You know by now that I am not a fan of strategic plans. They are often created in a vacuum, and then placed in a binder that is shelved. That may have worked for higher education 
WVU'S LAND-GRANT MISSION

291

50 - or even 20-years ago - but no more. Today we will be strategic and malleable to meet the needs of our world. (Gee, 2017b)

Linda elaborated on [Gee's] dislike of strategic plans. She shared that he regularly comments that he is "not a fan of strategic plans" and "is not shy about" declaring that preference because he "feels like there's a lot of effort that goes into the planning period" without "measurable outputs" to hold administrators accountable for their decisions. Instead, she indicated that his leadership team has been operating more on a project basis and using the three pillars as a guide for prioritizing projects and initiatives.

Jameson also described Gee's disdain for strategic plans. He said, "I do think a couple of years ago early on in [Gee] and [Provost Joyce McConnell's] time where they launched this thing where let's not talk so much about a plan which is, you know, a 15-page document that sits on a shelf and says we're going to do all the things we normally do. But let's really focus on strategic initiatives.” Nicole had a similar observation.

So, the interesting thing about [Gee] is, and he'd be the first to tell you, he doesn't like strategic plans. He'll say it even stronger. It isn’t as if he's not for being strategic. And I think that what he finds over time has been the plans, and if you think about the 2020 plan, it was already postured this way. We don't want a plan that sits on a shelf; we want to be dynamic. We want to have some strategic goals. So, I think that he's really more about [being] strategic.

However, it has not been shared publicly how the three pillars were determined, which has rendered some criticism from faculty and staff, especially. Jameson noted,

The three pillars are cool, but those aren't really a plan. They're, they're just like points of light that you need to pursue somehow . . . Those three were launched by the president 
WVU'S LAND-GRANT MISSION

292

without any discussion, as far as I know. Maybe among his inner circle, which is fine, and I don't resent that in any way. It's not likely there is a process by which we came to those three.

Others have applauded how Gee has reengaged with the land-grant mission and the state through the three pillars, observing that Gee identifies WVU as having an obligation to support the state and improve it for future generations and reflecting a servant leadership approach (Stone, Russell, \& Patterson, 2004) to the land-grant mission. William reflected, The land-grant role is about the ability to help your state address its future and to address some of the things that are holding it back from its future. Whether that's in the health areas, economic vitality. And, I think, of all the people you are looking at, [Gee] has been the most articulate. He believes it. He understands that it's a blessed role and it's one of the things that needs to guide this university strategically.

Sean, a key official in the president's office, shared a similar perspective, saying that the three pillars fit WVU's land-grant mission "perfectly." He described the pillars as Gee's method for carrying out the University's commitment to taking care of the people of West Virginia, a decision he believes stems from Gee's extensive experience leading land-grant universities. He talks about education, healthcare, and prosperity as being the way WVU can give back to West Virginia. Basically, to whom much is given much is expected, and the state has given us a lot in terms of its young people, in terms of its tax dollars, in terms support for our mission. We have an obligation to give back, and those three pillars are completely congruent with our land-grant mission.

Sean characterizes Gee's leadership as servant leadership (Stone, Russell, \& Patterson, 2004) through WVU fulfilling an "obligation of service to the state," which he believes is 
WVU'S LAND-GRANT MISSION

293

helping West Virginia's citizens to "see WVU differently" because of its "unique responsibility to serve the people of the state," a contribution to the imagery component of organizational saga. Gee himself acknowledged this sense of obligation in his Fall 2018 State of the University Address: "I am proud of the way West Virginia University is standing up for what matters to our students, to our faculty and staff, and to the citizens of this great state. Today, we are standing up for service by combating West Virginia's biggest problems, including economic stagnation and the opioid epidemic." These statements reflect that Gee has not waned from his focus outward to the entire state since the beginning of his presidency. That outlook has permeated every major planning decision he has made, which ultimately highlights his prioritization of the social base and imagery components of organizational saga because that external, community-oriented focus has shaped WVU's reputation and message to the state's citizens as well as to the state government in the midst of a trying budget climate.

\section{Defining the Land-Grant Mission: Vision and Messaging}

\section{Embodying the Land-Grant Mission in Leadership}

From a messaging perspective, Gee demonstrated from the onset of his presidency at WVU that the land-grant mission would guide how he shaped his leadership style and messaging. In the news release announcing his presidency, Gee shared:

West Virginia University is where my journey as a university president began more than three decades ago, so it has always had a special meaning for me. When I was 36 , this great land-grant institution gave me an extraordinary opportunity to serve as its president. Indeed, I understand the mission of land-grant institutions, and know the importance of WVU to the state and the university community. (West Virginia University University Relations, 2014) 
WVU'S LAND-GRANT MISSION

294

Then-Interim President of Ohio State University Joseph Alutto was also quoted in that news release on Gee's experience leading land-grant institutions: "West Virginia University will have a strong leader in Gordon Gee. Given Gordon's deep experience and understanding of the power of the land-grant mission in the 21st century, he is certain to move WVU forward in meaningful ways" (West Virginia University University Relations, 2014).

Gee shared in an introductory video to the campus community (emailed to faculty, staff, and students) how the land-grant mission influences the organization and operation of the University, which also reflected early “one WVU” messaging described earlier in this chapter:

I will just note that it is a land-grant institution and the pleasure of being part of the landgrant tradition is something that's very important. I think that the power of university is that we are one University - that were not a collection of colleges connected by a heating plant. We're not a vertical institution, but rather we're very horizontal, and so, you just don't have a Health Sciences Center and you have a College of Arts and Science[s] and you have a College of Engineering [and Mineral Resources] that they may meet once in a while. It is the power of this institution is its size and its scope and the integration of ideas. Our faculty I value and appreciate the world in which they work, and I want to be very engaged with them. (Gee, 2013)

This video contributed to the student subculture, personnel, social base, and imagery components of fulfillment in organizational saga because of all the audiences targeted by the message-Gee and his leadership intended to include and reach everyone. The theatrical nature in which it was presented, with the intention of making an impression of relatability, humor, and conversation represented his symbolic leadership style (Manning, 2013; Bolman \& Deal, 2013) early on, setting the tone for future message delivery. 
WVU'S LAND-GRANT MISSION

295

Gee also addressed the role of the land-grant mission for leaders of the University in his first memo to his leadership team, reminding them of the purpose of WVU and the standard to which every facet of the University will be held, which directly reflects the land-grant mission and operationalizing it across the institution as well as a commitment to the personnel element of fulfillment in organizational saga.

There is a coda to the expectation of hiring, nurturing, and being extraordinary people. We must always remember that we work for the people of this University and of this state. This University must become the heart and soul of West Virginia. For us as leaders, that means that we must leave our egos at the door. We must set the highest standards of integrity. We cannot cut corners. We must take risks, but not be foolhardy. And, we must be good stewards and good listeners by being open to challenges from those with whom we work as to whether what we are doing is in the best interest of the University. Never, ever pull rank ... My final thought is that I need you to recommit to your shared enthusiasm, energy, and passions for West Virginia University and for the people of West Virginia. I will expect your loyalty to our goals, to each other, and to me. Loyalty does not mean that we do not tolerate dissent, but it does mean that I will not tolerate disloyalty. Loyalty, passion, energy, enthusiasm, a sense of urgency, and a clear-minded commitment to excellence will allow us to be the architects for the future of this University. (Gee, 2014a)

The memo was intended to be shared by those leaders with their teams, allowing the message to trickle down and permeate the campus, making the tactic a contribution to both the personnel and imagery components of organizational saga because it was a directive to employees intended to shape the culture of the University from the inside out. The message in the memo also contributed to the student subculture and social base components of organizational saga because 
WVU'S LAND-GRANT MISSION

296

of the directives to the campus community to put the needs of the state's citizens and the University's students first in their day-to-day tasks. This tactic demonstrated how Gee used the land-grant mission as a foundation for both his servant and transformational leadership styles (Stone, Russell, \& Patterson, 2004) as well as his leadership from the symbolic framework (Meyer \& Rowan, 1977; Manning, 2013; Bolman \& Deal, 2013) as he attempted to change the culture of the University to one of service to the state from the inside (i.e. faculty, staff, students, and alumni) out (i.e. communities, partnering organizations, state government, etc.).

\section{Creating an Attitude of Resiliency}

Following the floods reaping havoc on southern West Virginia in June 2016, Gee described how WVU would help the state become more resilient, not just in the face of the floods, but the preceding pressing challenges of its education, health and well-being, and economy: "I believe one of the most important ways a university can serve its state is to help communities to be resilient. Although the word 'resiliency' does not appear in either of the Morrill Acts, I think nurturing resiliency is at the heart of the land-grant mission and, indeed, of higher education generally" (Gee, 2016e). This strategy exemplified how Gee has used exogenous circumstances to shape his messaging around the land-grant mission, continuing his leadership from the symbolic framework (Meyer \& Rowan, 1977; Bolman \& Deal, 2013; Manning, 2013) as well as his contributions to social base and imagery in the way he captured responses to community crises by addressing them publicly.

In this blog, Gee described five communities in crisis and how WVU is helping them bounce back from the situations they were experiencing, ranging from natural disasters to economic downtown. This messaging demonstrated his administration's commitment to the social base component of fulfillment in land-grant saga. He acknowledged that WVU is not "the 
WVU'S LAND-GRANT MISSION

297

most important player" in these communities, but that their citizens "are the soul of these places," "the real heroes and the real experts." That latter line shows Gee's commitment to Gavazzi's (2015) marital metaphor for land-grant universities and their communities and the importance of reaching out to the citizens first to hear their needs directly from them before taking action, as discussed in the community engagement literature in Chapter 2. Gee said, "The obvious but often-overlooked key is to treat the people in these communities as genuine and equal partners and always remember that we will learn more from them than they will learn from us. Building on that essential understanding, I believe the University has a critical role to play and it begins with making resilience a part of our mission."

Gee went on to call for that same commitment among WVU students, similar to Hardesty's call more than a decade earlier for students to find ways to serve their communities. Gee said, "WVU has a special obligation of service to our state - and our students are at the forefront of fulfilling this obligation." He sees that service as more than a line on a resume that could help them in the job market. Instead, he said, "Students will leave the University and go on to be citizens, residents, voters, taxpayers, and employees in communities, large and small, throughout West Virginia and around the world. If we are successful as universities, our students will enrich and empower those communities in countless ways throughout their lives" (Gee, 2016e). This anecdote highlights Gee's intersection of the transformational and servant leadership styles (Stone, Russell, \& Patterson, 2004) through how he worked to gain buy-in among students to be a part of operationalizing the land-grant mission through service and carrying that out even after graduating and departing from WVU. This effort simultaneously contributed to the student subculture, social base, and imagery components of organizational saga because it shows how student attitudes have changed over time through the contributions 
WVU'S LAND-GRANT MISSION

298

they have made in the community and how that has shaped both University culture and the way WVU is perceived beyond the campus.

Gee followed up that blog post with a July 2016 op-ed in the Charleston Gazette-Mail, sharing that "the thing (he) love(s) most about West Virginia is the resiliency of its people." He also described how the state's people have embodied a resilient attitude since the inception of the state and everything they have navigated since and that the state would rely on that foundation to overcome the crisis.

West Virginia was born on the very foundation of grit. We boldly chose an uncertain pathway to establish our own identity as one unified, rugged, and determined brand of people. That grittiness persists in everything we do — from the uniqueness of our art and music which embraces Appalachian heritage, to the extraction of our energy resources to the ever-changing nature of our economy and our demography caught between many different vectors and many different worlds. Our resilience is now being battle tested. And I must say we are answering the call faithfully. (Gee, 2016c)

In another piece for the Charleston Gazette-Mail, Gee also described WVU as a beacon of hope for the state through the work of its land-grant mission. "Our highest priority is — and always will be — to ensure that 1.8 million West Virginians can thrive, not merely survive. And by working together, we can make the future bright for our state and all our young people" (Gee, 2016a). All of these messages highlight how he continued to contribute to the social base component of organizational saga, using messages of "obligation" and "commitment" to the state's people to describe the work of the University. 
WVU'S LAND-GRANT MISSION

299

\section{A Year-Long Birthday Celebration}

Throughout 2017, Gee and his leadership team took advantage of WVU's

sesquicentennial anniversary to host a year-long birthday celebration, which demonstrated a commitment to both the imagery and programming components of fulfillment in organizational saga because it used new activities to shape the culture of the University and make an impression on its constituents - students, faculty, staff, alumni, and fans alike. He used this platform as an opportunity to not only launch a new mission statement and set of values, as described above, but also describe why WVU would continue to reconceptualize what it means to be a land-grant university to respond to challenges facing higher education, as described in Chapter 2 (Duderstadt, 2012).

Gee called for this change in his Spring 2017 State of the University Address, saying, "As a land-grant institution, we are a powerful catalyst for changing lives. The pathway to success is an educated citizenry. And if we are not the architects of change, we will become its victims. My observation is that change is debilitating when done to us, but exhilarating when done by us." He explained that WVU could "no longer function like the university that was established in 1867," and that it had to take the lead on becoming a nimble organization so that its operations had the flexibility to respond to and meet the exogenous demands "of an everchanging society." Like Duderstadt (2012), Gee acknowledged that stagnation from the past had the potential to hold the University back, which was the motivation for the new mission statement introduced at the beginning of this chapter.

In the latter part of 2017, Gee used the work happening through the three pillars to describe the motivations behind those efforts and their connection with the land-grant mission, which tie in to the previous discussions surrounding the idea of WVU's obligation to the state's 
WVU'S LAND-GRANT MISSION

300

citizens, particularly in the context of ongoing budget cuts. This exemplified work toward the social base element of the fulfillment stage in organizational saga because of the continued commitment to community engagement and overcoming challenges facing the state's citizens. Gee said in the Fall 2017 State of the University address that engagement in the state was WVU's raison d'etre as a land-grant university: "We exist to improve lives in our state, by strengthening education, delivering healthcare, and advancing our citizens into prosperity. Our state's current position makes our mission an urgent obligation." He went on to say that the landgrant mission is what makes WVU uniquely prepared to do this work and differentiates it from other higher education institutions in the state. "Due to our land-grant mission, we have the ability to move ideas from bench to market - ideas that can help 1.8 million West Virginians. And we have the responsibility to demonstrate why investment in higher education is a valuable investment."

Gee also warned against what he viewed as the biggest obstacle to reconceptualizing the mission: an unwillingness to change because of fear of failure. He declared these concerns in an op-ed in the Charleston Gazette-Mail (Gee, 2017a), saying, "Trying new things is risky, and often we search for alibis to avoid it. But change is inevitable, and if we are not the architects of change, we will become its victims. As the state's land-grant institution, West Virginia University embraces transformation to create a thriving future for West Virginians." He went on to use that op-ed to highlight the sesquicentennial celebration and acknowledge the role WVU has played in serving the state throughout its history, bringing back around his leadership through the symbolic framework (Meyer \& Rowan, 1977; Manning, 2013; Bolman \& Deal, 2013) through the way he used public platforms for celebrations, theatrical messaging (both 
WVU'S LAND-GRANT MISSION

301

positive and critical), and calls for radical transformation, a consistent strategy throughout his presidency.

\section{Summary}

With regard to organizational saga, Gee quickly reached the initiation phase, treating the presidency like a permanent role from the beginning even though he was first hired as an interim. He has demonstrated many examples of working toward the fulfillment phase as well, though as the sitting president, whether that stage will be fully reached can't be determined until after the conclusion of his administration.

Through the personnel stage, Gee distributed the Rules of Engagement memo to his leadership team, highlighting his expectations for them and encouraged them to share them with their own staffs. He restructured the human resources division as Talent and Culture and established new Mountaineer Values for the entire University to follow (i.e. service, curiosity, accountability, appreciation, and respect). A culture survey has been administered to understand challenges facing faculty and staff in terms of work culture and how it can be improved. He has hired new administrators, including an athletic director, provost, health sciences chancellor, vice president of the Division of Diversity, Equity and Inclusion, and "dean of completion." The University has also launched Campus Conversations to increase transparency and distribute information about University-wide pertinent issues while gaining input from faculty and staff.

The programming phase has been led by the launch of the three pillars (i.e. education, health and well-being, and prosperity) as well as a new mission statement. The largest programming initiative to come out of those was West Virginia Forward, a statewide collaboration with Marshall University and the state Department of Commerce to improve the state's economy. WVU Healthcare was rebranded to WVUMedicine to unify all health-related 
WVU'S LAND-GRANT MISSION

302

operations at the University and continues to expand with more facilities around the state and the surrounding region. WVU Institute of Technology was moved from Montgomery, West Virginia, to Beckley, West Virginia, to reach a broader population of students and expand in a fastergrowing geographic area of the state despite being wrought with criticism. WVU's research efforts were acknowledged with the Carnegie Research 1 classification in 2015. Service activities were expanded with monthly 12 BIG! Days of Service, large monthly campus-wide community projects around the state as well as through the Million Hour Match program, where students challenged faculty, staff, West Virginia residents, and government officials to match their goal of one million hours of service to the state. Finally, the Bureaucracy Busters initiative was established to improve efficiencies in policies and processes on campus.

In terms of social base, the State of Minds campaign continued, concluding in 2017. It reached its goal a year early. The Alumni Association launched WVU Connect, a social media platform targeted to alumni, with opportunities for students, faculty, and staff to join as well. The WVU Foundation launched Day of Giving, an annual 24-hour giving program to encourage the entire campus community to give back.

With student subculture, University College (established under Clements) was abolished. The pre-majors were reorganized under a new name, the Center for Learning, Advising, and Student Success. The University incorporated all of its student success, engagement, and retention initiatives in Project 168 to help students make the most of their time at WVU. The student organizations office was also reorganized as the Office of Student Engagement and Leadership, with a plan to address challenges with fraternity and sorority life relating to student behavior, safety, and culture. 
WVU'S LAND-GRANT MISSION

303

The “one WVU” attitude reflects the Gee administration's approach to the imagery phase. This messaging is seen through a rebranding initiative, "Mountaineers Go First," an attempt to unify all aspects of the system's marketing, recruitment, and alumni engagement efforts, including those of the regional campuses. The year-long birthday celebration was also part of this effort. New facilities, including the Agricultural Sciences Building, Engineering Research Building, Evansdale Crossing, Evansdale Library renovations, Monongalia County Ballpark, residence halls, and art museum also contribute to the imagery phase, as do new events on campus, including the expanded Welcome Week. The catalyst of the imagery phase is the attempts at transparency across the University, from Gee's 55-county tour, to the Campus Conversations, to his monthly "Gee Mail” emails to students, faculty, staff, and alumni.

The land-grant mission and how it shapes the University is included in every major speech that Gee has given since reassuming the presidency in January 2014 as well as many of the communications mentioned in the above discussion of organizational saga. It has been used to both shape proactive decision-making and respond to exogenous situations beyond the University. Gee uses it to frame calls for bold change and risk-taking to re-envision WVU's mission in response to the challenges facing both the state of West Virginia and higher education as a whole. However, beyond the discussion of three pillars of education, health and well-being, and prosperity, which have been used to fit in all of the various initiatives and activities of the institution since the beginning of Gee's presidency, no new strategic plan or blueprint for what this reengaged mission might look like has been shared at this point, begging the question of how all of these ideas and calls for change and flexibility will look like in the future. 
WVU'S LAND-GRANT MISSION

304

Chapter 9: Conclusion 
WVU'S LAND-GRANT MISSION

305

\section{Discussion}

This study was an opportunity to conduct an emerging exploration of the land-grant saga. By examining a modern land-grant university in the face of changing broader contexts for higher education and in more specific state-level contexts, this study showed how universities can respond to those contexts through strategic planning. Through the lens of a specific institution, i.e. West Virginia University, this study defined what it means to be an engaged land-grant university in the $21^{\text {st }}$ century, including identification of accountable publics, missional expectations, and responsibilities and how those are carried out through strategic planning.

Because strategic planning and mission-building cannot occur without the leadership initiating them, this study also highlighted the presidential visions pursuing these changes. The document analysis and interviews that took place investigated the embedded culture of higher education as an industry and the challenges it faces, including exogenous and endogenous factors, as well as characteristics like the role of the presidency in strategic planning and mission-building, presidential retention, average tenure, leadership frameworks used by the presidents, institutional reputation, and how all of those details shaped organizational saga. By considering how these characteristics were operationalized in the cases, the study also demonstrated how each presidential administration's interpretation of the land-grant mission influenced the institution's positionality in the land-grant saga and the work of the institution across these time periods.

Each of the presidents in this study continued to pursue goals relating back to the same constituents - students and parents, faculty and staff, alumni and donors, the community, and state and local government officials. However, the most variance was seen in how the administrations prioritized those goals and in the ways the presidents discussed them in public 
WVU'S LAND-GRANT MISSION

306

messages. As a result, those decisions shaped the way the organizational saga evolved in the administrations. This final section of findings collects and juxtaposes the findings across all five presidential administrations in this study, synthesizing across the administrations to examine how WVU's strategic planning approach and resulting goals have changed over time and influenced the University's land-grant mission while responding to changes in the shifting broader contexts of higher education.

\section{Operationalizing the Land-Grant Mission: How Strategic Planning Has Changed}

The structure and approach to input gathering to inform strategic planning has differed across all five of the WVU presidential administrations examined in this study, from small advisory groups to large strategic planning councils to transformation teams that pursued both informal, project-based approaches to strategic planning as well as more formal documentation with metrics for assessment. While all five of the presidents studied here approached strategic planning in their administrations with varying styles and for different motivations, they all shared a common starting point—gathering input and feedback from their constituents used to inform their preparation for the presidency and subsequent planning approaches. However, even the approaches to receiving that feedback varied greatly, from individual or small group counseling to focus groups to surveys to town halls in communities. A strategy they all shared in common, though, was their motivation to seek input and feedback, especially early on in their presidencies. These approaches often reflected the presidents' leadership styles from the four leadership frameworks introduced in Chapter 2: structural, collegial, political, and symbolic (Bolman \& Deal, 2013; Manning, 2013).

\section{Gathering Feedback: Structure and Size of Leadership Teams}


WVU'S LAND-GRANT MISSION

307

Some of the presidents in this study opted to work with and gather information from a small, close-knit team. Early on, David Hardesty convened a small group of advisors for preparation during his interview process even before he was chosen as president. This group was described as a "kitchen cabinet," a small team of hand-picked advisors who were selected for their expertise in niche areas to identify challenges, brainstorm solutions and implementation methods, and give input and feedback. Hardesty gathered input as a way to research the issues he and his "kitchen cabinet" identified as challenges facing WVU and implement solutions to them. Nicole, a staffer in the president's office, described the approach, saying, "[Hardesty] talked with a lot of people. From the time he was named to the time when he took office, he certainly spent time talking to folks." Hardesty wanted first-hand knowledge of what was happening on campus, in the state, and nationally_ primary sources reflecting and affected by the issues, and his "kitchen cabinet" served that purpose. At the beginning of the administration, he and his "kitchen cabinet" approached strategic planning from an issue-based or project-based model, tackling challenges as they arose through task forces and prioritizing and responding accordingly. This style reflected Hardesty's background in law, government, and business as well as leadership from the political framework (Manning, 2013; Bolman \& Deal, 2013) as this structure of counsel is often seen in politics. E. Gordon Gee has taken an approach similar to Hardesty's in this regard, working on issues and projects as they have arisen with his executive leadership team and "transformation teams" rather than working within a formal plan or with a large group. Both Hardesty and Gee's project-based approaches to planning represented their leadership as "strongwilled presidents," or their use of their individual power to pursue change, as described by several participants. 
WVU'S LAND-GRANT MISSION

308

In contrast, James Clements put together a 45 -member strategic planning council that represented all the major divisions and units within the University and various ranks of faculty and staff among them. The large, representational nature of the council exemplified Clements' leadership from the collegial framework (Manning, 2013; Bolman \& Deal, 2013). This council met regularly and eventually produced a five-goal strategic plan for the University that was encouraged to be duplicated or used as a template for creating and implementing strategic plans across all the University's divisions, academic colleges and schools, and other units.

Clements' group was similar to the large planning group Hardesty assembled later in his administration when he was tasked with creating a more formal strategic plan. The 2010 plan during his administration was informed by discussions and brainstorming by a 100-person committee. However, it different from Clements' planning council in that it came together just once during a two-day brainstorming retreat, described by Frank, an academic leader at the time, as a "marathon session."

Garrison's administration took a focus group approach to gathering feedback from faculty, staff, and students. Nicole remembered that he tried to "get [them] talking and learn directly from them.”

Not unlike the focus groups in Garrison's administration, Clements sought feedback from the broader campus community beyond just the large strategic planning council he put together to work on the formal document described above, demonstrating that he came into the role very preparation-minded. To gather this feedback, he reached out in the form of a survey. Clements' administration implemented a University-wide "Share Your Vision" survey across the entire campus as a strategy for gaining feedback and ideas to inform the strategic planning process, a reflection of his leadership from the collegial framework (Manning, 2013; Bolman \& Deal, 
WVU'S LAND-GRANT MISSION

309

2013) because all University constituents were invited to contribute. Sean, a staffer in the president's office, explained that Clements "made it very clear that [the strategic plan] was one of the first things he wanted to accomplish" to "give him a chance to learn more about the campus" and "set the University on a good course for the long-term" following the conflict from the Garrison administration. Sidney, a member of the faculty senate at the time, also observed this commitment to preparation and learning, recalling that Clements "knew everything he about [WVU] before he arrived" because he "read everything he could online" ahead of time.

Unlike the other presidents studied here, Gee employed his own unique approach to feedback gathering that he has continued each year of his presidency. He annually tours West Virginia's 55 counties to hear from citizens in those areas and uses that input to inform ideas and decisions.

\section{The Strategic Planning Process}

Just as with the feedback-gathering processes described above, the structure of strategic planning has also varied across the administrations in this study. While the Hardesty administration started off with a more project-based, one-off approach to planning, the creation and implementation of a formal strategic plan was pursued later in his tenure, when the Higher Learning Commission required one as part of the reaccreditation process (West Virginia University, 2004). Changes in governance at the state level during Hardesty's tenure also called for strategic planning documentation in the form of a campus compact, a planning document required for all West Virginia public higher education institutions following the passage of Senate Bill 653 in 2000 that was used to inform assessment of state appropriations. What resulted was a comprehensive document, led by five goals, with metrics for assessing whether each goal was met. The formal plan produced by Clements' administration (West Virginia 
WVU'S LAND-GRANT MISSION

310

University, n.d.a) was similar in structure in that it had five goals, but the document itself was much shorter and more concise with the intention of other units modeling their own plans after it. At the same time, Clements' administration used a transparent process, with a website dedicated to the effort with the published plan, a directory of council members, and progress reports from the subgroups.

Unlike Hardesty and Clements, in the short timeframe of Garrison's presidency, there was not much of an opportunity to pursue a formal strategic plan. However, he did create a structured First 100 Days planning document (Garrison, 2007b), a similar approach to planning made by politicians at the beginning of their terms in office, which complements his leadership from the political framework (Manning, 2013; Bolman \& Deal, 2013). This document (Garrison, 2007b) was informed by the focus groups he held early on in his tenure.

In contrast to these formal approaches to strategic planning, C. Peter Magrath was simply brought in as the interim president and tasked with restoring and healing the campus rather than pursuing any new initiatives. He utilized the collegial framework (Manning, 2013; Bolman \& Deal, 2013) to rebuild relationships with students, faculty, staff, alumni, donors, government officials, and community leaders and begin to restore the University's reputation as a national leader of land-grant universities. As a result, his approach to strategic planning was not one of formal documentation of new ideas and initiatives; instead, he aspired to unify the campus through inspirational messages, celebrations of strengths and success stories, and reengaging with the state, all avenues for uplifting the campus community.

Gee has also taken an informal, organic approach to strategic planning. While the plan implemented during the Clements' administration (West Virginia University, n.d.a) is technically active at the time of this writing, it has all but disappeared under Gee's administration, with no 
WVU'S LAND-GRANT MISSION

311

active website remaining and no references to the plan in official documents and speeches.

Several key officials interviewed in this study have affirmed this interpretation as well, though no formal conclusion or replacement has been announced. The absence of follow-up is reflected by frequent statements by the participants interviewed in this study that Gee "dislikes" strategic plans, which he commented in front of the original strategic planning council for the 2020 plan in a meeting early in his presidency, according to Edith, a faculty member. However, this gap has not been filled with any formal plan, with the question remaining of what will take its place. This dichotomy, particularly the absence of a tangible plan, poses a curious nuance for a president who often leads from the symbolic framework (Manning, 2013; Bolman \& Deal, 2013), one who seeks out the theater and culture of being in the spotlight and making a memorable impression among stakeholders with his words and actions.

These diverse approaches show that differing leadership styles can influence the way planning and mission-building is carried out as well as how goals are reached. With these varying approaches to planning and input gathering in mind, the next section will explore how those goals varied across the five administrations.

\section{Operationalizing and Reconstructing the Land-Grant Mission: Goals, The Work of the Institution, and Organizational Saga}

\section{Mission and Goals}

Despite the differing approaches to strategic planning, most of the presidents in this study focused their time on goals and initiatives in six broad areas: research, faculty and staff, students, community engagement around the state, operational processes and organizational structures within the University, and aspiring toward or building a national reputation for the University. A concept that was introduced in some shape or form by every participant interviewed was that all 
WVU'S LAND-GRANT MISSION

312

the presidents were dealing with the same core issues — students, faculty, teaching, research, and service. They just approached, presented, and responded to them differently. Frank, an academic leader throughout the administrations in this study, reflected on this tendency, saying, "I would say there's sort of the five big issues that everybody takes on almost all of the time. There isn't much difference in higher education - we just call it something different. It's about studentsundergraduates and graduates. It's about faculty. It's about pay. Facilities. If you look at higher education, you know there's just no other ways to cut it." Though how those initiatives, goals, and activities were presented differed from one president to the next, these common threads show that certain stakeholders, constituencies, and areas of the University continued to be a priority across all the administrations and rarely differed except in extreme circumstances, such as the Garrison scandal and his abrupt departure. The following paragraphs discuss those six broad goals and how they constructed the organizational saga in each of the cases studied here.

Research. WVU has continued to be more focused on research over time, starting with Hardesty's administration. He initiated a commitment to research with a research task force that identified focus areas in advanced materials, energy and environment, human development and culture, information technology, local and regional economic development, and molecular and biomedical sciences. The task force also established WVU Research Corporation to manage research operations and processes across the University and initiated planning for the Research Trust Fund, a campaign to receive private donations to support targeted research areas. Following Hardesty's retirement, Garrison continued the planning for this initiative and implemented it early in his tenure. Clements continued to advocate for support for the Research Trust Fund early on in his presidency, and he also launched his own research strategy with the Mountains of Excellence, targeted research areas supporting opportunities for economic 
WVU'S LAND-GRANT MISSION

313

development in the state. These included radio astronomy, shale gas, water resources, STEM education and scientific literacy, and health disparities in Appalachia. Research was the predominant goal of his 2020 Strategic Plan for the Future, culminating in the aspiration of receiving the Carnegie Foundation's Research 1 classification, which was eventually reached in 2015 during Gee's administration and renewed again in 2018, highlighting the University's continued commitment to research productivity. Gee's three pillars, education, health and wellbeing, and prosperity, also guide research prioritization with their framework. The research goal is reflected in the programming, personnel, and imagery components in fulfillment of organizational saga because it encompasses new initiatives (i.e. programming) carried out primarily by faculty (i.e. personnel) that contributed to reaching the most sought-after accolade in University history—Research 1 (i.e. imagery).

Faculty and staff. Beyond research, some of the presidents pursued goals or initiatives that were specific to faculty and staff. In the 2010 strategic plan, Hardesty's administration included a goal specifically supporting the development of high-quality faculty because of the role they play in educating and supporting students. As part of Senate Bill 547, WVU and the Hardesty administration were tasked with revamping its budget structure to allocate more funds for competitive employee salaries. Garrison called for a similar increase in staff salaries to help make them more competitive in the marketplace. He also attempted to improve employee morale by building a childcare center on campus, though the initiative followed a long-term study under the Hardesty administration. When Magrath was brought in as interim president following the Garrison, his primary task was to bring healing to campus and rebuilding the morale among the campus community. Clements focused on faculty to the extent that he was a proponent for 100 new faculty lines that supported his research Mountains of Excellence, discussed above. Gee 
WVU'S LAND-GRANT MISSION

314

brought renewed focus to faculty and staff issues by rebranding the Division of Human

Resources as Talent and Culture and introducing a new set of values to be shared across campus, including appreciation, one that resonates often with employees. The faculty and staff goal is reflected primarily in the personnel component of organizational saga, which encompasses any activities related to building relationships with the faculty and staff goal on campus.

Students. Students have been a priority in the goals set by three of the administrations in this study: Hardesty, Clements, and Gee. Hardesty kicked off the first day of his presidency with a student-centered initiative, led by a student affairs task force, that encompassed a revitalization of New Student Convocation, living-learning communities in residence halls led by faculty members, academic advising improvements, streamlining of student services such as student accounts, and other retention initiatives. He also launched, with wife Susan, a new Mountaineer Parents Club to share information to support their students and become more transparent. Clements aspired to build upon Hardesty's student-centered initiative with more programming surrounding retention and graduation rates, with a focus on student health and wellness. He also advocated for educational partnerships in the online, preK-12, and community and technical college arenas that promoted access to higher education in the state. Gee's student-focused initiatives have focused more on the experience students have as they are arriving on campus for their first semester, expanding Welcome Week and continuing to refine the retention initiatives established under Hardesty and Clements. The student goal is reflected in the student subculture, programming, and imagery components of organizational saga as it highlights new initiatives (i.e. programming) supporting students' experiences (i.e. student subculture) as well as new traditions (i.e. imagery) building momentum among the student body. 
WVU'S LAND-GRANT MISSION

315

Community engagement. Most of the presidents in this study spent extensive time engaging with the community on state-focused initiatives. Often quoting early WVU President Irvin Stewart in saying, “The state is our campus,” Hardesty's engagement efforts were initially kicked off with an Extension Service task force that reenergized the University's connection to the state and reinforced its presence all around the 55 counties with new focus areas in workforce education and job accommodation, sustainable agriculture and agromedicine, food safety and nutrition, and child care. Following the Garrison scandal, Magrath used community engagement as a strategy for uniting the campus and helping to rebuild its reputation and mission, often using the "Returning to Our Roots: The Engaged Institution" report from the Kellogg Commission on the Future of Public and Land-Grant Universities (1999), a community engagement white paper, to inspire and rally the campus community. Similar to Hardesty, Clements used his own crafted quote to shape his attitude toward community engagement, often saying that "no university means more to its state than WVU." He took a partnership approach to community engagement, expanding opportunities for WVU Extension and collaborating with community organizations on programming to promote economic development-driven research, educational opportunities, and the health and well-being of West Virginia citizens. He was also a proponent for pursuing the Carnegie Foundation's Engagement Classification to continue rebuilding the University's reputation and presence, which WVU received in 2011. With similar aspirations as Clements, Gee's three pillars - education, health and well-being, and prosperity for West Virginians_-have been a guiding framework for all of the University’s activities, specific to community engagement or not, during his tenure. The most prominent engagement initiative of Gee's is West Virginia Forward, an initiative attempting to grow the state's economy through human capital development and identifying sectors to diversify the economy. All of these efforts reflect 
WVU'S LAND-GRANT MISSION

316

the social base component of organizational saga as it is the element focused outward in the communities on building relationships.

Operational efficiencies. Improving the University's day-to-day operational efficiencies and technological capacity was a priority in some form for Hardesty, Magrath, Clements, and Gee. Hardesty's second major initiative was deemed "administrative organization initiatives." His administration was focused on making the day-to-day operations of the University more efficient, especially in the context of preparing for the next millennium technology-wise and navigating public funding challenges. One of the major projects that came out of it was Integration 2000, or the implementation of technical upgrades and synchronized data processing and business operations across the Morgantown campus, Health Sciences Center, WVU Extension Service, Potomac State College, and WVU Institute of Technology leading up to Y2K. Magrath's work toward operational efficiencies came in the form of modernization academic recordkeeping. In response to the degree scandal during Garrison's administration, Magrath brought in the Association of Collegiate Registrars and Admissions Officers to provide consultation on the WVU's approach to recordkeeping to avoid any similar issues in the future. Clements introduced operational efficiencies in his approach to structuring and organizing the institution, attempting to streamline student services through the establishment of a new academic college and bringing together all international activities and all diversity initiatives in their own respective divisions. Early on in his presidency, Gee advocated for elimination of bureaucracy across all of WVU's entities, calling for “one WVU” by creating a program called Bureaucracy Busters to address issues like travel, human resources, and purchasing. This operational goal is reflected in the programming, personnel, and student subculture components 
WVU'S LAND-GRANT MISSION

317

of organizational saga as it reflects new organizations and structures (i.e. programming) that faculty and staff (i.e. personnel) and students (i.e. student subculture) interface with daily.

Becoming a national university. Hardesty was the first WVU president to champion aspirations of becoming a national university. From messaging that often incorporated terms like “excellence and greatness," service in national higher education organizations and the Big East Conference, and efforts to overcome the negative party school image, Hardesty, especially later in his presidency, aspired to transform WVU into not only the state's university, as described in the community engagement section above, but also a national player. After the Garrison scandal, Magrath set out to regain the capital lost that Hardesty's administration had developed over time, using his network through past presidencies and national organizations, like the Association for Public and Land-Grant Universities, to help rebuild the University's identity nationally. Clements advanced this reputation-building process further, with pursuits of the Carnegie Engagement Classification and the Research 1 aspiration. He also pursued three goals that contributed to this external, forward-facing focus. They primarily only appear in his presidency: alumni, diversity, and globalization. While the other four presidents did not ignore these areas, they were really only a priority for Clements, and the work toward all three goals contributed to these national aspirations. His administration's 2020 strategic plan had specific goals fostering a more inclusive campus through both international and diversity-focused goals, including international recruitment, creating organizational structures for both of those areas within the University, and new programming. He also prioritized developing relationships with alumni and spent extensive time traveling to meet with alumni and donors, which resulted in record-setting private gifts. While Clements was not the only president to lead a capital campaign or to secure major gifts, he championed the fundraising responsibilities that are a cornerstone for any 
WVU'S LAND-GRANT MISSION

318

externally-minded president. Gee's more state-focused priorities have not taken away that national standing; instead, his leadership from the symbolic frame (Meyer \& Rowan, 1977; Bolman \& Deal, 2013; Manning, 2013) and the national reputation he brings as a prominent higher education leader have contributed to the University's reputation latently without assigning more tangible goals to it. This goal encompasses two of the components of organizational saga: social base, because of the external focus on building relationships with alumni and donors; and imagery, because of the changing culture on campus through the diversity and globalization goals as well as the shifts in reputation through rankings and by association with various national organizations.

Summary. These differing goals and ways of implementing them demonstrate how each of the presidents' in this study interpreted the land-grant mission at WVU and framed it in their respective messaging. Hardesty began with students first, using the Kellogg Commission on the Future of State and Land-Grant University's report on “The Student Experience” report, which called for all land-grant universities to refocus their missions on the student experience, to frame his student-centered initiative through the lens of the land-grant mission. He also aspired to reengage the WVU Extension Service across the state, bringing in new leadership and reorganizing its areas of responsibility to support a larger population of West Virginians, similar to what McDowell $(2001,2003)$ calls for in his renewed social contract with Cooperative Extension. Garrison took a very idealistic and romanticized view of the land-grant mission, often sharing platitudes celebrating the state and its people that lacked substance or tangible action or planning. He was also more focused internally on building faculty and staff morale and responding to the Board of Governors and the state government. Magrath used the Kellogg Commission's "Returning to Our Roots: The Engaged Institution" report as a framework for 
WVU'S LAND-GRANT MISSION

319

rallying the campus community around a common goal, community engagement, following the Garrison scandal. Clements defined the land-grant mission more externally, taking a global, world-grant perspective with initiatives focused on diversity, globalization, and partnerships beyond the campus. Finally, Gee has returned his focus closer to home, framing all of his initiatives through three pillars to serve the state, education, health and well-being, and prosperity, using the land-grant mission to direct the work of the institution. With the exception of Garrison's brief tenure, all four of the presidents have aspired to reengage with the land-grant mission in some way, though all of their approaches have varied, showing different constructs to operationalizing the land-grant mission.

\section{Shaping Organizational Saga}

The goals and aspirations above contribute in different ways toward reaching the components of the fulfillment phase in organizational saga. The next sections synthesize each presidential administration's contributions to or absence from the components of fulfillment in organizational saga, programming, personnel, student subculture, social base, and imagery, and how those changed over time.

Programming. Programming is by far the broadest category of fulfillment in organizational saga as any new program or initiative can be captured in it. As a result, all of the presidents made contributions in this area, whether it was Hardesty's Resident Faculty Leader program in the residence halls and establishment of WVU Research Corporation; Garrison's Research Trust Fund and childcare center; Magrath's audit of academic recordkeeping; Clements' research Mountains of Excellence, restructuring of international offices and programming, and creation of the Division of Diversity, Equity and Inclusion; or Gee's three pillars, West Virginia Forward, and Bureaucracy Busters. Because of the duration of their 
WVU'S LAND-GRANT MISSION

320

administrations, Hardesty, Clements, and Gee, respectively, have had the most time to

implement new programming.

Personnel. Both Hardesty and Garrison initially struggled with the personnel component of organizational saga because of the negative receptions they respectively received when they were first hired, as discussed in the beginning of Chapters 4 and 5. Hardesty's contributions to the personnel component came out of the pay raises resulting from Senate Bill 547. Despite his rocky start, if Garrison championed any component of organizational saga, it would have been personnel. He recovered somewhat from the initial reception he received when his First 100 Days plan targeted morale building among faculty and staff with pay raises and the construction of the childcare center. Personnel was a major focus of Magrath's because of the caretaking work he was tasked with in healing the campus community and rebuilding it. Clements contributed to this component through the 100 new faculty lines and diversity initiatives he pursued. Gee continues to work through this component through his work on improving the campus climate and culture, including restructuring of the Division of Human Resources to the Division of Talent and Culture with five new values and opportunities to participate in town halls, called Campus Conversations, discussing challenges impacting employees' experiences on campus.

Student subculture. Student subculture evolved across Hardesty, Clements, and Gee's administrations, with each successor's efforts building upon the previous ones. Hardesty initially championed student subculture, kicking off his presidency with a student-centered initiative focused on student development and retention with a revamped New Student Welcome, new programs in the residence halls, and streamlining processes for student accounts, financial aid, and advising. Clements expanded retention programming and attempted to streamline these efforts under one structural umbrella, University College, though that was ultimately disbanded 
WVU'S LAND-GRANT MISSION

321

and reorganized in a more decentralized fashion under Gee through an effort called Project 168. He also expanded Welcome Week as a strategy for making a memorable first impression on students and supporting their transition to campus.

One elusive student subculture strategy for all of the cases in this study was student retention. In some shape or form, student retention was a component of the goals set by all of the administrations studied here, but one that was accompanied by minimal progress, making it an aspiration that routinely appeared and was diligently pursued without demonstrated success. For future research, this will be a category to observe in future years and administrations to inform practice.

Social base. Social base can be organized into two areas, work with alumni and work with the community. Clements championed the former with the initiation of a capital campaign and some of the largest gifts in University history. In terms of community engagement, Hardesty set the foundation for his successors, beginning first with identifying new ways to expand WVU Extension Service's presence in the 55 counties. Magrath framed his leadership through a community engagement strategy, using that common ground to begin to heal the campus and find ways to move forward following the Garrison scandal. In addition to alumni and donor engagement, Clements' work in social base was often seen through expanded community partnerships, not only with WVU Extension Service, but also the preK-12 and community and technical college systems. Gee has ultimately championed the community aspect of social base with his 55-county tours, three pillars framework, work with West Virginia Forward, and expansion of WVUMedicine to have a presence across the entire state.

Imagery. Much of Hardesty's work in the imagery component of organizational saga is seen through new traditions created for the campus, such as New Student Convocation, Festival 
WVU'S LAND-GRANT MISSION

322

of Ideas, and FallFest, responses ultimately to attempt to overcome the University's negative party school image. Garrison's contribution to imagery was a stark contrast to the other administrations as his came from the series of events that comprised his inauguration as president, which celebrated him as an individual rather than the campus as a whole. Magrath's contributions came from his presence on campus following a scandal - the latent influence he brought as a nationally respected leader and how his own network helped rebuild the institution. With his external focus, Clements brought the aspirations for earning the Carnegie Foundation's Community Engagement and Research 1 classifications. Gee's imagery work came through his development of new traditions on campus, like Welcome Week and the $150^{\text {th }}$ birthday celebration. Finally, many of the major renovations and new buildings developed during this study were pursued during both Hardesty and Clements' respective administrations, which are tangible depictions of imagery.

Summary. The examples above show varying contributions to each of the five components of reaching fulfillment in organizational saga. As discussed in earlier in the findings chapters, only two of the presidents in this study have reached the fulfillment stage of organizational saga so far: Hardesty and Clements. Garrison was not president long enough to meet the criteria of the various components, and his administration was ultimately tainted by scandal, inhibiting any contributions made toward reaching the fulfillment stage of organizational saga. As an interim president, Magrath's position was intended to be short-term, and, therefore could not reach fulfillment. Gee's presidency is still ongoing, which prevents a complete assessment at this point.

\section{The Land-Grant Saga and WVU's Story}


WVU'S LAND-GRANT MISSION

323

A common theme across all five of the administrations in this study is how they constantly navigated and responded to exogenous and endogenous factors facing the University and higher education nationally, which represent the changing contexts of higher education driving the responses found in strategic planning and the decisions of leadership. Those circumstances, positive or negative, continued to shape the University's own organizational saga and its position in the land-grant saga as the goals and initiatives pursued by the presidents and their administrations were often strategies to respond to them. William reflected on how exogenous and endogenous circumstances change over time, saying that it is the responsibility of land-grant universities to not only acknowledge and respond to them, but to lead that change. He said, "Things that were strategically critical five years ago may not be critical for the next five years. You have to be prepared and able to make that kind of change. The world changes; you've got to change with it, particularly if you are the land-grant university." The following paragraphs explore some of those exogenous and endogenous factors and how the presidents and their administrations responded to them, demonstrating how leaders not only shape organizations, but how organizations - and their endogenous and exogenous circumstances - shape leaders.

\section{Endogenous Factors}

For all of the presidents in this case, a primary endogenous factor faced was the circumstances in which they were hired. Both Hardesty and Garrison faced tumultuous starts to their tenures because of the criticism they faced as nontraditional presidents who most faculty doubted were qualified to do the job or did not have the University's best interests in mind because of their political backgrounds, resulting in votes of no confidence by the faculty senate. Garrison also experienced rather large shoes to fill because he succeeded a president who had eventually become seen as one of the most successful presidents in University history, more than 
WVU'S LAND-GRANT MISSION

324

doubling the average tenure of a University president during his time. Magrath's interim status was an endogenous factor in and of itself, with the title limiting his capacity to just the healing and rebuilding he was tasked with completing along with the academic recordkeeping audit following the Heather Bresch degree scandal during Garrison's administration. Clements had the endogenous pressures of making a positive first impression as the first permanent successor following that scandal. Gee, initially, had the same endogenous limitation of the interim title until he was appointed by the Board of Governors as the permanent president, which was accompanied by its own questions because of the non-normative way he was hired permanently.

Though this factor can be seen as exogenous because of the role it plays in fundraising, marketing, the University budget, and building relationships with the fan base, the issues related to athletics navigated by Garrison, Magrath, and Clements were mostly endogenous because they primarily dealt with personnel. All three were involved in major regime changes for the University's most prominent two sports, football and basketball, as well as the transition from the Big East Conference to the Big 12 Conference.

Gee's navigation of endogenous factors is seen more through campus culture. During his tenure, he has implemented a series of culture surveys to gain input from faculty and staff about their work experiences. His administration has made efforts to address that feedback, rebranding the Division of Human Resources to the Division of Talent and Culture, which has been accompanied by five new values, a revamped new employee orientation and supervisor trainings, and opportunities for employees to participate in dialogue regarding the work of the institution through town halls called Campus Conversations and a program called Bureaucracy Busters that seeks to improve efficiencies across the operations of campus.

\section{Exogenous Factors}


WVU'S LAND-GRANT MISSION

325

Technology. One of the earliest exogenous factors navigated by the Hardesty

administration was technology. As $\mathrm{Y} 2 \mathrm{~K}$ approached, his administration had to determine the best route to take to prepare for the changing technology needs on campus. Frank recalled that effort, saying, "Technology permeates everything. So that has changed the way we go about business and changed the way one looks at one's mission." The Integration 2000 report responded to that with a plan for email, software changes, processing changes in student services and business operations, a digital student information system, and other resources.

Students. Students themselves — and their parents - are another exogenous factor as they have changing demands and needs for their experience, which directly influences the potential of recruiting and retaining students as the generations attending college have changed over time. Frank extrapolated on those changing demands from students and their families: "Parents want to spend money now at a place like [WVU]. Parents want to spend money on getting their sons and daughters an education that actually produces a career. It is no longer going to school for the sake of learning and being educated and then worrying about a career afterwards ... I think that [sic] situation has changed.” That need for customer service-oriented approaches motivated Hardesty's administration to lead with its student-centered initiative, including the launch of a Mountaineer Parents Club, and both Clements and Gee followed-up closely with their own student retention initiatives, including efforts related to health and wellness, diversity, livinglearning communities, and having an Instagram-worthy Welcome Week, respectively.

Governance and public funding. Governance and funding and how those two exogenous factors work together go hand-in-hand. The mandates set forth by Senate Bills 547 and 653 during Hardesty’s administration influenced his administration's decision-making as it found new ways to fulfill the Campus Compact by becoming a more efficient University and 
WVU'S LAND-GRANT MISSION

326

making faculty and staff salaries more competitive. Nicole remembered the motivations for these efforts and how they are still impacting the University today, saying, "That effort there was to try to get us to sort of think outside the box about how we can become more efficient and more effective. And I think those words efficiency and effectiveness have just ridden through the change of time because we still talk about it today." Similarly, Gee's administration's work with West Virginia Forward demonstrates that even though state appropriations to higher education continue to decrease, that WVU is taking the lead on generating new sources of economic development for the state's citizens. Linda, a staffer in academic affairs, reflected on the Gee administration's response, saying, "This state has been facing difficult financial problems more recently. And so, I think to some extent the circumstances of the state have dictated what we are prioritizing as our land-grant mission.”

These examples show how a culture of scarcity driven by governance changes and declining appropriations have inhibited quests for differentiation or progress (see Crow \& Dabars, 2015; Gavazzi \& Gee, 2018; Goldstein, Paprocki, \& Osborne, 2019). Changes in governance and resulting policies and funding structures continue to be an ever-evolving exogenous factor shaping decisions made by University leadership, particularly with the continued tension between the leadership's motivations for serving the state with simultaneous pursuits of autonomy when the state continues to allocate fewer and fewer appropriations over time. These trends in governance shifts and public funding decreases are also seen in land-grant universities broadly, with some institutions becoming increasingly more tuition-driven, thus limiting their commitments to traditional land-grant ideas, e.g. access and affordability. Others, like WVU, have found other ways to prioritize their mission through different aspects of community engagement and service, e.g. expansion of healthcare services around the state. 
WVU'S LAND-GRANT MISSION

327

\section{WVU's Story and Significance in the Saga}

As seen in the section above discussing the major goals pursued by the presidents over time, many of their goals are similar or are intended to reach the same stakeholders (i.e. students, faculty and staff, alumni and donors, community members, and state and local government officials), though worded differently. Frank observed this theme, saying, "There's these threads, and you just weave them a little bit differently to whatever seems to be the issue of the day. It's just in a different umbrella." These similarities demonstrate that some of those exogenous and endogenous influencers have persisted across the administrations with leaders responding through prioritization of different aspects of the land-grant mission.

They also highlight what has and has not changed about WVU's organizational saga through the $21^{\text {st }}$ century timeframe examined in this study. The three overarching challenges introduced by Lewis (2013) are still persistent today: insufficient financial resources, corrosive regionalism, and frequent changes to the structure of higher education governance in West Virginia. To those, this study adds a fourth challenge: the continued navigation away from and beyond the party school image that has permeated the culture of campus since prior to Hardesty's administration.

Beyond just these challenges, WVU continues to make national strides, reaching goals that were just forming as aspirations at the beginning of the time period where this study starts: receiving the Carnegie Foundation's Engagement Classification in 2011 and the Research 1 ranking in 2015 and again in 2018. Those capture the University's continued quest to become more relevant to the state and on a national stage, demonstrating that it has moved past the scandal that had once tainted its reputation and standing, something, at the time, many individuals in the campus community thought WVU would not overcome. Through all of that 
WVU'S LAND-GRANT MISSION

328

progress, there is more awareness of the land-grant mission than ever before. Sean, a staffer in the president's office, has observed this shift:

[Previously,] if you ask[ed] people what land-grant meant out on the street corners, except for those people who maybe have been in 4-H or worked with their county extension offices, that phrase would not have had any resonance. And the University itself did not use it very much. Now, we're using it in some of our commercials, in our 30-second ads at football games. In fact, when I really knew that [the land-grant mission] had really kind of reached the critical mass, the SportsLine radio program on WAJR uses it as their lead-in. Hoppy Kercheval ${ }^{6}$ uses it, too. They talk about 'from the state's land grant university.' ... People are talking about it. They weren't doing that in 2010. Today, eight years later, you've got people using it.

But that awareness is not just seen or heard in how the University or the public is talking about the mission. It is also apparent in the goals set and the work implemented by the institution, which is seen today as an obligation that the University has committed to seeing through. That work, as called for by many of the authors in Chapter 2 (Brackmann, 2015; Gavazzi, 2015; Kellogg Commission on the Future of State and Land-Grant Universities, 1999; Klein \& Woodell, 2015; Fitzgerald, Bruns, Sonka, Furco, \& Swanson, 2012; McDowell, 2001; McDowell, 2003; Reilly, 2003), will have to continue to evolve to maintain that engagement with the land-grant mission and how it is operationalized in communities across the state.

Whether or not land-grant universities evolve in that manner will determine their place in the land-grant saga. As discussed in Chapter 1, land-grant universities continue to navigate these endogenous and exogenous circumstances shaped by the shifting broader contexts happening in

\footnotetext{
${ }^{6}$ Hoppy Kercheval hosts Talkline, a prominent radio show covering state news in West Virginia.
} 
WVU'S LAND-GRANT MISSION

329

higher education nationally, forcing their leaders to make a difficult choice: maintain their operational status quo while monitoring the changes; move away from their traditional missions of access, affordability, and practical education in favor of increased tuition revenue and changing academic offerings; or reengage with their missions through increased accountability to their communities and innovative, economic development- and partnership-based approaches to research, teaching, and service.

As seen in this study, West Virginia University's leaders have made different choices in response. Over the course of his 12 years as president, Hardesty redefined the land-grant mission with a focus on student access and customer service and expanding the University's connection to the state through the Extension Service and targeted research, all the while navigating some of the most stringent governance shifts the University has faced in decades. Many of the programs, structures, and initiatives introduced during his administration are still in place today. Garrison's administration did not last long enough to make a significant contribution to the saga, so it could be argued that his administration either maintained the status quo or even moved away from the mission because of the lasting effects of the degree scandal during his tenure. Magrath's administration was an attempt to recover from those lasting effects, and his attempts to unite the campus through messages of community engagement and service to the state demonstrated a renewed sense of purpose for the campus community through the land-grant mission. The mission and goals launched by the Clements' administration through the 2020 plan were generic in nature, especially in the most comfortable budgetary and governance circumstances of all the administrations, representing the status quo of the land-grant mission. However, Clements did attempt to push the boundaries of the mission with his external vision focused on research, alumni engagement, diversity, and globalization. Despite the most governance changes and 
WVU'S LAND-GRANT MISSION

330

pressures from the West Virginia State Legislature since the Hardesty administration, the Gee administration has refocused the University in service to the state through initiatives like West Virginia Forward and the guiding framework of the three pillars, but at the price of an increasing tuition model, strategies which are in direct conflict in how they inform WVU's place in the saga in the current administration. As mentioned in Chapter 8, only time will determine that place.

Considering WVU's organizational saga broadly, it is also important to consider if WVU's story was genuinely a land-grant saga or just a foil for all of the transformations that have taken place in its recent history, characterized by the rise of a modern research university, student commodification, and commercialization in response to privatization. For example, Clements was critiqued for the 2020 strategic plan's broad, representational goals; yet, simultaneously, he formed a community engagement taskforce, pursued the Carnegie Foundation's Community Engagement Classification, and hired WVU's first provost for engagement. In contrast, Gee is known for his extravagant messaging on the importance of landgrant universities in society, regularly publishing op-eds in national media outlets and even coauthoring a book on the topic (Gavazzi \& Gee, 2018). This dichotomy shows how one president could be considered more land-grant oriented in practice and application while another is more land-grant-oriented in terms of imagery, messaging, and identity, ultimately having broader implications for the historical land-grant literature.

\section{Implications}

This study has implications for both WVU and other public, land-grant, research universities. For WVU, it represents an important historical documentation of how the University's mission, goals, and approaches to strategic planning have changed over time, which has not been documented in this manner to date. It also fills a gap in WVU's history since 
WVU'S LAND-GRANT MISSION

331

Lewis's 2013 work, which concludes during James Clements' administration, as discussed in Chapter 2. It has the potential to be used to inform future strategic planning efforts at the University in terms of understanding what strategies have been used in the past and evaluating them in terms of what could be useful to include or omit in future processes. This particular implication is timely as mentions and discussions of what the next iteration of strategic planning will look like have been circulating around campus along with announcements about conversations with various constituents being shared in 2019 to inform the next strategic planning process.

This study could be informative beyond WVU as well. It could be used as a model for other land-grant universities and presidents of those institutions to inform their own approaches to leadership, mission-building, strategic planning, and shaping their roles in the land-grant saga. When considering other institutions' quests for national research classifications or other prominent accolades, WVU's history and processes could be used as an example to inform potential strategies. It also contributes to the broader literature on community engagement and universities as well as in organizational leadership because of the examination of the role leadership frameworks play in influencing university presidents' decisions.

More specifically, this study highlights the importance of interrogating and awareness of institutional history and current situational analysis for new leaders - not just presidents, but other executive and academic leadership as well as governing board members. This study demonstrates the role of qualitative research and perspectives within a given institution that go beyond learning what the University appears to be like via a website, brochure, or video to convey the genuine pulse and direction of the campus. For leaders broadly, it also informs 
WVU'S LAND-GRANT MISSION

332

possible strategies for navigating the expectations of different stakeholders with differing priorities.

This study contributes to the leadership literature in terms of the way the role of the president has evolved over time, particularly in the 25-year span in which the study takes place. By focusing on presidents as the change agents of strategic plans, the findings show that the assumed roles or responsibilities of the university presidency have changed, becoming more externally focused. University presidents are expected to be the face of the institution, representing it to a variety of external stakeholders, including alumni and donors, community leaders, federal, state, and local government officials, and more. As a result, presidents have also become more reliant on their executive leadership team members, particular the provost, to manage the internal, day-to-day responsibilities. For example, provosts in the two cases with the most formal strategic planning, Hardesty and Clements, relied on their provosts and faculty senate chairs to take the lead on preparing for and implementing the 2010 and 2020 strategic plans, respectively. Similarly, Gee has relied on his provost to lead the three pillars framework and West Virginia Forward efforts, the two initiatives that most closely resembled strategic planning in the case. In the case of Hardesty, his administration began expanding the role and power of the student affairs division by moving the locus of control. The student affairs leader was moved into its own reporting line to the president rather than the provost. This position has since evolved to the title of dean of students/vice president of student affairs. All of these shifts are examples of administrative bloat, with the expanding roles and responsibility of administrators in the organization.

Another contribution to leadership literature is the examples of non-normative hiring practices seen in three of these cases. Of the four permanent presidential hires in this study, there 
WVU'S LAND-GRANT MISSION

333

were challenges and/or unexpected occurrences with three-Hardesty's experience criticisms and lawsuit, Garrison's experience criticisms and Faculty Senate vote of no confidence, and Gee's initial appointment as the interim president and subsequent sudden announcement as the permanent president. These examples demonstrate the power of different organizations and populations within higher education institutions, including governing boards, faculty senates, state legislatures, and alumni and donors, to ultimately direct the institution's response to the land-grant mission.

Finally, this study has implications for the future of strategic planning in higher education broadly. It highlights that strategic planning may no longer be a dynamic enough tool for some administrations, as seen in the example of the Gee case. As more institutions attempt to differentiate themselves from their competitors (see Crow \& Dabars, 2015; Gavazzi \& Gee, 2018; Goldstein, Paprocki, \& Osborne, 2019), leaders may seek out new ways to innovate their approaches to decision-making and more broadly setting their institutions apart in the marketplace. Decisions relating to strategic planning styles also reflects the concept of legitimacy because strategic plans are not binding, and they often are not accompanied by assessment metrics. In the case of the Clements administration, for example, the aspiration for pursuing a strategic plan highlighted the need for legitimacy for not only a first-time president but the institution's first president following a scandal. However, for more seasoned administrators, like Gee, a strategic plan does not offer a sense of legitimacy because that is already embodied in his own political capital and reputation as a symbol or embodiment of the land-grant university. In Hardesty's situation, hired as a nontraditional president with a professional background outside of academia, he used strategic planning as a legitimizing tool to qualify his ability to lead a university. Together, these examples show how strategic plans 
WVU'S LAND-GRANT MISSION

334

inclusive of all stakeholders, both internal and external, have become the expectation for landgrant institutions to help legitimize leaders.

\section{Future Research}

The first step to future research would be continuing this study with E. Gordon Gee's administration through its conclusion to observe how the land-grant mission and strategic plan continue to change over time. This continuation would include document analysis of future State of the University addresses and other major speeches and strategic planning documents that are published for the next series of strategic planning beyond the 2020 plan. It will also be important to follow what takes place in the state government with regard to higher education governance and policy changes, including the funding model and the work of the Blue Ribbon Commission to assess it as well as the state's new free community college bill and how it would impact the four-year institutions. An expanded look at the role of WVU's regional campuses, Potomac State College and WVU Institute of Technology, would also be valuable as only a few of the participants interviewed in this study currently or previously worked at or with those campuses.

Beyond just the implications at a single institution, another step would be using this study as a model for other land-grant universities. Similar data collection methods could be implemented at other institutions to identify their changing approaches to strategic planning and mission-building in $21^{\text {st }}$ century contexts. Another way to learn more about how the land-grant saga has changed over time would be examining these changes across different land-grant universities and comparing and contrasting them with exogenous circumstances occurring in higher education nationally.

One of the limitations in this study, as discussed in Chapter 3, was the inability to interview the presidents themselves in following Institutional Review Board protocols. Finding a 
WVU'S LAND-GRANT MISSION

335

way to include those voices would be an important addition to future research and an additional layer of rich detail because of the first-hand knowledge it would provide. The possibility of exploring this angle was particularly illuminated when all of WVU's living presidents, past and present (i.e. except Garrison), including several beyond the timeframe studied here, came together on WVU's campus in December 2018 as a panel discussing the most significant challenges facing higher education today. Taking the webcast of that event and juxtaposing its content with the findings in this study would continue to show how WVU's position in the saga has shifted since their administrations.

Finally, a quantitative or mixed methods study would give an opportunity to juxtapose the findings in this qualitative study with an examination of how enrollment and budget changes have influenced goals and executive decision-making.

\section{Conclusion}

With the public confidence in higher education continuing to decline (Jones, 2018), it is more important than ever for public universities to demonstrate their value to their communities and citizens. Because of their inherent mission of community engagement and service, land-grant universities, in particular, are responsible for taking the lead in redefining this social contract with the public (McDowell, 2001, 2003) and identify new ways to work with, rather than for, the community through their research, teaching, and service missions. "The Morrill Act funded an idea - the pursuit of an ideal to expand access to quality higher education and to purpose higher education with the responsibility to advance community and social prosperity through all of its meanings" (Hudzig \& Simon, 2012, p. 188). An intentional assessment of strategic planning approaches in the context of leadership styles (Manning, 2013; Bolman \& Deal, 2013), community engagement strategies (Brackmann, 2015; Gavazzi, 2015; Kellogg Commission on 
WVU'S LAND-GRANT MISSION

336

the Future of State and Land-Grant Universities, 1999; Klein \& Woodell, 2015; Fitzgerald, Bruns, Sonka, Furco, \& Swanson, 2012; McDowell, 2001; McDowell, 2003; Reilly, 2003), and organizational saga (Clark, 1971, 1972) is an opportunity to carry out that responsibility and commitment.

As seen in this study, most of the recent administrations at WVU have continued to pursue and reengage with this community engagement call-to-action, including David Hardesty's focus on West Virginia students and his re-envisioning of the Extension Service and targeted research strategies for economic development, C. Peter McGrath's use of community engagement messaging to rebuild the University's reputation, James Clements' external and inclusive 'world-grant' strategy, and E. Gordon Gee's three pillars framework (i.e. education, health and well-being, and prosperity) for West Virginia and implementation of West Virginia Forward. These efforts exemplify how four of the five presidents in this study have embraced community engagement in their own ways to continue to reengage with the land-grant mission and redefine what it means in the face of endogenous and exogenous challenges in the $21^{\text {st }}$ century. As land-grant universities continue to redefine what their missions mean and how to operationalize them in the future, this study can be a reference point for how one university has navigated these challenges and continues to differentiate and adapt its mission and strategic plan to respond to them. 
WVU'S LAND-GRANT MISSION

337

\section{References}

Academy for Educational Development, Inc. (1979). Support, performance, and protection of higher education in West Virginia: A final report to the Joint Committee on Government and Finance and the Joint Subcommittee on Higher Education of the West Virginia State Legislature. Washington, DC: Academy for Educational Development.

Acts of the Legislature of West Virginia. (1969, Regular Session).

Anderson, S. (2003, April 20). WVU cuts: We feel 'lost'. Pittsburgh Post-Gazette. Retrieved from http://old.post-gazette.com/sports/wvu/20030420wvucuts0420p4.asp

Associated Press. (1998, May 14). WVU creates panel to raise standards. Weirton Daily Times, pp. 3A.

Baldridge, J.V., Curtis, D.V., Ecker, G.P, \& Riley, G.L. (1977). Alternative models of governance in higher education. In J.V. Baldridge and T.E. Deal (Eds.), Governing Academic Organizations (pp. 2-25). Berkeley, CA: McCutchan Publishing Corporation.

Basham, L.M. (2012). Transformational and transactional leaders in higher education. SAM Advanced Management Journal, 77(2), 15-37.

Birnbaum, R. (1988). How colleges work: The cybernetics of academic organization and leadership. San Francisco, CA: Jossey-Bass.

Bolman, L.G., \& Deal, T.E. (2013). Reframing organizations: Artistry, choice, and leadership. San Francisco, CA: Jossey-Bass.

Bolt, J. (2017, August 16). West Virginia University system welcomes record enrollment [Press release]. Retrieved from https://wvutoday.wvu.edu/stories/2017/08/16/west-virginiauniversity-system-welcomes-record-enrollment 
WVU'S LAND-GRANT MISSION

338

Bornstein, R. (2002). Redefining presidential leadership in the 21 st century. The Presidency, 5(3), 16-19. https://search.proquest.com/docview/216471800?accountid=2837

Boselovic, L. \& Sabatini, P. (2008a, April 24). WVU faculty senate, in 77-19 vote, says Garrison must go. Pittsburgh Post-Gazette. Retrieved from http://old.postgazette.com/pg/08115/876164-298.stm

Boselovic, L. \& Sabatini, P. (2008b, May 5). WVU made 'flawed' decision. Pittsburgh PostGazette. Retrieved from http://old.post-gazette.com/pg/08115/876164-298.stm

Bowen, E. \& Meszaros, J. (2016). The economic impact of public higher education institutions in West Virginia. West Virginia University Bureau of Business and Economic Research. Retrieved from http://be.wvu.edu/bber/index.htm

Brackmann S.M. (2015). Community engagement in a neoliberalism paradigm. Journal of Higher Education Outreach and Engagement, 19(4), 115. Retrieved from http://openjournals.libs.uga.edu/index.php/jheoe/article/view/1533

Broido, E. \& Manning, K. (2002). Philosophical foundations and current theoretical perspectives in qualitative research. Journal of College Student Development, 43(4), 434. Retrieved from https://www.researchgate.net/publication/295994850_Philosophical_foundations_and_cu rrent_theoretical_perspectives_in_qualitative_research

Brown, J.C., Dearborn, N.H., Reeves, F.W., Works, G.A., Zook, G.F., \& Judd, C.H. (1928). Survey of education in West Virginia, volume IV: Institutions of higher education. Charleston, WV: State Department of Education.

Cavins, L.G. and Kirby, D. (1939). A study of the clientele of the institutions of higher education in West Virginia. Charleston, WV: State Board of Education. 
WVU'S LAND-GRANT MISSION

339

Clark, B.R. (1971). Belief and loyalty in college organization. The Journal of Higher Education, 42(6), 449-515. Retrieved from http://www.jstor.org/stable/1979081

Clark, B.R. (1972). The organizational saga in higher education. Administrative Science Quarterly, 17(2), 178-184. Retrieved from http://www.jstor.org/stable/2393952

Clark, L. (2009, December 15). Buoyed by public support, West Virginia rifle team returns to NCAA prominence. Washington Post. Retrieved from http://www.washingtonpost.com/wpdyn/content/article/2009/12/14/AR2009121401462.html

Clements, J.P. (2009a, June 17). State of the University Address [Transcript].

Clements, J.P. (2009b, October 12). State of the University Address [Transcript].

Clements, J.P. (2010a, June 23). State of the University Address [Transcript].

Clements, J.P. (2010b, October 11). State of the University Address [Transcript].

Clements, J.P. (2011, October 10). State of the University Address [Transcript].

Clements, J.P. (2012, October 8). State of the University Address [Transcript].

Cohen, M. D., March, J. G., \& Olsen, J. P. (1972). A garbage can model of organizational choice. Administrative Science Quarterly, 17(1), 1-25.

Corder, J.W. (1992). A history of the West Virginia Board of Regents as the governing board for higher education, 1969-1989. (Unpublished doctoral dissertation.) West Virginia University: Morgantown, WV.

Crow, M.M. \& Dabars, W.B. (2015). Designing the new American university. Baltimore, MD: Johns Hopkins University Press.

Creswell, J. (2007). Qualitative Inquiry and Research Design. Thousand Oaks, CA: SAGE. 
WVU'S LAND-GRANT MISSION

340

Crotty, M. (1998). The foundations of social research: Meaning and perspective in the research process. Thousand Oaks, CA: SAGE.

Dobies, T. (2014, November 17). WVU shows increasingly diverse student body; overall enrollment drops slightly [Press release]. Retrieved from http://wvutodayarchive.wvu.edu/n/2014/11/17/wvu-shows-increasingly-diverse-student-body-overallenrollment-drops-slightly.html

Doherty, W.T. \& Summers, F.P. (1982). West Virginia University: A symbol of unity in a sectionalized state. Morgantown, WV: West Virginia University Press.

Duderstadt, J.J. (2009). Aligning American higher education with a twenty-first-century public agenda. Higher Education in Europe, 34(3-4), 347-366. Retrieved from http://www.tandfonline.com/doi/abs/10.1080/03797720903355612?journalCode=chee20

Duderstadt, J.J. (2012). Creating the future: The promise of public research universities for America. In D.M. Fogel \& E. Malso-Huddle (Eds.), Precipice or Crossroads? (pp. 221240). Albany, NY: SUNY Press.

Fain, P. (2007, April 13). West Virginia U. ignores controversy and picks Garrison as new president. The Chronicle of Higher Education. Retrieved from https://www.chronicle.com/article/West-Virginia-U-Ignores/38555

Fain, P. (2008, January 3). West Virginia U. roiled over alleged transcript rewrite for governor's daughter. The Chronicle of Higher Education. Retrieved from https://www.chronicle.com/article/West-Virginia-U-Roiled-Over/114389

Fischer, K. (2005, May 13). Running for a different kind of office. The Chronicle of Higher Education. Retrieved from https://www.chronicle.com/article/Running-for-a-Different$\underline{\text { Kind } / 16397}$ 
WVU'S LAND-GRANT MISSION

341

Fisher, J.L. (1984). Power of the Presidency. New York, NY: Macmillan Publishing Company.

Fisher, J.L. (1985). Presidents will lead-If we let them. NACUBO Business Officer, 18(9), 37-

38. Retrieved from https://eric.ed.gov/?id=EJ314042

Fitzgerald, H.E., Bruns, K., Sonka, S.T., Furco, A., \& Swanson, L. (2012). The centrality of engagement in higher education. Journal of Higher Education Outreach and Engagement, 16(3), 7-27. Retrieved from http://openjournals.libs.uga.edu/index.php/jheoe/article/view/861

Forest, J.J.F. \& Kinser, K. (2002). Higher Education in the United States: An Encyclopedia. Santa Barbara, CA: ABC-CLIO.

Fumasoli, T. \& Stensaker, B. (2013). Organizational studies in higher education: A reflection on historical context themes and prospective trends. Higher Education Policy, 26, 479-496. Retrieved from https://link.springer.com/article/10.1057/hep.2013.25

Gamble, M.W. (2003). Living logos: Framing the discourse of the university presidency [Unpublished doctoral dissertation]. Morgantown, WV: West Virginia University. Retrieved from https://search-proquestcom.www.libproxy.wvu.edu/docview/305281083/D25B9A3280804383PQ/1?accountid= 2837

Garraway, J.E. (1996). The role of executive and legislative staff in the state policy formation process: Power or periphery? (Unpublished doctoral dissertation.) Florida State University, Tallahassee, FL. Retrieved from https://www.researchgate.net/publication/34798177_The_role_of_executive_and_legislat ive_staff_in_the_state_policy_formation_process_power_or_periphery

Garrison, M. (2007a, October 19). Inaugural Address [Transcript]. 
WVU'S LAND-GRANT MISSION

342

Garrison, M. (2007b, December 11). Transition Issues [Report to the Board of Governors].

Gaunch, E. (2016, June 2). Floor speech on state budget. West Virginia State Senate. Retrieved from https://www.youtube.com/watch?v=_oIAo5o96eg

Gavazzi, S.M. (2015). Engaged institutions, responsiveness, and town-gown relationships: Why deep culture change must emphasize the gathering of community feedback. Planning for Higher Education Journal, 43(4), 1-9. Retrieved from https://www.scup.org/page/phe/read/article?data_id=31618\&view=article

Gavazzi, S.M. \& Gee, E.G. (2018). Land-grant universities for the future: Higher education for the public good. Baltimore, MD: Johns Hopkins University Press.

Gayle, J., Tewarie, B., \& White, Jr., A.Q. (2003). Governance in the twenty-first-century university: Approaches to effective leadership and strategic management. San Francisco, CA: Jossey-Bass.

Geiger, R.L. (1998). Editor's introduction. History of Higher Education Annual: The Land-Grant Act and American Higher Education: Context and Consequences, 18, 5-10.

Geiger, R.L. \& Sorber, N.M. (2013). The land-grant colleges and the reshaping of American higher education. New Brunswick, NJ: Transaction Publishers.

Gee, E.G. (2013, December 11). Gee returns to WVU as president [Video file]. Retrieved from https://www.youtube.com/watch?v=4OoIxKbqxnw

Gee, E.G. (2014a, January 6). Rules of Engagement. Morgantown, WV: West Virginia University.

Gee, E.G. (2014b, October 4). State of the University Address [Transcript].

Gee, E.G. (2014c, October 26). At 100 years old, WVU Extension still puts knowledge in practice. Charleston Gazette-Mail. Retrieved from 
WVU'S LAND-GRANT MISSION

343

https://presidentgee.wvu.edu/speeches/at-100-years-old-wvu-extension-still-putsknowledge-in-practice

Gee, E.G. (2015, October 5). State of the University Address [Transcript].

Gee, E.G. (2016a, February 19). West Virginia University offers hope. Charleston Gazette-Mail. Retrieved from https://presidentgee.wvu.edu/speeches/e-gordon-gee-west-virginiauniversity-offers-hope

Gee, E.G. (2016b, March 1). State of the University Address [Transcript].

Gee, E.G. (2016c, July 3). Built on resiliency. Charleston Gazette-Mail. Retrieved from https://presidentgee.wvu.edu/speeches/built-on-resiliency

Gee, E.G. (2016d, October 10). State of the University Address [Transcript].

Gee, E.G. (2016e, December 8). West Virginia University offers hope. President2President. Retrieved from https://www.president2president.com

Gee, E.G. (2017a, March 11). Celebrate WVU's legacy by imagining the state's future. Charleston Gazette-Mail. Retrieved from https://presidentgee.wvu.edu/speeches/celebrate-wvu-s-legacy-by-imagining-the-state-sfuture

Gee, E.G. (2017b, March 22). State of the University Address [Transcript].

Gee, E.G. (2017c, September 11). State of the University Address [Transcript].

Gee, E.G. (2018a, February 27). State of the University Address [Transcript].

Gee, E.G. (2018b, October 8). State of the University Address [Transcript].

Gioia, D.A. \& Thomas, J.B. (1996). Identity, image, and issue interpretation: Sensemaking during strategic change in Academia. Administrative Science Quarterly, 41, 370-403. 
WVU'S LAND-GRANT MISSION

344

Retrieved from

https://www.jstor.org/stable/pdf/2393936.pdf?seq=1\#page_scan_tab_contents

Glassner, B. \& Schapiro, M. (2017, February 26). Advice for new presidents. The Chronicle of Higher Education. Retrieved from https://www.chronicle.com/article/Advice-for-NewPresidents/238943

Goldstein, J.E., Paprocki, K., \& Osborne, T. (2019). A manifesto for a progressive land-grant mission in an authoritarian populist era. Annals of the American Association of Geographers, 109 (673-684). Retrieved from https://www.tandfonline.com/doi/full/10.1080/24694452.2018.1539648

Hammond, T.H. (2004). Herding cats in university hierarchies: Formal structure and policy choice in American research universities. In R.G. Ehrenberg (Ed.), Governing academia (pp. 91-138). Ithaca, NY: Cornell University Press.

Hardesty, D.C. (1995a). Administrative Organization Initiatives. Morgantown, WV: West Virginia University.

Hardesty, D.C. (1995b, August 20). New Student Convocation [Transcript].

Hardesty, D.C. (1995c, September 8). Inaugural Address [Transcript].

Hardesty, D.C. (1996a, January 16). State of the University Address [Transcript].

Hardesty, D.C. (1996b, April). West Virginia Higher Education and West Virginia University: Driving Forces that Propel the Development of West Virginia. [Transcript].

Hardesty, D.C. (1997a, February 10). State of the University Address [Transcript].

Hardesty, D.C. (1997b, March 5). Building a High-Performance Organization at West Virginia University [Transcript].

Hardesty, D.C. (1997c, September 8). State of the University Address [Transcript]. 
WVU'S LAND-GRANT MISSION

345

Hardesty, D.C. (1998a, February). State of the University Address [Transcript].

Hardesty, D.C. (1998b, October). State of the University Address [Transcript].

Hardesty, D.C. (1999). Statement of Presidential Assessment in Connection with the Board of Trustees’ Presidential Evaluation. Morgantown, WV: West Virginia University.

Hardesty, D.C. (2001, September). State of the University Address [Transcript].

Hardesty, D.C. (2003). Statement of Presidential Assessment in Connection with the Four-Year Presidential Evaluation. Morgantown, WV: West Virginia University.

Hardesty, D.C. (2005). State of the University Address [Transcript].

Hardesty, D.C. (2007). Leading the public university: Essays, speeches, and commentary. Morgantown, WV: West Virginia University Press.

Hennen, J.C. (1996). The Americanization of West Virginia. Lexington, KY: The University Press of Kentucky. Retrieved from: http://www.jstor.org/stable/j.ctt130j893.8

Hoblitzell, J. R. (2000). History past and history future. Charleston, WV: West Virginia Higher Education Policy Commission. Retrieved from: https://www.wvhepc.org/resources/Hoblitzell.pdf

Hudzik, J. \& Simon, L.A. (2012). From a land-grant to a world-grant ideal. In D.M. Fogel \& E. Malso-Huddle (Eds.), Precipice or Crossroads? (pp. 159-196). Albany, NY: SUNY Press.

Jackameit, W.P. (1973). The political, social, and economic factors in the shaping of the structure of public higher education in West Virginia: A history. (Unpublished doctoral dissertation.) College of William and Mary, Williamsburg, VA.

Jessop, A. (2013, November 30). WVU sees financial gains in its move to the Big 12 Conference. Forbes. Retrieved from 
WVU'S LAND-GRANT MISSION

346

https://www.forbes.com/sites/aliciajessop/2013/11/30/wvu-sees-financial-gains-in-itsmove-to-the-big-12-conference/\#76816fa57265

Johnson, N. \& Yanagiura, T. (2015). How did revenue and spending per student change at fouryear colleges and universities between 2006-07 and 2012-13? Washington, D.C.:

Association of Public and Land-Grant Universities. Retrieved from

http://www.aplu.org/library/public-university-spending-per-student-between-2006-07and-2012-13/file

Joint Committee on Government and Finance. (1956). Public Higher Education in West Virginia. Charleston, WV: Joint Committee on Government and Finance.

Jones, J.M. (2018, October 9). Confidence in higher education down since 2015.

Gallup. Retrieved from https://news.gallup.com/opinion/gallup/242441/confidencehigher-education-down-2015.aspx

Jongbloed, B., Enders, J., \& Salerno, C. (2008). Higher education and its communities:

Interconnections, interdependencies and a research agenda. Higher Education, 56(3), 303-324.

Kellogg Commission on the Future of State and Land-Grant Universities (1999). Returning to our roots: The engaged university. Washington, D.C.: National Association of State Universities and Land-Grant Colleges. Retrieved from http://www.aplu.org/library/returning-to-our-roots-the-engaged-institution

Klein, E. \& Woodell, J. (2015). The centrality of engagement in higher education. Washington, DC: Association of Public and Land-Grant Universities.

Kleinman, D.L. (1994). Layers of interest, layers of influence: Business and the genesis of the National Science Foundation. Science, Technology, and Human Values, 19(3), 259-282. 
WVU'S LAND-GRANT MISSION

347

Retrieved from

http://journals.sagepub.com/action/doSearch?field1 $=$ Title\&text $1=$ Layers + of + Interests $+\mathrm{L}$ ayers + of + Influence $\% 3 \mathrm{~A}+$ Business + and + the + Genesis + of + the + National + Science + Founda tion $\&$ Ppub $=\& P$ pub $=\&$ AfterYear $=\&$ BeforeYear $=\&$ access $=$

Knott, J.H. \& Payne, A.A. (2004). The impact of state governance structures on management and performance of public organizations: A study of higher education institutions. Journal of Policy Analysis and Management, 23(1), 13-30.

Kvale, S. \& Brinkmann, S. (2009). Interviews. Thousand Oaks, CA: SAGE.

Lang, G.E. (1997, May 7). Re: Returning to our Roots. [Memo].

Lewis, R.L. (2013). Aspiring to greatness: West Virginia University since World War II. Morgantown, WV: West Virginia University Press.

Loftstead, B. (2015, September 1). WVU Beckley will become home to WVU Tech in 2017, WVU Board decides [Press release]. Retrieved from http://wvutodayarchive.wvu.edu/n/2015/09/01/wvu-beckley-will-become-home-to-wvu-tech-in-2017wvu-board-decides.html

Machesney, M.M. (1971). Development of higher education governance and coordination in West Virginia. (Unpublished doctoral dissertation.) West Virginia University: Morgantown, WV.

Magrath, C.P. (2008, October 13). State of the University Address [Transcript].

Magrath, C.P. (2009, January 8). Being a Mountaineer is a spirit that envelopes you [Press release]. West Virginia University. Retrieved from http://wvutodayarchive.wvu.edu/n/2009/01/08/7394.html 
WVU'S LAND-GRANT MISSION

348

Magrath, C.P. (2010, February 7). The challenge of an interim presidency after a scandal. The Chronicle of Higher Education. Retrieved from https://www.chronicle.com/article/Serving-as-a-Temp-The/63994

Magrath, C.P. (2011, September 12). The land-grant faith and its practice [Transcript]. Retrieved from http://landgrant150.wvu.edu/magrath_remarks

Magrath, C.P. \& Justice, R. (2009, March 17). One city, one university - and one strong economy. West Virginia University. Retrieved from http://wvutodayarchive.wvu.edu/n/2009/03/17/7602.html

Manning, C.W. (2000). The University System of West Virginia: A decade of excellence in higher education. Charleston, WV: The University System of West Virginia.

Manning, K. (1997). Authenticity in constructivist inquiry: Methodological considerations without prescription. Qualitative Inquiry, 3(1), 93-115. Retrieved from http://journals.sagepub.com/doi/10.1177/107780049700300105

Manning, K. (2013). Organizational Theory in Higher Education Policy. New York, NY: Routledge.

Marcus, L.R. (1997). Restructuring state higher education governance patterns. Review of Higher Education, 20(4), 399-418. Retrieved from http://muse.jhu.edu/article/30032

Marcy, M.B. (2008, May 2). Presidential power and the modern leader. The Chronicle of Higher Education. Retrieved from https://www.chronicle.com/article/PresidentialPowerthe/13822

Marek, M.W. (2005). The portrayal of the mission of higher education in the media: A national baseline [Unpublished doctoral dissertation]. Vermillion, SD: University of South Dakota. Retrieved from https://search-proquest- 
WVU'S LAND-GRANT MISSION

349

com.www.libproxy.wvu.edu/docview/305417509/65D413A886E54271PQ/1?accountid= 2837

Martin, J. \& Samels, J.E. (1994). Merging colleges for mutual growth: A new strategy for academic managers. Baltimore, MD: John Hopkins University Press.

Masten, S. E. (2006). Authority and commitment: Why universities, like legislatures, are not organized as firms. Journal of Economics \& Management Strategy, 15(3), 649-684.

Mays, M. (2014, August 31). W.Va. colleges make cuts to deal with less taxpayer funding. Charleston Gazette-Mail. Retrieved from http://www.wvgazettemail.com/article/20140831/GZ01/140839940

McDowell, G.R. (2001). Land-grant universities and extension into the 21st century: Renegotiating or abandoning a social contract. Ames, IA: Iowa State University Press.

McDowell, G.R. (2003). Engaged universities: Lessons from land-grant universities and extension. The Annals of the American Academy of Political Science, 585, 31-50. Retrieved from https://www.jstor.org/stable/1049749?seq=1\#page_scan_tab_contents

McElhinny, B. (2017, February 9). How Governor Justice came up with his first budget. WVMetrownews. Retrieved from http://wvmetronews.com/2017/02/09/how-justice-cameup-with-his-first-budget

Merriam, S.B. (2009). Qualitative Research. San Francisco, CA: Jossey-Bass.

Meyer, J. W. \& Rowan, B. (1977). Institutionalized organizations: Formal structure as myth and ceremony. American Journal of Sociology, 83(2), 340-363.

Miller, P. (1963). The West Virginia Center for Appalachian Studies and Development as approved on February 5, 1963. Morgantown, WV: WVU President's Office.

Miller, P. (1964, April 13). WVU Council of Administration retreat remarks [Speech]. 
WVU'S LAND-GRANT MISSION

350

Mitchell, M., Palacios, V., \& Leachman, M. (2014, May 1). States are still funding higher education below pre-recession levels. Center on Budget and Policy Priorities. Retrieved from: http://www.cbpp.org/research/states-are-still-funding-higher-education-below-prerecession-levels? $\mathrm{fa}=$ view\&id $=4135$.

Morphew, C.C. and Hartley, M. (2006). Mission statements: A thematic analysis of rhetoric across institutional type. Journal of Higher Education, 77, 456-471.

Morrill Act of 1862. (2018). 7 USC 301.

Mountwest Community and Technial College (2016). Mountwest history. Retrieved from: http://www.mctc.edu/about-us/history

Neumann, A. (2012). Organizational cognition in higher education. In M.N. Bastedo (Ed.), The Organization of Higher Education (pp. 304-331). Baltimore, MD: Johns Hopkins University Press.

Nevin, B. (2018, February 27). WVU's 'State of Minds' fundraising campaign brings in more than $\$ 1.2$ billion [Press release]. Retrieved from https://wvutoday.wvu.edu/stories/2018/02/27/wvu-s-state-of-minds-fundraisingcampaign-brings-in-more-than-1-2-billion

O’Leary, S. \& Boettner, T. (2016). Your guide to the state budget. Charleston, WV: West Virginia Center on Budget and Policy. Retrieved from http://www.wvpolicy.org/wpcontent/uploads/2016/04/WVCBP-Guide-to-the-State-Budget-2016-web.pdf

Owston, J.M. (2009). Survival of the fittest? The re-branding of West Virginia higher education. International Journal of Educational Advancement, 9(3): 126-146. Retrieved from www.palgrave-journals.com/ijea/

Pascarella, E. T., \& Terenzini, P. T. (2005). How college affects students: A third decade of 
WVU'S LAND-GRANT MISSION

351

research, Volume 2. San Francisco: Jossey-Bass.

Peters, S.J. (1998). Extension work as public work: Reconsidering Cooperative Extension's civic mission [Unpublished doctoral dissertation]. Retrieved from https://search-proquestcom.www.libproxy.wvu.edu/pqdtglobal/docview/304480649/previewPDF/86FBFD8E9A 434BCAPQ/1?accountid=2837

Pusser, B. (2003). Beyond Baldridge: Extending the political model of higher education organization and governance. Educational Policy, 17: 165-19.

Reilly, K.P. (2003). The engaged institution, the twenty-first century, and the new university extension. Journal of Higher Education Outreach and Engagement, 8(1), 29-35. Retrieved from http://openjournals.libs.uga.edu/index.php/jheoe/article/view/489/421

Sabatini, P. \& Boselovic, L. (2007, December 21). MBA mystery in Morgantown. Pittsburgh Post-Gazette. Retrieved from http://old.post-gazette.com/pg/07355/843469-28.stm

Saldaña, J. (2015). The coding manual for qualitative researchers. Thousand Oaks, CA: SAGE.

Seracki, J. (1995, April 19). COMER/COE merger discussed at meeting. The Daily Athenaeum, pp. 1,12 .

Sorber, N.M. \& Geiger, R.L. (2015) The welding of opposite views: Land-grant historiography at 150 years. In M.B. Paulsen (Ed.), Higher Education: Handbook of Theory and Research (385-422). New York, NY: Springer.

Sternberg, R.J. (2012). The modern land-grant university. West Lafayette, IN: Purdue University Press.

Stewart, I. (1946, July 19). Speech before the faculty dinner for the president. A\&M 1123. West Virginia University President's Office 1946-1958. West Virginia and Regional History 
WVU'S LAND-GRANT MISSION

352

Center, Historical Archives Manuscript Collection, West Virginia University, Morgantown, WV, https://wvrhc.lib.wvu.edu/, 16 February 2018.

Stewart, I. (1947, April 26). Inaugural address of President Irvin Stewart. A\&M 5132.West Virginia University Presidential Inaugural Speeches and Other Material 1867-1995. West Virginia and Regional History Center, Historical Archives Manuscript Collection, West Virginia University, Morgantown, WV, https://wvrhc.lib.wvu.edu/, 16 February 2018.

Stewart, I. (1958). West Virginia University 1946-1958: A report covering the administration of Irvin Stewart as president of the University July 1, 1946-June 30, 1958. Morgantown, WV: West Virginia University.

Stone, A. G., Russell, R. F., \& Patterson, K. (2004). Transformational versus servant leadership: A difference in leader focus. Leadership \& Organization Development Journal, 25(4), $349-361$.

Stump, J.S. (30 March, 2007). Garrison has followed path similar to Hardesty's. Times West Virginian. Retrieved from http://www.timeswv.com/news/garrisonhasfollowedpathsimilartohardestys/article_392c4 9402a1e55e5bf7df8cc74c97a70.html

Sullivan, T.V. \& Richardson, E.C. (2011). Living the plan: Strategic planning aligned with practice and assessment. The Journal of Continuing Higher Education, 59, 2-9. Retrieved from https://eric.ed.gov/?id=EJ916053

The Dominion Post. (1985, June 30). E. Gordon Gee: Outgoing WVU president discusses institution's roles. The Dominion Post, pp. 4-B, 5-B.

The Morgantown Post. (1951, March 8). The state's attitude toward the medical school. The Morgantown Post. 
WVU'S LAND-GRANT MISSION

353

Thelin, J.R. (2011). A history of American higher education. Baltimore, MD: The Johns Hopkins University Press.

Thomas, J.B. (2010). An Appalachian reawakening: West Virginia and the perils of the new machine age, 1945-1972. Morgantown, WV: West Virginia University Press.

Toren, J.R. (1987). WVU high tech scores twice. WVU Alumni Magazine, pp. 16.

Trachtenberg, S.J., Kauvar, G.B., \& Bogue, E.G. (2013). Presidencies derailed: Why universities fail and how to prevent it. Baltimore, MD: The Johns Hopkins University Press.

Weick, K.E. (1976). Educational organizations as loosely-coupled systems. Administrative Science Quarterly, 21(1), 1-19.

West Virginia University. (n.d.a). 2020 Strategic plan for the future. Morgantown, WV: West Virginia University. Retrieved from https://accreditation.wvu.edu/files/d/8ba280bd-04344b2f-b941-ab0b2dceadf5/strategicplanpdf.pdf

West Virginia University. (n.d.b). Mission. Retrieved from https:/www.wvu.edu/about$\mathrm{Wvu} / \mathrm{mission}$

West Virginia University. (1999). Overview of West Virginia University for New Members of the University System Board of Trustees. Morgantown, WV: West Virginia University. West Virginia University. (2004). Self-study submitted to the Higher Learning Commission of the North Central Association of Colleges and Schools. Morgantown, WV: West Virginia University. Retrieved from https://accreditation.wvu.edu/files/d/94dc0a40-7db7-4c25a4c1-e4f1e73f0440/hlc-wvu-self-study-2004.pdf

West Virginia University. (2005, September 30). 2010 Strategic plan: Building the foundation of academic excellence. Morgantown, WV: West Virginia University. 
WVU'S LAND-GRANT MISSION

354

West Virginia University. (2014). 2014 accreditation self-study report. Morgantown, WV: West Virginia University. Retrieved from https://accreditation.wvu.edu/reference

West Virginia University (2017, March 27). About WVU. Retrieved from http://about.wvu.edu

West Virginia University Bureaucracy Busters. (2017). Frequently asked questions: House Bill

2542. Retrieved from https://bureaucracybusters.wvu.edu/files/d/5bd88ead-5543-45a78280-bc07b5882d83/onesheet_housebill2542faq_v2.pdf

West Virginia University College of Law. (n.d.). David C. Hardesty, Jr. Retrieved from https://www.law.wvu.edu/faculty-staff/full-time-faculty/david-c-hardesty-jr

West Virginia University Economic Well-being and Engagement Roundtable. (2012, December 12). 2020 Strategic Plan for the Future: Lifelong Learning Progress Report. Morgantown, WV: West Virginia University.

West Virginia University Lifelong Learning Roundtable. (2012). 2020 Strategic Plan for the Future: Economic Well-Being and Engagement Progress Report. Morgantown, WV: West Virginia University.

West Virginia University Quality of Life Roundtable. (2014). 2020 Strategic Plan for the Future: Quality of Life Progress Report. Morgantown, WV: West Virginia University. West Virginia University Strategic Planning Council. (2013). 2020 Strategic Plan for the Future: 2013 Progress Report. Morgantown, WV: West Virginia University.

West Virginia University Student Affairs Task Force. (1996, January 16). Student Affairs Task Force Report. Morgantown, WV: West Virginia University.

West Virginia University University Relations. (2007, October 19). Garrison's path 'home' complete as he is formally installed as WVU's $22^{\text {nd }}$ president [Press release]. Retrieved from http://wvutoday-archive.wvu.edu/n/2007/10/19/6235.html 
WVU'S LAND-GRANT MISSION

355

West Virginia University University Relations. (2009, February 2). Inefficient record-keeping system to be corrected through adopting best practices; degrees will stand. West Virginia University. Retrieved from http://wvutoday-archive.wvu.edu/n/2009/02/02/7456.html

West Virginia University University Relations. (2014, March 3). Gee appointed West Virginia University president - for a third time [Press release]. Retrieved from http://wvutodayarchive.wvu.edu/n/2014/03/03/gee-appointed-west-virginia-university-president-for-athird-time.html

Williams, R.L. (1991). The origins of federal support for higher education: George Atherton and the land -grant movement. University Park, PA: The Pennsylvania State University Press.

Wilson, K. (2007, April 14). WVU's next president. Times West Virginian. Retrieved from https://www.timeswv.com/news/local_news/wvu-s-next-president/article_8c0f22496828-5465-8e95-fc9fb2b1d6a8.html

Woodring, P. (1968). The higher learning in America: A reassessment. New York, NY: McGraw-Hill.

Wowczuk, Z.S. (2010, March 21). Magrath's account of presidency at West Virginia U. is 'selfserving'. The Chronicle of Higher Education. Retrieved from https://www.chronicle.com/article/Magraths-Account-of/64766 


\section{Appendix A: Participant Cover Letter}

September 21, 2018

Dear Participant,

You are invited to take part in a research project to understand the history of West Virginia University's approach to strategic planning and its changing mission in the $21^{\text {st }}$ century. In the midst of the ongoing shifts of the perception of higher education and the state legislature's (and, in turn, the public's) question of the role and value of the public universities, WVU has also experienced change. It has seen leadership from five different presidential administrations in a decade. As a result of these administrative, strategic planning, and contextual changes, this study seeks to understand how WVU's mission as a land-grant university and its resulting strategic plan have shifted in the 21 st Century from one presidential administration to the next, and how those changes have positioned the University within the overarching land-grant saga.

This project is being conducted by Katlin Swisher, a doctoral candidate in higher education administration, for research purposes and to support her dissertation research. She is advised by Dr. Erin McHenry-Sorber, assistant professor of higher education in the College of Education and Human Services at West Virginia University. Your participation in this project is greatly appreciated.

Your involvement in this project will be kept as confidential as legally possible. You must be 18 years of age or older to participate. I will not ask any information that should lead back to your identity as a participant, and I will not publish your name during the course of the research. Your responses will be audio recorded, but all recordings and identities will be kept confidential. The recordings and their transcriptions will be saved on my password-protected personal computer as the principal investigator.

Your participation is completely voluntary. You may skip any question that you do not wish to answer, and you may discontinue at any time. The initial interview will last no more than 90 minutes. Your employment standing will not be affected if you decide either not to participate or to withdraw. West Virginia University's Institutional Review Board acknowledgement of this project is on file.

I hope you will participate in this research project, as it could be beneficial in better understanding WVU's history and position in the land-grant saga and the future of West Virginia. Should you have any questions about this letter or the research project, please feel free to contact me at kstinesp@mix.wvu.edu or Dr. McHenry-Sorber at ecmchenrysorber@mail.wvu.edu.

The study's title is West Virginia University's Changing Strategic Plan in the 21st Century and the Institutional Review Board Protocol Number is 1707668319. The study has been reviewed and approved by the IRB. Thank you for your time and help with this project.

Sincerely,

Katlin Swisher 
WVU'S LAND-GRANT MISSION

357

\section{Appendix B: Interview Protocol}

Interviewee (title and name):

Other topics discussed:

Recommended future interview contacts:

Documents obtained:

Post-interview comments or leads:

Topics: strategic planning, mission, vision, values, state and local government relations, budget, institutional history, land-grant identity, administration, leadership

\section{Introduction}

To facilitate our note-taking, I would like to audio tape our conversations today. For your information, only researchers on the project will be privy to the tapes, which will be eventually destroyed after they are transcribed.

I have planned this interview to last no longer than one hour. During this time, I have several questions that I would like to cover. If time begins to run short, it may be necessary to interrupt you in order to push ahead and complete this line of questioning.

\section{Opening}

You have been selected to speak with me today because you have been identified as someone who has a great deal to share about West Virginia University's current or past mission and strategic plan and how they have changed over time. This research project and my dissertation as a whole investigates West Virginia University's mission and strategic plan, how it has changed throughout the 21st century, and how the institution's identity and position as a land-grant university have been influenced by them. My study does not aim to evaluate your professional experience and achievements. Rather, I am trying to learn more about WVU's history through key officials who were part of the strategic planning and agenda setting processes.

\section{A. Interviewee Background}


WVU'S LAND-GRANT MISSION

358

How long have you been/were you...

a WVU employee?

WVU? involved in strategic planning, mission development, and/or other leadership roles at

Interviewee Demographics:

1. What was/has been your career trajectory at WVU? (e.g. years employed, positions held, offices represented, etc.)

2. How did you get involved in these roles/positions at WVU?

3. Have you worked at any other higher education institutions? If so, where?

4. Are you originally from West Virginia? If so, where?

5. Did you attend WVU at any point during your education? If so, what did you study?

\section{B. Interviewee Roles}

1. Briefly describe your position and responsibilities associated with it.

2. How would you define WVU's strategic plan, vision, and values during this time?

Probes (if applicable): How did it differ from past presidents? How did it differ from today?

3. What were WVU's overarching goals and priorities at that time?

Probe: How were they determined?

4. What were the most important issues you worked on? 
Probe: What policies (e.g. internal, federal, state, or local) resulted (or didn't result) from these initiatives?

5. Who were key individuals in the decision-making process?

Probe: What were their responsibilities? Why were they vital to these decisions? Should I reach out to this/these individual(s) for interviews?

6. Describe WVU's role as a land-grant university at the time.

Probe: How has it changed since then?

7. How would you categorize WVU's vision/strategic plan/focus now? How is it different from what you experienced?

Probe: What positions should WVU's leadership take or what moves should it make to move forward in the current state and federal higher education and budget climates?

\section{Post-interview comments and/or observations:}

